Nattan Roberto Caetano

Estudo Experimental de Chamas Turbulentas não Pré-Misturadas Empregando Simultaneamente as Técnicas de Diagnóstico Laser PLIF e PIV

Tese de Doutorado

\begin{abstract}
Departamento de Engenharia Mecânica Programa de Pós-Graduação em Engenharia Mecânica
\end{abstract}

Rio de Janeiro

Abril de 2012 


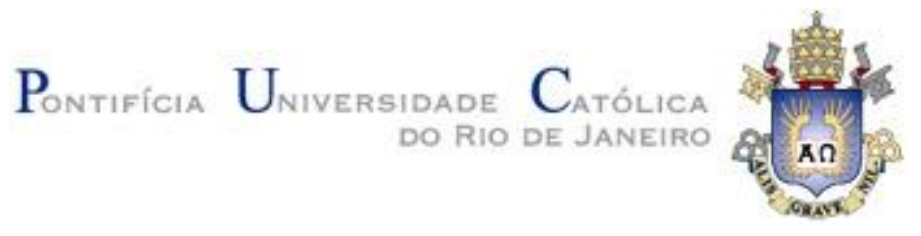

Nattan Roberto Caetano

Estudo Experimental de Chamas Turbulentas não Pré-Misturadas Empregando Simultaneamente as Técnicas de Diagnóstico Laser PLIF e PIV

Tese de Doutorado

Dissertação apresentada como requisito parcial para obtenção do título de Doutor pelo Programa de PósGraduação em Engenharia Mecânica da PUC-Rio.

Orientador: Prof. Luís Fernando Figueira da Silva

Rio de Janeiro

Abril de 2012 
Nattan Roberto Caetano

\section{Estudo Experimental de Chamas Turbulentas não Pré-Misturadas Empregando Simultaneamente as Técnicas de Diagnóstico Laser PLIF e PIV}

Tese apresentada como requisito parcial para obtenção do título de Doutor pelo Programa de Pós-Graduação em Engenharia Mecânica da PUC-Rio. Aprovada pela Comissão Examinadora abaixo assinada.

Prof. Luis Fernando Figueira da Silva

Orientador

Departamento de Engenharia Mecânica - PUC-Rio

Prof. Luis Fernando Alzuguir Azevedo

Departamento de Engenharia Mecânica - PUC-Rio

Prof. Marcos Sebastião de Paula Gomes Departamento de Engenharia Mecânica - PUC-Rio

Doutor Ricardo Serfaty

Petróleo Brasileiro S.A.

Prof. Pedro Lacava

Instituto Tecnológico de Aeronáutica - ITA

Prof. Amir Antônio Martins Oliveira Junior Universidade Federal de Santa Catarina - UFSC

Prof. Jose Eugénio Leal Técnico Científico - PUC-Rio

Rio de Janeiro, 16 de Abril de 2012 
Todos os direitos reservados. É proibida a reprodução total ou parcial do trabalho sem autorização da universidade, do autor e do orientador.

\section{Nattan Roberto Caetano}

Formado em Licenciatura em Física pela Universidade Estadual Paulista, em 2002. Mestre em Física Aplicada a Medicina na Universidade de São Paulo, desde 2004.

Ficha Catalográfica

\footnotetext{
Caetano, Nattan Roberto

Estudo experimental de chamas turbulentas não pré-misturadas empregando simultaneamente as técnicas de diagnóstico laser PLIF e PIV / Nattan Roberto Caetano ; orientador: Luís Fernando Figueira da Silva. -2012.

180 f. : il. (color.) ; $30 \mathrm{~cm}$

Tese (doutorado)-Pontifícia Universidade Católica do Rio de Janeiro, Departamento de Engenharia Mecânica, 2012.

Inclui bibliografia

1. Engenharia mecânica - Teses. 2. Combustão. 3. Turbulência. 4. Velocimetria por imagem de partículas. 5. Fluorescência induzida por laser. I. Silva, Luís Fernando Figueira da. II. Pontifícia Universidade Católica do Rio de Janeiro. Departamento de Engenharia Mecânica. III. Título.
} 


\section{Agradecimentos}

Aos meus pais Nilton e Therezinha Caetano e aos meus filhos Matteo e Maia. Principalmente ao meu falecido pai que não pôde nem mesmo presenciar o inicio deste curso, mas que sempre incentivou e deu forças para realizá-lo. Aos meus filhos pelo amor verdadeiro e minhas sinceras desculpas por tamanha e irreversível ausência, tão necessária para imensa dedicação depositada neste trabalho.

Ao orientador, Professor Doutor Luis Fernando Figueira da Silva pelo apoio prestado, pela confiança depositada, incentivo e incansável dedicação durante todo o tempo investido para a realização deste trabalho.

Aos professores e pesquisadores da PUC-Rio, IEAv e ITA: Luis Fernando A. Azevedo, Marcos Sebastião de Paula Gomes, Paulo Mendes, Marcio Carvalho, Cicero Martelli, Sidnei Paciornik, Gilberto Barreta, Esther Spambato, Leila Santos, Pedro Lacava e Cristiane Martins pelos ensinamentos concedidos, conhecimentos compartilhados e conselhos prestados durante todo o percurso.

À PETROBRAS pelo suporte financeiro destinado à infra-estrutura do laboratório e ao meu treinamento.

À CAPES, RNC, PUC-Rio e ao CNPq, pelos auxílios concedidos, sem os quais este trabalho não poderia ter sido realizado, exposto e finalizado.

À todos que ajudaram direta e indiretamente, em especial, para meus amigos de trabalho: Americo, Andrea, Andre, Elder, Fernando, Luis Enrique, Jonathan, Mauricio, Ricardo e muitos outros de igual importância. 


\section{Resumo}

Caetano, Nattan Roberto; Silva, Luís Fernando Figueira. Estudo Experimental de Chamas Turbulentas não Pré-Misturadas Empregando Simultaneamente as Técnicas de Diagnóstico Laser PLIF e PIV. Rio de Janeiro, 2012. 180p. Tese de Doutorado - Departamento de Engenharia Mecânica, Pontifícia Universidade Católica do Rio de Janeiro.

O escoamento em um queimador tipo corpo rombudo é estudado experimentalmente. Este queimador, representativo daqueles que podem ser encontrados em fornos industriais, propicia um amplo acesso óptico, fornecendo assim as condições necessárias para um estudo detalhado da combustão em escoamentos turbulentos. São realizadas medições simultâneas da luminosidade emitida pela fluorescência induzida do radical químico Hidroxila $(\mathrm{OH})$ e do campo de velocidade do escoamento aplicando as técnicas de Fluorescência Induzida por Plano Laser (PLIF) e Velocimetria por Imagem de Partículas (PIV), respectivamente. A análise de incerteza das medições realizada mostrou que nos casos reativos as incertezas experimentais associadas às técnicas PIV e PLIF, são de 6\% e 25\%, respectivamente. $\mathrm{O}$ estudo de dois casos quimicamente inertes, um com o escoamento dominado pelo jato e outro pela esteira, serve de base para o cálculo das incertezas nas medições e na análise da estrutura do escoamento. Em seguida são estudados diversos regimes de combustão utilizando diferentes vazões de combustível gás natural e ar. As características da frente de chama e as estruturas do escoamento a jusante da superfície do queimador são analisadas através da distribuição da fluorescência de $\mathrm{OH}$ e dos campos de velocidade medidos. A imagem média permite verificar a posição do escoamento em que a chama se estabiliza, além de indicar a superfície de estequiometria e a altura média de ancoramento da chama. Os valores de RMS da fluorescência de $\mathrm{OH}$ indicam a flutuação da frente de chama, tanto na posição quanto na intensidade. Uma análise do tensor de Reynolds do escoamento é realizada à luz da hipótese de Boussinesq, ou seja, é investigada a pertinência do mecanismo de conexão entre a taxa de deformação média do escoamento e as tensões de Reynolds, a fim de examinar o desvio em relação à isotropia da turbulência. Os resultados dos casos reativos são semelhantes aos inertes. Assim sendo, a hipótese de 
Boussinesq parece ser aplicável nos casos em que o escoamento é dominado pelo jato, mas não quando ocorre interrupção deste na região de esteira. Os resultados apresentados contribuem para formação de um banco de dados que possibilitará a validação de novos modelos computacionais destinados a realização de simulações numéricas, visando a otimizar a combustão e propiciar a construção de queimadores mais eficientes que possibilitem a economia de combustível e a diminuição nas emissões de poluentes e material particulado.

\section{Palavras-chave}

Combustão; Turbulência; Velocimetria por Imagem de Partículas; Fluorescência Induzida por Laser. 


\section{Abstract}

Caetano, Nattan Roberto; Silva, Luís Fernando Figueira (Advisor). Experimental Study of Turbulent Non-Premixed Flames by Simultaneously Applying PLIF and PIV Laser Diagnostic Techniques. Rio de Janeiro, 2012. 180p. Dsc. Thesis - Departamento de Engenharia Mecânica, Pontifícia Universidade Católica do Rio de Janeiro.

Turbulent non-premixed flames stabilized on a bluff-body burner are studied. This burner is representative of industrial furnace applications, provides ample optical access, allowing for the required conditions to perform a detailed combustion study in turbulent flowfield. Measurements of the fluorescence luminosity emitted by $\mathrm{OH}$ radical and the velocity field are achieved applying, Planar Laser Induced Fluorescence (PLIF) and Particle Image Velocimetry (PIV) techniques, respectively. An uncertainty analysis is presented considering specifically the reactive case, which yields experimental uncertainties associated to the PIV and PLIF techniques of 6\% and $25 \%$, respectively. The study of two chemically inert cases, the first dominated by jet and the second dominated by wake, supports the uncertainty calculations and the flowfield structure analysis. Subsequently, several combustion regimes using Natural Gas and air are studied. The flame front characteristics and flowfield structures are analyzed using the $\mathrm{OH}$ fluorescence distribution and measured velocity field. The mean images allow the determination of the flame stabilization position in the flowfield, and also indicate the stoichiometry surface and the mean lift-off height. The RMS values of fluorescence signal quantify the flame front fluctuation, both in position and intensity. The measured components of the Reynolds stress tensor are analyzed with respect to the Boussinesq hypothesis, i.e., the relation between mean strain rate and Reynolds stress tensor, in order to examine the tensor deviation from the isotropy. The Boussinesq hypothesis seems to be valid in cases where the jet is dominant and not valid when jet bursts in the wake region. The presented results are the first step towards the construction of a database to validate computational models aimed at optimizing the combustion process and designing more efficient burners.

\section{Keywords}

Combustion; Turbulence; Particle Image Velocimetry; Laser Induced Fluorescence. 


\section{Sumário}

1. Introdução 20

1.1. Objetivos 22

1.2. Motivações 23

1.4. Organização do manuscrito 23

2. Revisão Bibliográfica 24

2.1. Fluorescência Induzida por Plano Laser - PLIF 25

2.2. PIV e PLIF simultâneos 34

2.3. Instalações experimentais para medição simultânea com PLIF e PIV 52

2.4. Comentários finais 68

3. Metodologia Experimental 69

3.1. Estabilização da chama 69

3.2. Instalação do queimador $\quad 70$

3.3. Sistema de Fluorescência Induzida por Plano Laser (PLIF) 72

3.3.1. A fluorescência 72

3.3.2. Abordagem experimental para a técnica PLIF 74

3.3.3. Principais componentes do PLIF 75

3.3.3.1. Laser de bombeio Nd:YAG 76

$\begin{array}{ll}\text { 3.3.3.2. Laser de Corante } & 77\end{array}$

3.3.3.3. Sistema óptico de plano de luz laser 80

3.3.3.4. Câmara Intensificadora 81

3.3.3.5. Sistema de captura de imagens 83

3.3.4. Controle e Processamento de Dados 86

3.4. Sistema de velocimetria por imagem de partículas (PIV) 87

3.4.1. Princípios fundamentais da técnica PIV 88

3.4.2. Os principais componentes do PIV 89

3.4.2.1. Fonte de iluminação 89

3.4.2.2. Câmera CCD e sistema de lentes 90

3.4.2.3. Partículas traçadoras 90

3.4.3. Processamento das imagens de partículas 93

3.4.3.1. Correlação cruzada 94

3.4.4. Sistema de visualização e análise de dados 95

3.4.5. Definição do número mínimo de imagens experimentais 101 
3.4.6. Pós-processamento do campo vetorial 102

3.4.7. Calibração da técnica de medição 103

3.4.7.1. Calibração com anemômetro 104

3.4.7.2. Verificação das medidas de velocidade do jato central 104

3.5. Calibração do campo de visão 104

3.6. Análise e quantificação das incertezas experimentais 106

3.6.1. Estimativa da incerteza no número de Reynolds do jato 106

3.6.2. Fontes de Incerteza em PIV aplicado a chamas 108

3.6.2.1. Termoforese 108

3.6.2.2. Gradiente de índice de refração 109

3.6.2.3. Incerteza devido à imagem das partículas traçadoras $\quad 110$

3.6.2.4. Incerteza no processamento das imagens de PIV 112

3.6.3. Incerteza total das medidas PIV 113

3.6.4. Análise da incerteza nos resultados de PLIF 113

3.7. Comentários finais $\quad 117$

4. Análise de Resultados e Discussões 119

4.1. Hipótese de Boussinesq 120

4.2. Escoamento quimicamente inerte 122

4.2.1. Análise do escoamento no caso 1 (dominado pelo jato) 122

4.2.2. Análise do escoamento no caso 2 (dominado pela esteira) 126

4.2.3. Evolução na linha central, casos inertes 130

4.3. Escoamento Reativo 133

4.3.1. Análise do escoamento no caso $3 \quad 134$

4.3.2. Análise do escoamento no caso $4 \quad 139$

4.3.3. Análise do escoamento no caso 5

4.3.4. Análise do escoamento no caso $6 \quad 150$

4.3.5. Evolução na linha central, casos reativos 156

4.4. Coeficiente de correlação 158

5. Conclusões e perspectivas 162

6. Bibliografia 169

Apêndice A 178

$\begin{array}{ll}\text { Apêndice } B & 179\end{array}$ 


\section{Lista de Figuras}

Figura 2.1 Distribuição de temperatura e de fração de massa do $\mathrm{CH}$ em uma chama laminar estequiométrica de gás natural e ar. As linhas simples são os resultados numéricos e as linhas com símbolos são os resultados experimentais [15].

Figura 2.2. Distribuição de fração de mistura de $\mathrm{OH}$ e $\mathrm{CH}$ medidos com PLIF e calculados, respectivamente [72].

Figura 2.3. Espectro de fluorescência do $\mathrm{OH}$, na região próxima ao UV [61].

Figura 2.4. Imagem de PLIF-OH combinada com o sinal PLIF de acetona (esquerda). A imagem apenas do sinal de acetona (direita) [61].

Figura 2.5. Queimador para chama de difusão com ar anular [39].

Figura 2.6. Comparação entre medidas LIF e resultados calculados [38].

Figura 2.7. PLIF, radical $\mathrm{CH}$ (à esquerda) e $\mathrm{OH}$ (à direita). Imagens PLIF instantâneas (acima) e as médias das imagens (abaixo) [31].

Figura 2.8. Vetores de velocidade sobrepostos à concentração de reagentes em uma imagem simultânea [22].

Figura 2.9. Campo de velocidade instantâneo obtido com PIV, onde A e B representam as posições instantâneas da base da chama, C e D representam as posições da base da chama média, e E está ao longo da linha de centro do jato na posição média da altura da chama [45].

Figura 2.10. Imagem PLIF-OH da zona de reação (a). Contornos de vorticidade sobrepostos (b) e contornos de taxa de deformação calculados a partir imagens PIV (c). Detalhamento da região (i) do campo vetorial da taxa de deformação $(d)$ [52].

Figura 2.11. Campos de velocidade e concentração de $\mathrm{CH}$ simultâneos, extraídos das regiões da chama mostradas nas imagens no topo. O módulo dos vetores velocidade variam entre 0 e $8 \mathrm{~m} / \mathrm{s}$ [75].

Figura 2.12. (a) Imagens simultâneas de PLIF-OH (acima) e Rayleigh (abaixo), em quatro diferentes instantes de interação, onde a extinção pode ser vista no eixo de simetria. (b) Resultados simultâneos de PLIF-OH e PIV, detalhando a estrutura do escoamento, nos mesmos instantes de tempo das imagens em (a) [70].

Figura 2.13. (a) PLIF-CH; (b) PLIF-OH; (c) vorticidade; (d) taxa de deformação mínima (as linhas estão orientadas na direção do eixo de deformação e o 
comprimento de cada segmento é proporcional ao valor absoluto da deformação); (e) dilatação. As linhas negras marcam o centro das estruturas de $\mathrm{CH}$ [34].

Figura 2.14. PDF conjunta da taxa de dilatação nas regiões contendo $\mathrm{OH}$ [34]. 43 Figura 2.15. Imagem de PIV combinada com PLIF-OH (esquerda). Imagem da distribuição de temperatura seguida por imagens de PLIF-OH (direita) [47].

Figura 2.16. Imagem combinada de PLIF-OH e PIV em uma turbina a gás [57].

Figura 2.17. Sequência de campos de vorticidade (esquerda) e deformação (direita), sobrepostos aos resultados de PLIF-OH e PIV, em diversos instantes de tempo [10].

Figura 2.18. Padrões de escoamento associados ao estiramento de uma chama pré-misturada [67].

Figura 2.19. Resultados da interação da turbulência com a chama gerando uma dobra. Contornos de vorticidade são apresentados em vermelho (positivo) e azul (negativo). Os contornos da chama são mostrados pela linha negra. As dimensões do campo de visão são de aproximadamente $6 \times 10 \mathrm{~mm}$. À esquerda ficam os reagentes e o escoamento ocorre de baixo para cima na imagem [67].

Figura 2.20. Estruturas tri-dimensionais de chama. As isolinhas azuis revelam as distribuições $\mathrm{CH}$ sobre o plano de frente; As isolinhas brancas mostram as distribuições de $\mathrm{CH}$ sobre o plano de fundo; as regiões em amarelo são os gases não queimados, estimados pelas distribuições de $\mathrm{OH}$, no plano do meio [60].

Figura 2.21. Aparato experimental para medições simultâneas de PIV/PLIF [22].

Figura 2.22. Arranjo para emprego das técnicas de PIV-PLIF, simultaneamente [75].

Figura 2.23. Esquema do arranjo experimental para realizar medidas PLIF e PIV, separadamente, utilizando a mesma câmera [74].

Figura 2.24. Montagem experimental para realizar as técnicas PIV e PLIF-OH, simultaneamente; termometria Rayleigh e PLIF-OH e também PIV estéreo [47]. 
Figura 2.25. Montagem experimental das técnicas de PIV e PLIF combinadas [10].

Figura 2.26. Esquema detalhado dos sistemas PIV e PLIF [13].

Figura 2.27. Diagrama esquemático da montagem para realização de medidas simultâneas de PLIF-CH duplo plano, PLIF-OH e PIV estéreo duplo plano [60].

Figura 3.1. O queimador, cuja principal característica é a saída de ar, concêntrica ao jato, posicionado no centro de um corpo rombudo.

Figura 3.2. Diagrama de Jablonski para a fluorescência [36]. As linhas horizontais são os níveis de energia atômico, vibracional e rotacional, respectivamente.

Figura 3.3. Esquema da montagem e identificação dos principais componentes para realização de medições com a técnica PLIF [40].

Figura 3.4. Descrição dos componentes do laser de corante [40].

Figura 3.5. Sistema de controle de frequência do laser de corante [40]. 79

Figura 3.6. Esquema de lentes utilizadas para formar o plano de luz laser [40]. 81

Figura 3.7. Esquema da configuração do Intensificador de imagem [40].

Figura 3.8. llustração de parte do espectro de absorção e emissão do $\mathrm{OH}$ [40].

Figura 3.9. Resposta do sinal de fluorescência induzida por laser em função do comprimento de onda da excitação.

Figura 3.10. Curva característica de resposta espectral de sensores CCD [40]. 85

Figura 3.11. Sincronia entre os sinais elétricos dos componentes do PLIF [40]. 86

Figura 3.12. Esquema do aparato para realizar a técnica PIV [40].

Figura 3.13. Esquema do espalhamento Mie com escala de módulo de intensidade para uma gota de óleo de $1 \mu \mathrm{m}$ no ar [51].

Figura 3.14. Laser Nd:YAG de duplo pulso utilizado na técnica PIV [40].

Figura 3.15. Histogramas dos diâmetros das partículas de $\mathrm{TiO}_{2}$. As medidas foram realizadas na saída do ar (esquerda) e no jato central de Nitrogênio (direita).

Figura 3.16. A posição do máximo de correlação indica o deslocamento médio das partículas em uma janela de interrogação [40]. 
Figura 3.17. Deslocamento da janela de interrogação e sobreposição, respectivamente. As posições ( $x, y)$ são apresentadas em termos de pixels [40].

Figura 3.18. Imagem do campo de partículas capturada em uma condição de chama fuliginosa (esquerda) e a mesma imagem pré-processada (direita).

Figura 3.19. Imagem típica da distribuição de partículas do escoamento quando da combustão em um queimador tipo corpo rombudo, com velocidade de jato central e anular, ambas de aproximadamente $8 \mathrm{~m} / \mathrm{s}$. Os quadrados claros, de dimensões $64 \times 64$ pixels, mostram as posições das janelas de interrogação utilizadas para os cálculos, onde 1 é a posição no escoamento de ar anular, 2 a esteira e 3 o jato.

Figura 3.20. Casos de pares de imagens com boa correlação (esquerda) e com má correlação (direita), verificados pelo mapa 3D e os resultados correspondentes de campos vetoriais.

Figura 3.21. Distribuição de concentração de partículas nas áreas mostradas na Figura 3.19. Para Nitrogênio/ar (a) e para GN/ar em presença de combustão (b).

Figura 3.22. Avaliação do número ideal de imagens experimentais a serem capturadas, nas condições de velocidade de ar anular, $4 \mathrm{~m} / \mathrm{s}$, e de jato de nitrogênio, $8 \mathrm{~m} / \mathrm{s}$.

Figura 3.23. Calibração da imagem, utilizando uma placa de calibração.

Figura 3.24. Determinação do diâmetro ideal de imagem de partícula em PIV [51].

Figura 3.25. Imagem produzida pelo ruído de fundo da matriz CCD (esquerda)

e; Imagem do feixe de luz laser obtida por espalhamento Rayleigh (direita).

Figura 4.1. Caso 1: Projeção no plano $x y$ : $(\mathrm{a}, \mathrm{b}, \mathrm{c})$ Vetores velocidade

instantâneos; (d) Vetor velocidade médio e linhas de corrente.

Figura 4.2. Caso 1: Evolução na direção transversal $(x)$, para posições longitudinais espaçadas de $10 \mathrm{~mm}$ a partir da superfície do queimador, das componentes longitudinal $(V y)$ e transversal $(V x)$ da velocidade [m/s] e das componentes $R x x$, yy e xy do tensor de Reynolds [m2/s2].

Figura 4.3. Caso 2: Projeção no plano $x y$ : $(a, b, c)$ Vetores velocidade instantâneos; (d) Vetor velocidade médio e linhas de corrente. 
Figura 4.4. Caso 2: Evolução na direção transversal $(x)$, para posições longitudinais espaçadas de $10 \mathrm{~mm}$ a partir da superfície do queimador, das componentes longitudinal $(V y)$ e transversal $(V x)$ da velocidade $[\mathrm{m} / \mathrm{s}]$ e das componentes $R x x$, yy e xy do tensor de Reynolds.

Figura 4.5 Evolução da componente longitudinal da velocidade média e das componentes, transversal e longitudinal, dos tensores de Reynolds sobre a linha de centro a jusante do queimador, respectivamente.

Figura 4.6. Caso 3: Projeção no plano $x y:(a, b, c)$ Vetores velocidade e fluorescência do radical $\mathrm{OH}$ instantâneos; (d) Intensidade média de fluorescência de $\mathrm{OH}$ e linhas de corrente.

Figura 4.7. Caso 3: Evolução na direção transversal $(x)$, para posições longitudinais espaçadas de $10 \mathrm{~mm}$ a partir da superfície do queimador, das componentes longitudinal $(V y)$ e transversal $(V x)$ da velocidade $[\mathrm{m} / \mathrm{s}]$ e das componentes $x x, x y$ e $x y$ do tensor de Reynolds $\left[\mathrm{m}^{2} / \mathrm{s}^{2}\right]$.

Figura 4.8. Média e RMS da fluorescência do radical $\mathrm{OH}$ do caso 3 .

Figura 4.9. Caso 4: Projeção no plano $x y$ : $(a, b, c)$ Vetores velocidade e fluorescência do radical $\mathrm{OH}$ instantâneos; (d) Intensidade média de fluorescência de $\mathrm{OH}$ e linhas de corrente.

Figura 4.10. Caso 4: Evolução na direção transversal $(x)$, para posições longitudinais espaçadas de $10 \mathrm{~mm}$ a partir da superfície do queimador, das componentes longitudinal $(V y)$ e transversal $(V x)$ da velocidade $[\mathrm{m} / \mathrm{s}]$ e das componentes $x x, x y$ e $x y$ do tensor de Reynolds $\left[\mathrm{m}^{2} / \mathrm{s}^{2}\right]$.

Figura 4.11. Média e RMS da fluorescência do radical $\mathrm{OH}$ do caso 4.

Figura 4.12. Caso 5: Projeção no plano $x y:(a, b, c)$ Vetores velocidade e fluorescência do radical OH instantâneos; (d) Intensidade média de fluorescência de $\mathrm{OH}$ e linhas de corrente.

Figura 4.13. Caso 5: Evolução na direção transversal $(x)$, para posições longitudinais espaçadas de $10 \mathrm{~mm}$ a partir da superfície do queimador, das componentes longitudinal $(V y)$ e transversal $(V x)$ da velocidade $[\mathrm{m} / \mathrm{s}]$ e das componentes $x x$, yy e $x y$ do tensor de Reynolds $\left[\mathrm{m}^{2} / \mathrm{s}^{2}\right]$.

Figura 4.14. Média e RMS da fluorescência do radical $\mathrm{OH}$ do caso 5. 
Figura 4.15. Caso 6: Projeção no plano $x y:(a, b, c)$ Vetores velocidade e fluorescência do radical $\mathrm{OH}$ instantâneos; (d) Intensidade média de fluorescência de $\mathrm{OH}$ e linhas de corrente.

Figura 4.16. Caso 6: Evolução na direção transversal $(x)$, para posições longitudinais espaçadas de $10 \mathrm{~mm}$ a partir da superfície do queimador, das componentes longitudinal $(V y)$ e transversal $(V x)$ da velocidade $[\mathrm{m} / \mathrm{s}]$ e das componentes $x x$, yy e $x y$ do tensor de Reynolds $\left[\mathrm{m}^{2} / \mathrm{s}^{2}\right]$. 152 Figura 4.17. Média e RMS da fluorescência do radical $\mathrm{OH}$ do caso 6. Figura 4.18. Valores do coeficiente de correlação, $\rho_{12}$, para os sete cortes transversais extraídos a jusante da superfície do queimador.

\section{Lista de Tabelas}

Tabela 1. Parâmetros utilizados na técnica PLIF em diversos trabalhos.

Tabela 2. Parâmetros do escoamento para os casos estudados. 


\section{Nomenclatura}

\section{Siglas}

CCD - Charged Coupled Device.

CMOS - Complementary Metal-Oxide-Semiconductor

GN - Gás Natural

ICCD - Intensity Charged Coupled Device.

LES - Large Eddy Simulation

Nd:YAG - Neodímio Dopado de Ítrio, Alumínio e Garnet

PDF - Probability Density Function

PIV - Velocimetria por imagem de partículas.

PLIF - Fluorescência induzida por plano laser.

RMS - Root Mean Square

UPT - Unidade Programável de Tempo

\section{Caracteres Gregos}

$\alpha$ - Fração molar

$\lambda$ - Comprimento de onda da luz,

$\lambda_{0}$ - Livre caminho médio.

$\mu-\quad$ Viscosidade dinâmica.

$\eta_{F}$ - Eficiência da fluorescência.

$\eta_{h v}$ - Eficiência da detecção.

$\Omega$ - Ângulo sólido,

$\rho$ - $\quad$ Massa especifica do gás

$\sigma_{a b s}{ }^{-}$Coeficiente de absorção.

$v^{\prime \prime}, j^{\prime \prime}$. Números quânticos: vibracional e rotacional.

$v^{\prime}, j^{\prime}$ - Estados eletrônicos: fundamental e excitado.

\section{Simbologia}
$\Delta-\quad$ Intervalo.
$\Sigma-\quad$ Somatória. 


\section{Caracteres Latinos}

A - Coeficiente de Einstein para a emissão espontânea.

c - $\quad$ Fator de correção da lei de Stokes

C - Coeficiente de correlação.

$C_{a}$ - Coeficiente de arrasto.

$d_{i}$ - Diâmetro da imagem da partícula

$d_{\text {diff }}{ }^{-}$Diâmetro mínimo dos anéis de difração que formam a imagem da partícula.

$d_{p^{-}} \quad$ Diâmetro da partícula.

$d_{p_{\text {Cuibne }}}$ Diâmetro de corte para as partículas do ciclone.

$d_{p_{\text {Litio }}}$ - Diâmetro de corte para as partículas do leito fluidizado.

$d t \quad$ - Intervalo de tempo entre os pares de pulsos de laser em PIV.

$D_{j-} \quad$ Diâmetro do jato de combustível.

$E_{l}$ - Energia luminosa por unidade da área.

$E_{L}$ - Quantidade de fótons $/ \mathrm{cm}^{2}$.

$f_{\#}$ - Razão entre a distância focal e o diâmetro da abertura da lente.

$f_{v^{\prime \prime}, j^{\prime \prime}}$ - Fração de Boltzmann para o estado fundamental rotacional-vibracional.

$F_{t}$ - Força de empuxo que age sobre as partículas.

$g$ - Aceleração da gravidade.

$k_{B}$ - Constante de Boltzmann's.

$I_{c}$ - Intensidade corrigida para cada pixel da imagem.

$I_{E}$ - Intensidade equivalente de cada pulso.

$I_{i}$ - Intensidade de cada pixel da imagem adquirida.

$I_{R}$ - Intensidade de referência definida no programa DaVis.

$I_{1}$ - Intensidade da imagem da $1^{\underline{a}}$ janela de interrogação.

$M$ - Magnificação da imagem.

$n$ - Dimensão da janela de interrogação.

$n_{p}$ - Indice de refração da partícula. 
$\mathrm{N}_{2}-$ Nitrogênio.

$\mathrm{OH}-$ Radical Hidroxila.

p - Taxa de dissociação.

$P$ - Pressão.

$Q$ - Fator de eficiência.

$r$ - Raio da partícula.

Rey - Número de Reynolds.

$\mathrm{Re}_{\mathrm{j}}$ - Número de Reynolds do jato de combustível.

$S$ - Estado excitado singleto.

$S_{F}{ }^{-} \quad$ Sinal de fluorescência.

$S_{0}$ - Estado fundamental.

$T$ - Temperatura.

$T_{1}$ - Estado excitado tripleto.

$u_{c a p}$ - Incerteza na captura das informações.

$u_{\text {correl }}$ - Incerteza na correlação entre as imagens das partículas.

$u_{i}$ - Incertezas individuais.

$u_{d_{i}}$ - Incerteza no diâmetro da imagem da partícula.

$u_{D_{j}}{ }^{-} \quad$ Incerteza relativa no diâmetro do jato.

$u_{P I}$ - Incerteza devido ao processamento.

$u_{\text {subp } x}$ - Incerteza no ajuste subpixel.

$u_{\text {Total }}$ - Incerteza relativa dos resultados.

$U$ - Velocidade do escoamento.

$\mathrm{U}_{\mathrm{a}}-$ Velocidade do ar anular.

$\mathrm{U}_{\mathrm{j}}-\quad$ Velocidade do jato de combustível.

$\dot{V}$ - Vazão volumétrica.

$V_{t}$ - Velocidade de termoforese.

$x_{i}, y_{i}$ Medidas das variáveis.

$\bar{x}, \bar{y}$ Médias aritméticas. 
"É fazendo que se aprende a fazer aquilo que se deve aprender a fazer"

Aristóteles (384 - 322 a.C) 


\section{Introdução}

Uma das estratégias utilizadas no século XIX por Michael Faraday para promover o ensino de ciências foi a realização de conferências. Uma delas, intitulada "A história química de uma vela", acompanhada de demonstrações simples, produziu a publicação de um livro, em 1861, que se tornou um clássico [78]. Passados 150 anos da famosa apresentação de Faraday, o diagnóstico em combustão percorreu um longo caminho, desde a inspeção visual da chama, até a análise detalhada dos processos de combustão com técnicas sofisticadas, utilizando laser.

O conhecimento adquirido acerca dos fenômenos de combustão pela aplicação de técnicas de diagnóstico laser, auxiliadas pelos avançados métodos de simulação numérica do processo, contribui para o desenvolvimento de modernos dispositivos de combustão, mais eficientes e de emissão reduzida de poluentes. Além disso, técnicas de diagnóstico similares são empregadas atualmente para desenvolver sensores de controle dos processos de combustão [5]. O presente trabalho explora o potencial de técnicas de diagnóstico laser em combustão fazendo uso de materiais e métodos de última geração. A ênfase é dada no uso de técnicas que permitem medir simultaneamente a composição química e a velocidade do escoamento. Também são abordados aspectos relevantes do processamento das medidas e do tratamento estatístico dos resultados. As medidas simultâneas destas propriedades características são necessárias para caracterizar a estabilização de chamas em escoamentos turbulentos. Assim sendo, os resultados experimentais permitem uma análise detalhada das interações entre a turbulência, a mistura e as reações químicas que controlam a estabilidade das chamas. Além disso, o conhecimento gerado constitui uma base de dados para o desenvolvimento e a validação de modelos computacionais.

O presente trabalho prioriza a análise da influência da dinâmica do escoamento sobre a estabilização da chama turbulenta através de medidas de velocidade, obtidas com a técnica de Velocimetria por Imagem de Partículas, cuja sigla PIV vem do nome em inglês atribuído a esta técnica, Particle Image Velocimetry. As medidas da estrutura da chama e sua interação com o escoamento turbulento são realizadas utilizando a técnica de Fluorescência Induzida por Plano de Luz Laser, cuja sigla PLIF acrônimo de Planar Laser Induced Fluorescence. 
No presente estudo, chamas turbulentas não pré-misturadas são estabilizadas em um queimador do tipo corpo rombudo. Estas chamas são examinadas utilizando PIV, a fim de obter o campo de velocidade, simultaneamente, com a frente de chama obtida através do sinal de fluorescência do radical $\mathrm{OH}$ via PLIF. O sistema de diagnóstico laser em combustão é aplicado no estudo de chamas turbulentas utilizando como combustível o gás natural, reagindo com 0 ar ambiente. Para cada vazão dos reagentes é provocada, indiretamente, uma alteração do número de Damköhler, o qual possui papel fundamental no regime de combustão [49]. A estrutura instantânea das chamas é analisada para diferentes regimes de combustão através do processamento de imagens digitais, permitindo identificar os processos de interação entre a frente de chama e o escoamento turbulento. As medidas simultâneas de velocidade e fluorescência do radical $\mathrm{OH}$ permitem o desenvolvimento de um estudo estatístico sobre a chama, considerando os resultados de média temporal, flutuações RMS e tensores de Reynolds. Assim, o diagnóstico proposto seguido pelo processamento de imagens enriquece a gama de informações estatísticas disponíveis, contribuindo para a criação de um banco de dados de informações para comparações e calibração de modelos numéricos.

O gás natural (GN) é considerado como um vetor energético de transição com grande potencial de crescimento, ou seja, pode ser utilizado para substituir o uso dos derivados do refino do petróleo. A conversão de instalações industriais, comerciais e residenciais para o uso do GN se mostra viável para a maioria dos casos [4]. Neste contexto, é importante desenvolver trabalhos que contribuam para a ampliação da utilização do GN na matriz energética brasileira. Efetivamente, a utilização do GN pode acarretar melhorias em termos de eficiência energética e de qualidade do meio ambiente. Os produtos de combustão do gás natural são os mais limpos dentre os combustíveis fósseis [29]. Assim, após a aplicação das novas diretrizes energéticas do Brasil, o GN está sendo utilizado para geração de energia elétrica em novas termelétricas que foram construídas em todo o país, cuja maioria opera com GN. Outro aspecto relevante do uso do GN é no setor de transportes. A frota brasileira de veículos leves movidos a GN é a terceira maior do mundo ( $4 \%$ da frota nacional em atividade) [29]. As grandes empresas do segmento de energia vêm investindo e apoiando projetos que visam intensificar a utilização do GN no transporte ferroviário, e hidroviário, além do uso tradicional para a geração de energia elétrica. Estas aplicações têm o potencial de substituição de elevados 
volumes de óleo Diesel, o que significa também a redução na emissão de diferentes poluentes atmosféricos. De fato, o consumo parcial do GN em motores a Diesel proporciona reduções significativas na emissão de material particulado (fuligem), óxidos de nitrogênio $\left(\mathrm{NO}_{\mathrm{x}}\right)$, óxidos de enxofre $\left(\mathrm{SO}_{\mathrm{x}}\right)$ e dióxido de carbono $\left(\mathrm{CO}_{2}\right)$. Neste âmbito, novos métodos têm sido desenvolvidos para melhorar a eficiência de motores movidos a GN. Os resultados alcançados mostram que existe um melhor aproveitamento do combustível, com notáveis reduções das emissões de HC e CO [21].

O Gasbol (Gasoduto entre a Bolívia e o Brasil) que interligou os estados do Centro-Oeste, Sudeste e Sul permitiu que grandes quantidades de gás natural sejam empregadas em diferentes segmentos da indústria, como metalúrgica, cerâmica, vidro, têxtil e em refinarias. Considerando, pela primeira vez, as descobertas da camada pré-sal na Bacia de Santos, o Plano de Negócios da Petrobras (2009 a 2013) [48] estima investir US $\$ 174,4$ bilhões, cerca de $35 \%$ a mais do que o valor previsto no plano anterior, dos quais US $\$ 11,8$ bilhões $(7 \%$ do investimento total) serão destinados ao GN e Energia. Isto representa um aumento no setor de $76 \%$ com relação ao plano anterior.

\subsection{Objetivos}

O trabalho visa estudar escoamentos turbulentos, tanto quimicamente inertes quanto reativos, em um queimador tipo corpo rombudo. O principal objetivo é analisar a interação do escoamento turbulento com a frente de chama e caracterizar os diferentes tipos de chama produzidos por este tipo de queimador, utilizando as medidas obtidas do campo bidimensional de vetores velocidade simultâneo ao mapeamento da frente de chama. Este estudo também visa obter os momentos estatísticos e os tensores de Reynolds, com a finalidade de gerar resultados que contribuam para formação de um banco de dados de desenvolvimento e validação de modelos capazes de descrever a interação entre combustão e turbulência. 


\subsection{Motivações}

A aplicação das técnicas ópticas de PLIF-OH e PIV permite a medição instantânea, bidimensional e, de forma não intrusiva, da estrutura do escoamento reativo turbulento. As imagens obtidas possibilitam a visualização do processo de conversão de reagentes em produtos da combustão que ocorre na da frente de chama [26]. A correlação entre a distribuição de velocidade e a posição da frente de chama desempenha papel importante no desenvolvimento de novos modelos teóricos, portanto, é fator determinante no trabalho onde se pretende analisar a chama em diferentes regimes de combustão. Assim sendo, o foco do presente trabalho é fornecer informações a fim de melhorar o entendimento da combustão do GN em um queimador típico de aplicações práticas, como em fornos industriais, produzindo resultados que relacionam as configurações do escoamento com a combustão. Desta forma, os resultados podem ser utilizados para estudos de combustão e para a validação de modelos numéricos, os quais permitem projetar e desenvolver queimadores mais eficientes, incentivando assim o uso do GN de forma consciente.

\subsection{Organização do manuscrito}

O trabalho está estruturado em cinco capítulos, dentre os quais, o presente. O segundo capítulo apresenta uma revisão bibliográfica dos principais trabalhos que utilizam as técnicas PIV e PLIF, cada uma isoladamente até a aplicação simultânea de ambas e, também, a evolução dos aparatos experimentais correspondentes. $O$ terceiro capítulo aborda os princípios físicos e os componentes do experimento utilizados para a realização das técnicas, assim como o processamento dos resultados experimentais e a análise das incertezas envolvidas nas medições. No quarto capítulo são apresentados e discutidos os principais resultados experimentais obtidos. Finalmente, o quinto capítulo apresenta as conclusões e recomendações para trabalhos futuros. 


\section{Revisão Bibliográfica}

Este capítulo é destinado à apresentação de estudos contendo informações importantes para o desenvolvimento do presente trabalho, as quais contribuem para a formação dos conhecimentos e auxiliam no entendimento da evolução dos componentes necessários para a realização das técnicas utilizadas [5, 33]. Em particular, são apresentados quais os principais resultados e conclusões obtidas a partir dos trabalhos que utilizam técnicas não intrusivas de diagnóstico laser em combustão, com a aplicação simultânea das técnicas de fluorescência induzida por plano laser (PLIF) [20,33] e de velocimetria por imagem de partículas (PIV) [51, 76].

As imagens de PLIF-OH fornecem a posição da zona de reação. Nota-se que o radical $\mathrm{OH}$ é frequentemente considerado como um marcador de frente de chama, devido ao papel que exerce nas reações de recombinação. Porém, este radical é suscetível ao transporte por convecção e difusão para fora da zona de reação. Em combustão pré-misturada, $\mathrm{O} \mathrm{OH}$ apresenta grande gradiente de concentração no lado da mistura dos gases frescos e se difunde lentamente na região dos gases queimados. Por outro lado, em chamas não pré-misturadas $\circ \mathrm{OH}$ difunde para todos os lados da zona de reação. Isto torna possível identificar a zona de reação e distinguir se a chama é pré-misturada ou não pré-misturada, examinando o gradiente do sinal PLIF-OH.

Algumas técnicas laser para medidas simultâneas de velocidade $\mathrm{e}$ temperatura são incompatíveis, uma vez que o espalhamento Rayleigh que poderá ser usado para medir temperatura é suprimido pelo espalhamento Mie das partículas traçadoras introduzidas no escoamento para realizar medidas com PIV.

Para uma melhor apreciação das contribuições descritas nos trabalhos abordados na revisão bibliográfica sugere-se a leitura das primeiras seções do Cap. 3 que descreve os fundamentos e a metodologia utilizada para realizar as medições.

O capítulo está dividido em três partes. A primeira apresenta uma pesquisa bibliográfica, em ordem cronológica, da evolução da técnica experimental PLIF e de suas aplicações. A segunda parte apresenta uma revisão dos resultados obtidos com a utilização da técnica PLIF aplicada simultaneamente com a técnica PIV. A terceira parte consiste em uma descrição dos equipamentos envolvidos nestas 
técnicas de PLIF e PIV e utilizados nos trabalhos citados, visando apresentar a evolução dos componentes e situar as instalações da PUC-Rio, utilizadas para a realização deste trabalho, entre as demais existentes atualmente.

\subsection{Fluorescência Induzida por Plano Laser - PLIF}

Grieneisen et al. (1971) [26] realizaram o trabalho pioneiro no estudo de fluorescência induzida por uma fonte de luz coerente. Os valores para o momento de dipolo e tempo de relaxação foram obtidos neste estudo de espectroscopia. Entretanto, a técnica de emissão de fluorescência induzida por laser foi desenvolvida por Jankow et al. (1971) [30]. Esta técnica foi aplicada ao estudo de chamas, oito anos mais tarde, por Wrobel e Pratt (1979) [79] que realizaram medidas de fluorescência do sódio em uma chama turbulenta não pré-misturada de propano e ar. Porém, devido à inexistência de medidas simultâneas de temperatura, as incertezas experimentais resultantes eram maiores que $30 \%$. Assim, os resultados foram analisados apenas nas proximidades da frente de chama, sem 0 detalhamento da composição local e da temperatura. A análise realizada foi baseada em descrição estatística, incluindo espectro de potência e funções densidade de probabilidade (PDF), visando comparar os resultados de temperatura obtidos por outros autores em chamas similares.

Anderson et al. (1988) [1] apontam o processo de sublimação (Quenching), ou seja, a desativação da excitação sem a emissão de fótons quando a energia se dissipa mediante colisões eletrônicas, como sendo uma das limitações da técnica PLIF. Os fatores que influenciam a sublimação são, principalmente, o aumento da pressão e a interação entre o composto fluorescente e outra sustância presente no sistema, tal como oxigênio.

Smooke et al. (1991) [62] realizaram a caracterização experimental e computacional de uma chama laminar não pré-misturada. Foram medidas a temperatura e as concentrações de espécies químicas minoritárias, mediante a utilização das técnicas de espalhamento Rayleigh e LIF. As medidas de $\mathrm{OH}$ e $\mathrm{NO}$ são quantitativas e as medidas de $\mathrm{CH}$ são qualitativas. Todas produziram relativa concordância com os resultados calculados, com desvio máximo de $30 \%$. Naquele trabalho, foi realizada também uma descrição quantitativa detalhada da estrutura dinâmica e termoquímica da chama. Além disso, foi determinada a validade da hipótese de equilíbrio químico, parcial ou completo, nesta chama de difusão. $O$ 
radical $\mathrm{OH}$ não é detectável em algumas regiões na base da chama, nos resultados computacionais e experimentais, devido à rápida reação do $\mathrm{OH} \operatorname{com} \circ \mathrm{H}_{2}, \circ \mathrm{CH}_{4} \mathrm{e}$ outros hidrocarbonetos. Também, foi analisada a evolução da fração molar em função da fração de mistura em modelos de elementos de chama.

Smooke et al. (1992) [63] comparam a evolução da fração molar dos radicais $\mathrm{OH}$ e $\mathrm{CH}$ em função da fração de mistura em seções radiais de uma chama anular turbulenta. A concentração máxima de $\mathrm{CH}$ medida no estado fundamental coincide com a região de ancoramento da chama, onde a chama é estabilizada. Assim, foram estudadas a cinética química e sua interação com a fluidodinâmica.

Smooke et al. (1996) [64] estudaram experimentalmente a distribuição da concentração do radical NO em uma chama realizando medidas com a técnica LIF. Os resultados numéricos de NO apresentam desvio de aproximadamente $30 \% \mathrm{em}$ relação com os resultados experimentais.

Chen e Mansour (1997) [15] capturaram imagens da zona de reação de gás natural/ar em chamas pré-misturadas, utilizando simultaneamente espalhamento Rayleigh e LIF do radical $\mathrm{CH}$. Desta forma, os resultados medidos são ajustados a fim de obter medidas quantitativas do radical $\mathrm{CH}$. A intensidade do sinal $\mathrm{CH}$ medido e a concentração de $\mathrm{CH}$ calculada apresentam uma relação linear, com faixa de incerteza de no máximo $30 \%$. A

Figura 2.1 mostra a distribuição de temperatura de $\mathrm{CH}$ obtida por estes autores. Os resultados de temperatura da chama e o sinal de PLIF-CH, são utilizados para avaliar o estiramento da chama. A comparação de imagens de chamas nos limites de extinção sugere que a termometria Rayleigh é a técnica mais adequada para caracterizar uma frente de chama.

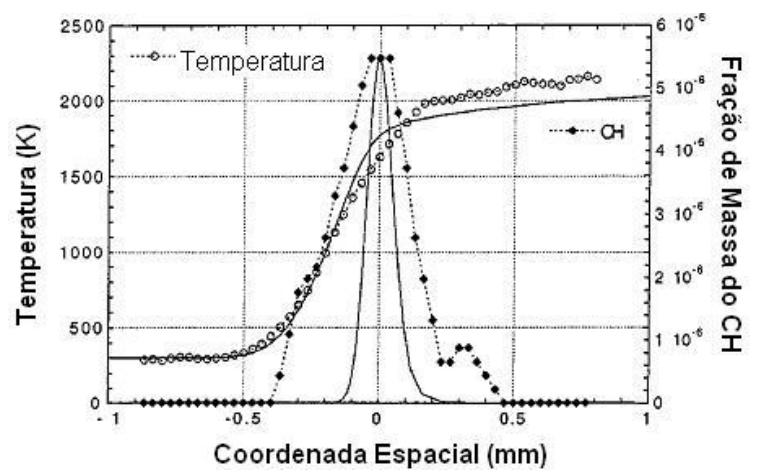

Figura 2.1 Distribuição de temperatura e de fração de massa do $\mathrm{CH}$ em uma chama laminar estequiométrica de gás natural e ar. As linhas simples são os resultados numéricos e as linhas com símbolos são os resultados experimentais [15]. 
Walsh et al. (1998) [72] utilizaram a técnica PLIF para medir a concentração dos radicais $\mathrm{CH}$ e $\mathrm{OH}$, os quais foram excitados a 431,2 nm e 426,8 nm, respectivamente. O queimador é do tipo corpo rombudo contendo uma saída de jato de $4 \mathrm{~mm}$ e um túnel concêntrico de $50 \mathrm{~mm}$ de diâmetro com ar em mesmo sentido de corrente. O combustível utilizado foi $65 \%$ de gás natural e $35 \%$ de nitrogênio a fim de reduzir a quantidade de fuligem. A velocidade de saída de ambos, combustível e ar, foi selecionada em $35 \mathrm{~cm} / \mathrm{s}$. Isto produziu uma chama de aproximadamente $3 \mathrm{~cm}$ de comprimento com uma altura de ancoramento de 5,5 $\mathrm{mm}$. Os resultados computacionais para a comparação foram obtidos utilizando os mecanismos GRI 2.11 [9]. Conforme mostra a Figura 2.2, os dados experimentais foram comparados para a chama laminar não pré-misturada.
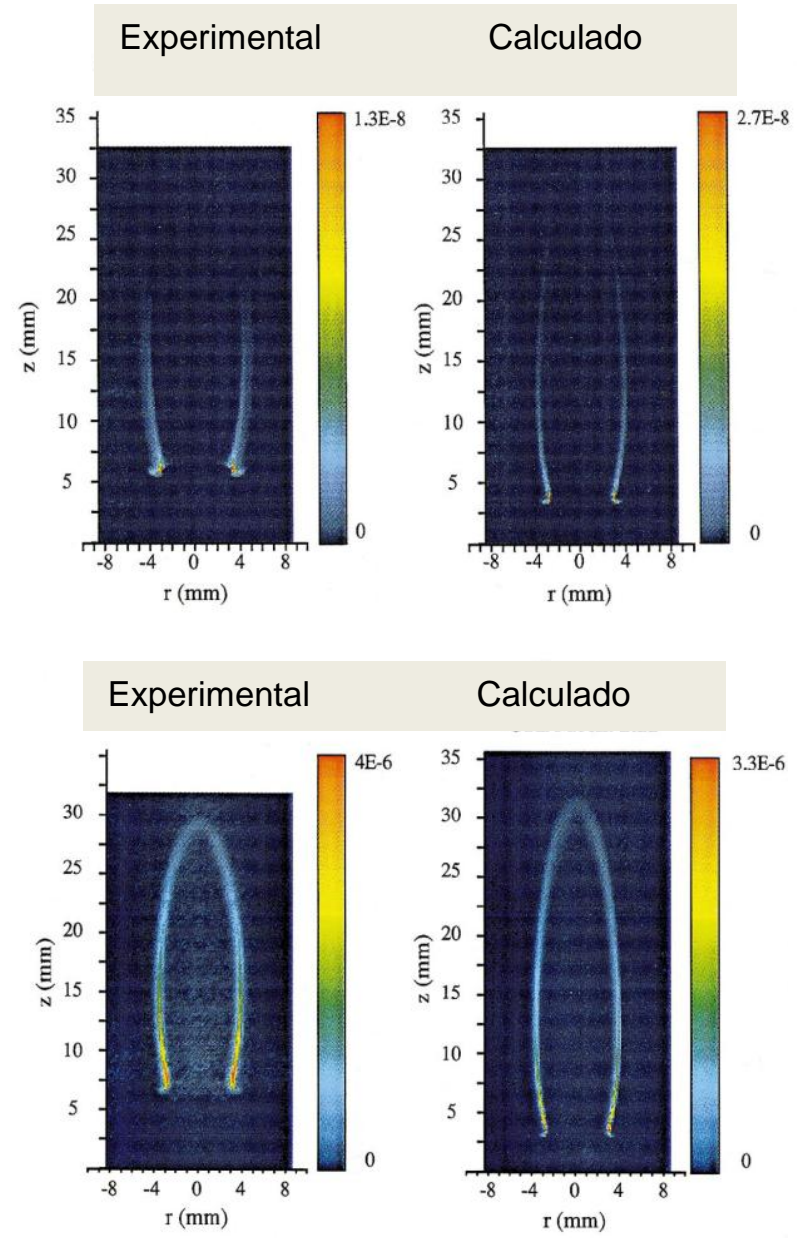

Figura 2.2. Distribuição de fração de mistura de $\mathrm{OH}$ e $\mathrm{CH}$ medidos com PLIF e calculados, respectivamente [72]. 
A comparação entre os resultados de medições de temperatura e a comparação com os resultados calculados apresentam desvio de $20 \%$. Estes resultados permitem obter valores absolutos de concentração de $\mathrm{OH}$ e $\mathrm{CH}$. Assim sendo, a calibração de medidas de concentração pode ser realizadas com base em modelos que utilizem uma cinética química conhecida.

Ryuta et al. (1999) [56] mediram concentrações de $\mathrm{OH}$ em chamas turbulentas anulares não pré-misturadas de gás natural e ar utilizando PLIF. A distribuição de concentração de $\mathrm{OH}$ medida foi comparada com a estrutura de chama calculada, utilizando um mecanismo de reação química que envolve 49 espécies e 279 reações elementares, bem como uma descrição detalhada das propriedades termodinâmicas e de transporte. Essa análise revela que o PLIF é uma técnica adequada para obter a distribuição de concentração relativa de $\mathrm{OH}$.

Smooke et al. (1998) [65] discutem a dificuldade da calibração para obter medidas de concentração, devido à instabilidade química do $\mathrm{OH}$. Além disso, verificam que a utilização de termopares para medir a temperatura da chama causa ignição catalítica, produzindo interferência em medições de temperatura com desvios de $50 \mathrm{~K}$. O depósito de fuligem no termopar é outro fator que causa desvios nas medidas de temperatura, os quais são geralmente cerca de $100 \mathrm{~K}(5 \%)$ menores do que os calculados.

Bombach e Kappeli (1999) [8] utilizaram PLIF para a visualização de espécies que exibem comportamento transiente como $\mathrm{CH}, \mathrm{CN}$ e Formaldeido em chamas turbulentas de gás natural e ar. Os autores se basearam em métodos de conversão não-linear de frequência, os quais permitem a excitação simultânea de diversas espécies, com um único corante, nos comprimentos de onda de $355 \mathrm{~nm}$ e $426 \mathrm{~nm}$. Assim, foi estudado o $\mathrm{OH}$, espécie característica da frente de chama, pois é encontrada em abundância e seu espectro de fluorescência favorece a detecção, mesmo nas situações experimentais mais difíceis, como por exemplo, em chamas com alta concentração de fuligem. A concentração de $\mathrm{OH}$ é menos apropriada para o estudo da sequência de caminhos químicos dentro da frente de chama. Para tanto, as espécies quimicamente mais ativas são de maior interesse. Pequenos tempos de vida geram pequenas concentrações de espécies, mas que podem ser medidas com LIF de $\mathrm{CH}, \mathrm{CN}$ e $\mathrm{CH}_{2} \mathrm{O}$. O radical $\mathrm{CH}$ pode ser utilizado como traçador de frente de chama, além de possuir papel importante na formação de poluentes como o $\mathrm{NO}_{x}$. 
Luque et al. (2000) [38] obtiveram medidas das concentrações de $\mathrm{CH}$ e OH mediante a medição da emissão óptica estimulada de $\mathrm{CH}$ e OH em uma chama laminar não pré-misturada, excitando os estados eletrônicos em 390 nm e em 283 $\mathrm{nm}$, respectivamente. Um modelo numérico de transporte químico foi utilizado considerando os processos reativos, radiativos e de transferência de energia colisional. A comparação entre os resultados medidos e calculados apresentou desvio máximo de $30 \%$.

Tanoff et al. (1996) [69], Gore e Zhan (1996) [25], Blevins e Gore (1999) [7] e McEnally et al. (2000) [42] desenvolveram estudos computacionais e experimentais, nos quais foram examinadas chamas laminares não pré-misturadas em várias configurações. As propriedades analisadas são velocidade, vorticidade, temperatura e fração molar das espécies envolvidas, incluindo o termo de dissipação viscosa. A altura de chama, medida com PLIF-OH, é o parâmetro inicial abordado na comparação entre os resultados numéricos e os medidos experimentalmente.

Bennett et al. (2000) [6] estudaram chamas parcialmente pré-misturadas, as quais apresentam grande dificuldade em serem modeladas com detalhamento químico e transporte multicomponente. O tipo de chama estudado, em condições turbulentas de escoamento, produz localmente uma pré-mistura parcial, observada por McEnally et al. (1999) [42] em configuração anular, a qual contém uma frente de chama pré-misturada na base do queimador e uma chama não pré-misturada no topo. As medidas de temperatura com termopares apresentam desvios de até $50 \mathrm{~K}$ com relação às medidas com diagnóstico laser e as concentrações de $\mathrm{OH}$ e de formaldeído $\left(\mathrm{C}_{2} \mathrm{H}_{2} \mathrm{O}\right)$ apresentam incerteza relativa de $30 \%$ para uma resolução espacial de $1 \mathrm{~mm}$. As medidas de formaldeído são realizadas a fim de obter informações sobre a taxa de liberação de calor pela reação química.

Sick e Wermuth (2004) [61] utilizaram um bico de Bunsen para produzir chamas laminares não pré-misturadas e pré-misturadas de gás natural e ar. Assim, capturaram imagens simultâneas de $\mathrm{OH}$ e acetona, a qual foi diluída no escoamento de combustível. Para tanto, foi utilizado um laser para excitação e detecção em comprimentos de onda próximos a 280 e $310 \mathrm{~nm}$, respectivamente. A Figura 2.3 mostra o espectro de LIF do radical $\mathrm{OH}$, indicando as linhas de fluorescência na faixa de $260 \mathrm{~nm}$ até $340 \mathrm{~nm}$. 


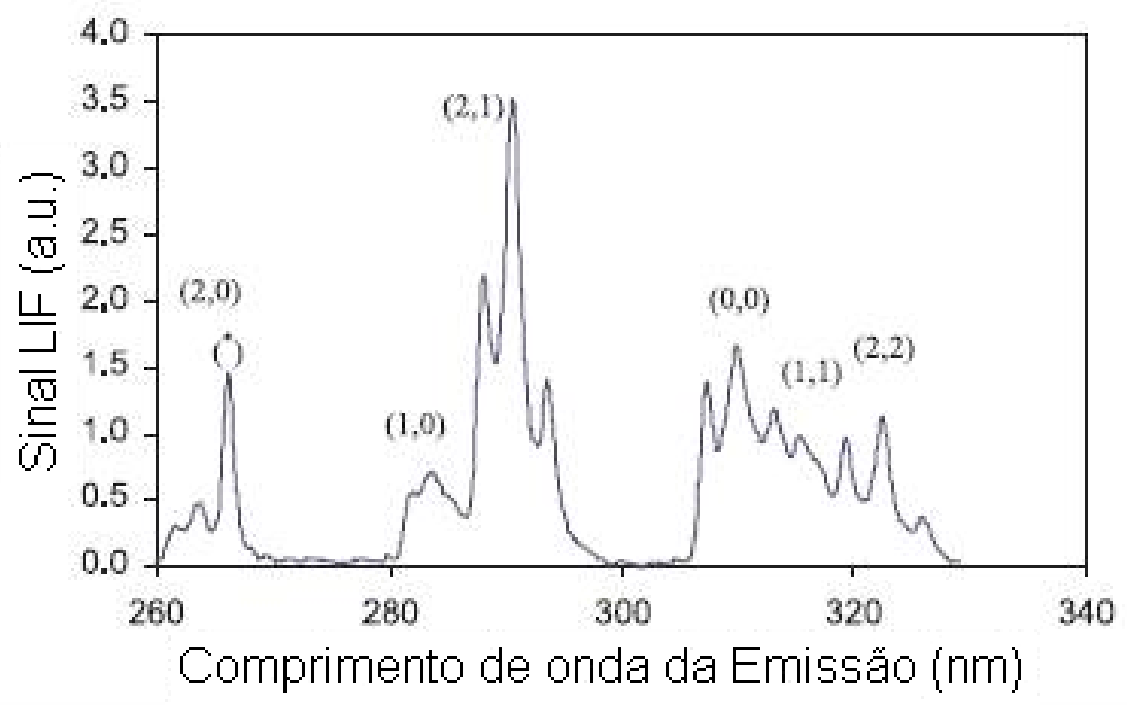

Figura 2.3. Espectro de fluorescência do $\mathrm{OH}$, na região próxima ao UV [61].

A acetona foi dissolvida no escoamento de forma que a intensidade do sinal de sua fluorescência se ajustasse à do sinal de fluorescência do $\mathrm{OH}$, possibilitando que as imagens, como as da Figura 2.4, fossem capturadas por apenas uma câmera ICCD. Isto permite que a área com gases não-queimados seja visualizada simultaneamente ao sinal de $\mathrm{OH}$, a partir da fluorescência da acetona.
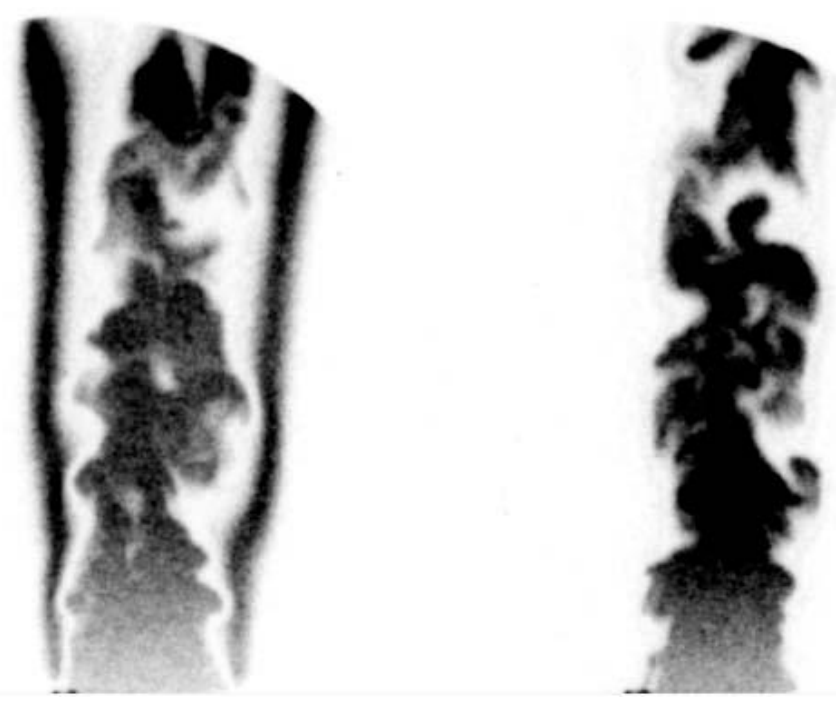

Figura 2.4. Imagem de PLIF-OH combinada com o sinal PLIF de acetona (esquerda). A imagem apenas do sinal de acetona (direita) [61]. 
Lyons et al. (2005) [39] estudaram através de medidas de PLIF-CH, com excitação em 390,30 nm, a existência de descontinuidades em chamas de gás natural e ar. Mostra-se que as descontinuidades são resultado da extinção local, devido à grande taxa de deformação imposta à zona de reação por parte do escoamento. A taxa de deformação é medida simultaneamente com a técnica PIV, segundo a configuração mostrada na Figura 2.5. O estudo da estrutura das chamas turbulentas não pré-misturadas permite analisar a influência da interação do escoamento turbulento com a chama. Os resultados das medidas simultâneas PLIF$\mathrm{CH}$ e PIV permitiram analisar a interação entre o escoamento de combustível e a superfície da chama.

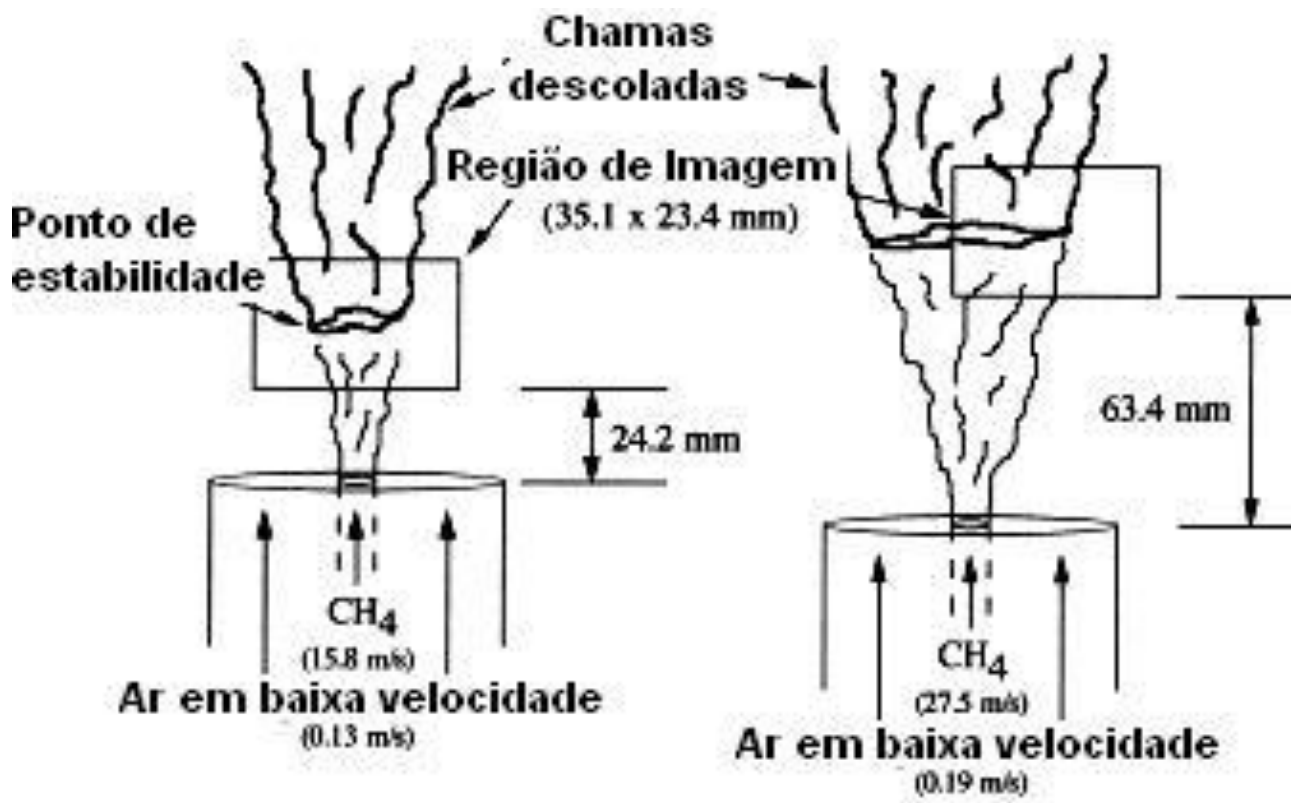

Figura 2.5. Queimador para chama de difusão com ar anular [39].

Dunn et al. (2005) [19] propuseram uma técnica experimental que permite realizar medidas simultâneas de temperatura e distribuição de $\mathrm{OH}$, excitado em 283,2 nm. Investigaram também os erros existentes quando da aplicação simultânea das técnicas de Rayleigh e PLIF. Os fatores mais relevantes são a flutuação da potência do laser, reflexo no ambiente e não uniformidade nas seções de choque dos elementos químicos medidos. Para avaliar estas influências foram realizadas medidas com a técnica LIF, variando a intensidade do feixe de luz laser e comparando o sinal de resposta de fluorescência do $\mathrm{OH}$ em uma chama laminar 
não pré-misturada de gás natural e ar. Em seguida os resultados obtidos experimentalmente foram comparados, tal como mostrado na Figura 2.6, com resultados calculados por Luque (2000) [38]. Um novo modelo analítico é apresentado neste trabalho para a quantificação da fração molar do $\mathrm{OH}$, o qual foi validado através da comparação com os resultados experimentais, apresentando discrepância de cerca de $6 \%$. O sistema foi calibrado a fim de se obter imagens quantitativas, com medidas absolutas de concentração de $\mathrm{OH}$.

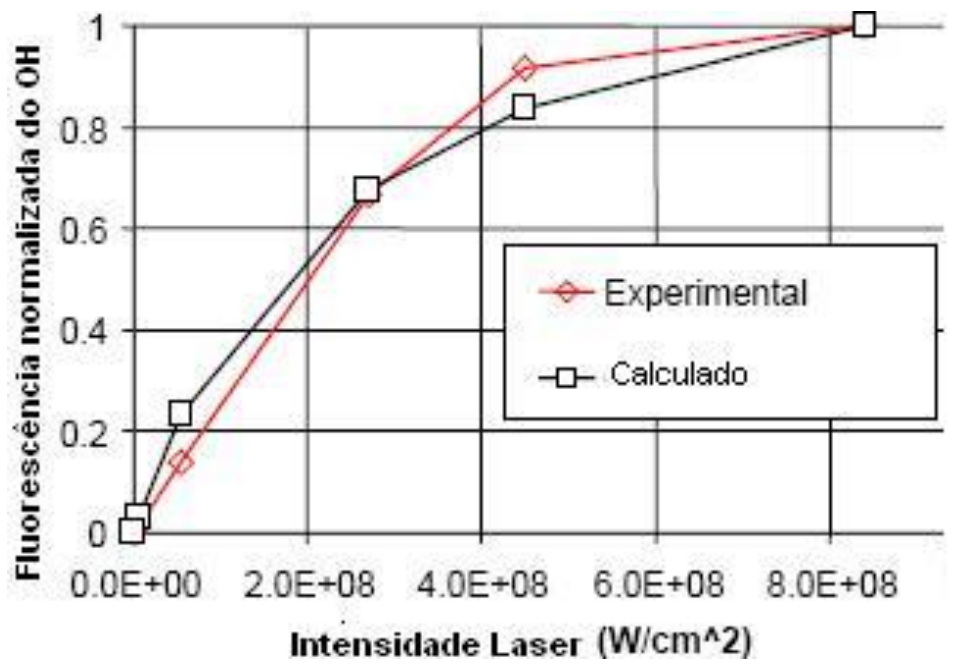

Figura 2.6. Comparação entre medidas LIF e resultados calculados [38].

Walsh et al. (2005) [73] compararam, computacional e experimentalmente, as alturas de descolamento de chamas laminares anulares não pré-misturadas através da medida do radical $\mathrm{CH}$, o qual é um traçador sensível da estrutura da chama. São examinadas as concentrações de $\mathrm{CH}$ e $\mathrm{OH}$, excitados em 431,2 e $307,8 \mathrm{~nm}$, respectivamente. A distribuição desses radicais fornece informação sobre a estrutura da chama, e as alturas de descolamento podem ser diretamente comparadas com as previsões computacionais. A análise indica que a altura de descolamento da chama em relação ao queimador é sensível à velocidade da chama laminar pré-misturada correspondente às condições encontradas na borda da chama. Desta forma, é possível modificar a previsão da altura de descolamento, variando no modelo a velocidade de propagação da chama para valores mais próximos aos experimentais. Também foi demonstrado que a capacidade de modelar o transporte e a cinética química detalhada é crítica para descrever escoamentos reativos turbulentos e o processo de formação de fuligem e de transferência radiativa. A temperatura medida com Rayleigh simultaneamente com 
PLIF de $\mathrm{OH}$, apresenta boa concordância com os resultados obtidos através de modelos. A discrepância entre os cálculos e os valores medidos é menor do que $15 \%$ e $20 \%$ para $\mathrm{OH}$ e $\mathrm{CH}$, respectivamente.

Rothamer et al. (2008) [55] utilizaram a excitação a partir de duas linhas espectrais de luz laser, 277 e 308 nm, a fim de obter medidas simultâneas de temperatura e concentração relativa de $\mathrm{OH}$ em um motor sob condições reais. Assim, os resultados experimentais foram comparados com aqueles obtidos utilizando modelos computacionais, visando determinar a precisão das medidas de temperatura, a qual foi estimada calculando as PDFs de temperatura e concentração de $\mathrm{OH}$. O diagnóstico obteve sucesso na investigação, resultando em desvios menores que $5 \%$ entre os resultados medidos e calculados.

Kiefer et al. (2008) [31] investigaram a estrutura local da chama através de imagens de $\mathrm{OH}$ e PLIF-CH. Para este fim, utilizaram um queimador de jatos coaxiais capazes de estabilizar vários tipos de chamas de gás natural e ar a números de Reynolds de até 13.200. A excitação dos radicais $\mathrm{OH}$ e $\mathrm{CH}$ é produzida com luz laser sintonizada em $387,3 \mathrm{~nm}$ e o laser de Alexandrita de pulso longo, operando em multímodo, excita três linhas de fluorescência do radical $\mathrm{CH}$ sobrepostas em aproximadamente $431 \mathrm{~nm}$.

As imagens de PLIF dos radicais $\mathrm{CH}$ e $\mathrm{OH}$, mostradas na Figura 2.7, revelaram a estrutura local das chamas. A densidade de superfície da chama é determinada pela concentração de $\mathrm{OH}$ obtida nas imagens PLIF. Nas zonas de reação existem grandes concentrações de $\mathrm{OH}$, o que é típico de uma estrutura de chama de difusão, as quais também foram utilizadas para estimar a densidade de superfície da chama. As informações sobre as distribuições de $\mathrm{CH}$ e $\mathrm{OH}$ e os desvios-padrão foram calculados para permitir a comparação dos resultados a fim de validar os resultados das simulações numéricas da chama estudada neste trabalho.

As densidades de superfície de chama determinadas pela média das imagens de PLIF-CH e OH concordam entre si, nos casos de intensidade de turbulência baixa e moderada. Porém, a camada de $\mathrm{CH}$ é quebrada em alta intensidade de turbulência, levando a diferenças significativas entre a forma das superfícies de $\mathrm{OH}$ e $\mathrm{CH}$. Os momentos estatísticos das concentrações dos radicais e as densidades de superfície de chama das imagens fornecem informações que promovem o entendimento das estruturas locais da chama. 

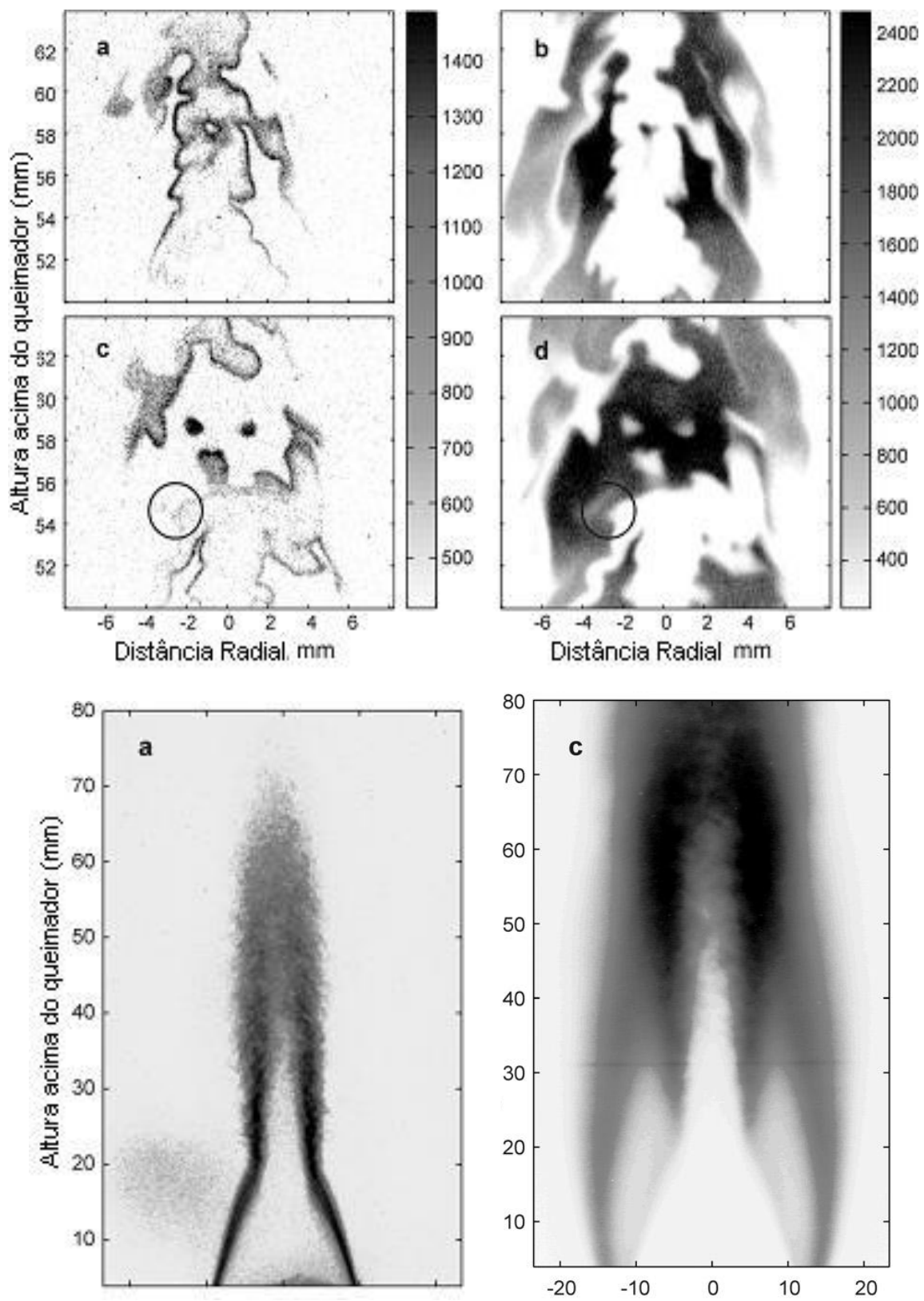

Figura 2.7. PLIF, radical $\mathrm{CH}$ (à esquerda) e $\mathrm{OH}$ (à direita). Imagens PLIF instantâneas (acima) e as médias das imagens (abaixo) [31].

\subsection{PIV e PLIF simultâneos}

Mueller et al. (1995) [44] deram o primeiro passo na análise dos modelos de elemento de chama comparando medidas de fluorescência do $\mathrm{OH}$, obtidas durante a interação entre um vórtice e uma chama laminar contracorrente, com os valores 
calculados. As medidas instantâneas foram realizadas na mesma posição em que foi simulada a frente de chama. O procedimento experimental consiste em interagir uma chama pré-misturada com um vórtice de reagentes. A distribuição da concentração de $\mathrm{OH}$ foi medida utilizando PLIF, enquanto o campo tridimensional da taxa de estiramento foi obtido utilizando as medidas realizadas com PIV. Este estudo aborda os processos físicos presentes nas chamas turbulentas prémisturadas, considerando uma chama instável, curvada, propagando-se livremente e longe das paredes. A diferença entre as propriedades calculadas e medidas foi de aproximadamente $25 \%$. Mesmo onde a taxa de estiramento era constante os valores de $\mathrm{OH}$ apresentaram variações, indicando que a concentração de $\mathrm{OH}$ não é função única do estiramento local instantâneo, mas também é dependente do escoamento. As maiores diferenças são vistas nas medidas de taxa de estiramento tridimensionais, indicando a importância da determinação experimental completa da taxa de estiramento tridimensional, a fim de gerar comparações significativas com modelos. Desta forma a anisotropia também pode ser calculada.

Frank et al. (1996) [22] combinaram diversas técnicas de imagem a fim de estudar escoamentos inertes e reativos. A técnica combinada de PIV e PLIF fornece valores instantâneos de campos escalares e de velocidade, simultaneamente, de uma chama turbulenta pré-misturada de propano/biacetil e ar. Estes autores mostram que implementar PIV em escoamentos reativos apresenta desafios devidos à falta de homogeneidade na dispersão de partículas causada pela liberação de calor pela reação química. A larga faixa dinâmica e grande sensibilidade da câmera CCD diminuem a necessidade de grandes quantidades de partículas na imagem, reduzindo os problemas de saturação do detector. Essas características da técnica PIV permitem medições precisas quando aplicadas a escoamentos com grande variação de homogeneidade, como os que envolvem chamas. Essas imagens foram utilizadas para medir as distribuições de velocidades relativas aos contornos de escalar, em particular, as variações de velocidade dos contornos de concentração de combustível.

As técnicas de PLIF e PIV, quando aplicadas simultaneamente, produzem informações relevantes da correlação entre os campos de velocidade e escalar, tais como os efeitos da deformação exercida por um vórtice sobre uma chama prémisturada. Entretanto, são necessárias medições tridimensionais para estudos dos efeitos relativos à curvatura e deformação da frente de chama. 
As medições PIV/PLIF realizadas naquele trabalho [22] demonstraram a viabilidade de obter medidas das interações de chamas com escoamentos turbulentos. O campo de velocidade foi medido com uma distância de separação entre os vetores de $170 \mu \mathrm{m}$. Os resultados permitiram o cálculo de médias e flutuações da velocidade de produtos e reagentes, como mostra a

Figura 2.8. As quantidades estatísticas da interação entre esses dois campos são comparadas com resultados de simulações numéricas.

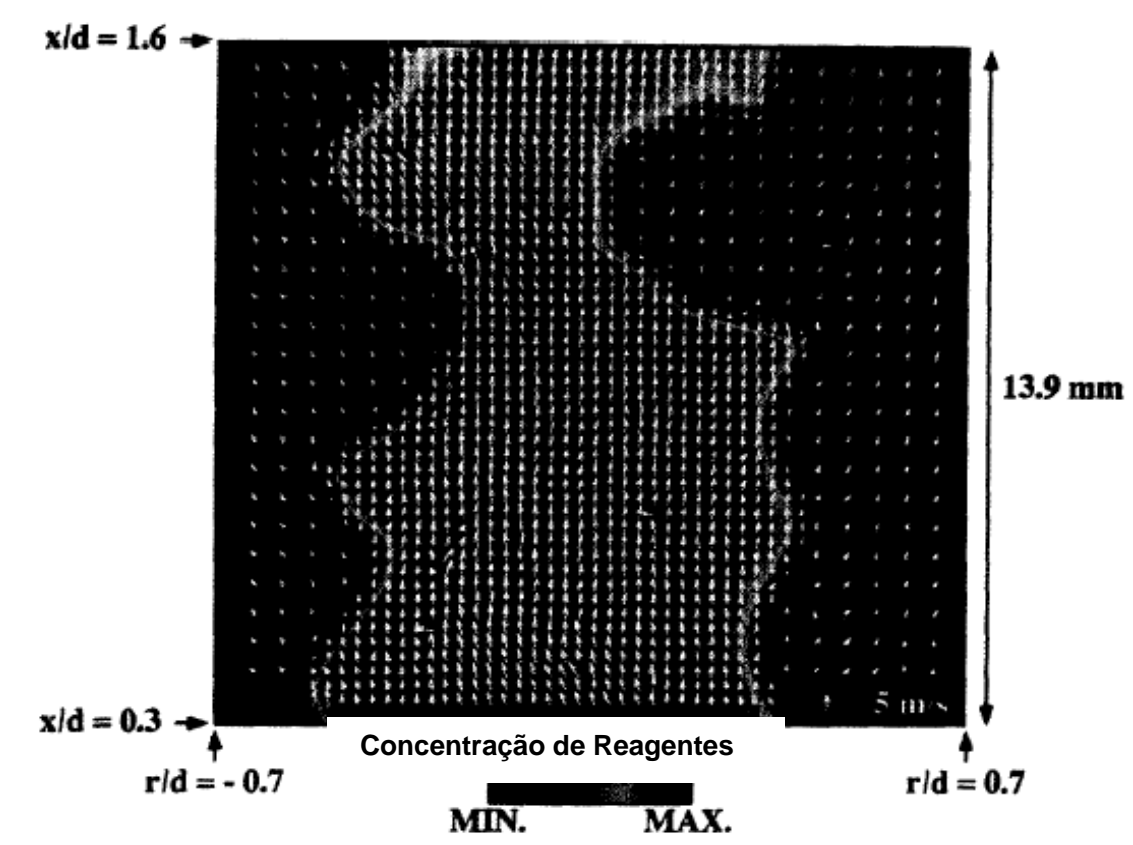

Figura 2.8. Vetores de velocidade sobrepostos à concentração de reagentes em uma imagem simultânea [22].

Muñiz e Mungal (1997) [45] investigaram chamas turbulentas de misturas de gás natural e etileno com ar. O número de Reynolds foi variado de 3.800 a 22.000, a fim de examinar o efeito da velocidade do escoamento anular. A altura média de descolamento aumenta proporcionalmente às velocidades do jato e do escoamento anular, enquanto que a flutuação da velocidade é diretamente proporcional à distância a partir da saída do jato. A técnica PIV em duas dimensões foi utilizada para fornecer os campos de velocidade instantâneos, bidimensionais, da região da base da chama descolada. A janela de medida ocupa uma região de $4,9 \times 4,9 \mathrm{~cm}^{2}$ na base da chama. As imagens são processadas resultando em um campo vetorial, tal como aquele mostrado na Figura 2.9. 


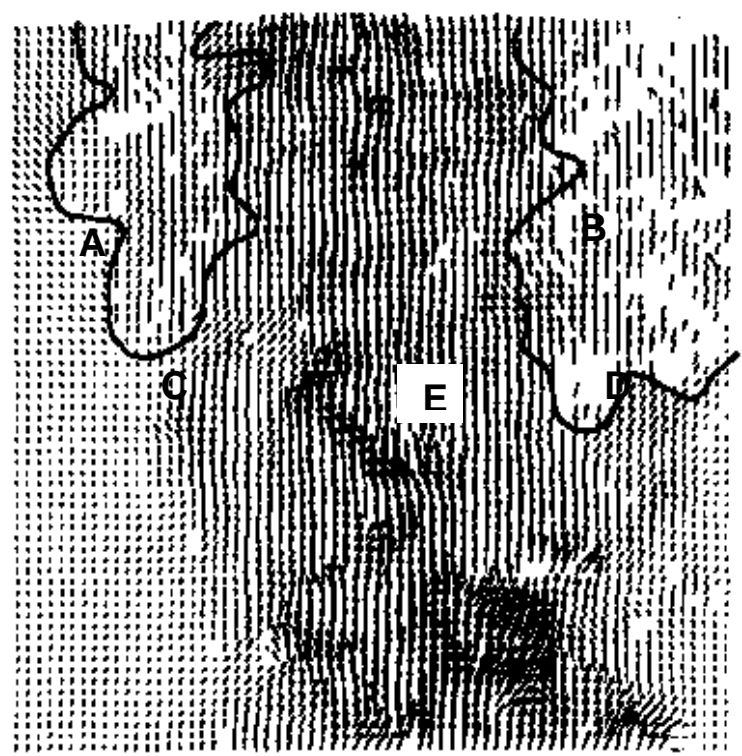

Figura 2.9. Campo de velocidade instantâneo obtido com PIV, onde $A$ e $B$ representam as posições instantâneas da base da chama, $C$ e $D$ representam as posições da base da chama média, e E está ao longo da linha de centro do jato na posição média da altura da chama [45].

As velocidades nas regiões denotadas por A e B indicam com qual velocidade de escoamento a chama é estabilizada. A posição da velocidade média na base da chama é indicada em C e D. O estudo consiste em medir o campo de velocidade a fim de correlacionar os valores de velocidade medidos nos pontos $\mathrm{A} e$ $B$ com aqueles em $C$ e $D$, respectivamente. $O$ comportamento da velocidade através da base da chama é similar aos resultados previstos em simulações de chamas triplas. Os efeitos da velocidade do escoamento anular sobre a posição da chama e a velocidade do ponto de estabilização fornecem informações importantes sobre os mecanismos de estabilização de chamas descoladas.

Rehm e Clemens (1998) [52] realizaram medidas simultâneas de campos de velocidade e concentração de $\mathrm{OH}$ em chamas laminares e turbulentas não prémisturadas, a fim de investigar a relação entre vorticidade, taxa de deformação e estruturas da zona de reação. O campo de visão das imagens de PIV e PLIF é de $33 \times 33 \mathrm{~mm}^{2}$ e a resolução efetiva dos vetores na imagem de PIV foi estimado em 1 $\mathrm{mm}^{3}$. A resolução das imagens de PLIF-OH é de $150 \mu \mathrm{m}$. Um algoritmo foi utilizado para aumentar a resolução da imagem do campo de velocidade de tal forma que pode ser comparada à micro-escala de Taylor da turbulência. 
As imagens de PLIF do radical $\mathrm{OH}$ foram utilizadas para marcar a zona de reação, enquanto as medidas com PIV forneceram duas componentes da velocidade. As estimativas de incerteza experimental de PIV em chamas, realizadas naquele trabalho, consideram os efeitos da incerteza do algoritmo de processamento, a direção do feixe de luz laser, a distorção da imagem e a termoforese. A termoforese influencia o deslocamento das partículas através do gradiente de temperatura, criando um movimento das regiões mais quentes para as mais frias. Este efeito, no caso reativo, cria um componente majoritário do erro sistemático em PIV. A incerteza introduzida pelo algoritmo de auto-correlação é de $1 \%$. Porém, foi verificado naquele trabalho que um erro de $1 \%$ na velocidade causa um erro de até $15 \%$ na taxa de deformação nas imediações da zona de reação.

A Figura 2.10 mostra que as regiões onde há presença de $\mathrm{OH}$ são altamente correlacionadas com os máximos de vorticidade, indicando a ação de cisalhamento através da zona de reação. No caso turbulento, as finas zonas de reação são associadas a grandes valores de deformação por compressão, tendendo a se alinhar na direção normal da máxima deformação por compressão. 0 alinhamento ocorre predominantemente à $45^{\circ}$ da direção do escoamento devido ao cisalhamento dominante nas proximidades das zonas de reação. Os autores recomendam a aplicação da técnica PIV em três dimensões para possibilitar a verificação detalhada destes efeitos em zonas de reação.

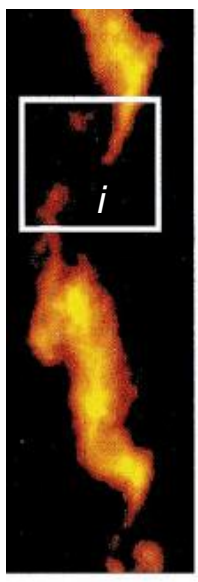

a

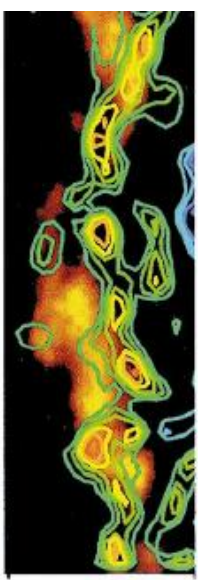

b

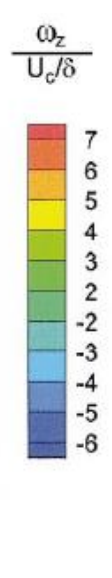

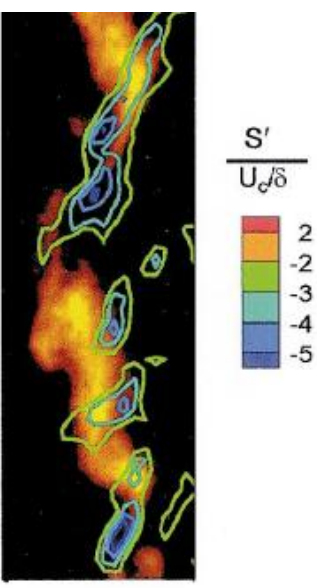

C

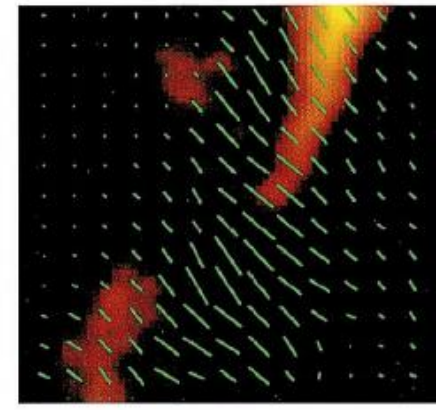

d

Figura 2.10. Imagem PLIF-OH da zona de reação (a). Contornos de vorticidade sobrepostos (b) e contornos de taxa de deformação calculados a partir imagens PIV (c). Detalhamento da região (i) do campo vetorial da taxa de deformação (d) [52]. 
Watson et al. (1999) [75] descreveram técnicas experimentais para medidas simultâneas de PIV/PLIF-CH e PLIF-CH/OH em chamas não pré-misturadas, descoladas, de gás natural e ar. Os objetivos do trabalho são obter visualizações da posição da chama, estabelecer o campo de velocidade no ponto de estabilização na vizinhança da chama e analisar as interrupções na zona de reação, as quais indicam regiões de extinção local da chama. Os resultados obtidos com PLIF$\mathrm{CH} / \mathrm{OH}$ simultâneo permitem estudar o movimento das estruturas de grandes escalas, assim como seu papel na extinção local da chama. Além disso, os vórtices de grande escala desempenham um papel crucial na extinção local da chama.

As medições combinadas de PIV/PLIF-CH indicam que as chamas estabilizadas em regiões de baixa velocidade possuem velocidade de queima $\left(\sim 3 S_{L}\right)$. Isto indica que a chama turbulenta parece estar estabilizada em uma região de pré-mistura. A localização das estruturas turbulentas, obtida a partir das imagens de PLIF-CH, permitem identificar a estrutura do escoamento na região de extinção local da chama.

As medidas, apresentadas na Figura 2.11, são limitadas no sentido de fornecerem imagens instantâneas, aleatórias e que não possuem corelação temporal. Os autores sugerem utilizar a técnica PLIF de pulso duplo como uma alternativa, a fim de examinar a evolução temporal das estruturas de grandes escalas que influenciam diretamente na extinção da chama.

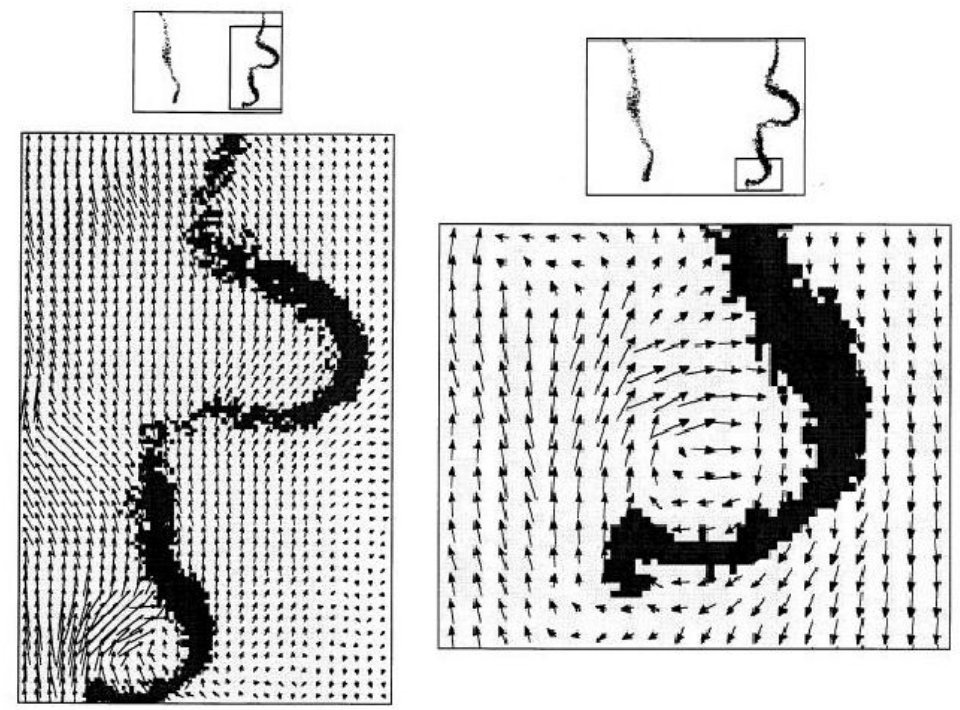

Figura 2.11. Campos de velocidade e concentração de $\mathrm{CH}$ simultâneos, extraídos das regiões da chama mostradas nas imagens no topo. O módulo dos vetores velocidade variam entre 0 e $8 \mathrm{~m} / \mathrm{s}$ [75]. 
Maurey et al. (2000) [41] confirmam que o mecanismo de estabilização das chamas turbulentas descoladas é a propagação das bordas da chama, focando o trabalho no entendimento da influência da dinâmica do escoamento sobre a estabilização da chama turbulenta utilizando PIV e PLIF-OH, simultaneamente. A sustentação deste tipo de chama é controlada pela forte interação entre a fluidodinâmica, a mistura e as reações químicas. Desta forma, medições simultâneas e condicionais são necessárias para a investigação da estrutura do escoamento. O campo turbulento do escoamento quimicamente inerte foi medido a montante da base da chama, a fim de ser comparado com o caso reativo, o qual apresentou uma maior velocidade devido à expansão térmica.

Thévenin et al. (2000) [70] estudaram interações entre uma chama laminar não pré-misturada contra-corrente de hidrogênio e vórtices, o que permitem melhorar o entendimento dos regimes de combustão turbulentos. Para tanto, combinaram um estudo experimental com um estudo numérico realizado. Diversas técnicas ópticas de diagnóstico foram empregadas, entre elas PLIF de acetona para visualizar a distribuição de combustível, medidas simultâneas de PLIF-OH/Rayleigh para analisar a distribuição de temperatura e, medidas simultâneas de PIV/PLIF-OH para quantificar a estrutura do vórtice e a interação entre o campo de velocidade do escoamento e a combustão.

A construção de um diagrama de interação foi obtida através de um pósprocessamento dos resultados, combinado com simulações numéricas diretas usando cinética química e modelos de transporte detalhados. Assim, foram encontrados oito tipos diferentes de interação, enfatizando a importância relativa de fenômenos físicos assim como a deformação, curvatura, dobramento, estiramento e extinção da chama, como mostra a Figura 2.12. Esses regimes e os limites entre eles possuem implicações importantes na modelagem em combustão turbulenta não pré-misturada. Os resultados foram obtidos variando, principalmente, a riqueza global da mistura da chama e a velocidade de propagação do vórtice. 
(a)
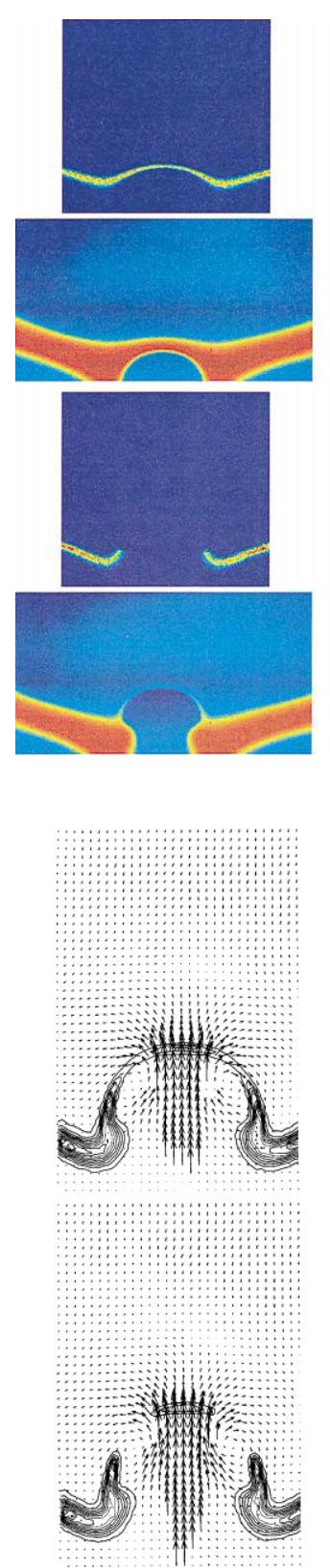

(b)
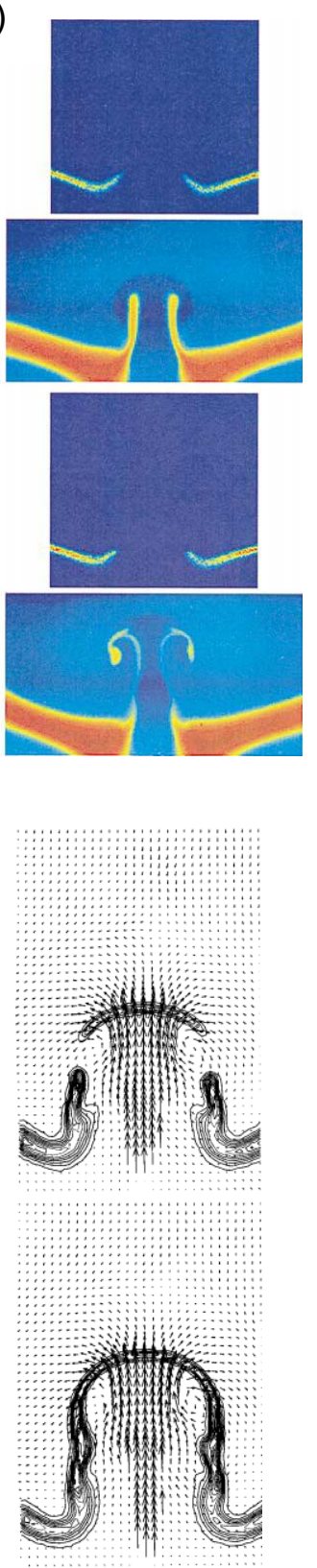

Figura 2.12. (a) Imagens simultâneas de PLIF-OH (acima) e Rayleigh (abaixo), em quatro diferentes instantes de interação, onde a extinção pode ser vista no eixo de simetria. (b) Resultados simultâneos de PLIF-OH e PIV, detalhando a estrutura do escoamento, nos mesmos instantes de tempo das imagens em (a) [70].

Kothnur et al. (2002) [34] investigaram a estrutura de chamas turbulentas não pré-misturadas utilizando $70 \%$ de nitrogênio em $30 \%$ de gás natural em um escoamento anular de oxigênio por um tubo de $150 \mathrm{~mm}$ de diâmetro ao redor do 
jato central de $5 \mathrm{~mm}$, utilizando as técnicas de PLIF-OH e $\mathrm{CH}$ simultaneamente com PIV. O foco deste estudo foi estudar a relação entre as regiões com altas concentrações de $\mathrm{CH}$ e $\mathrm{OH}$ com as propriedades cinemáticas, como vorticidade, taxa de deformação e dilatação. Como mostram os resultados das Figura 2.13 e Figura 2.14, as imagens de PLIF-CH/OH e PIV, obtidas simultaneamente, foram utilizadas para estudar a estrutura de uma chama. Campos bi-dimensionais de vorticidade, taxa de deformação e dilatação estão associados às regiões de alta concentração de $\mathrm{CH}$ e $\mathrm{OH}$.

Os resultados indicam que, na parte mais baixa da chama, a taxa de deformação da frente de chama possui uma direção preferencial de $45^{\circ}$ com relação a direção do escoamento e que as estruturas de $\mathrm{CH}$ não tendem ao alinhamento ortogonal com o eixo principal da deformação compressiva. Por outro lado, a extremidade superior da chama é aleatória, e as estruturas de $\mathrm{CH}$ são alinhadas na direção ortogonal da deformação compressiva. Além disso, as PDFs conjuntas de deformação e dilatação mostram que as estruturas de $\mathrm{CH}$ são mais provavelmente associadas com a dilatação positiva do que as estruturas de $\mathrm{OH}$. Os resultados também mostraram que as estruturas de $\mathrm{CH}$ exibem uma correlação mais forte do que as estruturas de $\mathrm{OH}$ com as variações do escoamento resultantes da liberação de calor.

(a)

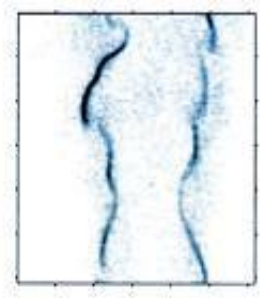

(b)

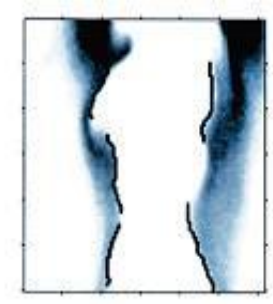

(c)

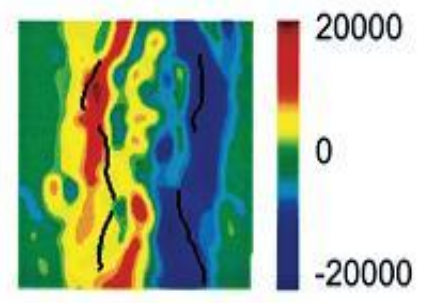

(d)

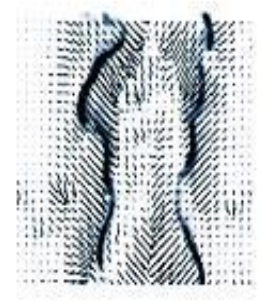

(e)

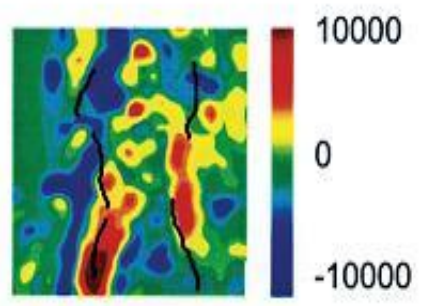

Figura 2.13. (a) PLIF-CH; (b) PLIF-OH; (c) vorticidade; (d) taxa de deformação mínima (as linhas estão orientadas na direção do eixo de deformação e o comprimento de cada segmento é proporcional ao valor absoluto da deformação); (e) dilatação. As linhas negras marcam o centro das estruturas de $\mathrm{CH}$ [34]. 


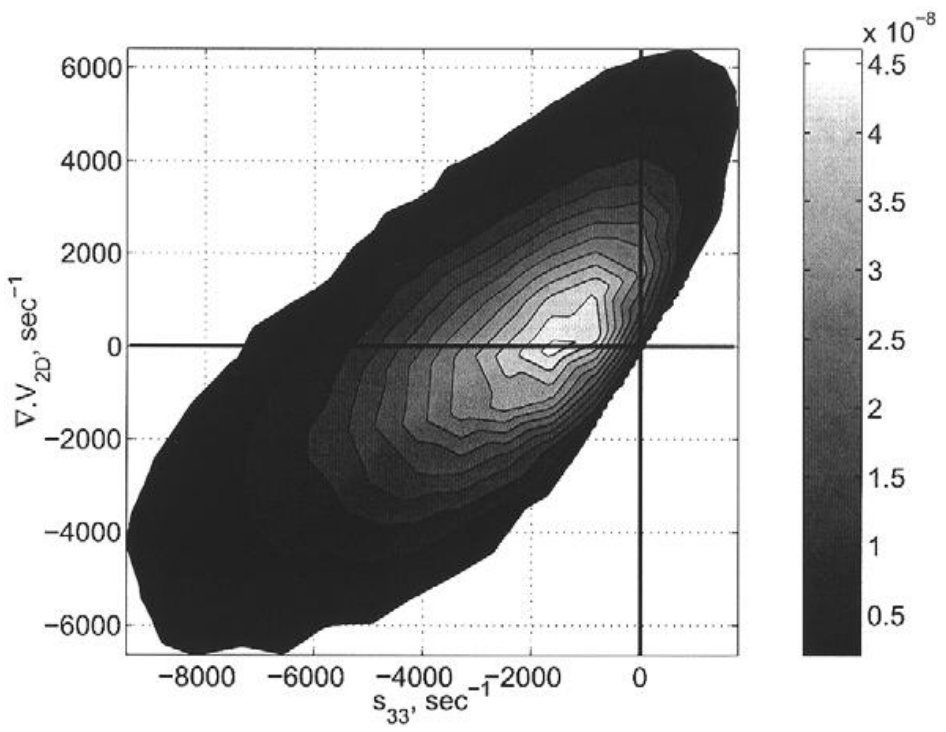

Figura 2.14. PDF conjunta da taxa de dilatação nas regiões contendo $\mathrm{OH}$ [34].

Petersson et al. (2007) [47] realizaram medidas simultâneas com PIV e PLIF-OH; termometria Rayleigh, PLIF-OH e também PIV estéreo em uma chama turbulenta produzida com swirl. Os resultados extraídos das imagens mostradas na Figura 2.15 incluem momentos estatísticos das quantidades fluido-dinâmicas, distribuição de $\mathrm{OH}$, temperatura, velocidade do escoamento e fluxos turbulentos. A variável de progresso foi extraída das distribuições de $\mathrm{OH}$ capturadas em intervalos de $400 \mu$ s e, a partir daí, o fluxo escalar foi deduzido. A comparação das imagens permite avaliar as informações de temperatura ao redor da frente de chama. Isto permite gerar dados para desenvolver simulações de grandes escalas (LES) e validar modelos para chamas turbulentas. 

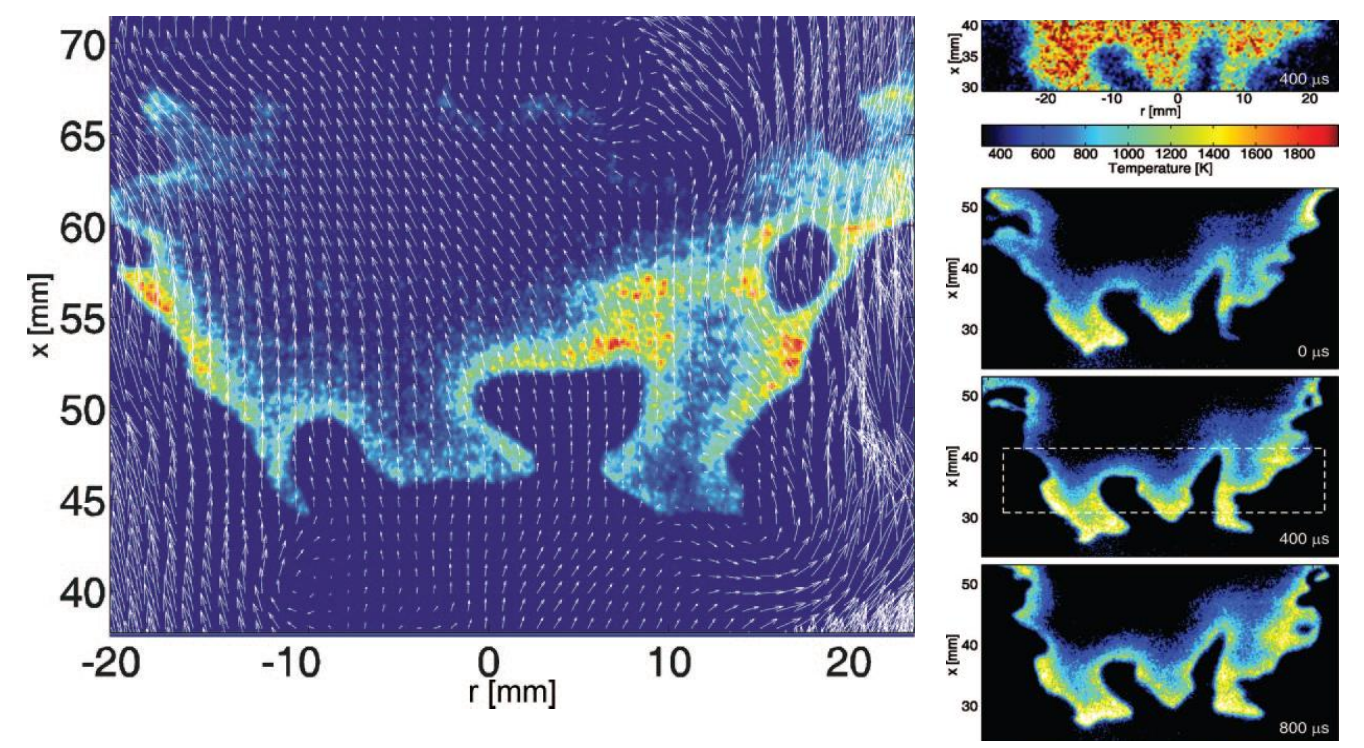

Figura 2.15. Imagem de PIV combinada com PLIF-OH (esquerda). Imagem da distribuição de temperatura seguida por imagens de PLIF-OH (direita) [47].

Gautam (2008) [24] realizou medidas simultâneas de PIV e PLIF em um jato livre homogêneo com número de Reynolds de 1.960. O sistema PIV permite a determinação do campo de velocidade, tensores de Reynolds transversal, longitudinal e cruzado e a vorticidade, enquanto as imagens de PLIF caracterizam a distribuição da concentração de espécies químicas minoritárias do escoamento, como $\mathrm{OH}$ e $\mathrm{CH}$. Os resultados característicos satisfazem os aspectos teóricos dos modelos de jatos livres homogêneos turbulentos.

Sadanandan et al. (2008) [57] aplicaram as técnicas de PLIF-OH e PIV, simultaneamente, em um modelo de câmara de combustão de turbina a gás, utilizando gás natural como combustível, onde o processo de combustão é fortemente influenciado pelas interações entre reações químicas e turbulência. Os resultados mostrados na Figura 2.16 revelam a formação de zonas de reação, onde os gases queimados da recirculação interagem com a mistura fresca de combustível e ar. A imagem PIV simultânea com PLIF-OH mostra a existência pequenos vórtices, os quais possuem papel vital na formação e destruição das estruturas internas das zonas de reação. As variações dos vetores velocidade próximos às regiões da imagem com altas concentrações de $\mathrm{OH}$ indicam a existência de uma zona de reação. Assim, os gradientes destas quantidades, nas direções transversal e longitudinal, permitem identificar, espacial e estruturalmente, as zonas de reações transientes. 


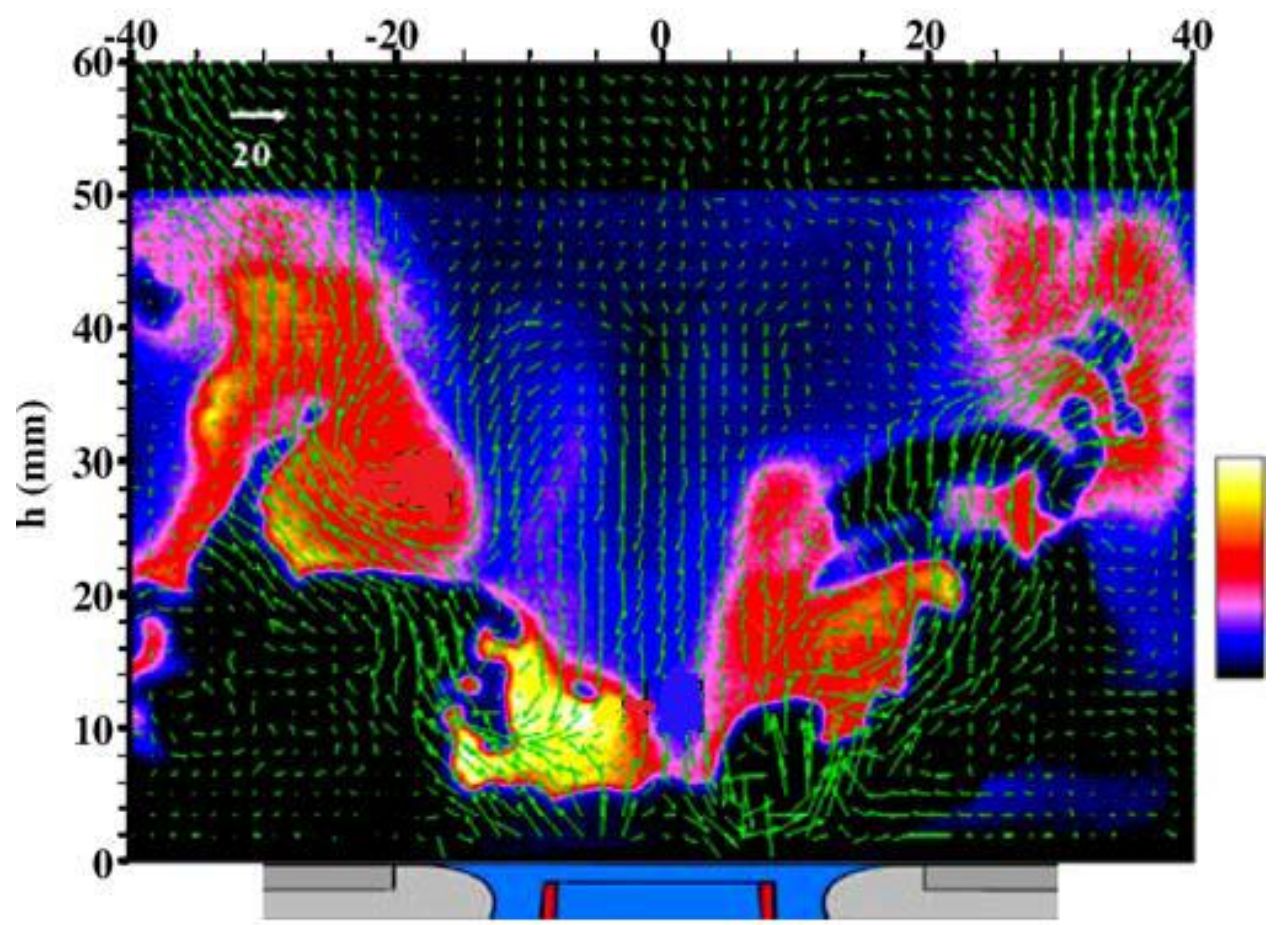

Figura 2.16. Imagem combinada de PLIF-OH e PIV em uma turbina a gás [57].

Böhm et al. (2009) [10] utilizaram imagens simultâneas de PIV e PLIF-OH em alta taxa de captura $(5 \mathrm{kHz})$ para obter resultados de propriedades flutuantes resolvidos no tempo em uma chama turbulenta com jatos opostos. Essa taxa de repetição permite acompanhar os eventos transientes de extinção em combustão turbulenta e, também, o estudo da evolução das interações dos vórtices e da chama de eventos individuais de extinção.

A Figura 2.17 mostra a sequência de uma extinção, onde são superpostos os campos de vorticidade e deformação, coplanares aos vetores velocidade. Os contornos de concentração de $\mathrm{OH}$ instantâneos são representados pelas linhas negras. As médias condicionais das propriedades do escoamento foram calculadas, assim como, a taxa de deformação e a vorticidade no momento anterior à extinção. A estatística condicional mostra que os vórtices tendem a se alinhar ao redor da chama, gerando regiões de alta taxa de deformação na zona de extinção da chama. 


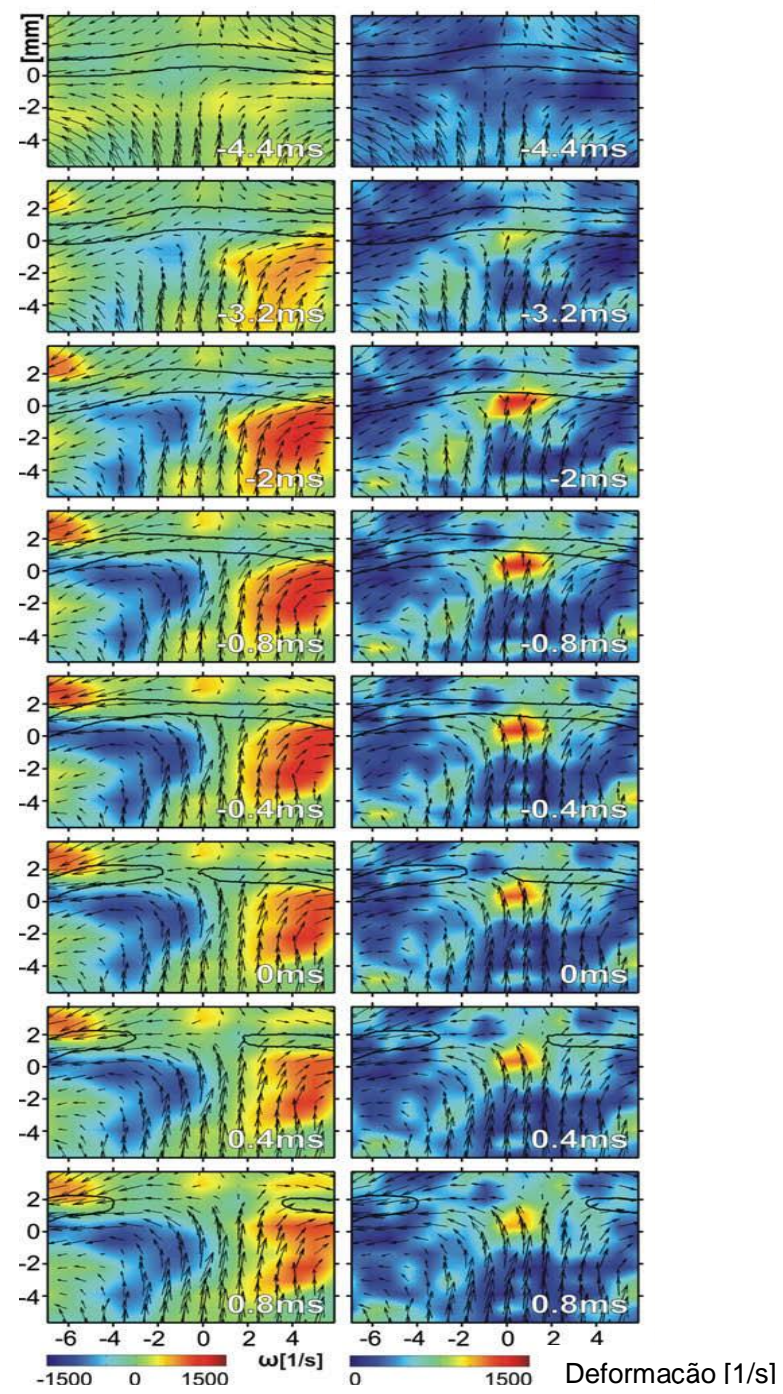

Figura 2.17. Sequência de campos de vorticidade (esquerda) e deformação (direita), sobrepostos aos resultados de PLIF-OH e PIV, em diversos instantes de tempo [10].

Foi verificado que os vórtices da turbulência geram deformação junto à chama, a qual se extingue quando os valores críticos de taxa de deformação são excedidos. Este estudo conclui que apenas a taxa de deformação é insuficiente para parametrizar a extinção em condições de escoamento transiente.

Steinberg et al. (2009) [67] estudaram a evolução temporal da taxa de estiramento de uma chama devido à turbulência e, também, da instabilidade hidrodinâmica causada pela aceleração do gás através da frente de chama. A taxa de deformação de uma chama turbulenta pré-misturada foi medida experimentalmente utilizando a técnica de PIV estéreo, com medidas simultâneas de PLIF-CH. 
O aumento das componentes dos tensores de Reynolds medidos é associado à diferença entre a velocidade na extremidade a jusante da chama, curvada ora positiva ora negativamente, na qual é aplicada uma taxa de deformação por compressão por parte do escoamento. Como mostra a Figura 2.18, a chama é deformada devido aos gradientes de velocidade, os quais são associados diretamente à turbulência e, também, pelo efeito da instabilidade hidrodinâmica.

Produrtos

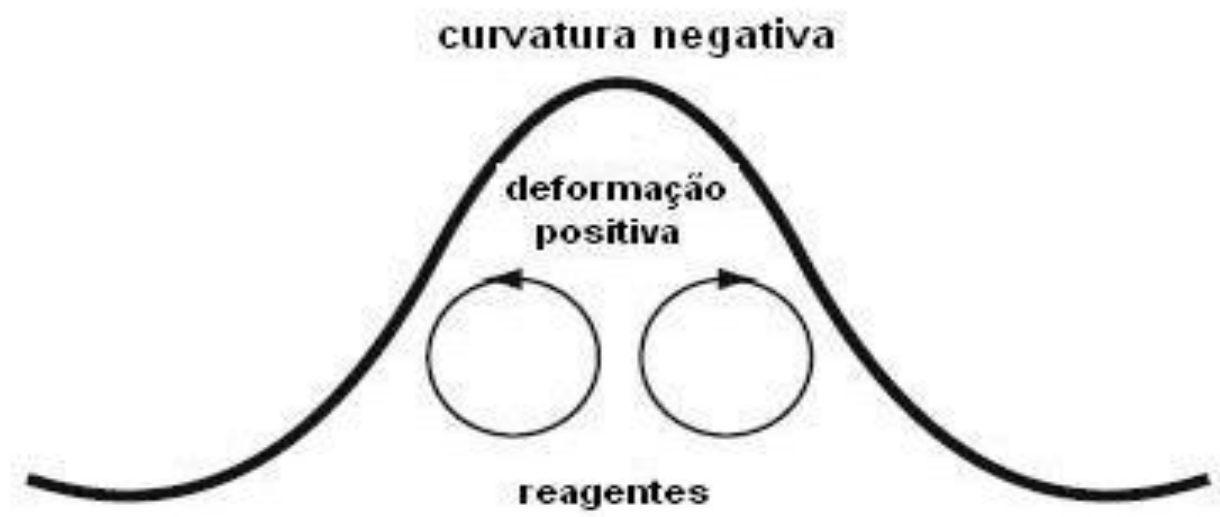

(a) Rotação externa

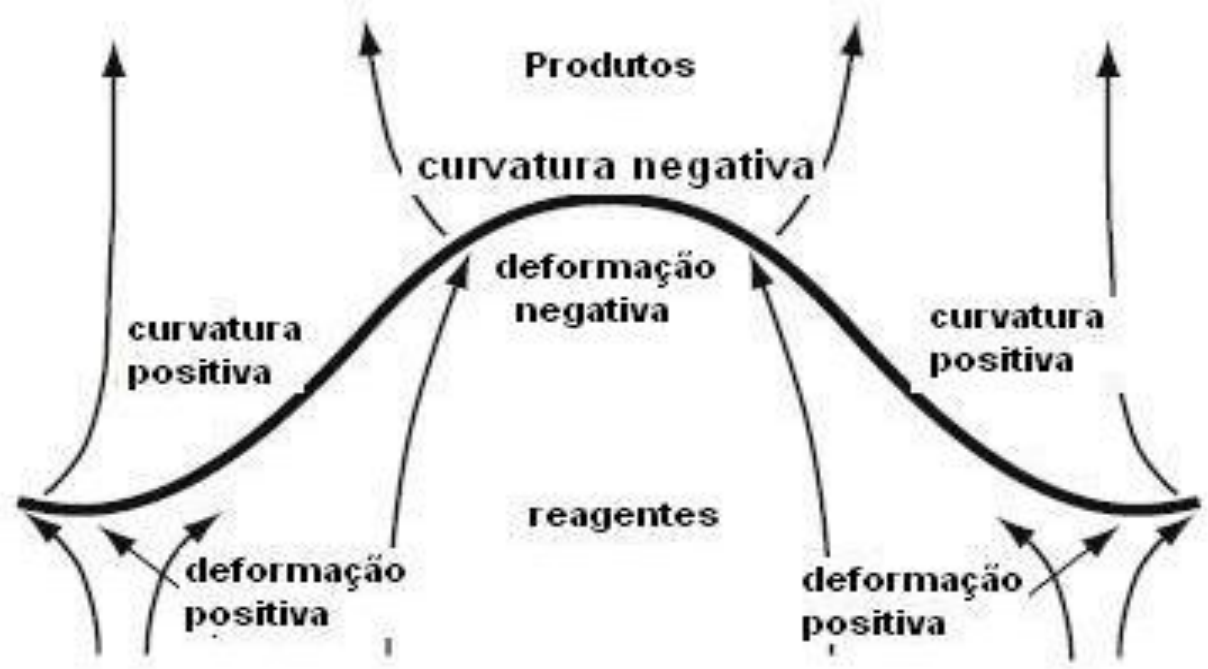

(b) Instabilidade Hidrodinâmica

Figura 2.18. Padrões de escoamento associados ao estiramento de uma chama pré-misturada [67]. 
As imagens da interação entre a turbulência e a superfície da chama são capturadas a uma taxa de $1,1 \mathrm{kHz}$. Uma sequência temporal destas imagens é mostrada na Figura 2.19. As linhas mostradas nesta figura apresentam as regiões que correspondem às curvaturas devidas à taxa de deformação. $O$ desenvolvimento de dobras nas chamas causadas por esses mecanismos foi observado nos resultados obtidos. A chama é dobrada pelos vórtices gerados pela turbulência, os quais são atenuados ao passarem pela chama. Além disso, o padrão desenvolvido de instabilidade hidrodinâmica do escoamento é deformado após a passagem das estruturas turbulentas. A instabilidade hidrodinâmica também causa o aumento de pequenas perturbações na frente de chama, dentro de grandes dobras da chama. Assim, o mecanismo de instabilidade hidrodinâmica afeta significativamente a deformação da chama e deve ser incluído nos modelos de combustão turbulenta.

A evolução da taxa de deformação causada pela interação da turbulência com a chama segue um padrão envolvendo três regimes temporais de interação entre turbulência e combustão. No primeiro, a turbulência exerce uma deformação positiva e a curvatura negativa da dobra é formada. O período de transição ocorre quando os efeitos da turbulência e dos mecanismos de instabilidade hidrodinâmica são de importância similar, no momento em que os vórtices passam através da chama. No segundo e no terceiro regimes, a taxa de deformação é dominada pela instabilidade. Esses regimes são caracterizados por diferentes correlações entre taxa de deformação e curvatura. No primeiro a correlação é negativa e aumenta com o tempo. No segundo a correlação é positiva e aumenta com o tempo, enquanto que no terceiro, a correlação é positiva e constante. 


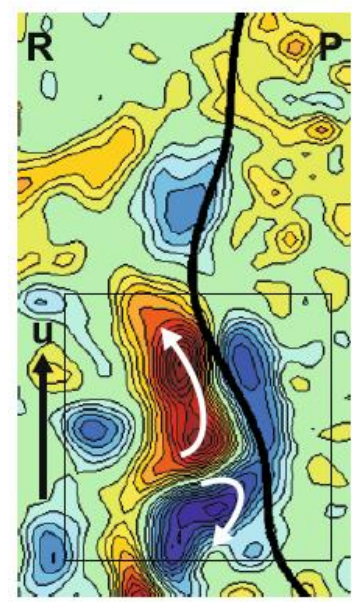

(a) $t=0 \mathrm{~ms}$

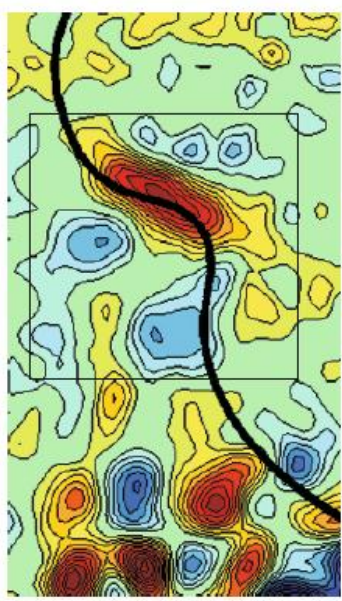

(e) $t=3.6 \mathrm{~ms}$

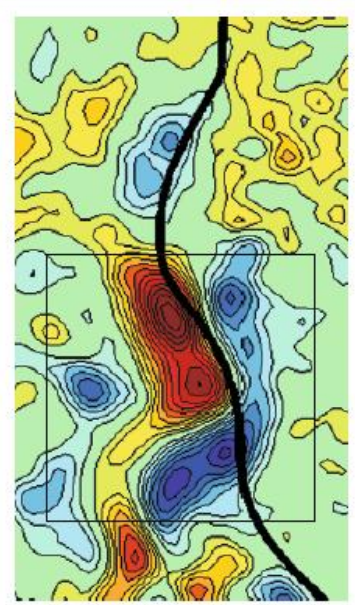

(b) $t=0.9 \mathrm{~ms}$

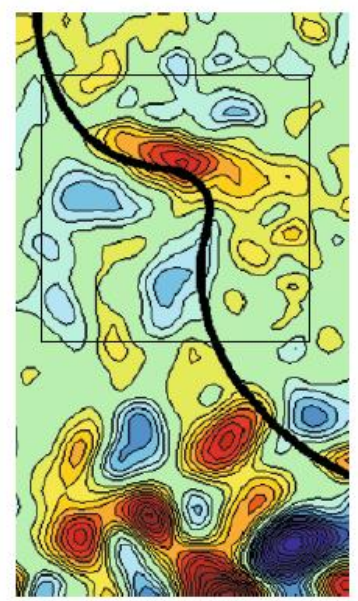

(f) $t=4.5 \mathrm{~ms}$

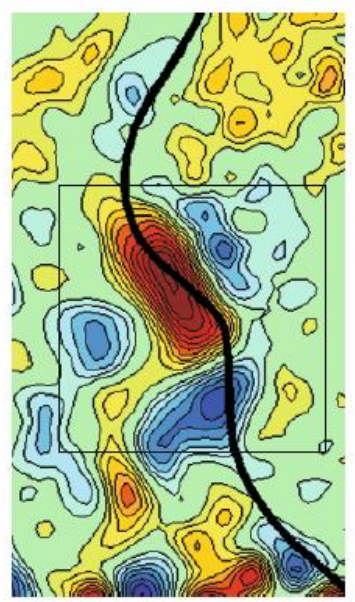

(c) $t=1.8 \mathrm{~ms}$

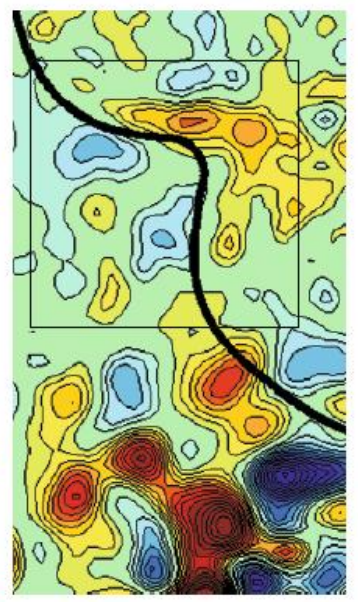

(g) $t=5.4 \mathrm{~ms}$

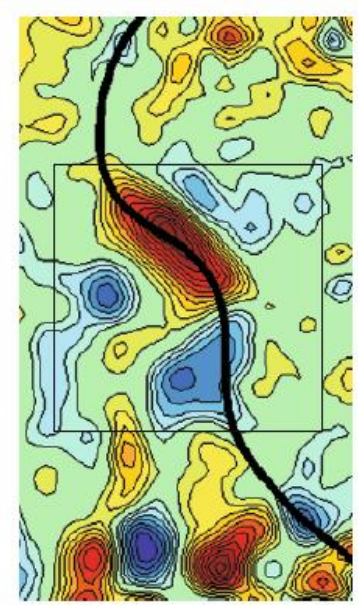

(d) $t=2.7 \mathrm{~ms}$

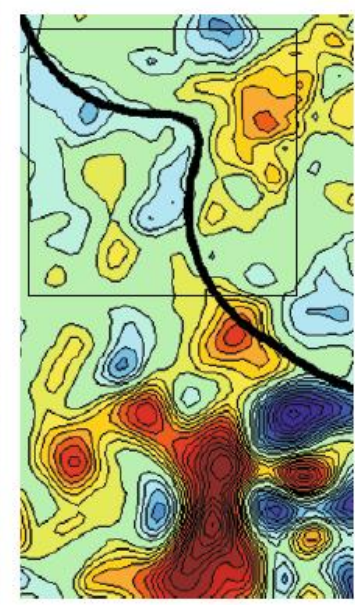

(h) $t=6.3 \mathrm{~ms}$

Figura 2.19. Resultados da interação da turbulência com a chama gerando uma dobra. Contornos de vorticidade são apresentados em vermelho (positivo) e azul (negativo). Os contornos da chama são mostrados pela linha negra. As dimensões do campo de visão são de aproximadamente $6 \times 10 \mathrm{~mm}$. À esquerda ficam os reagentes e o escoamento ocorre de baixo para cima na imagem [67].

Troiani et al. (2009) [71] estudaram chamas turbulentas pré-misturadas estabilizadas sobre um queimador corpo rombudo, axisimétrico. O combustível utilizado foi uma mistura de $\mathrm{H}_{2}$ e $\mathrm{CH}_{4}$ com composição variável. Medidas simultâneas de concentração de $\mathrm{OH}$ e velocidade do gás foram realizadas utilizando as técnicas de PLIF e PIV. A velocidade do jato de combustível é variada com intuito de investigar a influência do número de Damköhler sobre o escoamento na zona de recirculação. A altura do descolamento da chama aumenta com a 
velocidade de saída do jato, alterando assim a região de recirculação onde a chama é ancorada. Foi realizado um estudo paramétrico dos efeitos da turbulência no transporte escalar sob condições controladas, variando a intensidade da turbulência que interage com a chama. A chama é fortemente influenciada pela recirculação induzida pelo corpo rombudo, onde a posição da chama se torna bastante sensível à riqueza da mistura. Isto permite investigar o comportamento de escoamentos turbulentos para diferentes valores locais de intensidade turbulenta, velocidade de chama laminar e taxa de expansão térmica a um número de Reynolds constante. As medidas são realizadas na mesma janela, de 10 a $100 \mathrm{~mm}$ acima da superfície do queimador e os resultados obtidos são média, RMS e PDF. A partir dos resultados pode-se notar que turbulência afeta a estrutura da frente de chama.

Shimura et al. (2011) [60] utilizaram simultaneamente as técnicas de PLIF$\mathrm{CH}$ duplo plano, PLIF-OH e PIV estereoscópico duplo plano, a fim de realizar medidas em combustão para investigar as estruturas tri-dimensionais de chamas turbulentas pré-misturas de gás natural e ar.

As medidas simultâneas fornecem a estrutura da frente de chama em três dimensões, as três componentes da velocidade e as nove componentes do tensor taxa de deformação. As medidas foram realizadas em chamas estabilizadas utilizando swirl. As medidas tri-dimensionais possibilitam a visualização de diversas estruturas na chamas turbulentas pré-misturas estabilizadas em escoamentos com altos números de Reynolds. A taxa de deformação apresenta valores elevados na região dos gases não queimados. Os resultados, mostrados na Figura 2.20, indicam o potencial destas técnicas, realizadas simultaneamente, com respeito à investigação das características da turbulência e de sua interação com a combustão.

A taxa de deformação calculada a partir das componentes de velocidade é cerca de 10\% maior do que aquela obtida utilizando-se PIV estéreo em um único plano. Os resultados de curvatura e da taxa de deformação fornecem informações sobre o estiramento da chama, contribuindo para estudos de modelagem de chamas. 

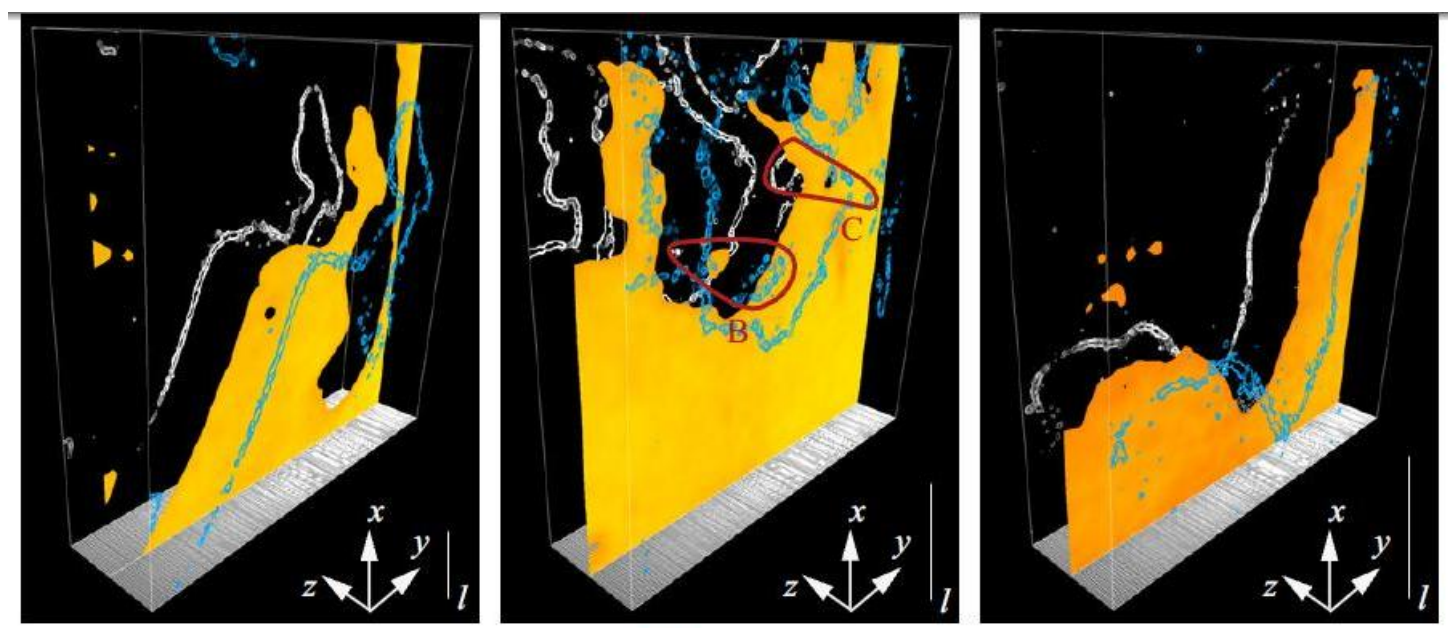

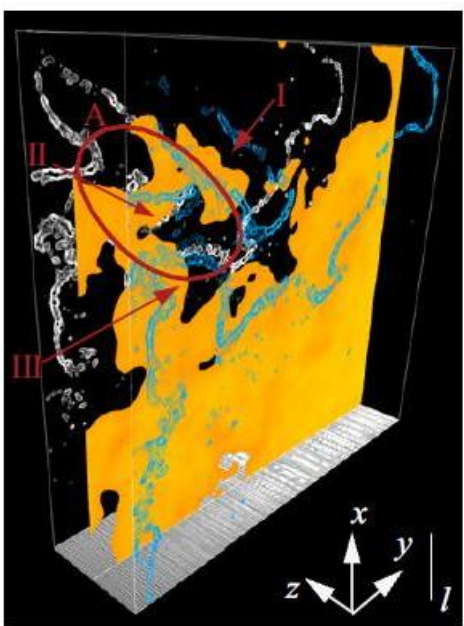

(a) $200 \mathrm{~L} / \mathrm{min}$

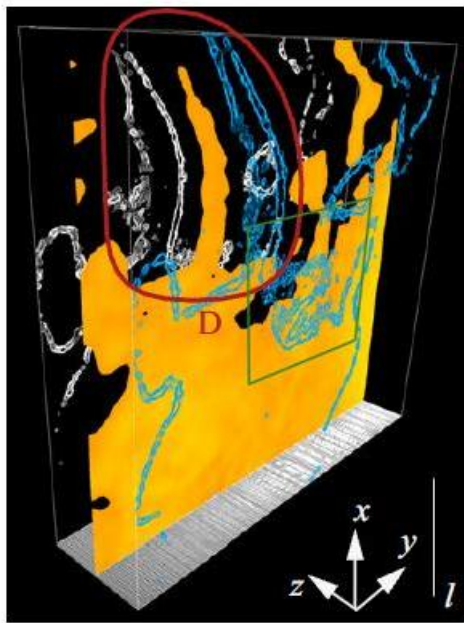

(b) $250 \mathrm{~L} / \mathrm{min}$

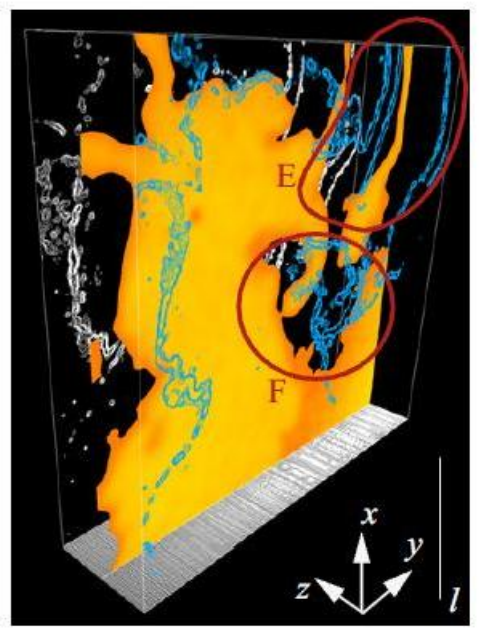

(c) $300 \mathrm{~L} / \mathrm{min}$

Figura 2.20. Estruturas tri-dimensionais de chama. As isolinhas azuis revelam as distribuições $\mathrm{CH}$ sobre o plano de frente; As isolinhas brancas mostram as distribuições de $\mathrm{CH}$ sobre o plano de fundo; as regiões em amarelo são os gases não queimados, estimados pelas distribuições de $\mathrm{OH}$, no plano do meio [60]. 


\subsection{Instalações experimentais para medição simultânea com PLIF e PIV}

Frank et al. (1996) [22] mediram velocidade com PIV em um escoamento inerte utilizando, para traçar o escoamento, aerossol de cristais de açúcar submicrométricos por apresentarem relativa facilidade em controlar a homogeneidade de dispersão. Esse aerossol foi disperso no escoamento de ar anular e no jato central de combustível utilizando um equipamento da marca TSI, modelo 93061. A velocidade média do jato de combustível na saída do queimador era de $4,8 \mathrm{~m} / \mathrm{s}$, com $\operatorname{Re}_{\mathrm{j}}=3.500$.

Tal como mostra a Figura 2.21, a excitação do biacetil para a técnica de PLIF é obtida em $440 \mathrm{~nm}$, utilizando um laser de corante (Candela, LFDG 20) com Coumarino. O segundo harmônico (532 nm) de um laser Nd:YAG laser (Quanta-Ray DCR-2A), duplo pulso foi utilizado para a iluminação das partículas na técnica PIV. O feixe de luz laser passa por um conjunto de lentes para formar um plano de luz, com $2 \mathrm{~cm}$ de altura, na região do escoamento. $O$ tempo entre os pulsos pode ser selecionado entre 25 a $200 \mu$ s para otimizar a correlação entre os pares de quadros de imagem em medições PIV, dependendo da velocidade do escoamento.

Um detector CCD (Photometrics KAF4200) com arranjo de 2048x2048 pixel foi utilizado para capturar imagens em uma região de $10 \times 10 \mathrm{~mm}^{2}$ do escoamento. Do lado oposto, uma segunda câmera CCD (Photometrics Star 1) é acoplada a um intensificador de imagem (ITT F4767P), a qual foi utilizada para capturar a fluorescência do biacetil. A resolução deste detector é de 384x576 pixels, o que abrange um campo de visão do escoamento com dimensões de $15 \times 22 \mathrm{~mm}^{2}$. O conjunto óptico relativo à fluorescência inclui também duas lentes que filtram a luz, a qual possui comprimento de onda igual a $532 \mathrm{~nm}$. O sistema completo trabalha com uma frequência de aquisição de $10 \mathrm{~Hz}$, limitada pela cadência dos pulsos de luz laser.

Em estudos anteriores a este, os resultados de PLIF e PIV eram gravados em filmes fotográficos, os quais possuem maior definição espacial, porém, são limitados no que diz respeito à captura de diversas imagens em uma sequência quando comparados com a utilização de detectores eletrônicos. 


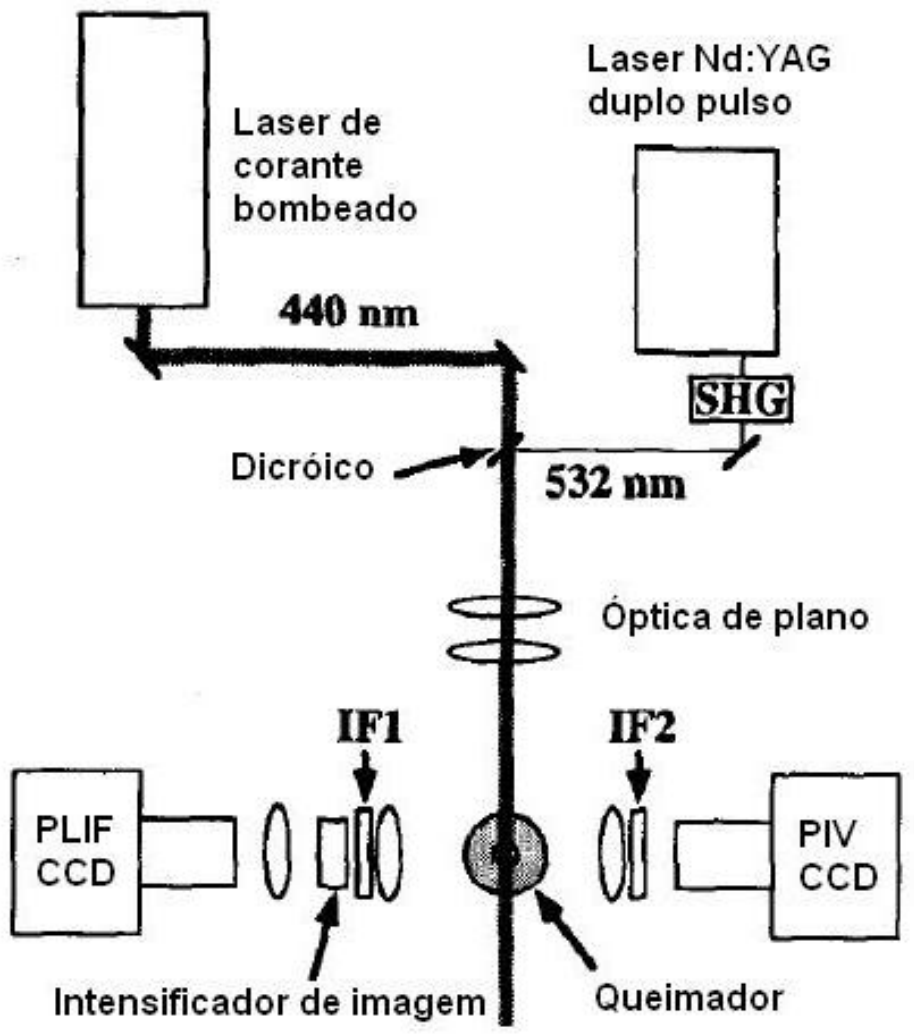

Figura 2.21. Aparato experimental para medições simultâneas de PIV/PLIF [22].

Muñiz e Mungal (1997) [45] empregaram a técnica de PIV com partículas de alumina $\left(\mathrm{Al}_{2} \mathrm{O}_{3}\right)$ como traçador, as quais foram dispersas através do uso de um leito fluidizado. Um ciclone é utilizado na sequência a fim de permitir que apenas as partículas da ordem de $1 \mu \mathrm{m}$ sejam carregadas pelo jato. Uma máquina de fumaça comercial (Rosco 1500) foi utilizada para dispersar uma mistura, aquecida e atomizada, de glicerol e água no escoamento de ar anular. Esta mistura nãoinflamável evapora a temperaturas superiores a $100^{\circ} \mathrm{C}$, desempenhando um papel importante como traçador de fluído que não é aquecido pela chama, indicando a corrente livre de fluido ao redor do jato da chama. Por outro lado, a alumina é utilizada no jato de combustível pelo fato de resistir a altas temperaturas produzidas pelas chamas. Estas partículas também são utilizadas para a visualização do jato. Foram realizadas fotografias do jato e da chama, a uma taxa de $6 \mathrm{~Hz}$, utilizando uma câmera Nikon F3 com uma lente $f / 1.8$, Nikkor de 50 mm, e filme Kodak Gold ISO 1600 , com $1 / 30 \mathrm{~s}$ de tempo exposição. Para cada caso foram capturadas 88 
imagens, as quais foram digitalizadas e transferidas para um computador para serem processadas.

A luz emitida pela chama é coletada por meio de uma câmera de vídeo Pulnix com arranjo do CCD de $512 \times 480$ pixels. A lente utilizada no caso da chama de gás natural é de $50 \mathrm{~mm}, \mathrm{f} / 1.2$ e para os casos de etileno é de $102 \mathrm{~mm}, \mathrm{f} / 4$, ambas da marca Nikkor. O campo de visão das imagens varia de $20 \times 20 \mathrm{~mm}^{2}$ até $80 \times 80 \mathrm{~mm}^{2}$, dependendo da altura do descolamento da chama. O tempo de exposição de $1 / 30 \mathrm{~s}$ e a taxa de captura de $6 \mathrm{~Hz}$ são suficientes para fornecer informações instantâneas da forma da chama. O procedimento automatizado permite o cálculo da altura de descolamento da chama.

O sistema PIV utilizado neste estudo consiste em um laser duplo pulso Nd:YAG (Spectra Physics PIV-400, 400 mJ/pulso em $532 \mathrm{~nm}$ ), o qual forma um plano de luz de $\sim 0.2 \mathrm{~mm}$ de espessura para iluminar as partículas da seção de teste, uma câmera CCD de alta resolução (2000x2000 pixel, Kodak Megaplus 4.2, com lentes de $105 \mathrm{~mm}$, Nikkor, f/5.6) foi utilizada para capturar imagens do escoamento, utilizando um filtro passa-banda centrado em 532 nm, com largura de banda de $10 \mathrm{~nm}$. Uma estação de trabalho (IBM, RISC 6000) processa as imagens com o programa computacional MKIV, comercializado pela TSI, o qual é baseado em uma técnica de auto-correlação para determinar o deslocamento médio das partículas em sub-regiões de 60x60 pixels para cada par de imagens.

Os resultados de PIV são coletados em uma região de $49 \times 49 \mathrm{~mm}^{2}$ na base da chama suspensa. As imagens são processadas resultando em um campo de 4356 (66x66) vetores. Cada vetor representa a velocidade média em um volume de interesse de dimensões de $1,5 \times 1,5 \times 0,2 \mathrm{~mm}^{2}$. O sistema completo permite a captura de imagens a uma taxa de $2 \mathrm{~Hz}$.

Watson et al. (1999) [75] utilizaram a montagem experimental, representada pela Figura 2.22, a fim de obter medidas simultâneas de PIV duas cores e PLIF-CH. O queimador consiste em um jato de metano de $5 \mathrm{~mm}$ diâmetro com um tubo concêntrico de $150 \mathrm{~mm}$ ao redor, no interior do qual circula o ar com baixa velocidade. Ambos os escoamentos contém partículas de alumina selecionadas quanto ao diâmetro por meio de um ciclone. 


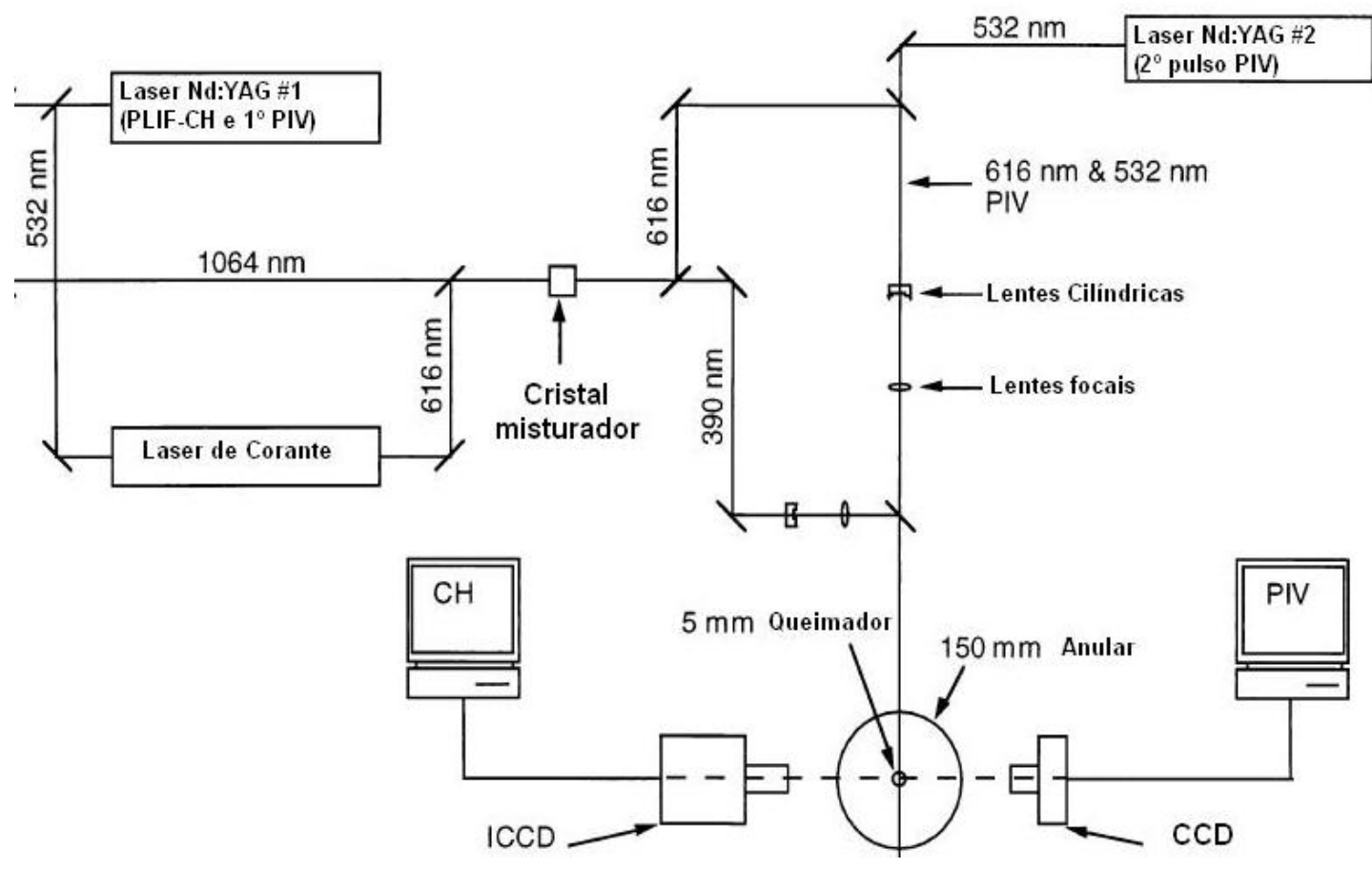

Figura 2.22. Arranjo para emprego das técnicas de PIV-PLIF, simultaneamente [75].

O sistema PIV duas cores consiste de dois lasers Nd:YAG e um laser de corante, uma câmera digital e diversos componentes ópticos para o direcionamento dos feixes. O primeiro pulso, de $616 \mathrm{~nm}$, é obtido pelo laser Quanta-Ray Nd:YAG, bombeando um laser de corante Lumonics, com o corante Rodamina 640 após passar por um cristal gerador de segundo harmônico. A energia do pulso de $10 \mathrm{~ns}$ de duração é de $40 \mathrm{~mJ}$. O segundo pulso de $532 \mathrm{~nm}$ é gerado por um laser QuantaRay Nd:YAG. Após passar através de uma lente cilíndrica de $2200 \mathrm{~mm}$ e uma esférica de $1 \mathrm{~m}$, os pulsos são expandidos em um plano de luz laser de $35 \mathrm{~mm}$ de altura e $0,75 \mathrm{~mm}$ de espessura antes de iluminarem as partículas contidas na chama de metano e ar. O intervalo de tempo entre os dois pulsos é selecionado dependendo das condições do escoamento e do local de medida, de maneira a permitir que as partículas estejam separadas por cerca de 5 pixels de um quadro para o outro, a fim de obter uma melhor correlação entre os pares de quadros de imagem de partículas. As imagens de PIV são gravadas com $5 \mathrm{~ms}$ de abertura do obturador, utilizando uma câmera digital Kodak de $3000 \times 2000$ pixels, com $f_{\#}=5.6 \mathrm{e}$ lentes Nikkor de $105 \mathrm{~mm}$. 
Certos parâmetros de processamento são selecionados no software de PIV dependendo das condições de teste. A janela de interrogação utilizada foi de $64 \times 64$ pixel com $50 \%$ de sobreposição das janelas de interrogação. A matriz de pixels cobre uma região de dimensões $35,9 \times 23,9 \mathrm{~mm}^{2}$ produzindo um campo de 93×61 vetores, onde cada vetor representa um deslocamento médio em uma região de 0,75 mm. A velocidade é determinada pela relação entre o deslocamento da partícula e o tempo de separação entre os pulsos de laser, o qual é de $60 \mathrm{~ms}$, neste caso.

O processamento das imagens de PIV envolve técnicas de auto-correlação especial, ou análise de padrões de franjas de Young, para determinar deslocamentos centrados ao redor de um grande pico de auto-correlação. Os mapas de correlação dessas técnicas permitem determinar o deslocamento das partículas, mas com simetria de 180ㅜ, assim, o sentido do deslocamento da partícula é desconhecida. Uma alternativa para este problema é a utilização do método de correlação cruzada PIV de duas cores (Innovative Scientific Solutions), o qual possui a vantagem de determinar a direção das partículas.

A técnica de imageamento de fluorescência do $\mathrm{CH}$ envolve a excitação na linha de transição $Q_{1}(7.5)$ utilizando uma fonte laser de $390 \mathrm{~nm}$ e um detector CCD com filtro centrado em $431 \mathrm{~nm}$. O pulso de luz laser de $390 \mathrm{~nm}$ possui energia de 20 $\mathrm{mJ}$ e duração de $10 \mathrm{~ns}$. Este pulso é formado pela interferência construtiva, que ocorre dentro de um cristal, a partir de um pulso de $1064 \mathrm{~nm}$, proveniente de um laser Nd:YAG, com o primeiro pulso do laser de $616 \mathrm{~nm}$ utilizado para a técnica PIV, simultaneamente.

Maurey et al. (2000) [41] desenvolveram um queimador para estudar chamas do tipo jato de metano e ar nas condições de descolamento. O aumento da velocidade do jato levanta a chama, a qual descolou à uma altura média de $6,5 \mathrm{~mm}$, em $16,3 \mathrm{~m} / \mathrm{s}$, correspondendo a um $R e=4.100$. A estabilização da chama foi estudada sem nenhum tipo de confinamento, a fim de evitar a perturbação do escoamento natural do jato livre. Um escoamento ao redor do jato e de mesma direção foi introduzido a uma baixa velocidade $(8 \mathrm{~cm} / \mathrm{s})$. No escoamento do jato foram dispersas gotas de azeite de oliva e no escoamento anular foram utilizadas partículas de óxido de zircônio $\left(\mathrm{ZrO}_{2}\right)$ de $1 \mu \mathrm{m}$ de diâmetro. A utilização de gotas de azeite não influenciou na localização da base da chama e características das partículas de $\mathrm{ZrO}_{2}$ permitem medidas de PIV em chamas. 
A montagem experimental de PLIF-OH usa uma câmera CCD intensificada, a qual foi sincronizada com o sistema PIV para capturar uma imagem de $\mathrm{OH}$ entre duas imagens de partículas. O aparato de PIV consiste de um laser Nd:YAG (SpectraPhysics, $400 \mathrm{~mJ}$ ), duplo pulso, com dobrador de frequência. A luz espalhada pelas partículas foi coletada por uma câmera CCD Kodak, a qual permitiu a aquisição de duas imagens sucessivas de $1024 \times 1024$ pixels. O campo de visão das imagens de PIV era de $23,2 \times 23,4 \mathrm{~mm}^{2}$, com um fator de magnificação de 22,8. A técnica PIV mede o campo de velocidade na base da chama utilizando um algoritmo convencional, baseado em correlação cruzada com precisão de sub-pixel, alcançando uma incerteza na velocidade de $0,05 \mathrm{~m} / \mathrm{s}$.

Law e Wang (2000) [37] utilizaram um sistema PIV (Dantec FlowMap), o qual inclui os estágios necessários no processo de aquisição de dados, como: dispersão de partículas, iluminação, gravação, processamento e análise. Neste estudo, a fonte de luz utilizada foi um laser Nd:YAG, pulsado, com duas cavidades que produzem pulsos de $25 \mathrm{~mJ}$ de energia, com duração de $7 \mathrm{~ns}$ e comprimento de onda de 532 $\mathrm{nm}$ à uma taxa de repetição máxima de $15 \mathrm{~Hz}$. O laser de cavidade dupla permite selecionar o intervalo de tempo entre os pulsos, o qual é adequado para cada velocidade de escoamento. Além disso, é possível realizar medições em escoamentos com altas velocidades pelo fato do intervalo de tempo entre os pulsos poder ser muito curto.

Foram utilizadas partículas de poliamida com um diâmetro nominal de $50 \mu \mathrm{m}$ para traçar o escoamento em quantidade suficiente para cobrir a área de interesse. Um sistema de lentes é utilizado para produzir um plano de luz de $3 \mathrm{~mm}$ de espessura com um ângulo de divergência de $32^{\circ}$. Os dois feixes laser são alinhados co-linearmente, a fim de iluminar a mesma área. Duas câmeras CCD Kodak Megaplus ES1.0 de 8 bits de resolução de intensidade e matriz de 1008×1018 pixel, especialmente desenvolvidas para análise de movimento, são utilizadas para PIV e outra para PLIF. O par de quadros é capturado com uma taxa de aquisição máxima de $7 \mathrm{~Hz}$, limitada pelo sistema de aquisição e então tratado com um algoritmo de correlação cruzada. O primeiro quadro é capturado com um tempo de integração de sinal de aproximadamente $5 \mu$ s e o segundo integrando cerca de $65 \mathrm{~ms}$, o que leva a interferência da luz de fundo do ambiente. Assim, o contraste é menor neste quadro e, para o caso reativo, usa-se um filtro óptico passa banda, centrado no comprimento de onda da fonte utilizada. Da mesma forma, outro filtro óptico é 
utilizado na câmera destinada para o PLIF, na qual é utilizado um filtro passa banda, centrado em $590 \mathrm{~nm}$, a fim de evitar a luz do ambiente e a luz espalhada pelas partículas utilizadas para medidas simultâneas com PIV.

Wason et al. (2006) [74] estudaram experimentalmente chamas descoladas utilizando PIV e PLIF-OH, separadamente. O estudo aborda chamas parcialmente pré-misturadas de metano e ar, cuja estabilização está sujeita a interações com o escoamento turbulento, onde múltiplos pontos estequiométricos podem existir em pequenas distâncias. Para medição das chamas foi utilizada a técnica PIV a fim de obter o campo bidimensional de velocidade, utilizando o sistema da empresa LaVision.

O esquema mostrado na Figura 2.23 relaciona os componentes utilizados, entre eles estão, um laser Nd:YAG de dupla cavidade com $50 \mathrm{~mJ}$ por pulso, uma câmera CCD com matriz de 1024×1280 pixels e um software de processamento de dados (DaVis). Para a dispersão das partículas traçadoras foi construído um leito fluidizado. A densidade de partículas foi parcialmente controlada usando um vibrador pneumático acoplado ao dispersor. $O$ tempo entre os dois pulsos de luz laser foi de $70 \mu \mathrm{s}$. Para cada caso, foram capturadas 100 pares de imagens, a fim de obter uma média da velocidade. A janela de interrogação utilizada para medições com PIV foi de $32 \times 32$ pixels com $50 \%$ de sobreposição no modo multipasso com janela inicial de $64 \times 64$ pixels. A dimensão de cada pixel é de $18 \mu \mathrm{m}$ no plano de medida produzindo uma resolução espacial de cerca de 0,6 mm em cada janela de interrogação. Medidas de velocidade foram realizadas sem chama, para cada caso, a fim de analisar os escoamentos não-reativos, dos quais foram capturadas 250 imagens. 


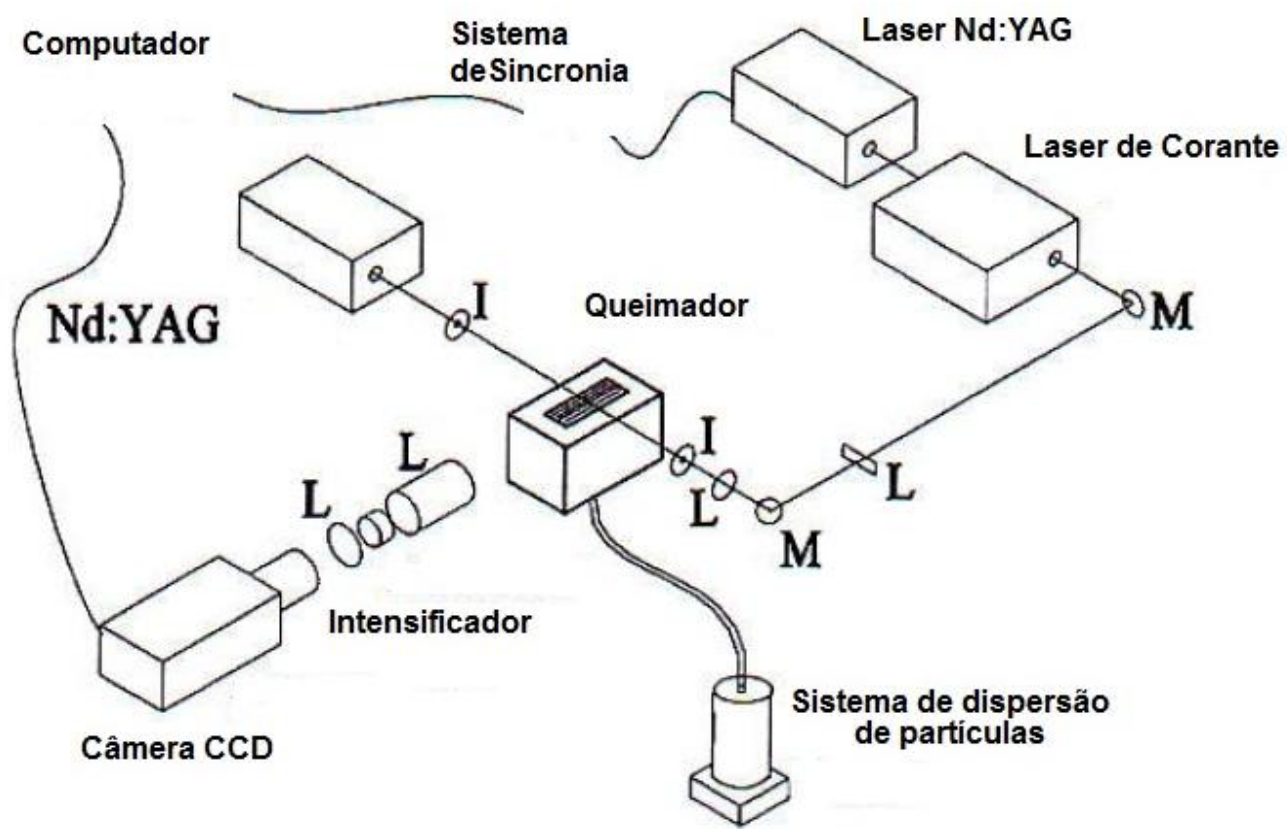

Figura 2.23. Esquema do arranjo experimental para realizar medidas PLIF e PIV, separadamente, utilizando a mesma câmera [74].

As medidas da estrutura das chamas foram realizadas utilizando PLIF-OH. Para tanto, foi utilizado um laser Nd:YAG (Spectra Physics) para bombear um laser de corante (Sirah, Precision) utilizando corante Rodamina 590, cuja frequência fundamental foi duplicada para gerar um pulso de comprimento de onda igual a $284,978 \mathrm{~nm}$ de $7 \mathrm{~ns}$ de duração. O feixe é expandido em um plano vertical por meio de uma lente cilíndrica com distância focal de $25 \mathrm{~mm}$. Este plano, de $25 \mathrm{~mJ}$ de energia por pulso, passa por uma lente esférica de $500 \mathrm{~mm}$ de distância focal para formar um plano de luz laser de espessura menor que $0,5 \mathrm{~mm}$. A luz laser excita a transição $P_{1}(7)$ do radical $\mathrm{OH}$. A fluorescência é coletada à $90^{\circ}$ a partir da direção do feixe de luz laser por um intensificador de imagem (DEP-Genll) com um sistema de lentes Nikon de f/4,5. A imagem produzida na matriz de fósforo do intensificador, com tempo de exposição ajustado para $1 \mu \mathrm{s}$, foi coletada através de um sistema de lentes (Nikkor) de $105 \mathrm{~mm}, \mathrm{f} / 4,5$ e $15 \mathrm{~mm}$ de distância focal, o qual transmite a imagem para a câmera CCD (LaVision, Flowmaster 3S) de 1280x1024 pixels.

As medidas de PIV e PLIF foram realizadas separadamente, com a dispersão de partículas apenas para o caso de PIV, a fim de evitar a interferência causada pelo espalhamento da luz por parte das partículas. Foi verificado que a 
altura do descolamento das chamas é inversamente proporcional à riqueza da chama.

Petersson et al. (2007) [47] realizaram medidas simultâneas com PIV e PLIF-OH, termometria Rayleigh e PLIF-OH e também PIV estéreo em uma chama turbulenta produzida com swirl. Para realizar medidas PIV foi utilizado um laser Nd:YAG (Quantel), duplo pulso, para iluminar uma janela de $60 \mathrm{~mm}$ de altura e 0,7 $\mathrm{mm}$ de espessura com energia de aproximadamente $40 \mathrm{~mJ}$ e o intervalo entre os pulsos foi otimizado, variando de 30 a $50 \mu \mathrm{s}$, dependendo da velocidade de cada escoamento. As partículas traçadoras utilizadas foram de $\mathrm{ZrSiO}_{4}$ com diâmetro médio de 0,5 $\mu \mathrm{m}$, as quais são capazes de acompanhar flutuações de velocidade de $7 \mathrm{kHz}$ com erro menor que 1\%. O sistema de captura consiste em uma câmera CCD (Flowmaster 3S, LaVision) com matriz de 1280X1024 pixels. Um algoritmo de correlação cruzada com um método adaptativo multi-passo, desenvolvido pela empresa LaVision, foi utilizado para a avaliação das velocidades. O processamento das informações foi realizado com janelas de interrogação de 32×32 pixels de dimensão, produzindo resultados com resolução espacial de aproximadamente 0,8 $\mathrm{mm}$.

No sistema PLIF foi utilizado um conjunto de lasers de Nd:YAG (BMI), com comprimento de onda de $532 \mathrm{~nm}$, para bombear um conjunto de lasers (Sirah) de corante (Rodamina 590, dissolvido em etanol). O plano de luz laser formado possui espessura de $300 \mu \mathrm{m}$ na região de medida e a energia de cada pulso é de aproximadamente $2 \mathrm{~mJ}$. As moléculas de $\mathrm{OH}$ foram excitadas na linha de fluorescência $Q_{1}(8)$ em um comprimento de onda de aproximadamente $283 \mathrm{~nm}$, cuja distribuição de população de elétrons (nível N8) não depende da temperatura. A detecção da fluorescência ocorre a um comprimento de onda de emissão de 310 nm que é filtrada com um passa-banda (Schott, UG11) atravessa um sistema de lentes UV (Nikkor, Japan, $f=105 \mathrm{~mm}, f / \#=4.5$ ) e chega a uma câmera CCD (Imager Intense 1376X1040, LaVision) acoplada à um intensificador de imagem (Hamamatsu, Japan), produzindo uma imagem de resolução igual a $100 \mu \mathrm{m}$. Utilizando-se dois lasers do conjunto, tal como mostrado na

Figura 2.24, uma sequência de duas imagens de PLIF-OH da frente de chama foi capturada. As câmeras são conectadas em um computador, permitindo que as imagens de PLIF e PIV sejam armazenadas em um mesmo arquivo. 


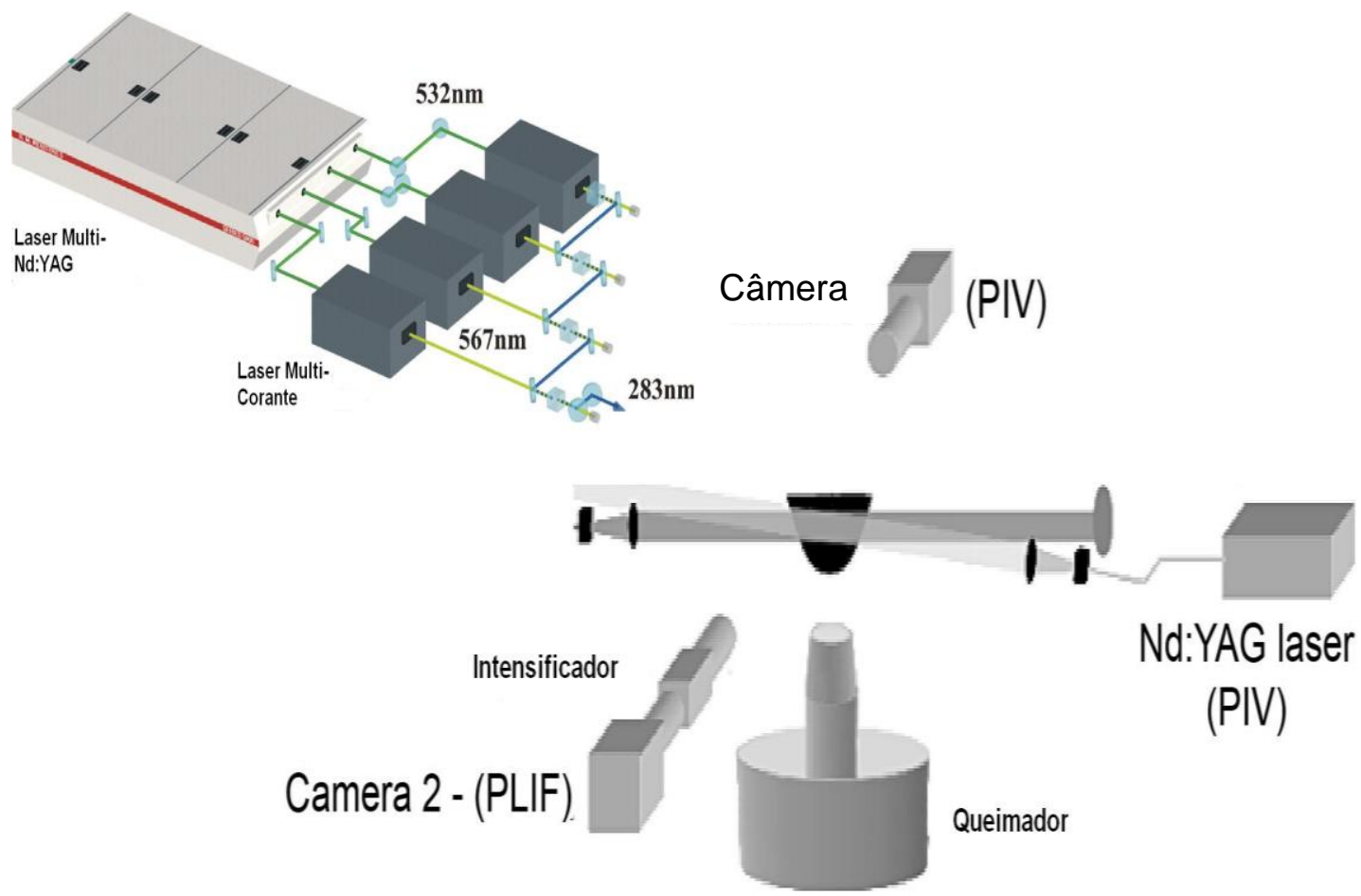

Figura 2.24. Montagem experimental para realizar as técnicas PIV e PLIF-OH, simultaneamente; termometria Rayleigh e PLIF-OH e também PIV estéreo [47].

Shao e Law (2009) [59] combinaram as técnicas de PIV e PLIF para realizar medições de jatos verticais em um ambiente de estagnação, a uma frequência de 5 $\mathrm{Hz}$ durante $60 \mathrm{~s}$, mostrando que os resultados dessas medidas são adequados para análises estatísticas da turbulência. Uma avaliação foi realizada a fim de se determinar o número mínimo de amostras necessário para obter resultados com significância estatística. Com base nos resultados das variações dos momentos estatísticos de primeira e segunda ordem foi observado que um conjunto de 600 amostras fornece uma convergência estatística satisfatória.

Para a montagem do experimento um laser Nd:YAG de duas cavidades, utilizando o segundo harmônico de $532 \mathrm{~nm}$, foi posicionado de modo à coincidir com o plano vertical do centro da saída do jato, a fim de iluminar esta área com um plano de luz laser de $3 \mathrm{~mm}$ de espessura. Os pulsos de $10 \mathrm{~ns}$ de duração foram disparados com um intervalo de $2 \mathrm{~ms}$, otimizado para as velocidades deste experimento. Partículas de cerca de $50 \mu \mathrm{m}$ de diâmetro nominal, de poliamida, e uma pequena quantidade de corante fluorescente, Rodamina B, foram dispersas no escoamento. 
As imagens foram capturadas utilizando duas câmeras CCD (Kodak, Megaplus ES 1.0), com resolução de 1008×1018 pixels, sendo uma para PIV e outra para PLIF. Estas câmeras foram posicionadas de frente uma para outra de lados opostos do escoamento. A luz emitida pela fluorescência do corante e espalhada pelas partículas incide no sistema de aquisição. As imagens produzidas são combinadas a fim de se quantificar os processos de mistura com as características do escoamento obtidas através dos perfis instantâneos e médias temporais da distribuição de velocidade a partir das imagens de PIV. Os resultados obtidos com PLIF permitem o acesso à distribuição de concentração, concomitantemente com os campos de velocidade para analisar a estrutura do escoamento, onde ocorre a mistura.

Böhm et al. (2009) [10] desenvolveram a montagem experimental, mostrada na Figura 2.25, que utiliza uma modificação convencional no laser de corante (Radiant Dyes) para técnica de PLIF, com um gerador de segundo harmônico para excitar a linha de fluorescência $Q_{1}(6)$ do radical químico $\mathrm{OH}$. O feixe de luz de 283 $\mathrm{nm}$, com $25 \mu \mathrm{J}$, a uma taxa de $5 \mathrm{kHz}$, forma um plano com $16 \mathrm{~mm}$ de altura e 200 $\mu \mathrm{m}$ de espessura. O laser que excita o corante é um Nd:YLF (Edge Wave IS8II-E). O feixe de luz desse laser possui um dos harmônicos com comprimento de onda de $523 \mathrm{~nm}$, gerando $3,4 \mathrm{~mJ} /$ pulso a uma taxa de $5 \mathrm{kHz}$, assim, são obtidos 4.000 quadros em apenas $0,8 \mathrm{~s}$.

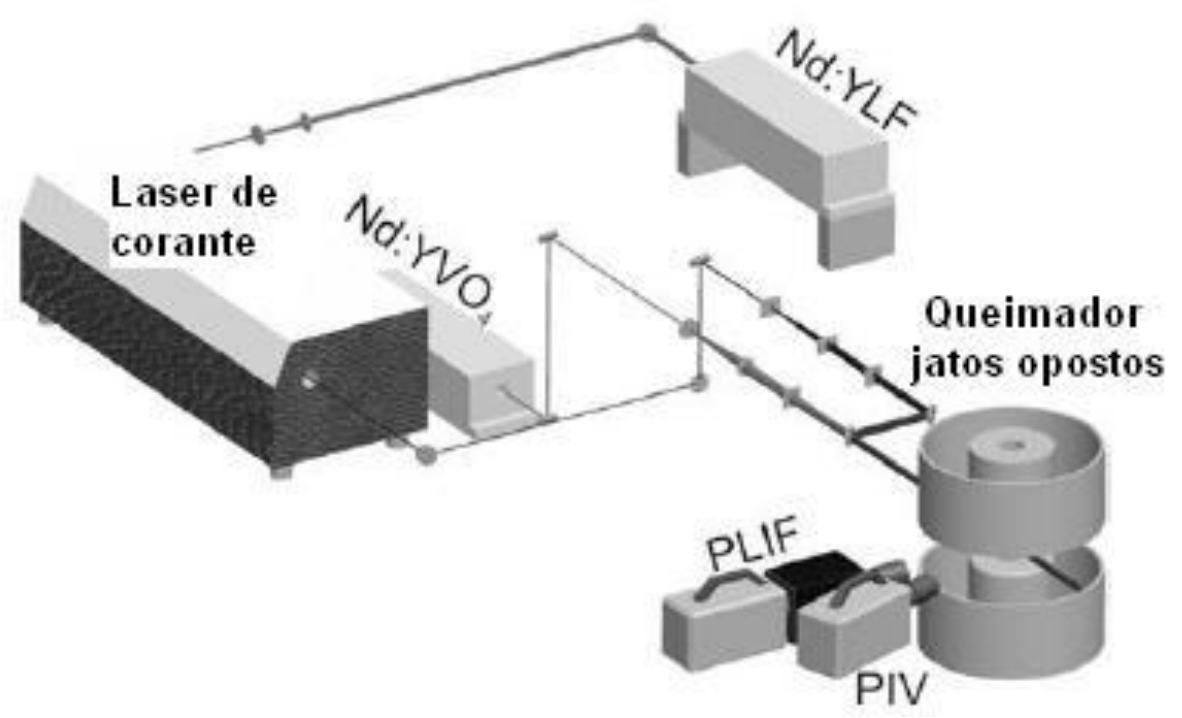

Figura 2.25. Montagem experimental das técnicas de PIV e PLIF combinadas [10]. 
A fluorescência é monitorada com uma câmera CMOS da LaVision, modelo HSS5, de 2,6 Gb de memória, com um sistema que auto sobre-escreve as imagens de modo a permitir a captura contínua, em um arranjo de 768x768 pixels e um intensificador de sinal (HS-IRO).

Para medir duas componentes da velocidade simultaneamente com a

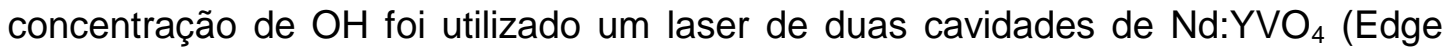
Wave IS4II-DE) de comprimento de onda igual a $532 \mathrm{~nm}$. O espalhamento Mie das partículas de $\mathrm{MgO}$ de $1 \mu \mathrm{m}$ de diâmetro foi capturado por uma câmera (HSS5 LaVision) CMOS com de 100 us de separação entre os quadros. As câmeras foram devidamente calibradas utilizando um alvo na posição do campo de visada e as partículas foram inseridas no escoamento, utilizando dois dispersores independentes entre si, um para o ar e outro para o combustível. Os feixes foram sobrepostos espacialmente utilizando um espelho dicróico. O pulso de luz laser de PLIF é disparado $50 \mu$ s após o primeiro feixe de luz do laser de PIV.

Baawain et al. (2010) [3] utilizaram resultados obtidos a partir de medidas simultâneas de PIV/PLIF para caracterizar o encontro entre um jato de bolhas de ozônio com saídas de difusores, onde o PIV foi empregado para estudar os padrões do escoamento e o PLIF foi utilizado para determinar o coeficiente de dispersão do líquido.

O sistema de medição é composto por uma fonte de luz laser de Nd:YAG de dupla cavidade com pulso de luz de 532 nm e duração de 10 ns com uma taxa de repetição de $8 \mathrm{~Hz}$. As câmeras foram configuradas para usar quadros duplos para PIV, dupla exposição, e quadro único para PLIF. Um sistema de processamento comercial (Dantec Dynamics, Skovlund, Denmark) transferiu as informações para o computador, onde o programa Flowmap permitiu as análises dos dados obtidos. As medições com PIV foram conduzidas utilizando duas câmeras CCD com dupla exposição, com filtros especiais acoplados. Para obter as medidas de velocidade foram utilizadas esferas de Melamina-Formaldeído, cobertas com Ródio B. Os vetores de velocidade foram obtidos empregando uma janela de interrogação de $64 \times 64$ pixels a partir de uma área de visão de $1344 \times 1024$ pixels, com 25\% de superposição, gerando $21 \times 21$ vetores para cada amostra instantânea de velocidade. O processo de medição com PLIF capturou duas imagens de cada condição experimental, a fim de reduzir a incerteza associada ao processo de medição. 
Chaudhuri et al. (2010) [13] estabilizaram chamas pré-misturadas em um queimador corpo rombudo composto de um disco de $10 \mathrm{~mm}$ de diâmetro no centro de um tubo de $40 \mathrm{~mm}$ de diâmetro, como mostra a Figura 2.26. O sistema PIV e PLIF simultâneo é comercializado pela empresa LaVision, contendo um laser, $\mathrm{Nd}$ :YAG de duas cavidades, que produzem um feixe de luz laser com energia de 50 $\mathrm{mJ} /$ pulso (New Wave Solo PIV III), uma câmera CCD (Flow Master 3S) com arranjo de $1024 \times 1280$ pixels e um programa de processamento (DaVis 7.0). São utilizadas lentes de $50 \mathrm{~mm}$ e um filtro óptico centrado em $532 \mathrm{~nm}$ para auxiliar na formação de imagens de partículas. Em cada caso são capturados 100 pares de imagens, as quais são processadas em sub-regiões de 16x16 pixels, em modo multi-passo, com uma janela de $128 \times 128$ pixels de tamanho inicial, aplicando $50 \%$ de sobreposição dos dados de uma janela para a outra nos pares de imagens. A aquisição de dados foi realizada a uma taxa de $2,5 \mathrm{~Hz}$, devido ao tempo de leitura das placas de aquisição que fazem a interface entre a câmera e o computador.

O plano de luz laser foi criado utilizando uma lente cilíndrica de $20 \mathrm{~mm}$ de distância focal e um jogo de lentes esféricas, a fim de focar em uma região de $5 \mathrm{~mm}$ até $40 \mathrm{~mm}$ na direção principal do escoamento. O intervalo de tempo entre os pulsos laser utilizado foi de $10 \mu \mathrm{s}$. A dispersão de partículas no escoamento foi realizada através da utilização de um leito fluidizado (TSI, 9310) que fornece partículas de alumina de aproximadamente $1 \mu \mathrm{m}$ de diâmetro. 


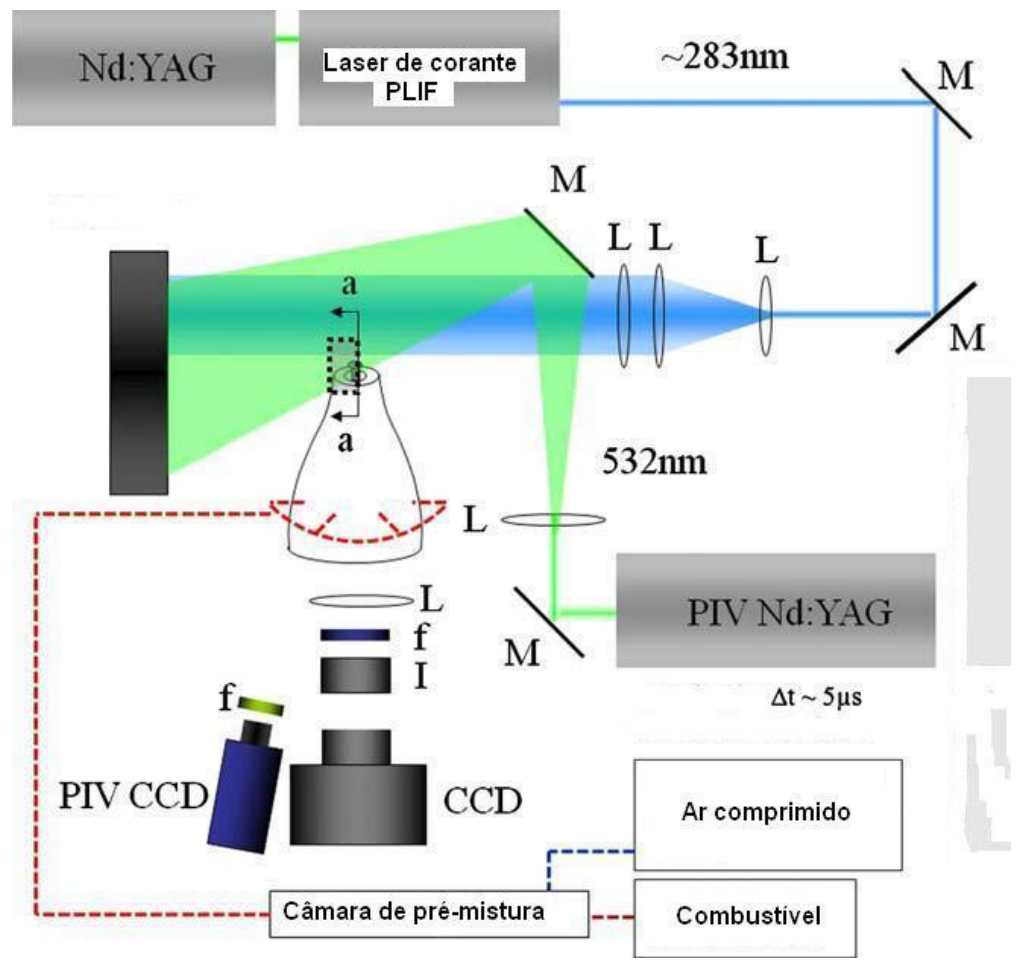

Figura 2.26. Esquema detalhado dos sistemas PIV e PLIF [13].

O sistema PIV foi combinado com o sistema PLIF para medidas simultâneas do radical químico $\mathrm{OH}$ e velocidade. O sistema PLIF consite de um laser Nd:YAG (Continuum, Surelite II) bombeando a $10 \mathrm{~Hz}$ um laser de corante (Lumonics, HyperTrax-1000), contendo o corante Rodamina 590, a fim de criar um feixe de luz laser na faixa do ultra-violeta de $282,67 \mathrm{~nm}$ de comprimento de onda e $3 \mathrm{~mJ}$ de energia para excitar $\mathrm{O} \mathrm{OH}$. Este feixe excita a linha de fluorescência ro-vibracional $\mathrm{Q}_{1}(5)$ do $\mathrm{OH}$. Esta linha de fluorescência foi escolhida por ter baixa sensitividade no que diz respeito à fração de Boltzmann entre as temperaturas de 1000 a $2500 \mathrm{~K}$, ou seja, a intensidade de fluorescência não varia com a temperatura. $O$ feixe de luz laser passa por duas lentes cilíndricas, uma lente de $250 \mathrm{~mm}$ de distância focal e, em seguida, por uma de $500 \mathrm{~mm}$ para formar o plano de luz laser PLIF, o qual é monitorado por um medidor de potência óptica (Gentec, EO ED-200UV) e disparado em um instante entre os dois pulsos do sistema PIV. O sinal de fluorescência foi coletado por uma câmera CCD com um intensificador de imagem (Photometrics, $\mathrm{CH}$ 200), após ser transmitida por um filtro centrado em $320 \mathrm{~nm}$ com largura de banda de $40 \mathrm{~nm}$, no qual a transmissão é maior que 70\%. O intensificador foi ajustado para integrar 80 ns de captura do sinal de fluorescência, a fim de evitar a interferência da 
químio-luminescência da chama, da incandescência da fuligem e dos ruídos de fundo. Todos os resultados apresentados neste trabalho foram obtidos com uma velocidade média de $10 \mathrm{~m} / \mathrm{s}$ e intensidade de turbulência de $5 \%$ em torno da média. A temperatura era de 298 K, o número de Reynolds de 6.293, o número de Damköhler de 2,5 e a razão entre combustível e ar de 0,05.

Shimura et al. (2011) [60] construíram a montagem, detalhada na Figura 2.27, com um sistema de plano duplo de PLIF-CH, consiste de dois sistemas de PLIF convencionais independentes e os feixes de luz laser são distribuídos em paralelo utilizando diferentes polarizações, realizado em duas seções bidimensionais. A transição $Q_{1}(7,5)$ é excitada a $390,30 \mathrm{~nm}$ e a detecção acontece nas bandas de 420 e $440 \mathrm{~nm}$. O primeiro laser de corante (Lambda Physik, Scanmate2) é bombeado por um laser excimero ( $\mathrm{XeCl}$, Coherent Inc., COMPex102, $308 \mathrm{~nm}, 200 \mathrm{~mJ} /$ pulse) com um corante (BiBuQ, dissolvido com p-dioxane) e o segundo laser de corante (Sirah, Cobra-Stretch), utilizando um corante (Exalite389, dissolvido com p-dioxane), o qual é bombeado por um laser Nd:YAG (Spectra Physics, Quanta Ray PRO-230-10, 355 nm, 400 mJ/pulso). Estes sistemas produzem feixes de luz laser de cerca de 15 e $20 \mathrm{~mJ}$, respectivamente. A fluorescência do $\mathrm{CH}$ é detectada por duas câmeras CCD com intensificador de sinal (Andor Technology, iStar, 1024×1024 pixels) com um filtro óptico passa-banda (Semrock, FF01-434/17-50.8-D, de 92\% de transmissão) utilizado para bloquear a radiação proveniente da chama e a luz espalhada pelas partículas. Para as medidas de PLIF-OH, em um plano, realizadas na transição $Q_{1}(7)$ com excitação em 282,93 $\mathrm{nm}$ e detecção entre 306 e $320 \mathrm{~nm}$ foi utilizada uma fonte de luz que consiste em um laser Nd:YAG (Continuum, Powerlite9030, 532 nm, 200 mJ/pulso) e um laser de corante (Lambda Physik, Scanmate2) com Rhodamina 590, dissolvida em metanol, e um gerador de segundo harmônico. O feixe foi direcionado paralelamente ao feixe de PLIF-CH por um espelho dicróico e a imagem da fluorescência do $\mathrm{OH}$ foi capturada por uma terceira câmera CCD (Princeton Instruments, PI-MAX 51RB-G1, $512 \times 512$ pixels) e filtrada (SCHOTT, WG-305 e UG-11, com transmissão de 55\%).

A técnica de PIV estéreo em dois planos foi empregada utilizando diferentes comprimentos de onda (532 e $560 \mathrm{~nm}$ ), combinados com a técnica de PLIF-OH, a qual possui o feixe de luz laser centrada entre os dois planos de PLIF-CH e o PIV estéreo. Dois lasers (Spectra Physics, INDI-40, 532 nm, 200 mJ/pulso) e dois lasers de corante (Lambda Physik, Scanmate2), com Rhodamina 590 dissolvida em 
metanol, foram utilizados como fonte luminosa para a técnica PIV. A distância de separação entre cada um dos planos é de $170 \mu \mathrm{m}$. A resolução espacial foi ajustada para $175 \times 175 \times 210 \mu \mathrm{m}$, o que corresponde a cerca de três vezes a escala de Kolmogorov. A luz espalhada pelas partículas é capturada por quatro câmeras CCD de duplo quadro (Princeton Instruments, MegaPlus II ES4020, 2048X2048 pixels). As câmeras foram posicionadas ao lado de cada câmera ICCD com um ângulo de 17,5ำ aplicando a técnica de Scheimpflug. Os filtros ópticos (Shonan Optical Thin Film Laboratories, 532 nm) e (Semrock, FF01-560/14-25, 560 nm) foram utilizados para evitar interferência. As partículas traçadoras utilizadas são de $\mathrm{S}_{i} \mathrm{O}_{2}$, com $1 \mu \mathrm{m}$ de diâmetro.

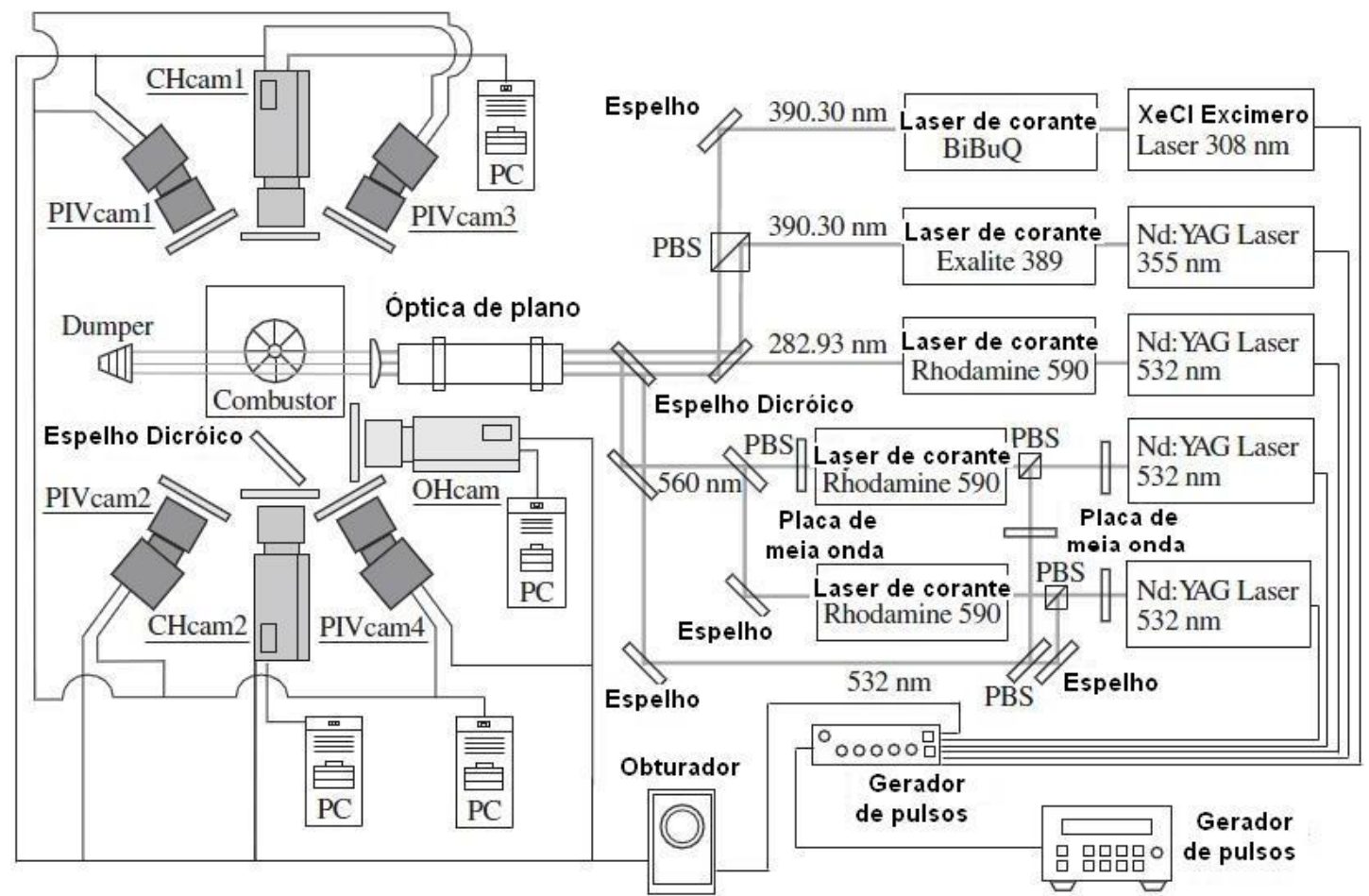

Figura 2.27. Diagrama esquemático da montagem para realização de medidas simultâneas de PLIF-CH duplo plano, PLIF-OH e PIV estéreo duplo plano [60].

A tabela 1 relaciona os parâmetros referentes à técnica PLIF utilizados em trabalhos selecionados dentre os presentes na revisão bibliográfica, a fim de mostrar a evolução dos aparatos experimentais e comparar os equipamentos utilizados no presente trabalho com os existentes na literatura. O compromisso entre taxa de aquisição e resolução espacial é verificado pela comparação do trabalho de Böhm com os demais. 
Tabela 1. Parâmetros utilizados na técnica PLIF em diversos trabalhos.

\begin{tabular}{ccccc|c}
\hline & Frank & Petersson & Böhm & Shimura & PUC-Rio \\
\hline ano & 1996 & 2007 & 2009 & 2011 & 2012 \\
\hline Energia $(\mathrm{mJ} /$ pulso) & - & 2 & 3,4 & 20 & 2,5 \\
\hline Matriz CCD $\left(\right.$ pixel $\left.{ }^{2}\right)$ & $384 \times 576$ & $1376 \times 1040$ & $768 \times 768$ & $2048 \times 2048$ & $1376 \times 1040$ \\
\hline Resolução $(\mu \mathrm{m} /$ pixel) & 170 & 100 & - & 5 & 90 \\
\hline Janela $\left(\mathrm{mm}^{2}\right)$ & $15 \times 22$ & $130 \times 100$ & $16 \times 16$ & $120 \times 120$ & $120 \times 90$ \\
\hline Taxa de captura $(\mathrm{Hz})$ & 10 & 8 & 5.000 & 10 & 3,3 \\
\hline
\end{tabular}

\subsection{Comentários finais}

Da revisão bibliográfica apresentada neste capítulo, é possível perceber que, no que tange às técnicas de medição de parâmetros da combustão em escoamentos turbulentos baseados no uso de lasers, duas tendências são observadas. A primeira é o uso destas técnicas para medição simultânea, em um ou mais planos de interesse, de várias propriedades do escoamento, por exemplo, múltiplos escalares e a velocidade. A segunda tendência é a utilização de equipamentos com cadência de amostragem de vários $\mathrm{kHz}$ para medição, em um plano, do campo de velocidade e de um escalar. Esta medição se faz em áreas de interesse de poucos $\mathrm{mm}^{2}$, devido a limitações de energia dos lasers, o que é pequeno, quando comparado às técnicas mais usuais, que permitem realizar medidas em "janelas" da ordem de $100 \mathrm{~cm}^{2}$. No que diz respeito ao uso destas medidas, os trabalhos mais avançados buscam descrever não somente a estrutura do escoamento reativo e os dois primeiros momentos estatísticos das propriedades aerotermoquímicas medidas, mas também a evolução da função densidade de probabilidade destas propriedades e de suas quantidades derivadas como, por exemplo, os tensores vorticidade ou a taxa de deformação e a taxa de estiramento. Como será visto no próximo capítulo, o presente trabalho utiliza técnicas laser com cadência de medição da ordem do $\mathrm{kHz}$ que permitirão, na sequência do presente estudo, trilhar este caminho de pós-processamento avançado dos resultados. 


\section{Metodologia Experimental}

Neste capítulo a instalação experimental do queimador é descrita. Além disso, são detalhados os equipamentos e as técnicas de medição da fluorescência do radical químico Hidroxila $(\mathrm{OH})$ e do campo de velocidade do escoamento, por fluorescência induzida por plano laser (PLIF) e velocimetria por imagem de partículas (PIV), respectivamente. Por fim, as incertezas das medidas são calculadas.

\subsection{Estabilização da chama}

Quando um corpo bloqueia uma área relativamente grande a jusante da injeção dos reagentes no queimador, a chama pode ser ancorada pelos produtos de combustão quentes capturados no interior da esteira produzida no escoamento por este corpo. As propriedades da esteira, em particular, o tempo de residência dos gases, influenciam as propriedades turbulentas.

Nas chamas turbulentas, as flutuações de velocidade e de concentração dos reagentes fornecem informações sobre o processo de mistura turbulenta entre as espécies químicas. Alguns modelos matemáticos do processo de combustão turbulenta consideram que reações químicas em chamas difusivas são infinitamente rápidas, quando comparados com a velocidade da mistura turbulenta [49]. Nesta situação, uma abordagem possível passa pela descrição da fração de mistura, a qual representa o transporte de espécies não reativas. Medidas da concentração de espécies intermediárias do processo de combustão (radicais químicos) são capazes de revelar efeitos devidos à velocidade de reação. Um radical químico adequado para tal propósito é o $\mathrm{OH}$, o qual possui papel relevante na quebra de moléculas estáveis e na conversão de $\mathrm{CO}$ em $\mathrm{CO}_{2}$ e é uma das espécies mantenedoras da combustão. Este radical, que se encontra presente em abundância próximo à zona de reação, pode ser utilizado como indicativo da taxa de deformação da zona de reação devido à influência da turbulência [18]. Além disso, o tempo de vida de sua fluorescência, 3 ns, é curto o suficiente para colocar em evidência as extinções locais da chama [33]. Assim sendo, uma das formas de caracterizar as diferenças entre os regimes de combustão é realizar uma estimativa da espessura da imagem instantânea da chama, mediante a fluorescência de OH [12]. 


\subsection{Instalação do queimador}

O projeto do queimador, do tipo corpo rombudo, foi desenvolvido visando obter ampla faixa de operação $[2,28]$. O queimador corpo rombudo apresenta relevância em diferentes aplicações de engenharia, sendo interessante em problemas de escoamentos industriais, por ser capaz de estabilizar chamas em sua zona de recirculação. Desta forma, permite alcançar os regimes de combustão que vão do regime laminar até a extinção, passando pelo regime de elemento de chama e o de efeitos transientes, maiores detalhes podem ser obtidos no trabalho de [28]. Este queimador permite realizar estudos detalhados da interação entre a turbulência e a cinética química. $\mathrm{O}$ queimador corpo rombudo fornece amplo acesso óptico, possibilitando medições baseadas em técnicas de diagnóstico laser em combustão [16]. Este queimador foi especificamente escolhido para permitir o desenvolvimento e a validação de modelos de interação entre cinética química e turbulência. A simetria de revolução e as condições de contorno simples também permitem simplificar os algoritmos de soluções numéricas.

As dimensões do queimador e suas características geométricas são mostradas na Figura 3.1. As dimensões do queimador foram escolhidas visando obter uma diferença significativa entre o diâmetro do jato de combustível, $7,1 \mathrm{~mm}$, e a espessura do plano de luz laser utilizado nas medições, o qual é da ordem de 0,5 $\mathrm{mm}$. O canal de fornecimento de combustível tem comprimento de $150 \mathrm{~cm}$, o que permite garantir que o escoamento neste será plenamente desenvolvido. $O$ corpo rígido no centro do queimador tem diâmetro de $60 \mathrm{~mm}$ e o diâmetro de saída do túnel de vento anular, responsável pelo fornecimento de ar, é de $200 \mathrm{~mm}$. O comprimento do duto de ar anular é de $100 \mathrm{~cm}$, contando a partir de uma grade geradora de turbulência com orifícios de diâmetro de $12 \mathrm{~mm}$, separados cerca de 10 $\mathrm{mm}$ entre si. A região de medição é de $120 \times 90 \mathrm{~mm}^{2}$ localizada acima da superfície do queimador com o centro na linha do jato de combustível. Este queimador gera um escoamento turbulento contendo um jato central concêntrico a uma saída de ar anular, separados por uma região de esteira produzida pelo corpo rígido central. A configuração geométrica simples deste queimador facilita o trabalho de modelagem computacional, o qual se encontra fora do escopo do presente estudo. Além disso, apresenta amplo acesso ótico, viabilizando a caracterização detalhada do escoamento através de medições com técnicas laser. 
A instalação experimental, utilizada por [28], foi aprimorada visando aumentar a homogeneidade do escoamento de ar. Para isto, foi introduzida uma grade geradora de turbulência a montante do duto de saída de ar no queimador [17]. Um ventilador centrífugo (Deltra, VC-400) foi utilizado para alimentação de ar do experimento. A mínima e a máxima vazão do ar anular geram velocidade de saída de ar de cerca de $1 \mathrm{~m} / \mathrm{s}$ e $12 \mathrm{~m} / \mathrm{s}$, respectivamente, para as graduações de 20 e $60 \mathrm{~Hz}$ do inversor de frequência que controla a rotação do ventilador. Nota-se que nesta instalação, aberta, a vazão de ar não é medida.

A vazão de combustível é medida por um rotâmetro (OMEL, 3P5-0401V01), o qual possui vazão nominal de $3 \mathrm{Nm}^{3} / \mathrm{h}$ que limita a potência do sistema em $30 \mathrm{~kW}$, considerando-se o uso de gás natural. Assim, a velocidade máxima do gás natural obtida com esta montagem sob condições de operação de 1 bar e $20^{\circ} \mathrm{C}$ é de cerca de $30 \mathrm{~m} / \mathrm{s}$. O diâmetro do jato de ar e sua vazão são escolhidos de modo a evitar que haja interação entre o jato de combustível e o ar ambiente.

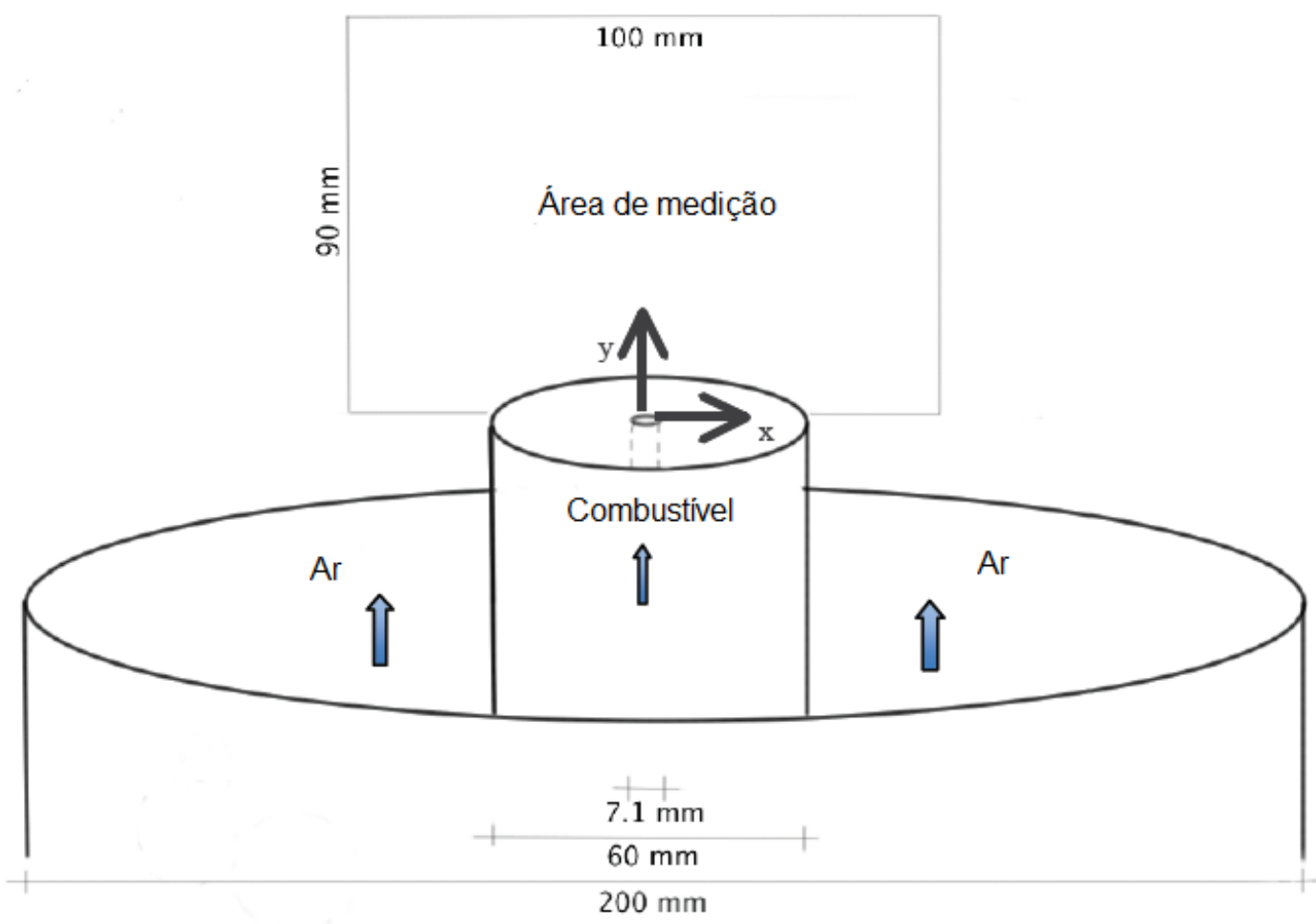

Figura 3.1. O queimador, cuja principal característica é a saída de ar, concêntrica ao jato, posicionado no centro de um corpo rombudo. 


\subsection{Sistema de Fluorescência Induzida por Plano Laser (PLIF)}

Com a redução do custo de equipamentos ocorrida nas últimas décadas, a espectroscopia laser se tornou uma alternativa usual para o diagnóstico de processos de combustão. Técnicas baseadas na utilização de laser têm a capacidade de medir propriedades do escoamento de modo não intrusivo, o que é especialmente interessante no caso de processos de combustão, os quais são facilmente perturbados por sondas de amostragem. Além disso, a utilização do laser pode proporcionar alta resolução espacial (tipicamente da ordem de milímetros), alta resolução temporal (da ordem de nanossegundos) e alta sensibilidade, sendo capaz de medir concentrações na faixa de ppm. A técnica PLIF é a Fluorescência Induzida por Laser, LIF, em duas dimensões, utilizando um sistema de lentes para formação de um plano de luz laser e câmeras para captura das imagens, ao invés de fotosensores pontuais, como no caso da técnica LIF clássica [58].

Nesta seção, inicialmente apresenta-se uma breve revisão dos fundamentos da técnica LIF. Os sinais de interesse para o estudo da combustão detectados em um espectro LIF são, basicamente, decorridos de efeitos inelásticos, isto é, interações onde há transferência de energia da radiação para a matéria ou, mais raramente, e com menor intensidade, da matéria para a radiação [20].

\subsubsection{A fluorescência}

A luminescência é a emissão de radiação eletromagnética proveniente de moléculas que de alguma maneira foram excitadas, quando retornam ao seu estado fundamental. Tal como ilustrado na Figura 3.2 este fenômeno, também denominado fotoluminescência, ocorre quando a absorção de fótons de luz é responsável pela excitação da molécula mediante à elevação de níveis de energia dos elétrons de valência de um orbital menos energético para um orbital de maior energia, $k_{12}$. De maneira clássica, a luminescência molecular é dividida em fluorescência e fosforescência, dependendo da natureza do estado excitado envolvido no processo. Se o estado excitado envolvido é singleto, $S$, onde o spin do elétron no orbital excitado mantém sua orientação original, resulta a fluorescência. Por outro lado, na fosforescência a orientação do elétron que foi promovido ao estado excitado é invertida, dando origem ao estado excitado tripleto, $T_{1}$. Uma consequência da 
retenção da orientação original do spin é o retorno de uma população que se encontra no estado excitado singleto, $S_{1}$, para o estado fundamental, $S_{0}$, que tem caráter singleto $k_{21}$, o qual é permitido e ocorre muito rapidamente, quando comparado com a fosforescência, $k_{23}$ e $k_{31}$. A título de ilustração o tempo de vida da fluorescência do $\mathrm{OH}$ é de aproximadamente 3 ns em uma chama não pré-misturada de $\mathrm{CH}_{4}$ e ar [33].

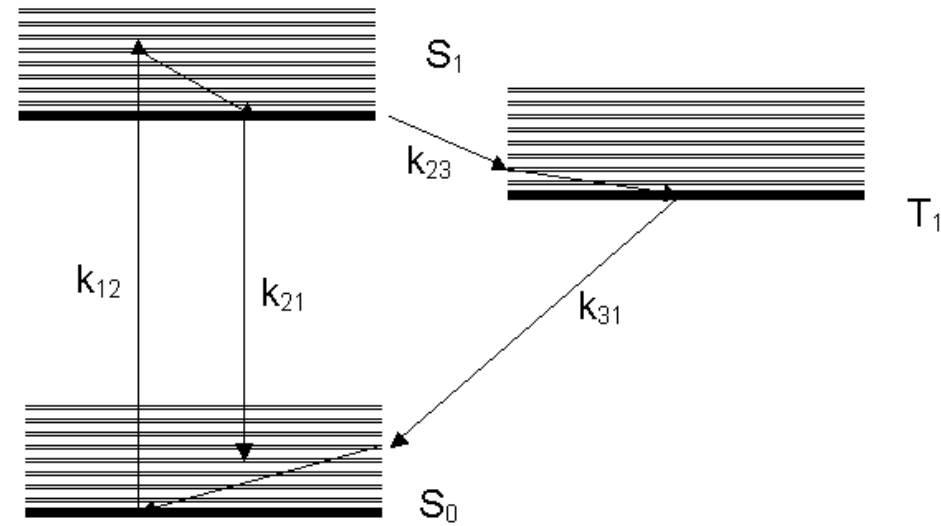

Figura 3.2. Diagrama de Jablonski para a fluorescência [36]. As linhas horizontais são os níveis de energia atômico, vibracional e rotacional, respectivamente.

Assim, após a absorção da radiação, a população de elétrons de uma dada molécula é promovida para um estado excitado singleto. Em seguida, a molécula se desativa por relaxamento através dos níveis vibracionais de estados eletrônicos de mesma multiplicidade até atingir o primeiro nível vibracional do estado excitado singleto de menor energia. A partir deste estado excitado, a molécula pode seguir dois caminhos para retornar ao estado fundamental. No primeiro, se a diferença de energia entre o estado excitado e o estado fundamental não for muito grande e existir possibilidade de sobreposição de níveis vibracionais, a molécula pode ser levada ao nível vibracional mais baixo por relaxação sem emissão de radiação eletromagnética. No segundo, se a diferença energética entre o estado excitado e 0 estado fundamental for relativamente grande, a desativação para o estado fundamental se dá com emissão de radiação na forma de fluorescência [36].

O sinal de fluorescência relacionada a um estado energético com energia $E\left(v^{\prime \prime}, j^{\prime \prime}\right)$ é determinado por:

$$
S_{F}=c(\Omega / 4 \pi) \cdot \alpha_{i} \cdot n(T, P) \cdot f_{v^{\prime \prime}, j^{\prime \prime}}(T) \cdot E_{l} \cdot\left\{A /\left(A+Q\left(n_{i}, T\right)+p\right)\right\},
$$


onde $v^{\prime \prime}, j^{\prime \prime}$ e $v^{\prime}, j^{\prime}$ são os números quânticos vibracionais e rotacionais, para os estados eletrônico fundamental e excitado, respectivamente. $S_{F}$ é o sinal de fluorescência, $c$ é uma constante, $\Omega$ é o ângulo sólido, $\alpha_{i}$ é a fração molar da espécie $n_{i}, n(T, P)=P / k_{B} T$ é a densidade total à pressão $P$ e temperatura $T, k_{B}$ é a constante de Boltzmann's, $f_{v^{\prime \prime}, j^{\prime \prime}}(T)$ é a fração de Boltzmann para o estado fundamental (rotacional-vibracional) com os números quânticos $v^{\prime \prime}$ e $j^{\prime \prime}$. A energia luminosa por unidade da área é $E_{l}$ e $\left\{A /\left(A+Q\left(n_{i} T\right)+P\right)\right\}$ é o fator Stern-Volmer, o qual limita a taxa de fluorescência. O coeficiente de Einstein para a emissão espontânea é $A, Q$ é a taxa de extinção de colisões e $p$ é a taxa de dissociação [33]. A equação 1 indica que o sinal de fluorescência é função da fração molar $\alpha_{i}$, temperatura $T$ e pressão $P$. Desta forma, medidas da distribuição de propriedades do escoamento podem ser obtidas no caso em que dois destes parâmetros são constantes.

Para fins práticos de utilização da técnica PLIF em medições da fluorescência de espécies é utilizada [40].

$$
S_{F} \propto n \cdot E_{L} \cdot \sigma_{a b s} \cdot \eta_{F} \cdot \eta_{h v}
$$

onde $E_{L}$ é a quantidade de fótons $/ \mathrm{cm}^{2}, \sigma_{a b s}$ é a área da secção transversal de absorção, $\eta_{F}$ é a eficiência quântica da fluorescência $A /(A+Q)$ e $\eta_{h v}$ é a eficiência quântica da detecção.

\subsubsection{Abordagem experimental para a técnica PLIF}

A Fluorescência Induzida por Plano Laser (PLIF) é uma técnica que consiste em gerar um plano de luz laser, visando realizar uma medição bidimensional da distribuição do sinal de fluorescência. Desta forma, a técnica PLIF envolve a iluminação do escoamento utilizando um fino plano de luz laser, a fim de excitar uma transição eletrônica de uma espécie química selecionada, dentre as presentes no escoamento. A medição da fluorescência emitida na região estudada é obtida com o auxílio de uma câmera intensificadora, onde é acoplado um filtro óptico passa-banda, a fim de restringir a transmissão apenas ao comprimento de onda do 
sinal de fluorescência. Um esquema básico da montagem dos principais componentes para a realização de medições com PLIF é mostrado na Figura 3.3. O feixe de luz atravessa um conjunto de lentes, uma cilíndrica $(-10 \mathrm{~mm})$ e outra esférica (300 mm), visando gerar um plano de luz laser com espessura mínima na região de interesse. A abertura e altura do plano de luz laser são determinadas, principalmente, pela distância focal da lente cilíndrica e, o ajuste da espessura é controlado pela separação entre as lentes. O plano de luz laser produzido é transmitido através da chama, onde excita o radical escolhido, produzindo assim, a fluorescência que fornece a informação sobre a zona de reação.

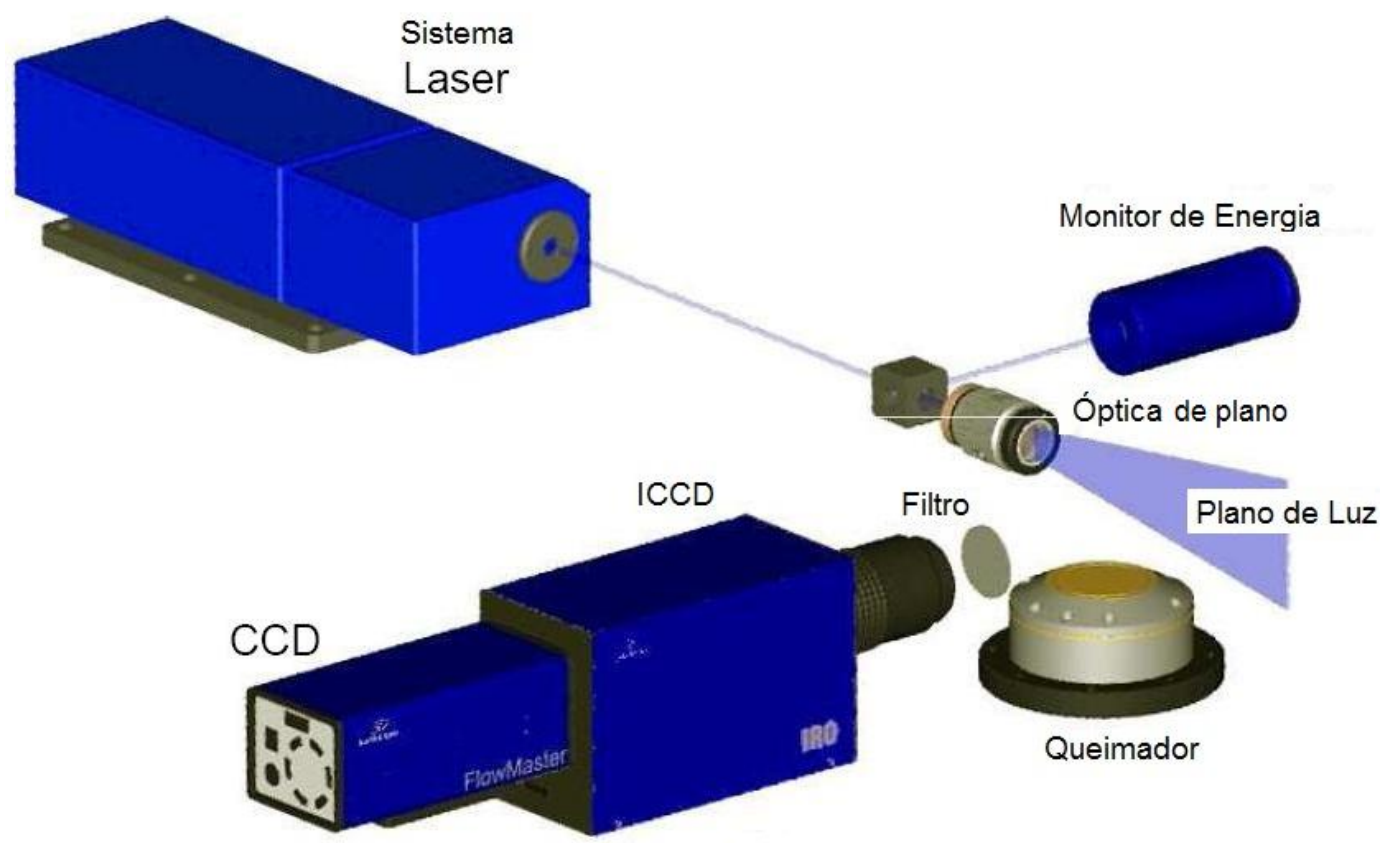

Figura 3.3. Esquema da montagem e identificação dos principais componentes para realização de medições com a técnica PLIF [40].

\subsubsection{Principais componentes do PLIF}

Os lasers pulsados (Nd:YAG) apresentam o feixe de luz com distribuição de energia que segue a tendência de uma distribuição tipo "chapéu". Porém, cada pulso de luz laser apresenta quantidade e distribuição de energia diferentes entre si, mesmo que sejam produzidos pela mesma cavidade em um curto intervalo de tempo. Para contornar essa limitação, existem componentes no sistema PLIF com o papel de monitorar a energia do feixe, os quais são utilizados a fim de normalizar a energia dos feixes e atribuir a mesma relação de energia por pulso para todas as 
imagens resultantes. Por outro lado, os lasers pulsados possuem alta intensidade luminosa. Um laser de Nd:YAG de $25 \mathrm{~mJ}$ com pulso de $7 \mathrm{~ns}$ de duração produz 3 MW de potência. As dimensões do laser de estado sólido são reduzidas, o que confere maior versatilidade na montagem experimental. Desta forma, a relação sinal/ruído se torna substancialmente melhor do que aquela que pode ser obtida com lasers contínuos. O pulso de curta duração permite que a estrutura do escoamento seja capturada com resolução temporal da ordem de nanossegundos, permitindo medir a estrutura instantânea do escoamento, mesmo em altíssimas velocidades.

A sincronia do sistema de excitação com o sistema de captura é um aspecto importante que deve ser levado em consideração, pois a fluorescência dos traçadores acontece durante um período de alguns nanossegundos. $\mathrm{O}$ alinhamento da câmera com o laser deve ser realizado cuidadosamente de modo que ambos estejam perfeitamente perpendiculares entre si, a fim de evitar a distorção geométrica do plano da imagem.

O sistema adquirido junto à empresa LaVision $\mathrm{GmbH}$, implementa a técnica de diagnóstico PLIF. Os principais componentes deste sistema, mostrados na Figura 3.3, serão apresentados nas seções seguintes.

\subsubsection{Laser de bombeio Nd:YAG}

O equipamento utilizado para o processo conhecido como bombeio do laser de corante é um laser do estado sólido, sendo constituído de uma barra de Ítrio, Alumínio e Garnet dopada com Neodímio (Nd:YAG), a qual é excitada por uma lâmpada pulsante. $O$ feixe laser de alta energia de luz possui o comprimento de onda fundamental de $1064 \mathrm{~nm}$ e seus harmônicos são 532, 355, 266 e $213 \mathrm{~nm}$. Neste trabalho, foi utilizado um laser (Quantel, Brilliant b), com as seguintes características de emissão: o terceiro harmônico, de $355 \mathrm{~nm}$, possui duração de pulso de $4 \mathrm{~ns}$. A energia deste pulso é da ordem de $260 \mathrm{~mJ}$, com potência de $6 \mathrm{MW}$ por pulso à uma cadência de $10 \mathrm{~Hz}$. A divergência do feixe de luz deste laser é de $0,5 \mathrm{mrad}$. O critério para a escolha deste tipo de laser é alta energia do pulso e o comprimento de onda que permite excitar o laser de corante.

Os riscos causados pelo uso do laser são grandes devido às características das emissões laser (comprimento de onda UV, alta energia, etc.). O laser Nd:YAG 
faz parte dos lasers da classe 4, os quais são capazes de produzir reflexos perigosos que podem causar danos aos olhos, à pele e também riscos de queimaduras, etc.

Após a emissão, o feixe laser passa pelo obturador que é controlado via computador pelo sistema de sincronia do programa DaVis. Desta forma, o laser de corante recebe a luz do laser de bombeio apenas quando o obturador estiver aberto, isto é, durante a aquisição de dados ou ensaios controlados. A abertura do obturador é sincronizada com o restante do sistema de medição por meio de uma Unidade Programável de Tempo (UPT).

\subsubsection{Laser de Corante}

O laser de corante, mostrado na Figura 3.4, tem o papel de permitir a varredura de determinadas faixas de comprimentos de onda, nos quais as espécies químicas são excitadas. Para tanto, o laser de corante utilizado (Sirah, CSTR-G3000) possui frequência de repetição, energia do pulso e duração diretamente relacionados aos valores destes parâmetros do laser de bombeio. Este laser possui um sistema de recirculação do corante, a fim de se evitar danos por superaquecimento no sistema.

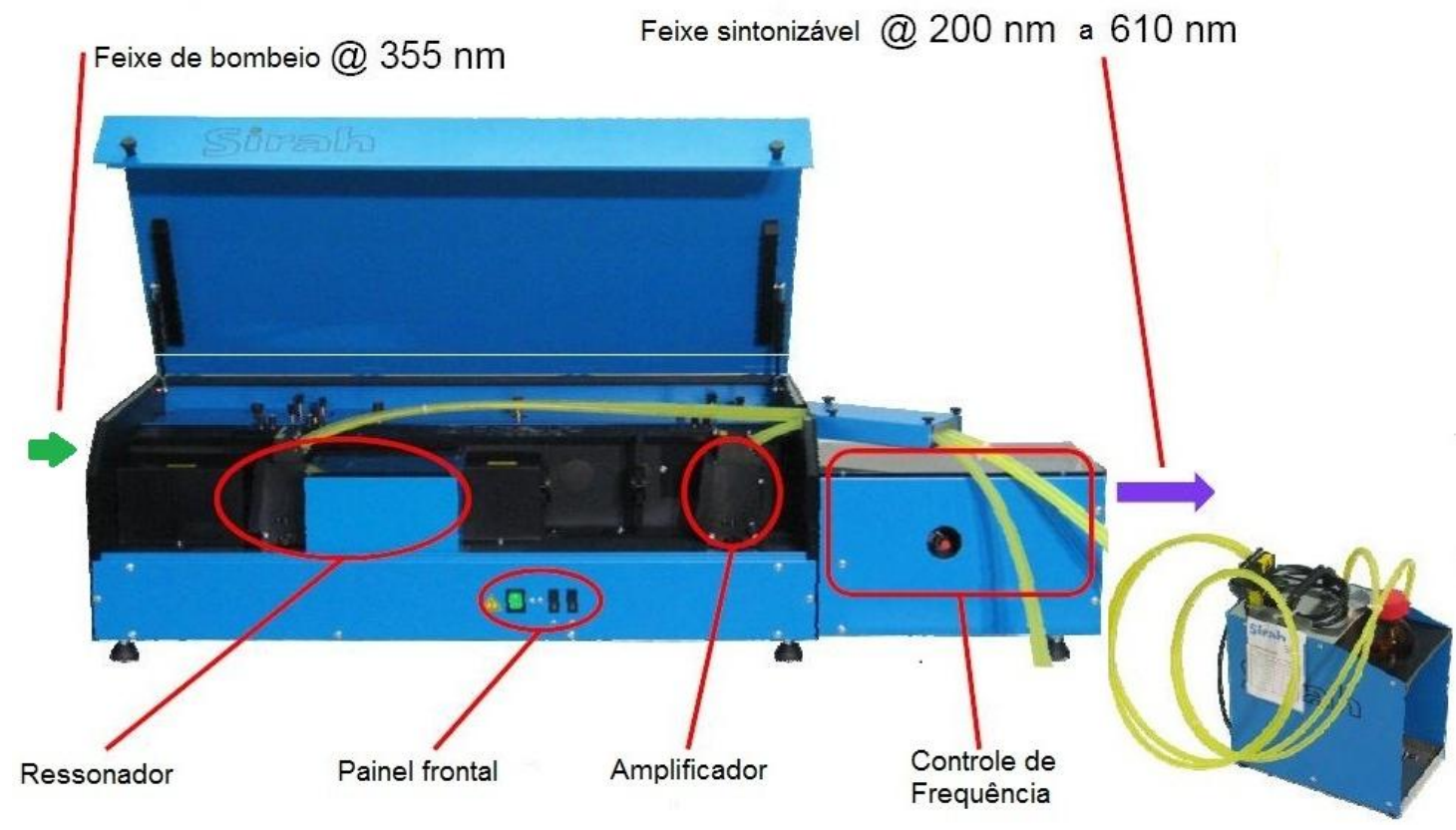

Figura 3.4. Descrição dos componentes do laser de corante [40]. 
Para estudar o radical $\mathrm{OH}$ foi usado o corante Coumarino-153, dissolvido em etanol absoluto, a uma concentração de 1,6 g/l. O laser de corante é composto por um sistema óptico, no qual o feixe de luz passa por múltiplas reflexões, na fase de pré-amplificação na cavidade do laser. O feixe atravessa um sistema ressonante composto por uma célula de corante e três placas de Brewster que são usadas a fim de transmitir apenas a luz polarizada. Em seguida, é utilizada uma rede de Bragg de 3000 linhas/mm, a qual trabalha como uma grade de refração, a fim de sintonizar o comprimento de onda da luz com precisão da ordem de picômetros. Devido ao arranjo, uma célula com maior concentração de corante é utilizada para amplificar a energia do laser. Conforme mostra a Figura 3.5, em seguida, o feixe passa por um cristal óptico não linear $\mathrm{BBO}\left(\beta-\mathrm{BaB}_{2} \mathrm{O}_{4}\right)$, onde a frequência da luz é duplicada [14]. O mecanismo físico que descreve a duplicação da frequência da onda eletromagnética é baseado em uma deficiência de simetria da rede cristalina dos materiais, os quais podem exibir um tipo de não linearidade óptica, $\chi^{(2)}$, associada à não linearidades na polarização [11]. Um campo elétrico, $E_{\omega}$, na frequência fundamental $\omega$, incide sobre um material não-linear e não centro-simétrico, o qual possui uma susceptibilidade não-linear de segunda ordem. O campo fundamental induz uma resposta de polarização não-linear na frequência $2 \omega$ no material. Os dipolos polarizados irradiam em uma frequência $2 \omega$, produzindo um campo elétrico $E_{2 \omega}$. Se ambas as ondas se propagam com velocidade de fase igual, ao longo do comprimento do material, a potência flui da onda fundamental à onda do segundo harmônico, ocorrendo casamento de fase entre as ondas fundamental e duplicada. Desta forma, o comprimento de onda do laser produz neste material uma onda de polarização não-linear que oscila com frequência igual ao dobro da frequência fundamental de bombeio. 


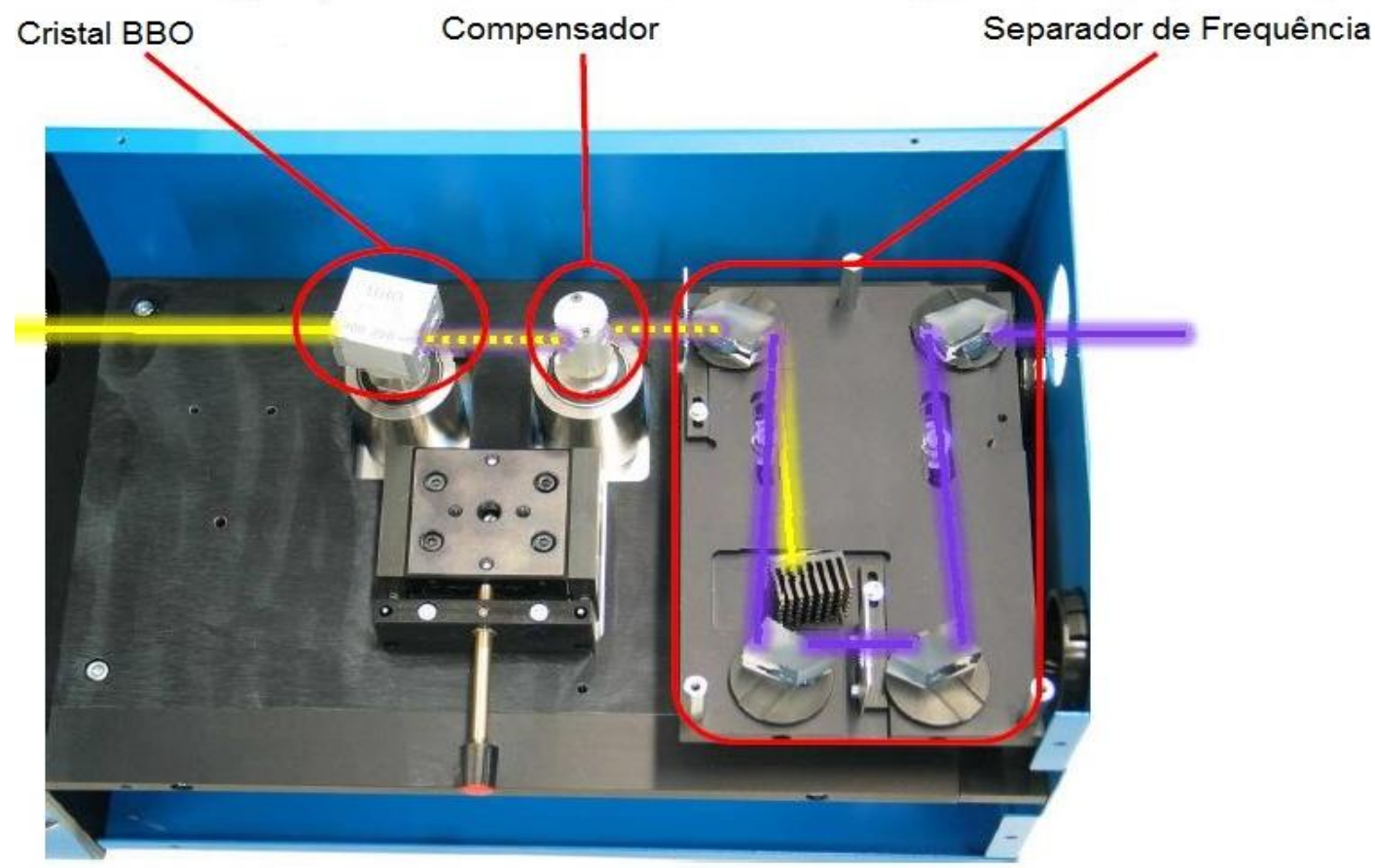

Figura 3.5. Sistema de controle de frequência do laser de corante [40].

A energia transferida pelo laser para a formação do segundo harmônico aumenta linearmente com a intensidade da fonte de luz. Assim, a intensidade da luz laser de frequência duplicada aumenta com o quadrado da intensidade da luz de bombeio. Em seguida, um sistema de prismas separa os dois feixes de luz de comprimentos de onda diferentes, no qual o feixe desejado passa por um compensador apropriado e está pronto para induzir a fluorescência. Nesta etapa, apenas $2,5 \%$ da energia do feixe de bombeio incidente deixa o laser de corante e cerca de $1 \%$ de toda energia fornecida inicialmente pelo feixe de luz laser de bombeio será aproveitada para excitar as moléculas de $\mathrm{OH}$. A eficiência máxima alcançada por este sistema laser de corante é de $15 \%$, com faixa de comprimento de onda de emissão situada entre 517 e $574 \mathrm{~nm}$. Isto é, se o laser de bombeio fornece $260 \mathrm{~mJ}$, então, um feixe de apenas $40 \mathrm{~mJ}$ de energia será emitidos pelo laser de corante.

A fonte de luz laser de bombeio apresenta diferenças nas intensidades dos pulsos, devido ao sistema eletrônico, a alimentação e, principalmente, à probabilidade de ocorrem os fenômenos físicos necessário para a produção da luz laser. Por esta razão as variações da energia que ocorrem entre os pulsos de luz laser devem ser corrigidas. Neste trabalho esta correção é realizada via programa 
de computador, na fase de pós-processamento. Para tanto, é utilizado um monitor de energia, (LaVision, E-monitor), capaz de medir a energia de cada pulso de luz laser, simultaneamente, com aquisição das imagens pela câmera. Para este fim, o monitor de energia desvia $4 \%$ da luz, o que permite ao sistema de aquisição de dados comparar a diferença de energia entre os pulsos, visando compensar as variações de intensidade do laser, o que se repercute em uma correção que é aplicada a cada pixel de cada imagem [40], durante a fase de pós-processamento. As correções de energia aplicadas para o plano de luz laser serão abordadas na seção 3.5.4.

Os valores de energia medidos pelo monitor são usados para compensar as variações de intensidade do laser, chamada correção de intensidade, a qual calcula a intensidade corrigida, $I_{c}$, para cada pixel da imagem, da seguinte forma:

$$
I_{c}=I_{i} \frac{I_{R}}{I_{E}},
$$

onde $I_{i}$ é a intensidade de cada pixel da imagem adquirida, $I_{R}$ é a intensidade de referência definida no programa DaVis e $I_{E}$ é a intensidade equivalente de cada pulso, medida pelo monitor de energia.

\subsubsection{Sistema óptico de plano de luz laser}

A Figura 3.6 mostra a disposição das lentes utilizadas para a obtenção de um plano de luz laser. O sistema óptico para a criação do plano de luz laser consiste em um conjunto de lentes de quartzo de $12 \mathrm{~mm}$ de diâmetro (transmitância de $75 \%$ na faixa de 230 a $800 \mathrm{~nm}$ ) unidas por um envelope, cuja disposição permite ajustes de foco. Este sistema é capaz de trabalhar nas altas potências, $2 \mathrm{~J} / \mathrm{cm}^{2}$. A espessura do plano de luz laser pode ser medida utilizando um papel especial que registra as dimensões do feixe de luz laser incidente por meio de uma marcação enegrecida, a qual foi de aproximadamente $0,5 \mathrm{~mm}$, medida por um paquímetro com incerteza de $1 \%$. A altura do plano pode ser facilmente ajustada pela distância entre as lentes cilíndricas e esféricas. A abertura pode ser escolhida através da distância focal da lente divergente. A separação variável das lentes permite posicionar o foco do plano de luz laser entre 300 a $2000 \mathrm{~mm}$. 


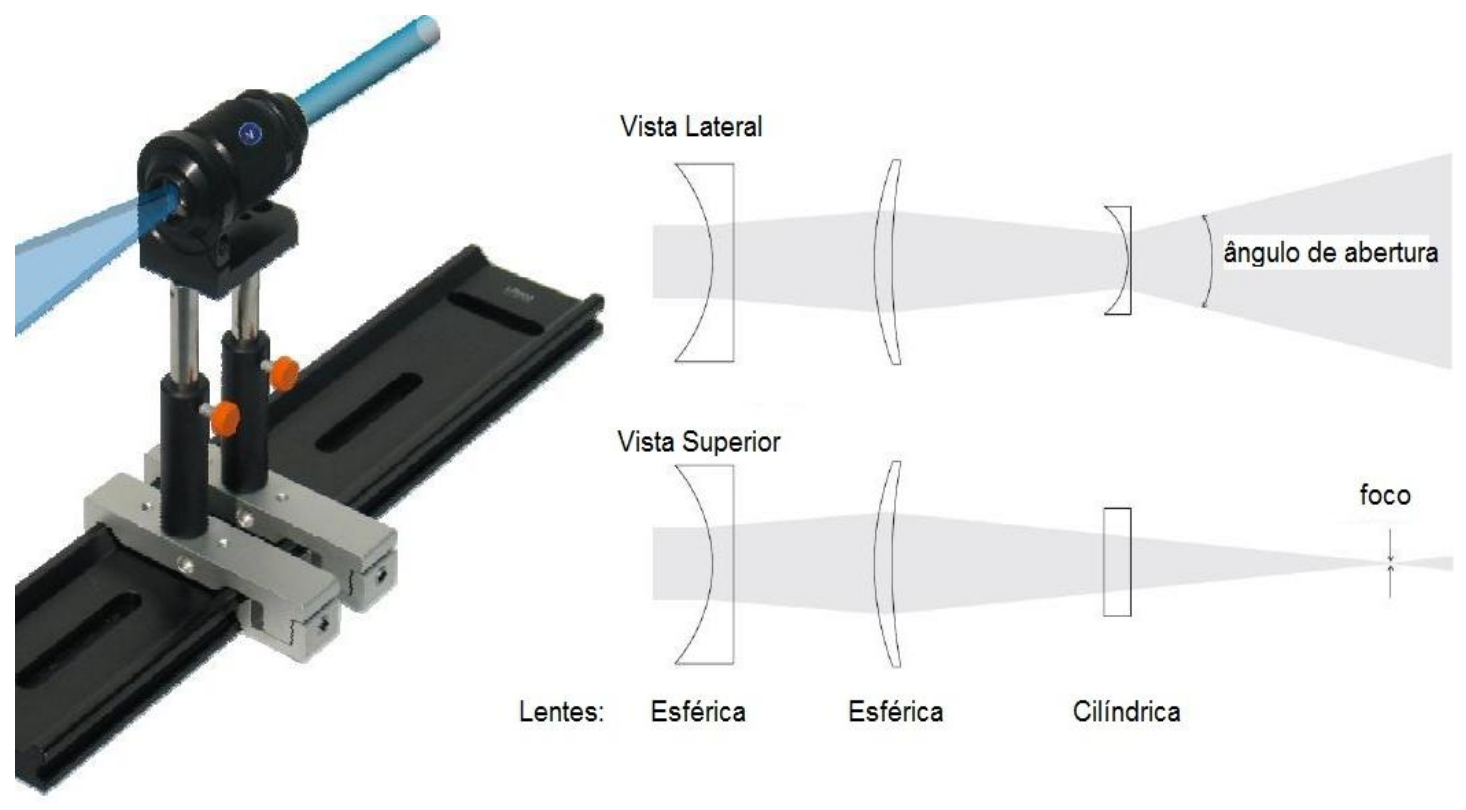

Figura 3.6. Esquema de lentes utilizadas para formar o plano de luz laser [40].

\subsubsection{Câmara Intensificadora}

A intensidade do sinal de fluorescência do $\mathrm{OH}$ não é suficiente para sensibilizar os sensores CCD de câmeras comuns, por isto é necessário utilizar um intensificador de imagens. A fluorescência emitida pelo $\mathrm{OH}$ quando excitado com $283,560 \mathrm{~nm}$, nesta linha de transição, possui comprimento de onda de $310 \mathrm{~nm}$. Os fótons provenientes da fluorescência atravessam um filtro passa banda, centrado em $305 \pm 5 \mathrm{~nm}$ e são focados por uma lente Nikon f/1.4 de $50 \mathrm{~mm}$. O intensificador modula o CCD capturando as imagens de PLIF-OH em um tempo de exposição de 10 ns, com dimensão do pixel de 6,5 $\mu \mathrm{m}$.

A câmera Intensificadora ICCD é composta por uma câmera CCD (Charged Coupled Device), um dispositivo eletro-óptico, uma placa de fósforo e um fotocátodo [53], como mostra a Figura 3.7. Os fótons oriundos do processo de fluorescência são focalizados na janela de entrada do intensificador de imagem, onde os fótons incidentes na tela frontal do ICCD (Lavision, High Speed Intensifier Relais Optic - HSIRO) são convertidos em elétrons, pelo foto-cátodo, através do efeito fotoelétrico. Em seguida, esta corrente elétrica dentro do cátodo é amplificada 
pela diferença de potencial e, finalmente, convertida na forma de luz ao atingir uma superfície de fósforo, criando um sinal de fluorescência na saída do intensificador de imagem. Este sinal ocorre sempre na faixa de comprimentos de onda na região da cor verde e, então, a única variável é a intensidade desta fluorescência na saída do intensificador, a qual produz a imagem digital em níveis de cinza. A imagem que sai da janela do intensificador é focalizada no CCD (Lavision, Image Intense), por meio de um conjunto de lentes. A exposição efetiva da câmera é produzida pela integração dos intervalos de tempo da emissão por parte do fósforo. O tempo de vida da câmera ICCD é aproximadamente 5000 horas para uma intensidade de luz de $10 \mathrm{mLux}$. O computador controla o ICCD através do gatilho eletrônico durante a aquisição das imagens, visando limitar o funcionamento do sistema ao tempo de aquisição de dados desejado, através da função gate, ou abertura, a qual controla o tempo de exposição da câmera.

O intensificador é um dispositivo eletrônico com tempo de exposição extremamente variável, o qual permite que a câmera CCD, usualmente com faixa de tempo de exposição da ordem de milissegundos, seja modulada através do intensificador, reduzindo o tempo de exposição para apenas alguns nanossegundos. A eletrônica do sistema intensificador permite alta taxa de repetição com frequências acima de $2 \mathrm{MHz}$, a duração dos pulsos eletrônicos é de 30 ns. A unidade lógica do sistema opera em uma frequência de $200 \mathrm{MHz}$, isso assegura a possibilidade de selecionar intervalos de tempo de captura em porções de até 5 ns.

A placa de fósforo padrão, tipo P43, possui alta eficiência e um tempo de decaimento razoavelmente curto. Assim, a eficiência quântica da P43 é de 90\% para um tempo de decaimento de $1 \mathrm{~ms}$ na faixa do ultra-violeta no espectro eletromagnético. A imagem intensificada possui uma resolução máxima de 10 $\mu \mathrm{m} /$ linha. $\mathrm{Na}$ imagem, o tamanho de cada pixel é da ordem $90 \mu \mathrm{m}$ no plano de medição. 


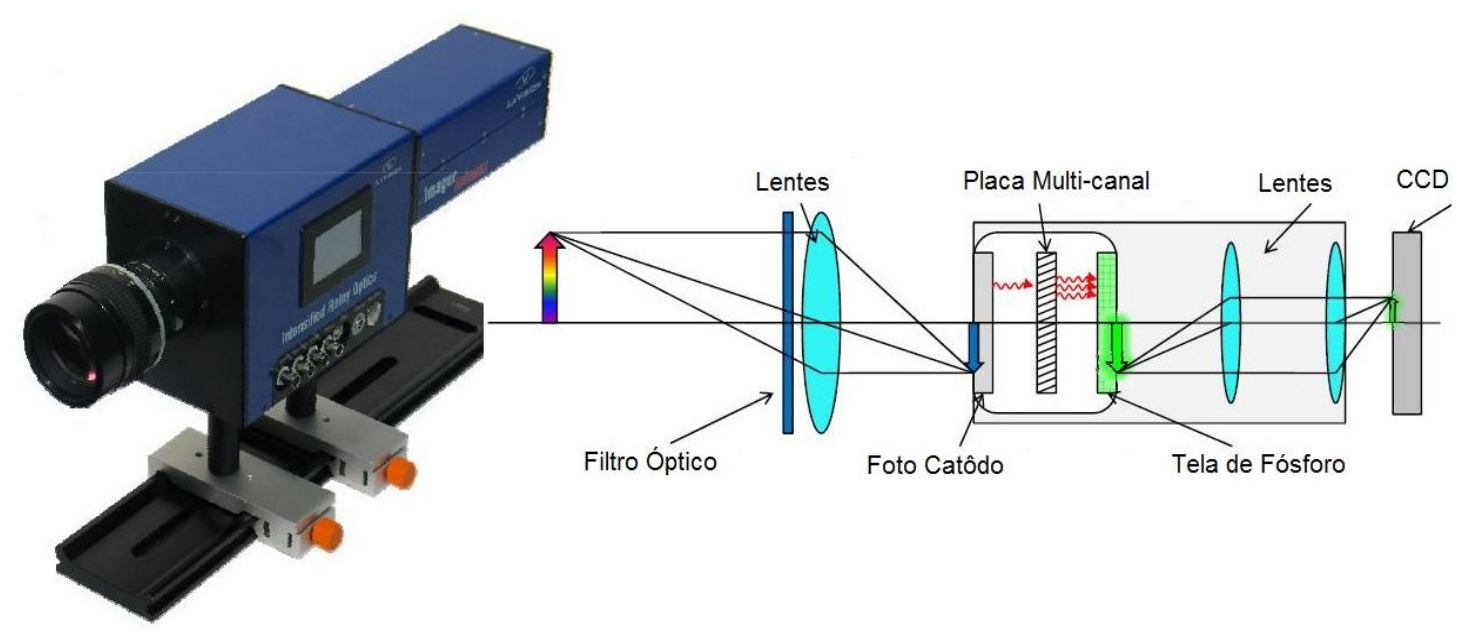

Figura 3.7. Esquema da configuração do Intensificador de imagem [40].

\subsubsection{Sistema de captura de imagens}

A fluorescência é obtida excitando a linha de transição $Q_{1}(8)$, da molécula de $\mathrm{OH}$, vide Figura 3.8, relativa aos estados, rotacional $\left(v^{\prime}=0\right)$ e vibracional $\left(v^{\prime \prime}=1\right)$ do sistema $A-X(1,1)$ e $(0,0)$, respectivamente. A transição $j=8$ é escolhida pelo fato de não sofrer influência significativa da temperatura [47]. Para a captura desta informação é utilizado um sistema composto por uma câmera CCD (LaVision, Image Intense) com uma matriz de 1376×1040 pixels, taxa de captura máxima de $10 \mathrm{~Hz}$, 500 ns de intervalo entre aquisições e uma eficiência quântica de $70 \%$ na faixa de $532 \mathrm{~nm}$.

Neste trabalho, foi percorrida a faixa de comprimentos de onda de excitação desde 283,560 até $283,570 \mathrm{~nm}$. São capturadas imagens de uma chama laminar, isto é, uma chama estável, para cada comprimento de onda de excitação neste intervalo, com incrementos de 1 picômetro. $O$ máximo de resposta da linha de fluorescência foi obtido com o comprimento de onda de excitação igual a 283,564 $\mathrm{nm}$, conforme mostra a Figura 3.9. O programa DaVis controla todo o processo de procura de máximo sinal de fluorescência, dados o intervalo de comprimentos de onda de excitação desejado e o valor do incremento, que neste trabalho foi de 1 picômetro. Então, o sistema ilumina a chama, captura a fluorescência produzida para cada um dos comprimentos de onda do intervalo selecionado e identifica qual deles produz a melhor resposta, a qual é avaliada pela soma dos níveis de cinza em todos os pixels da imagem. Os níveis de cinza das imagens produzidas são 
subdivididos em unidades chamadas de counts pelo fabricante [40]. As diversas varreduras realizadas durante o desenvolvimento deste trabalho mostram que este valor pode variar, em \pm 3 picômetros, dependendo das condições do ambiente. Os motivos pelos quais essa variação ocorre não foram analisados por não fazerem parte do escopo deste trabalho.

A Figura 3.10 mostra a curva característica da eficiência quântica de sensores CCD, cuja definição é a razão entre o número de fotoelétrons coletados e o número de fótons incidentes por pixel. Nota-se que, para a região espectral de comprimentos de onda da fluorescência obtidos neste trabalho, da ordem de 310 $\mathrm{nm}$, a resposta do sensor é muito baixa, cerca de apenas $20 \%$ do total incidente. Isto reforça a necessidade da utilização do intensificador de imagens, cujo comprimento de onda da luz na saída corresponde a uma maior eficiência quântica do CCD (60-70\%).

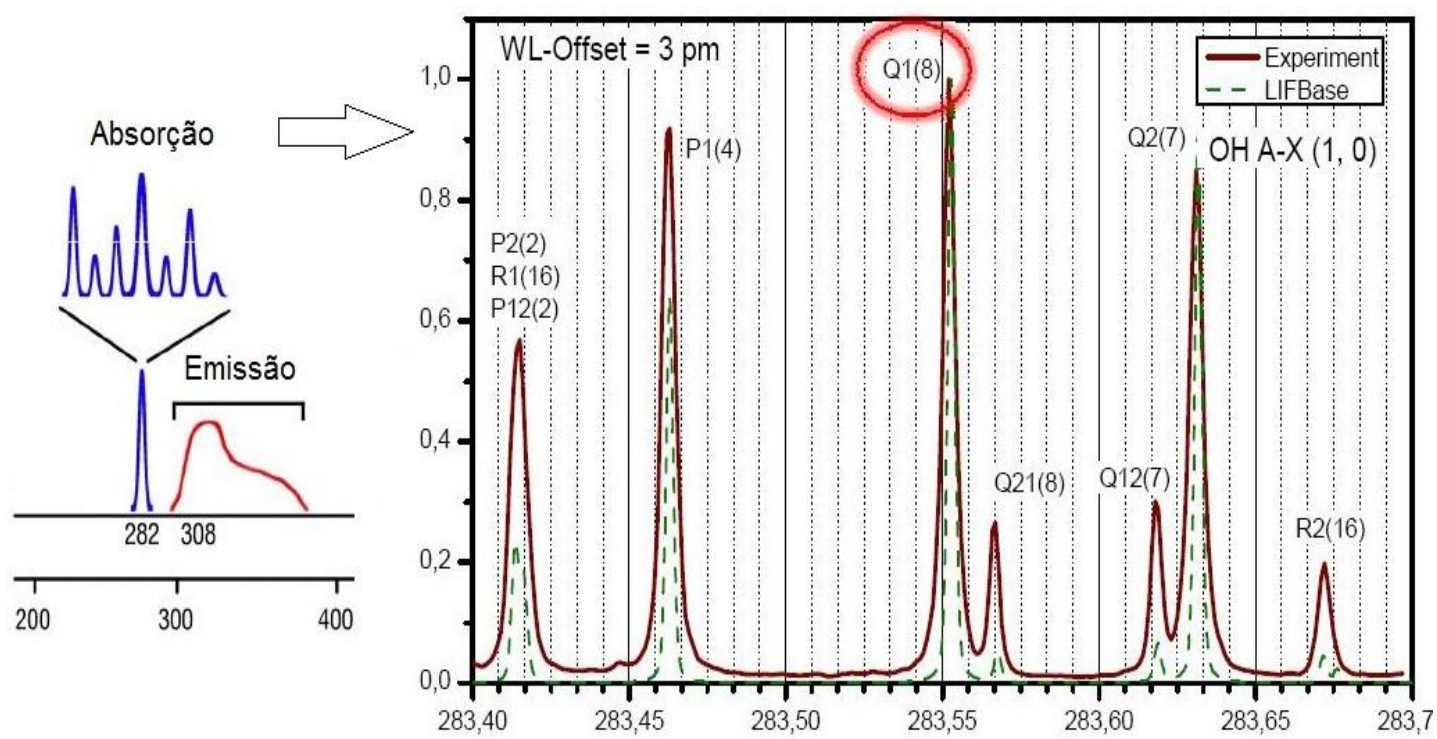

Figura 3.8. Ilustração de parte do espectro de absorção e emissão do OH [40].

O sistema de controle e processamento de dados utiliza o software DaVis 7.2.2, o qual processa as imagens através da interface com uma placa de processamento digital (Framegrabber, 525 KP). O sistema de análise de dados é parte integrante do programa DaVis 7.2.2, devidamente explorado neste trabalho a fim de obter resultados com alta resolução e baixa incerteza. 


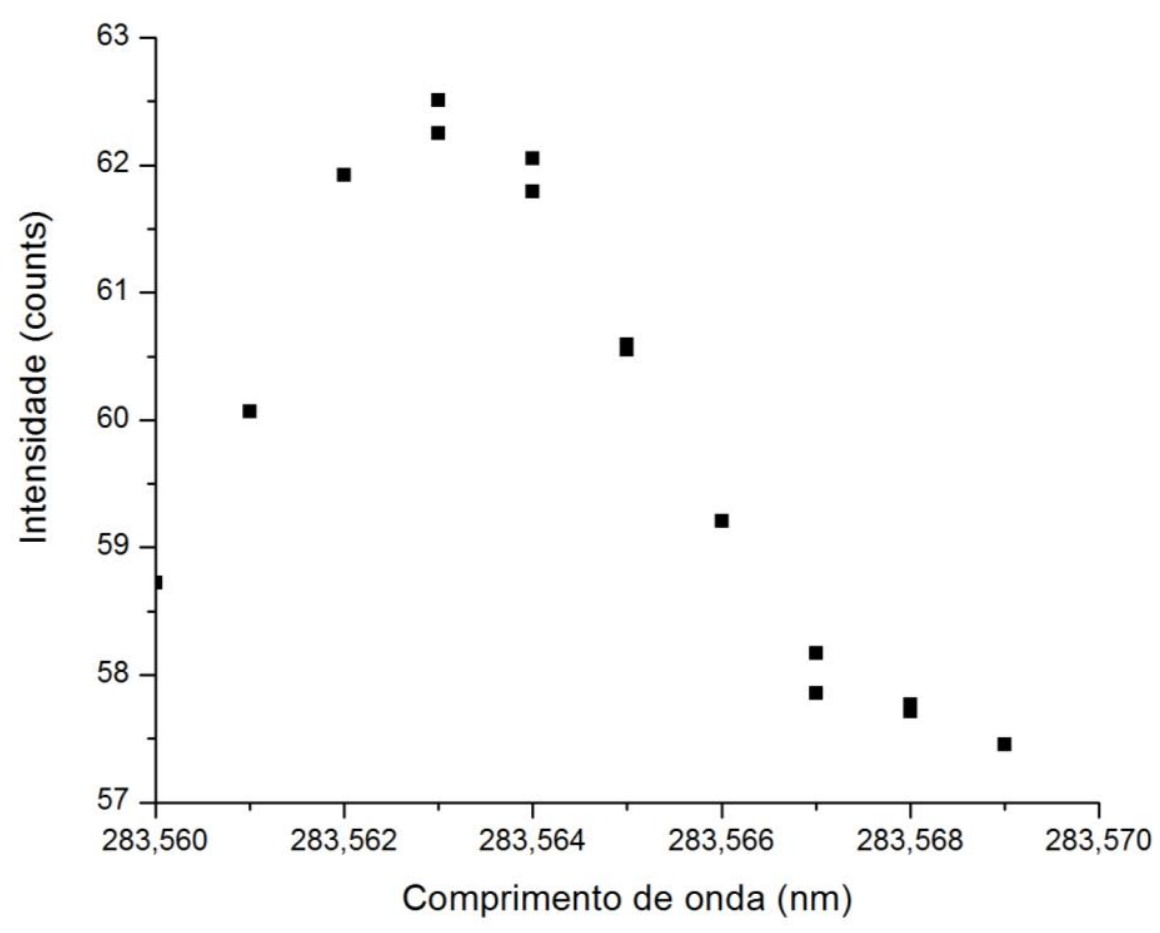

Figura 3.9. Resposta do sinal de fluorescência induzida por laser em função do comprimento de onda da excitação.

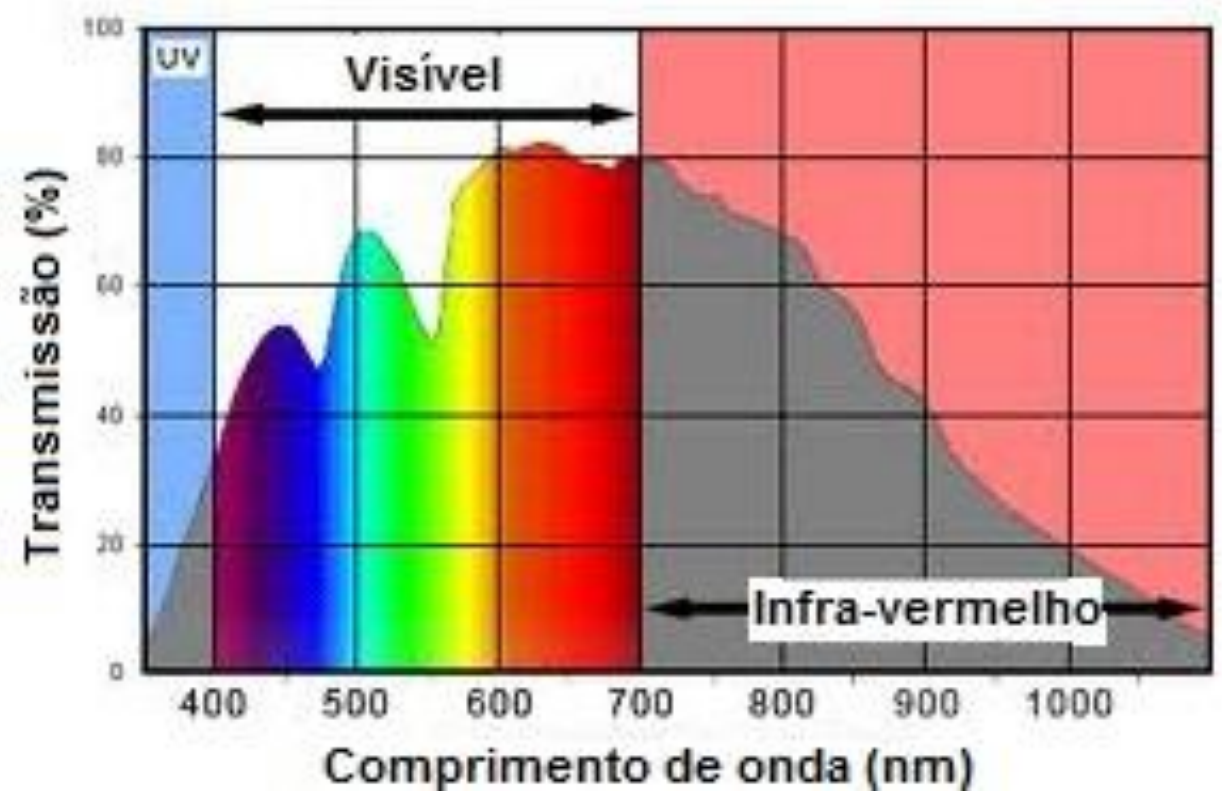

Figura 3.10. Curva característica de resposta espectral de sensores CCD [40]. 


\subsubsection{Controle e Processamento de Dados}

A Figura 3.11 ilustra a sincronia dos sinais elétricos que controlam o sistema PLIF, onde o disparo inicial da lâmpada pulsada é dado pela UPT. Em seguida, o obturador do laser (Q-Switch) UPT Q1 é ativado emitindo um pulso de luz laser. O intensificador de imagens e a câmera CCD são ativados durante o período do pulso da lâmpada, porque apresentam um atraso intrínseco do sistema pelo qual é formado. Só então o sistema inicia a captura, a qual deve ocorrer alguns nanossegundos após a emissão do laser. O tempo de exposição do intensificador de imagens é muito mais curto que o CCD, permitindo sincronizar o início da captura no instante em que houver maior sinal de fluorescência. Além disso, o intensificador pode ser modulado pelo ganho eletrônico, que consiste em uma tensão elétrica aplicada no foto-cátodo, durante o período de exposição, o qual acelera os elétrons no interior do intensificador, amplificando o sinal.

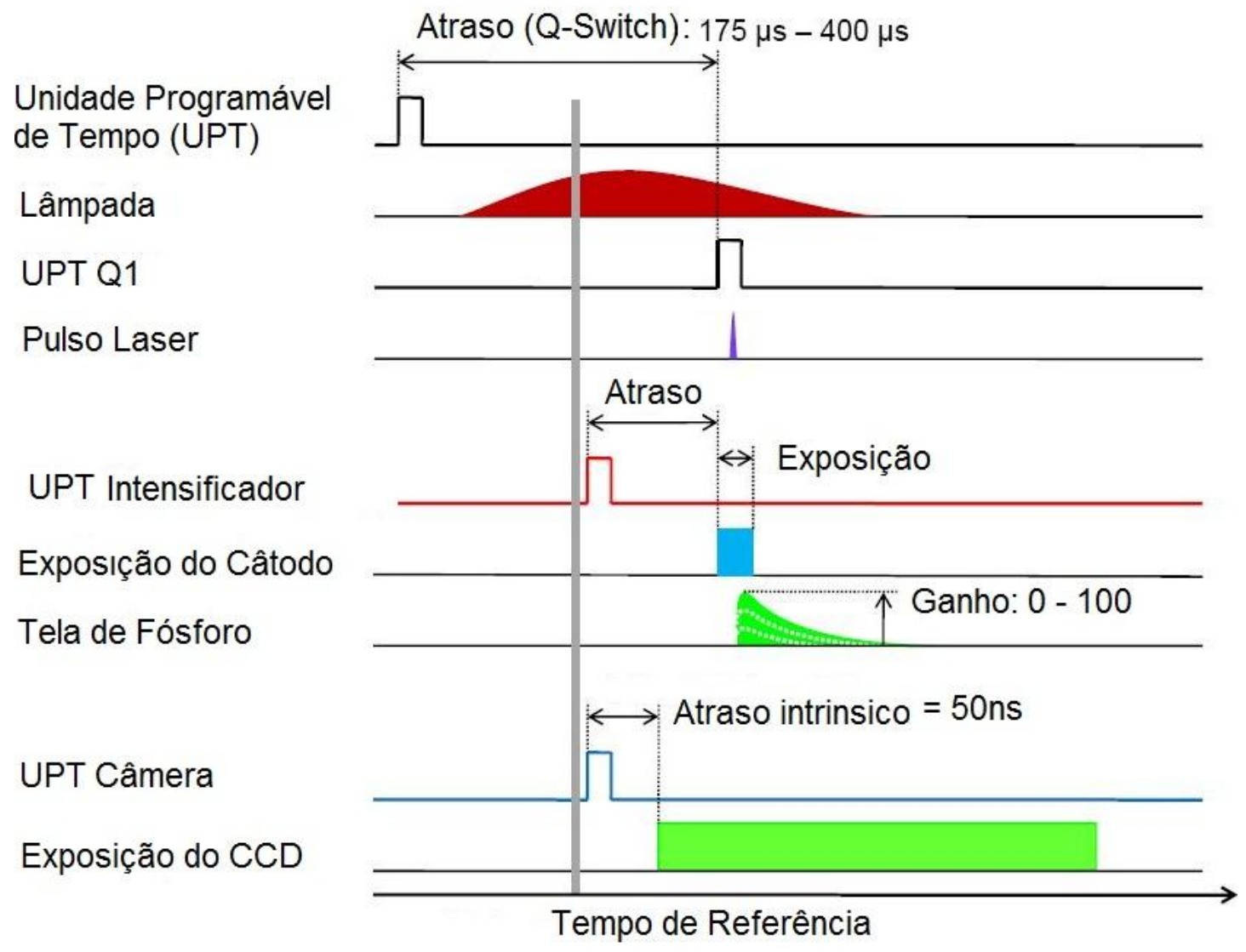

Figura 3.11. Sincronia entre os sinais elétricos dos componentes do PLIF [40]. 


\subsection{Sistema de velocimetria por imagem de partículas (PIV)}

A montagem experimental de um sistema PIV é constituída de diversos componentes, como mostra a Figura 3.12. O primeiro, cujas dimensões são dadas no apêndice A, é constituído por um sistema de dispersão e seleção de partículas traçadoras nas regiões de interesse do escoamento. Este sistema de dispersão de partículas é composto por um dispersor que contém uma placa porosa acima da qual são depositadas as partículas, criando assim um leito fluidizado quando da passagem de escoamento. As menores partículas são carregadas pelo escoamento de gás e seguem para um ciclone especificamente desenvolvido para selecionar as partículas pelas dimensões, neste caso o diâmetro de corte é de aproximadamente $1 \mu \mathrm{m}$. As partículas selecionadas são, então, iluminadas duas vezes por um plano de luz laser em um intervalo de tempo prescrito. A luz espalhada pelas partículas, por efeito Mie, é capturada por uma câmera formando um padrão em dois quadros, os quais são correlacionados, usando transformadas de Fourrier, para identificar os mesmos grupos de partículas em ambos os quadros. O deslocamento dos grupos de partículas entre os dois pulsos de luz laser é então determinado, permitindo o cálculo da componente da velocidade do campo de partículas projetada no plano de luz laser. $O$ tempo de duração de cada pulso de luz laser deve ser curto o suficiente para produzir uma imagem instantânea das partículas, durante o tempo de exposição da câmera. $O$ intervalo de tempo entre os dois pulsos do laser deve ser escolhido para que seja possível determinar o deslocamento das partículas entre as duas imagens, mas com resolução temporal suficientemente pequena para evitar que a componente da velocidade de direção ortogonal ao plano leve a partícula para fora do plano de luz laser antes do segundo pulso. Uma regra empírica recomenda que o deslocamento de uma partícula entre as duas imagens seja de até $1 / 4$ do tamanho da janela de medição utilizada na fase de processamento, a fim de permitir que a partícula percorra uma distância adequada para que o programa de processamento correlacione os padrões do par de imagens [51]. Entretanto, o valor ótimo de intervalo entre os pulsos do laser é função da qualidade da dispersão, isto é, da homogeneidade e concentração suficiente de partículas na imagem.

Assim, para o bom uso da técnica PIV, é necessária uma dispersão homogênea das partículas e em uma concentração suficiente para se obter a 
resolução espacial desejada. No presente trabalho, busca-se garantir a presença de ao menos 1 partícula em uma matriz de $5 \times 5$ pixels, o que de fato só é alcançado nas regiões em que o escoamento é uniforme, como será visto na seção 3.5.1.2. Além disso, durante o processo de calibração, as lentes acopladas às câmeras devem ser ajustadas para focar adequadamente a imagem das partículas iluminadas pelo plano de luz laser.

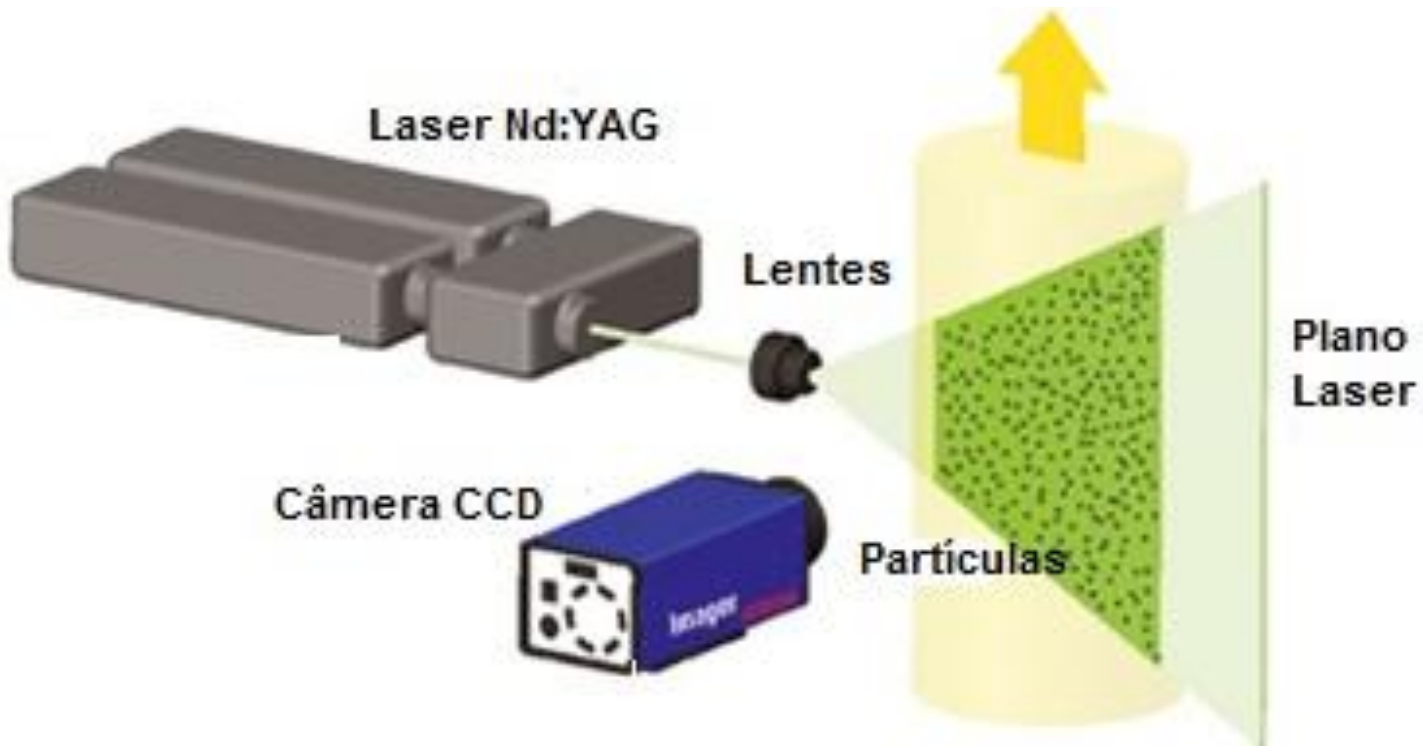

Figura 3.12. Esquema do aparato para realizar a técnica PIV [40].

\subsubsection{Princípios fundamentais da técnica PIV}

Quando a radiação eletromagnética é espalhada por partículas cuja dimensão se aproxima ou excede 4 vezes o comprimento de onda incidente, a radiação é espalhada igualmente em todos os comprimentos de onda. Este fenômeno é chamado de espalhamento Mie [51]. O comportamento do espalhamento direcional pode ser visualizado na Figura 3.13. A interação da radiação eletromagnética com partículas dielétricas induz um espalhamento de grande intensidade. O espalhamento Mie causa uma ampla oscilação senoidal da onda eletromagnética que pode ser descrita pela equação,

$$
Q=2-\frac{4}{p} \operatorname{sen} p+\frac{4}{p^{2}}(1-\cos p),
$$


onde $Q$ é o fator de eficiência do espalhamento, e a grandeza $p=4 \pi r(n-1) / \lambda$ é a diferença de fase da onda que passa pela partícula, onde $\lambda$ é o comprimento de onda da luz, $n$ é a razão entre o índice de refração dentro e fora da partícula esférica e $r$ é o raio da partícula. Assim, é a luz espalhada pelas partículas quando da incidência do feixe de luz laser que será capturada pela câmera.

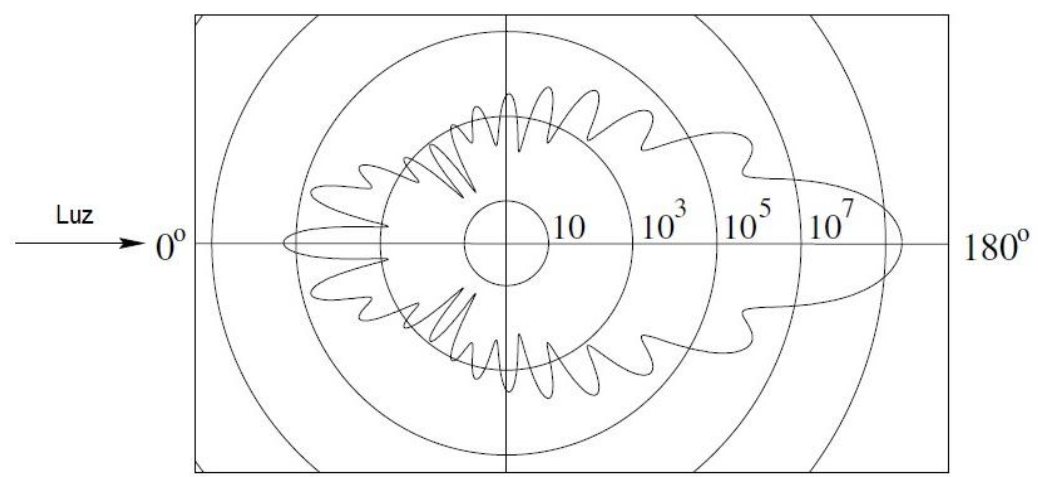

Figura 3.13. Esquema do espalhamento Mie com escala de módulo de intensidade para uma gota de óleo de $1 \mu \mathrm{m}$ no ar [51].

\subsubsection{Os principais componentes do PIV}

\subsubsection{Fonte de iluminação}

Um laser Nd:YAG de dupla cavidade (Quantel, Twins), mostrado na Figura 3.14, é utilizado como fonte de luz para iluminação das partículas dispersas no escoamento, por meio de um plano de luz laser de $532 \mathrm{~nm}$. As duas cavidades do laser são independentes e os pulsos de luz laser, emitidos por ambas, podem ser defasados. Isto é indispensável para a técnica PIV porque permite ajustar o intervalo entre o par de imagens, a fim de se obter um deslocamento adequado das partículas em diferentes velocidades do escoamento. Além disso, em escoamentos com altas velocidades, o intervalo de tempo entre os pulsos deve ser muito curto. Cada uma das cavidades do laser emite luz no comprimento de onda fundamental de $1064 \mathrm{~nm}$ para o Nd:YAG. Os dois feixes são alinhados em um mesmo ponto $P$ e, atravessam um cristal gerador de segundo harmônico, SHG, e são direcionados para fora do equipamento por meio de espelhos, $M$. 


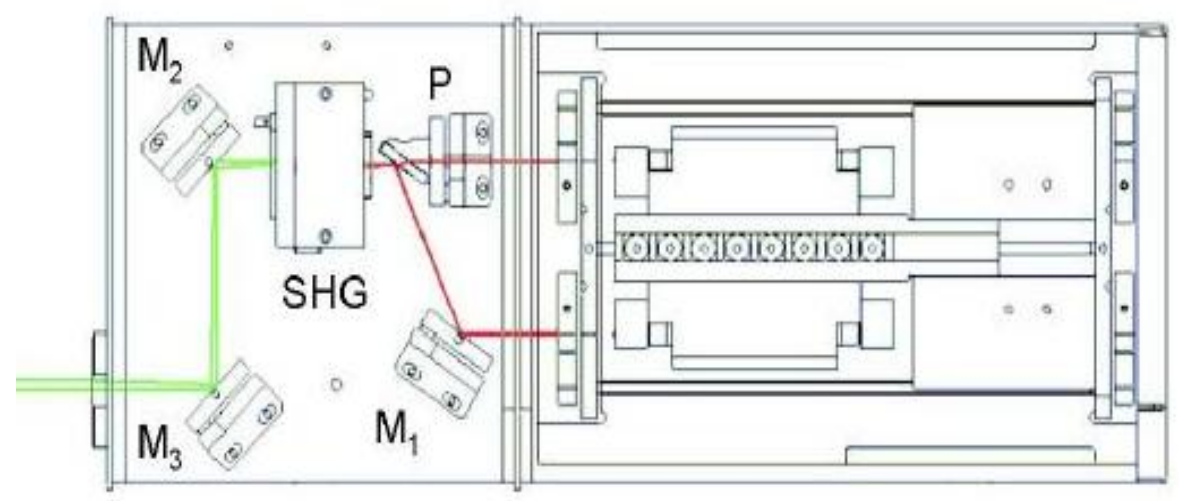

Figura 3.14. Laser Nd:YAG de duplo pulso utilizado na técnica PIV [40].

\subsubsection{Câmera CCD e sistema de lentes}

A intensidade do sinal de espalhamento Mie deve ser suficiente para sensibilizar o sensor de uma câmera CCD. No arranjo empregado neste estudo os fótons de luz laser espalhados pelas partículas atravessam um filtro passa banda, centrado em $532 \pm 5 \mathrm{~nm}$, e são focados por uma lente da marca Nikon (Nikkop, f/1.4 e $50 \mathrm{~mm}$ ). Para a captura das imagens é utilizada uma câmera CCD (LaVision, Image Intense) com uma matriz de 1376x1040 pixels, de 12 bit, com 6,45 $\mu \mathrm{m}$ de dimensões de pixel, taxa de captura máxima de $10 \mathrm{~Hz}$ no sistema, $500 \mathrm{~ns}$ de intervalo entre aquisições e uma eficiência quântica de 70\% na faixa de $532 \mathrm{~nm}$.

\subsubsection{Partículas traçadoras}

As partículas traçadoras empregadas em PIV devem atender três requisitos fundamentais. Primeiro, as partículas devem ter dimensões mínimas para que espalhem a luz laser, conforme descrito na seção 3.4.1. Segundo, as partículas devem acompanhar as flutuações turbulentas do escoamento. Terceiro, as partículas devem possuir ponto de vaporização superior à temperatura do escoamento, no caso de aplicação em chamas [35]. A exatidão na determinação das dimensões das partículas traçadoras é muito importante para o cálculo da incerteza das medições em PIV [23].

Para aplicações em escoamentos de gases são necessárias partículas diminutas e potência da fonte de luz laser suficiente para obter uma intensidade de espalhamento de luz que possa sensibilizar o CCD, de tal forma que a relação 
sinal/ruído seja capaz de produzir imagens de qualidade. Estes requisitos são cruciais na aplicação de PIV em chamas, devido à possível interferência na imagem ocasionada por parte do sinal de incandescência da fuligem, tal como será visto na seção 3.6.1.2. O compromisso entre o tamanho das partículas e a intensidade de luz espalhada deve ser avaliado caso a caso, dependendo da aplicação.

A dispersão das partículas deve ser realizada a montante da região de interesse que, no caso deste trabalho, é a zona de esteira do queimador. A distribuição de partículas deve abranger todos os detalhes do escoamento, pois no caso de haver poucas partículas dispersas no fluido a resolução espacial da medida da velocidade será baixa. As partículas utilizadas devem ter o diâmetro, a densidade e o espalhamento escolhidos de modo a garantir a medida da velocidade dentro da faixa de variação esperada. Assim, a dimensão e a densidade das partículas traçadoras influenciam diretamente a incerteza da medição. Em particular, o tempo de resposta da partícula à flutuações de velocidade deve ser inferior ao tempo característico desta flutuação. Neste trabalho, foram utilizadas partículas de Dióxido de Titânio $\left(\mathrm{T}_{i} \mathrm{O}_{2}\right)$ com diâmetro aproximado de $1 \mu \mathrm{m}$, devido à facilidade de acesso ao material. Este tipo de partícula é extensamente utilizada e recomendada para os fins de medição em escoamentos com combustão [76, 23, 47].

A escolha das dimensões das partículas traçadoras é de fundamental importância para que acompanhem corretamente o escoamento. O tamanho ideal da partícula pode ser estimado pela medida do tempo de relaxação de uma partícula escoando em um fluido, o qual é obtido a partir da equação de Stokes [51]. O tempo de relaxação é uma medida conveniente para estimar a tendência das partículas em permanecer em equilíbrio com o escoamento.

$$
t_{s}=d_{p}^{2} \frac{\rho_{p}}{18 \mu}
$$

onde $d_{p}=1 \mu \mathrm{m}$ é o diâmetro médio das partículas, $\mu=17 \cdot 10^{-6}$ Pa.s é a viscosidade cinemática do ar e $\rho_{p}=4.230 \mathrm{~kg} / \mathrm{m}^{3}$ é a massa específica do $\mathrm{TiO}_{2}$, material que compõe as partículas. Assim sendo, o tempo de relaxação é de aproximadamente $14 \mu \mathrm{s}$. Isto equivale a dizer que as partículas são capazes de acompanhar flutuações da ordem de $70 \mathrm{kHz}$ no escoamento. 
Neste trabalho, foi utilizado um equipamento (TSI, APS 3320) para medir a dimensão e a concentração de partículas no escoamento. Trata-se de um espectrômetro de tempo-de-voo, o qual mede a velocidade das partículas em um escoamento acelerado através de um tubo. Neste instrumento, as partículas são confinadas na linha de centro em um escoamento. As partículas passam através de dois feixes de laser, os quais são espalhados pelas partículas contidas no escoamento. A luz espalhada é coletada por meio de um espelho elíptico que foca a luz capturada na superfície de um fotodetector, convertendo os pulsos de luz em pulsos elétricos. Assim, a velocidade pode ser calculada pela razão entre a distância dos feixes e o tempo entre os pulsos medidos para cada partícula.

A determinação das dimensões das partículas traçadoras foi realizada com os escoamentos de ar e do jato escolhidos de modo a representar uma das condições experimentais deste trabalho, isto é, $40 \mathrm{~Hz}$ do inversor de frequência que comanda o ventilador e $1 \mathrm{Nm}^{3}$ de vazão no jato central, onde o combustível foi substituído por Nitrogênio. Cabe ressaltar que por razões de segurança é impossível realizar esta medição em escoamento de combustível. A quantidade de partículas adequada para o experimento foi determinada pela visualização direta da distribuição das partículas nas imagens de PIV, quando então as medidas de diâmetro foram realizadas. A Figura $\mathbf{3 . 1 5}$ mostra os histogramas de concentração para cada escoamento.

Os resultados deixam claro que, em ambos os escoamentos, a média da distribuição de diâmetros é próxima a $1 \mu \mathrm{m}$ e a dispersão em torno deste valor médio é relativamente pequena para a aplicação desejada $(\sigma=0,3)$. 

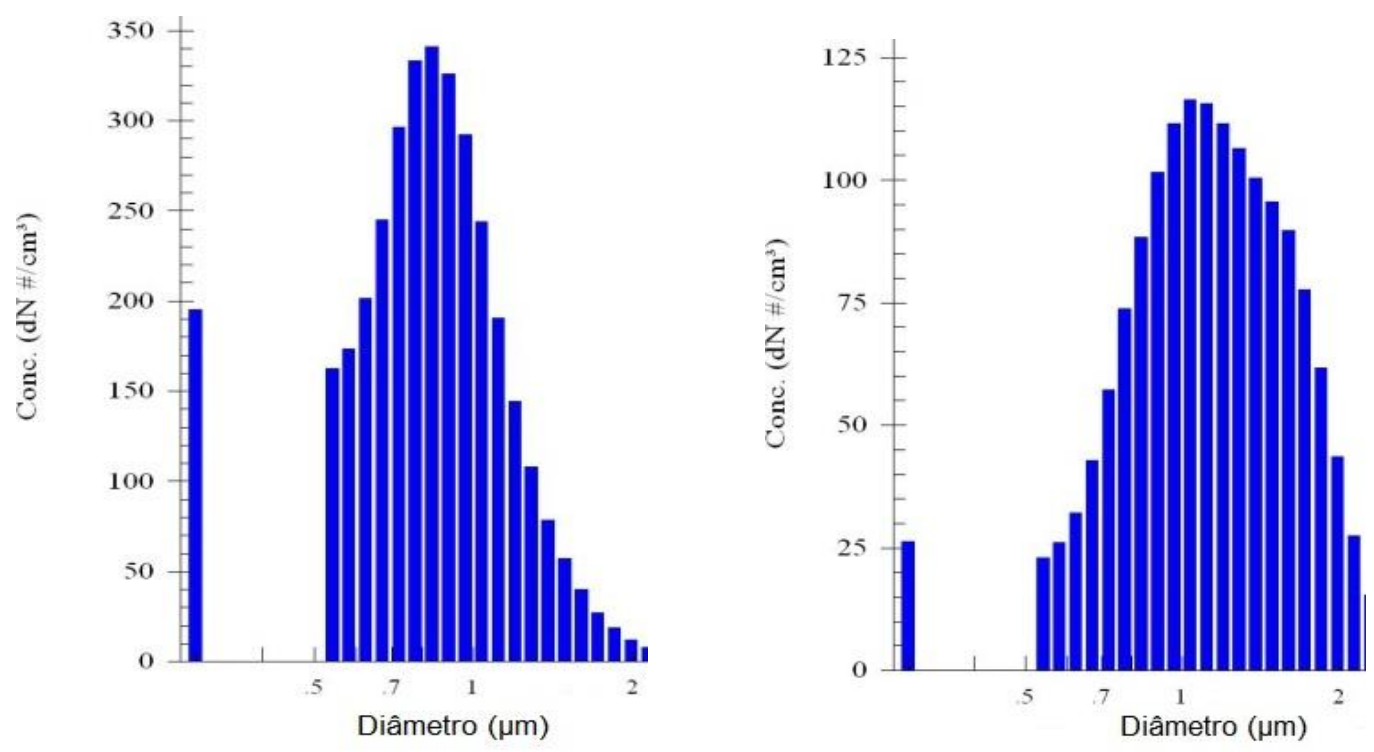

Figura 3.15. Histogramas dos diâmetros das partículas de $\mathrm{TiO}_{2}$. As medidas foram realizadas na saída do ar (esquerda) e no jato central de Nitrogênio (direita).

\subsubsection{Processamento das imagens de partículas}

A Figura 3.16 mostra, esquematicamente, dois quadros distintos com as janelas de interrogação empregadas no modo de correlação cruzada. Cada uma das janelas é deslocada de $( \pm d x / 2, \pm d y / 2)$. Assim sendo, a posição da janela de interrogação no segundo quadro é deslocado por $(d x, d y)$ em relação à janela de interrogação do primeiro quadro. O processamento utiliza os vetores deslocamento e o tempo entre pulsos para calcular os vetores velocidade em cada uma das janelas de interrogação.

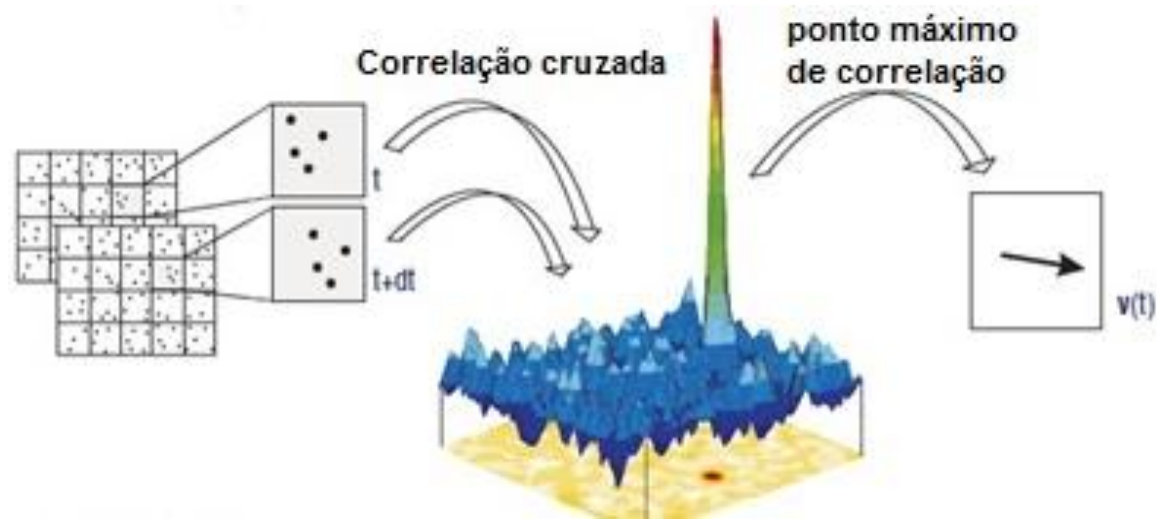

Figura 3.16. A posição do máximo de correlação indica o deslocamento médio das partículas em uma janela de interrogação [40]. 


\subsubsection{Correlação cruzada}

A correlação indica o grau e a direção de relacionamento entre duas variáveis aleatórias. O coeficiente de correlação, também chamado de correlação de Pearson (produto-momento) é definido como,

$$
C=\frac{\operatorname{cov}(X, Y)}{\sqrt{\operatorname{var}(X) \cdot \operatorname{var}(Y)}} \equiv \frac{\sum_{i=1}^{n}\left(x_{i}-\bar{x}\right)\left(y_{i}-\bar{y}\right)}{\sqrt{\sum_{i=1}^{n}\left(x_{i}-\bar{x}\right)^{2}} \cdot \sqrt{\sum_{i=1}^{n}\left(y_{i}-\bar{y}\right)^{2}}},
$$

onde $x_{i}$ e $y_{i}$ são cada uma das $n$ medidas das variáveis, $\bar{x}$ e $\bar{y}$ são as médias aritméticas. Quanto mais próximo de 1 for o valor absoluto de $C$, melhor é a correlação.

A equação pode ser substituída por uma fórmula equivalente, a qual evita o cálculo das médias tornando o custo computacional cerca de 50 vezes menor. Esta equação é baseada em um algoritmo que calcula a correlação da janela de interrogação através de uma relação similar,

$$
C(d x, d y)=\sum_{\substack{x=0, y=0 \\ x<n, y<n}} I_{1}(x, y) I_{2}(x+d x, y+d y), \quad-n / 2<d x, d y<n / 2
$$

onde $I_{1}$ e $I_{2}$ são as intensidades das imagens da $1^{\underline{a}}$ e $2^{\underline{a}}$ janela de interrogação, $C(d x, d y)$ é o grau de correlação para todos os deslocamentos integrados entre duas janelas de correlação e $n$ é a dimensão da janela de interrogação [40].

Quando uma janela de interrogação de dimensões 32x32 pixels é aplicada sem sobreposição, caso 1 da Figura 3.17, o espaçamento da grade entre os vetores computados é de 32 pixels. A origem do primeiro vetor é exibida no pixel $(16,16)$, no centro da janela de interrogação. Se o deslocamento inicial é a partir da origem $(0,0)$ as janelas de interrogação podem ser encontradas na mesma posição em ambos os quadros, os quais vão de $(0,0)$ para $(32,32)$. Porém, quando é usada uma sobreposição de $50 \%$, caso 2 , o espaçamento final da grade de vetores é de 16 pixels, então, o primeiro vetor é exibido em $(8,8)$. A região fora da imagem recebe 0 valor de intensidade igual a zero. $O$ mesmo acontece para janelas com dimensões diferentes, como o caso 3. A posição do vetor depende do tamanho da janela de interrogação e da sobreposição prescritos. Assim, quanto menor a janela de interrogação e maior a sobreposição maior será a resolução espacial do campo vetorial. 
caso 1

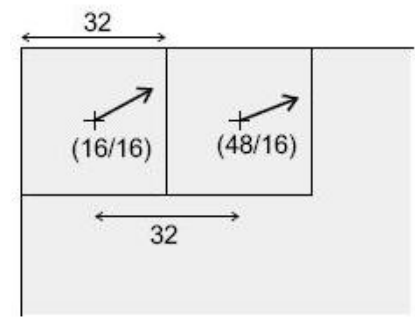

$32 \times 32$ pixels

$0 \%$ caso 2

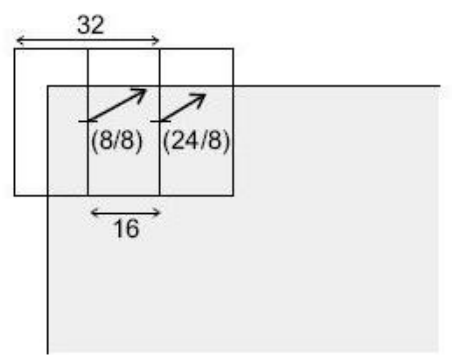

$32 \times 32$ pixels

$50 \%$ caso 3

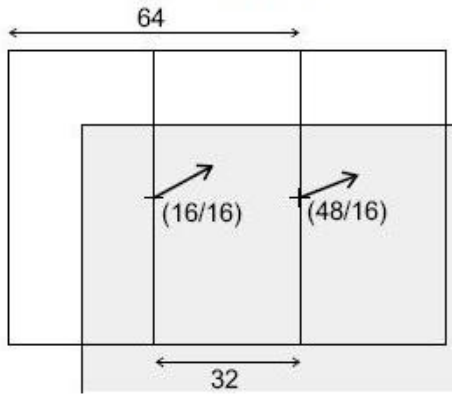

$64 \times 64$ pixels

$50 \%$

Figura 3.17. Deslocamento da janela de interrogação e sobreposição, respectivamente. As posições ( $x, y$ ) são apresentadas em termos de pixels [40].

\subsubsection{Sistema de visualização e análise de dados}

O sistema de análise de dados é composto pelos diferentes módulos que compõem o programa de computador DaVis, o qual oferece diversas ferramentas para aquisição de dados, processamento e visualização de imagens. Neste trabalho, duas etapas foram realizadas para obtenção de imagens de PLIF-OH e também nas imagens de PIV. A primeira consistiu na aquisição das imagens e, após a aquisição, as imagens das partículas traçadoras foram pré-processadas, a fim de eliminar a imagem da fuligem. Este procedimento consiste em realçar o contraste e homogeneizar as dimensões e intensidade das partículas na imagem. Para tanto, são utilizadas algumas ferramentas de processamento de imagens digitais tais como um filtro passa-alta com núcleo (kernel) igual a 3 pixels e limiar de intensidade de 20 counts, a fim de eliminar as grandes flutuações de intensidade. $O$ resultado deste processo aplicado a uma imagem de má qualidade é mostrado na Figura 3.18. Esta figura mostra que parte considerável do sinal espúrio oriundo da presença de fuligem pode ser eliminado, permitindo discernir partículas traçadoras na maior parte do campo de visão. 
A interferência produzida na imagem de partículas, por parte do sinal de incandescência da fuligem, também pode ser eliminada utilizando um obturador eletromecânico junto ao sistema de lentes, o qual restringe o tempo de exposição (de $100 \mathrm{~ms}$ para $15 \mathrm{~ms}$ ) para captura do segundo quadro da técnica PIV, por intermédio de um controlador eletrônico. Este equipamento não se encontrava disponível no momento em que as medições foram realizadas, mas será utilizado em trabalhos futuros.

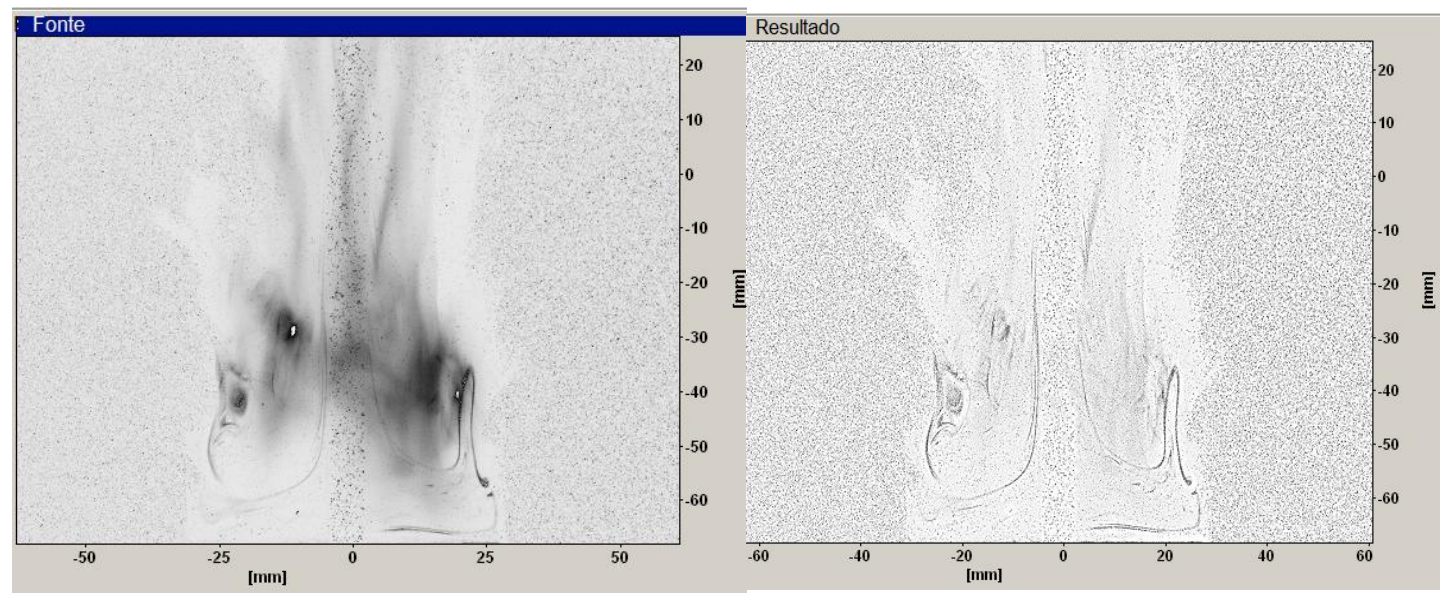

Figura 3.18. Imagem do campo de partículas capturada em uma condição de chama fuliginosa (esquerda) e a mesma imagem pré-processada (direita).

A dispersão não uniforme das partículas, especificamente aquela relacionada à dispersão em dois escoamentos distintos com presença de chamas, um de combustível e outro de ar, pode produzir falhas nos mapas de correlação entre os dois quadros de imagem de partículas, causando assim erros no processamento. Em presença de combustão, a densidade de partículas é influenciada por variações da densidade do gás no escoamento, tornando as regiões mais quentes do escoamento desprovidas de partículas. Assim sendo, foram escolhidas três posições para realizar as medidas de concentração de partículas a partir de uma imagem típica de escoamento no queimador, mostrada na Figura 3.19. Nestas posições foram consideradas janelas de interrogação, com área de 64 pixels $^{2}$, nos escoamento de ar, da esteira e do jato central. 


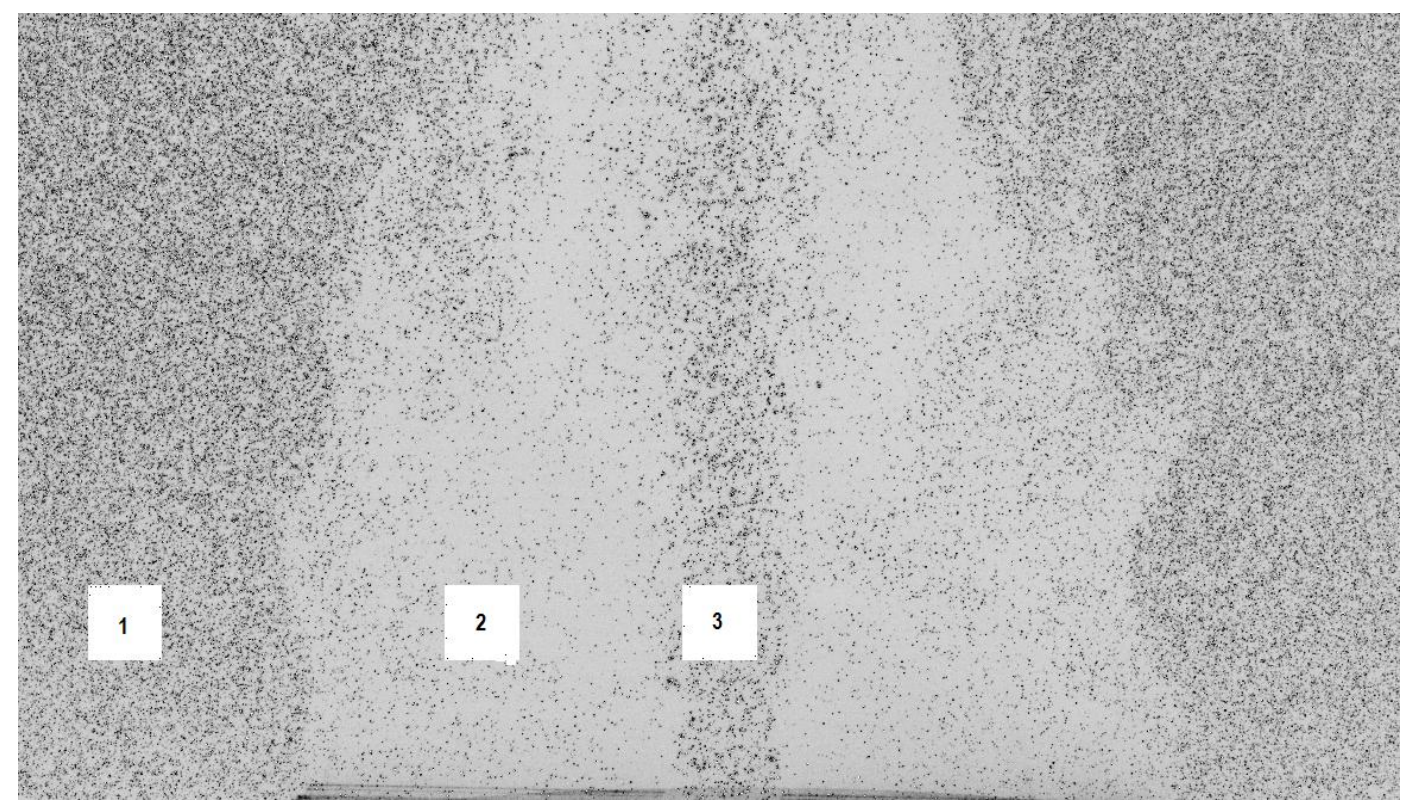

Figura 3.19. Imagem típica da distribuição de partículas do escoamento quando da combustão em um queimador tipo corpo rombudo, com velocidade de jato central e anular, ambas de aproximadamente $8 \mathrm{~m} / \mathrm{s}$. Os quadrados claros, de dimensões 64x64 pixels, mostram as posições das janelas de interrogação utilizadas para os cálculos, onde 1 é a posição no escoamento de ar anular, 2 a esteira e 3 o jato.

A falta de partículas pode impedir a construção dos mapas de correlação entre as duas imagens, o que prejudica a qualidade dos resultados e contribui para a incerteza. A Figura 3.20, obtida a partir da luz espalhada pelas partículas dispersas no escoamento, ilustra a dificuldade em se obter a dispersão uniforme em presença de combustão. Para caracterizar a dispersão não uniforme de partículas no escoamento, foram utilizadas cem imagens, nas quais a densidade de partículas é determinada em três janelas de interrogação, cujas regiões de medição são mostradas na Figura 3.19. 

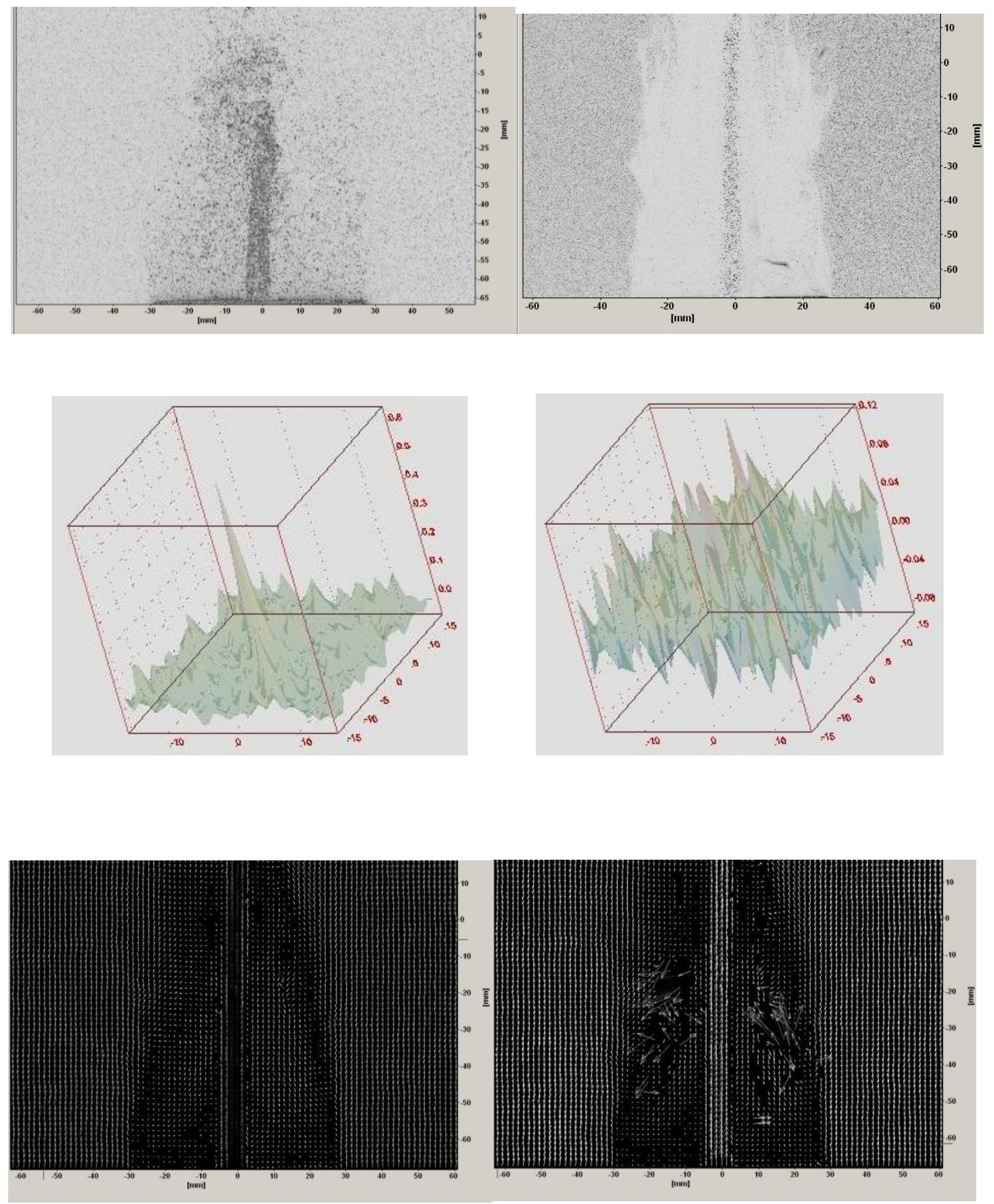

Figura 3.20. Casos de pares de imagens com boa correlação (esquerda) e com má correlação (direita), verificados pelo mapa $3 D$ e os resultados correspondentes de campos vetoriais. 
A porcentagem da área ocupada por partículas nestas janelas é obtida através da razão entre o número de pixels escuros, que representam as partículas, e os pixels claros, do fundo. A relação entre a concentração de partículas e o erro é considerada neste trabalho com base na literatura [51]. Para a avaliação da contribuição da não-homogeneidade das partículas foram comparados os resultados da distribuição de partículas nas imagens obtidas no caso inerte, utilizando Nitrogênio no jato central, com os resultados reativos, com GN. Os histogramas, apresentados na Figura 3.21, mostram a distribuição de concentração de partículas. Onde $A$ é a razão entre os pixels ocupados pelas partículas e os pixels de fundo da imagem e, $\sigma$ o desvio padrão das medidas realizadas com Carl Zeiss, KS400. As imagens para o Nitrogênio apresentam a distribuição uniforme.

Os resultados da Figura 3.21 permitem notar que no caso do Nitrogênio e ar a distribuição de partículas apresenta uma concentração de 35\% no ar, 30\% no jato e $25 \%$ na esteira, o que é razoavelmente próximo da situação desejada de concentração uniforme. No caso da combustão do Metano e ar a concentração é de $40 \%$ no ar, 30\% no jato, mas de apenas 10\% na esteira. Esta baixa concentração de partículas na região de esteira do escoamento, associada à presença de chama, causa falhas na correlação das imagens, produzindo vetores espúrios, como o caso ilustrado na pela Figura 3.20. Estes vetores podem ser eliminados em uma fase de pós-processamento das imagens, entretanto, isso não é desejável. Nota-se que no caso reativo ilustrado, há uma grande dispersão do histograma no jato, o que foi atribuído a um funcionamento intermitente do conjunto dispersor de partículas. Este comportamento foi corrigido pela redução do diâmetro do ciclone aliado à uma alteração do caminho percorrido pelo gás.

As falhas de dispersão de partículas no escoamento devido à chama foram avaliadas a partir de uma comparação entre os resultados obtidos utilizando Nitrogênio, os quais são considerados como padrão. A diferença entre os dois casos ocorre principalmente na região de esteira, pois é onde a chama se estabiliza. Assim, a concentração de partículas no caso do Nitrogênio é o triplo do valor obtido para o caso do GN. Assim, a estimativa de falhas na medição devido à dispersão de partículas é de 10\%. Esta dispersão não uniforme não contribui para a incerteza, mas sim causa falhas no processamento, as quais produzem imagens com regiões sem informação. Uma solução para este problema, é empregar a extrapolação dos resultados vizinhos, mas isto deve ser realizado com cautela, em casos turbulentos. 
$\operatorname{Ar}$

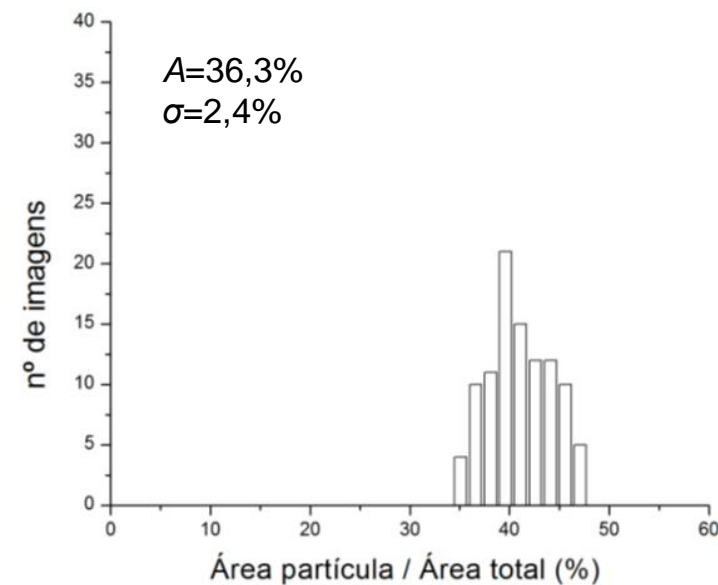

Esteira

(a)

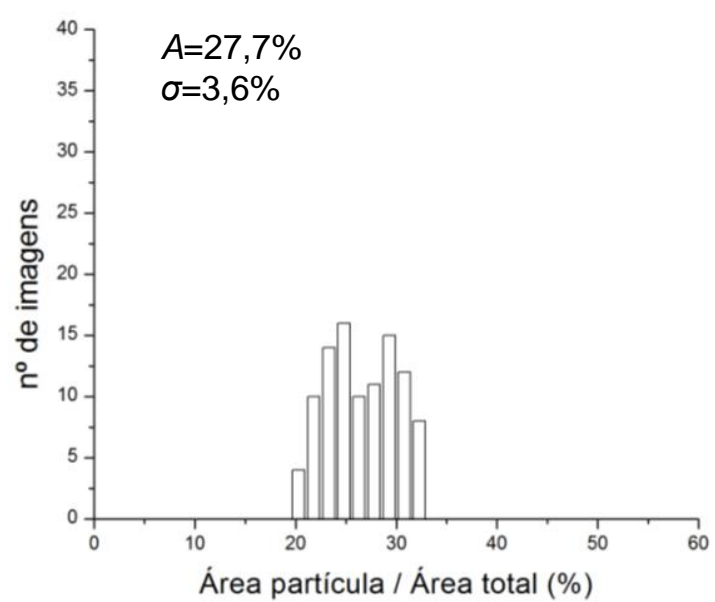

Jato

(a)

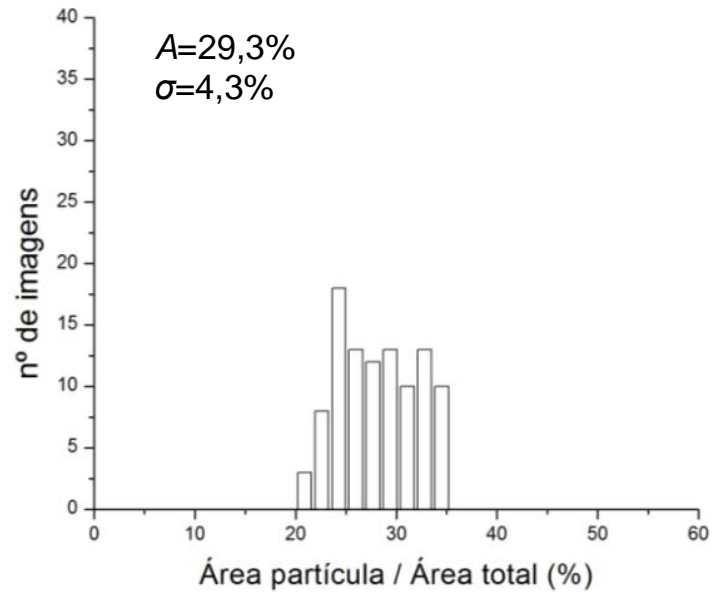

(b)

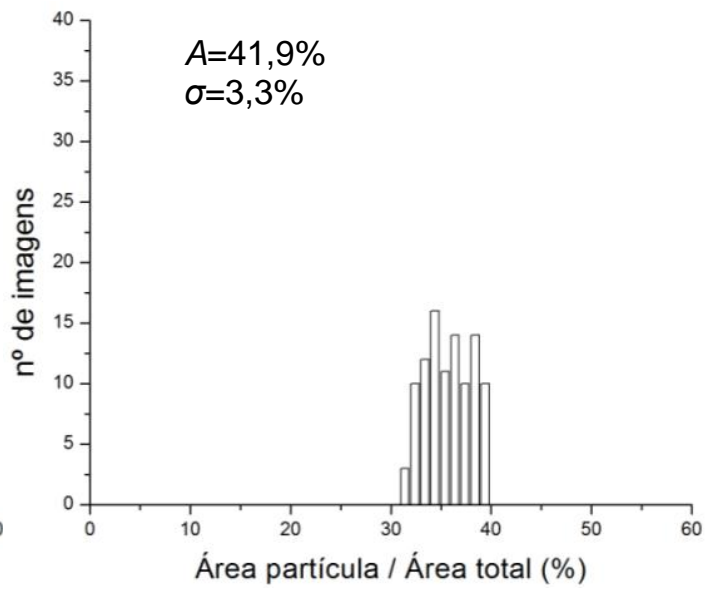

(b)

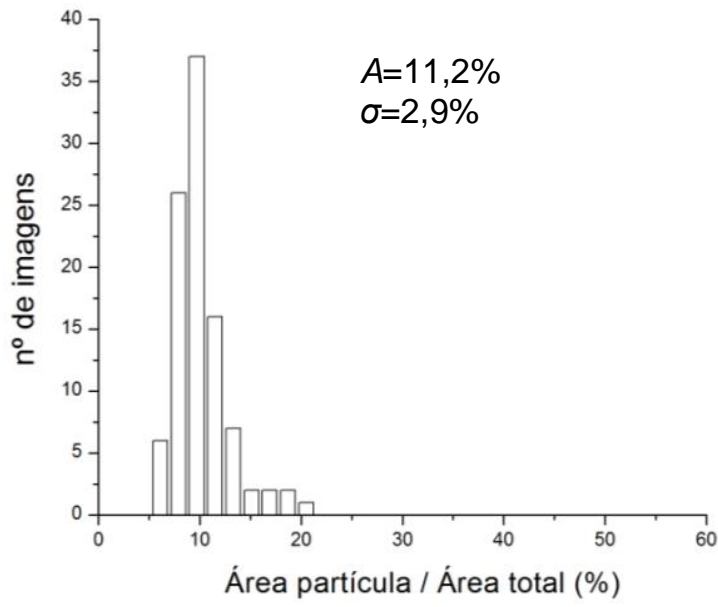

(b)

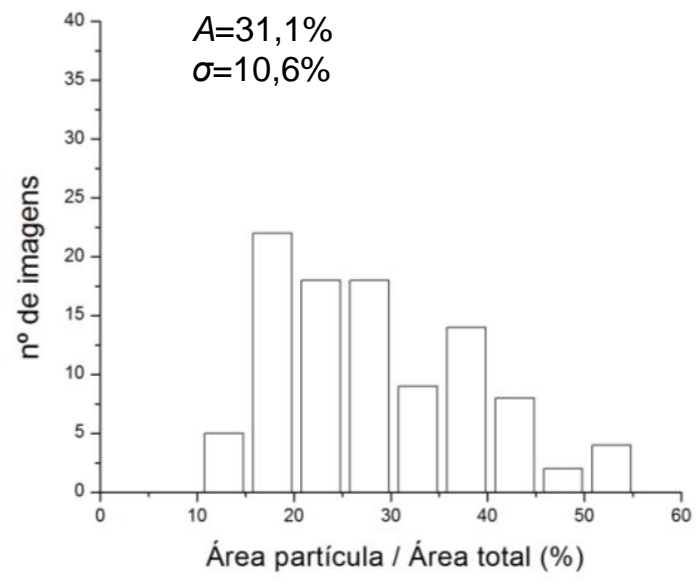

Figura 3.21. Distribuição de concentração de partículas nas áreas mostradas na Figura 3.19. Para Nitrogênio/ar (a) e para GN/ar em presença de combustão (b). 


\subsubsection{Definição do número mínimo de imagens experimentais}

A cada sequência de aquisição de dados realizada com o objetivo de estudar uma chama turbulenta deve ser capturado um número suficiente de imagens que permita obter resultados confiáveis. Isto é necessário a fim de reduzir a dispersão dos valores dos momentos estatísticos calculados, então, neste trabalho foram capturadas 1000 imagens para cada caso, apesar da maior parte dos trabalhos na literatura utilizarem apenas 600 imagens para este fim [5].

Para avaliar qual a quantidade mínima de imagens necessárias para produzir resultados precisos de velocidade média foram adquiridas 2000 imagens experimentais. Nesta análise, foi calculada a média da velocidade para 500, 1000, 1500 e 2000 imagens ao longo de uma linha horizontal traçada $10 \mathrm{~mm}$ acima da superfície do queimador. O desvio entre a média obtida com 2000 imagens e as outras médias foi calculado. A Figura 3.22 mostra que os valores da média da velocidade do escoamento variam menos que $0,1 \%$ a partir de 1000 imagens experimentais capturadas. Desta forma, a aquisição de um menor número de imagens é desaconselhada para obter resultados com pequeno viés estatístico. Por outro lado, a captura de mais de 1000 imagens é desnecessária por pouco contribuir para redução do desvio no cálculo do valor da velocidade média.

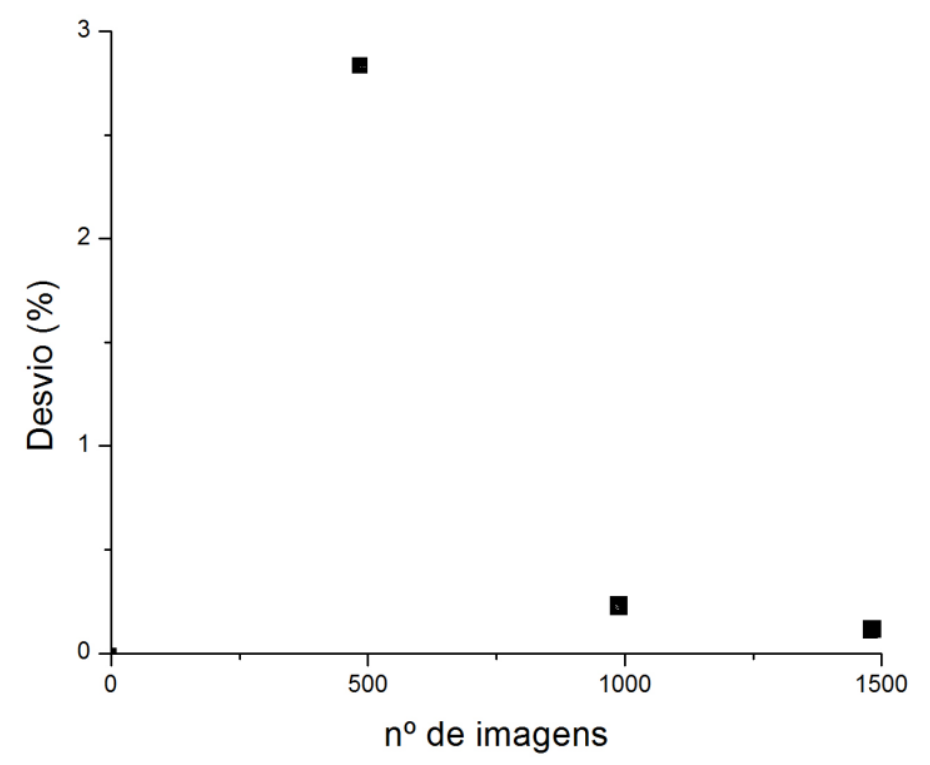

Figura 3.22. Avaliação do número ideal de imagens experimentais a serem capturadas, nas condições de velocidade de ar anular, $4 \mathrm{~m} / \mathrm{s}$, e de jato de nitrogênio, $8 \mathrm{~m} / \mathrm{s}$. 


\subsubsection{Pós-processamento do campo vetorial}

O sistema de processamento realiza os cálculos de velocidade, a partir dos 1000 pares de imagens capturados no experimento, de 4 MB cada. A taxa de aquisição utilizada neste trabalho é de $3 \mathrm{~Hz}$, limitado pelo sistema de captura, o que não é suficiente para descrever as flutuações turbulentas instantâneas nos escoamentos estudados. Os campos resultantes são obtidos após 7 horas de processamento, no modo multi-passo com tamanho de janela decrescente, de 64x64 para 32×32 pixels em dois passes, com os parâmetros de sobreposição de 50 e $75 \%$, respectivamente.

Estas condições de processamento foram escolhidas, dentre várias outras, pois (i) as imagens de partículas apresentarem melhor correlação em janelas com arestas de 64 pixels nas condições experimentais deste trabalho e, (ii) a função multi-passo, com decréscimo no tamanho e sobreposição da janela de interrogação, produz resultados de campo vetorial com melhor resolução espacial. No primeiro passo, isto é, para as janelas de 64 pixels, são calculados 1376 vetores e, para o segundo passo, janela de 32 pixels, 5590 vetores resultam em uma malha com espaçamento de $1,5 \mathrm{~mm}$ nas direções $x$ e $y$. Uma matriz de pixels, denominada núcleo (kernel), de formato quadrado é utilizada no processamento e modo de alta precisão, isto é, o método de reconstrução de Whittaker [77, 54]. Esta técnica de reconstrução permite recuperar uma informação a partir de amostras pontuais da mesma. Esta ferramenta foi utilizada para aumentar a resolução espacial dos resultados de velocidade obtidos a partir de medidas utilizando a técnica de PIV. A reconstrução do sinal original é um processo de interpolação que, matematicamente, define um sinal contínuo no tempo a partir de dois fatores, as amostras discretas do sinal e os instantes de tempo da amostragem. A reconstrução do sinal proposta por Whittaker consiste em multiplicar cada valor da amostra por uma função sinc, ou função de Bessel, de modo que os zeros sejam ajustados com os instantes de tempo em que da amostragem. A posição central da função sinc é combinada ao instante inicial de capturada. A soma das funções, dimensionadas e posicionadas em fase, permitem recuperar o sinal original. As funções sinc são contínuas, fazendo com que a soma delas também seja contínua. Assim sendo, esta operação produz um sinal contínuo como resultado, o que confere maior exatidão aos resultados e evita os defeitos sistemáticos causados pela baixa resolução na imagem, como o erro de atribuição (aliasing). 
Variações nas opções dos parâmetros de processamento como tamanho, formato e sobreposição das janelas de interrogação acarretam diferentes tempos de processamento e diferentes números de vetores, ou seja, alteram a resolução do campo vetorial. Por exemplo, a utilização de $75 \%$ de sobreposição sobre as janelas de interrogação ao invés de $50 \%$ triplica o número de vetores criados, aumentando a resolução, porém, isto dobra o tempo de processamento. O mesmo acontece com a utilização de janelas de interrogação de 32 ao invés de 64 pixels.

Os campos das propriedades médias do escoamento, em particular, aquelas relacionadas às flutuações de velocidade, como é o caso dos tensores de Reynolds, são afetados pela presença de vetores espúrios nas imagens. Mesmo com todos os cuidados na captura das imagens de partículas, pré-processamento e análise exaustiva para escolha dos parâmetros de processamento, os resultados obtidos ainda continham vetores espúrios, principalmente nos casos em que há presença de chama. O pós-processamento do campo vetorial é realizado a fim de limitar o módulo da velocidade em foi utilizada a fim de eliminar alguns destes vetores indesejados. Como poderá ser verificado no próximo capítulo, os valores dos componentes de velocidade são próximos em todos os experimentos realizados. Assim, foram utilizados os limiares de $V_{x}= \pm 6$ e $V_{y}= \pm 25 \mathrm{~m} / \mathrm{s}$ por serem, aproximadamente, iguais a dois desvios padrão em torno da velocidade média na região próxima ao jato, além da qual a maioria dos vetores espúrios é encontrada.

\subsubsection{Calibração da técnica de medição}

A técnica PIV fornece resultados de baixa incerteza para medições de velocidade, principalmente em escoamentos laminares quimicamente inertes. Porém, a realização de medições com PIV envolve a seleção de diversos detalhes da configuração de vários parâmetros envolvidos na técnica, os quais podem introduzir erros, conforme será discutido na seção 3.5. Portanto, os resultados das medidas de velocidade obtidos através de PIV foram comparados com resultados de medições realizadas com um anemômetro de fio quente e, também, com resultados calculados. 


\subsubsection{Calibração com anemômetro}

A velocidade do ar anular foi medida por meio de um anemômetro de fio quente (Dwyer, S471 DTA, sonda de $3 \mathrm{~mm}$ ), com o intuito de comparar os resultados obtidos com aqueles oriundos da técnica PIV, a fim de verificar o nível de confiança dos resultados. As medidas com o anemômetro foram realizadas em dois pontos a jusante da superfície do queimador. O primeiro é exatamente na saída do túnel de vento do queimador, cujo resultado da velocidade foi de $8,0 \mathrm{~m} / \mathrm{s}$. A outra medida foi realizada em um ponto $100 \mathrm{~mm}$ acima do primeiro, apresentando um resultado de $7,8 \mathrm{~m} / \mathrm{s}$. Este anemômetro foi calibrado pela empresa Skilltech, a qual calculou uma incerteza de $0,17 \mathrm{~m} / \mathrm{s}$ para medidas de velocidade de $7,0 \mathrm{~m} / \mathrm{s}$, o que corresponde a um desvio de 2,5\%. Entretanto, o fabricante adota uma postura conservadora, fornecendo uma incerteza de medição de 3\%. As medidas obtidas com PIV nestes pontos são de 8,0 e $7,8 \mathrm{~m} / \mathrm{s}$, respectivamente. Estes valores indicam que as técnicas não apresentam grande diferença nas medidas em tais condições.

\subsubsection{Verificação das medidas de velocidade do jato central}

Uma leitura de vazão de $\dot{Q}=0,75 \mathrm{Nm}^{3} / h$, corresponde a $0,78 \mathrm{Nm}^{3} / h$ após ser corrigida para o Nitrogênio em condições normais de temperatura e pressão. Considerando o diâmetro da saída do jato de 7,1 $\mathrm{mm}$, a velocidade média na saída do jato central é de $5,5 \mathrm{~m} / \mathrm{s}$. As medidas de velocidade, realizadas com PIV nas mesmas condições de vazão, apresentam uma média de $5,6 \mathrm{~m} / \mathrm{s}$, ou seja, $4 \%$ de desvio, o que é compatível com a incerteza de medição deste modelo de rotâmetro, $5 \%$.

\subsection{Calibração do campo de visão}

As imagens experimentais devem ter suas dimensões calibradas para que 0 deslocamento das partículas seja conhecido e a velocidade possa ser determinada. Para isso, tal como mostrado na parte inferior da Figura 3.23 é utilizada uma placa 
de calibração posicionada no campo de visão da câmera, de modo a que a dimensão dos pixels na imagem possa ser determinada a partir de padrões. A câmera para PLIF é posicionada na direção normal à placa e a câmera para PIV é posicionada em um ângulo diferente, tal como mostrado na parte superior da Figura 3.23. A focalização a partir da inclinação requer a aplicação do método de Scheimpflug para alcançar todas as regiões da imagem [51]. A placa de calibração é posicionada no plano de medição, uma imagem é então capturada. As medidas características do alvo são introduzidas no programa DaVis, no alvo utilizado neste trabalho os cerca de 3000 furos de $0,3 \mathrm{~mm}$ de diâmetro são distantes $2 \mathrm{~mm}$ entre si. O programa DaVis reconhece os pontos da imagem do alvo, através de um algoritmo de busca e reconhecimento, criando sobre a imagem, uma grade de dimensões conhecidas, onde a dimensão de cada pixel no plano de medição é de $90 \mu \mathrm{m}$ para a montagem deste trabalho. A incerteza nas dimensões dos pixels produzida pela calibração do campo de visão para PIV e PLIF são de 0,4\% e 0,6\%, respectivamente, com base nos resultados de ajuste fornecido pelo próprio DaVis.
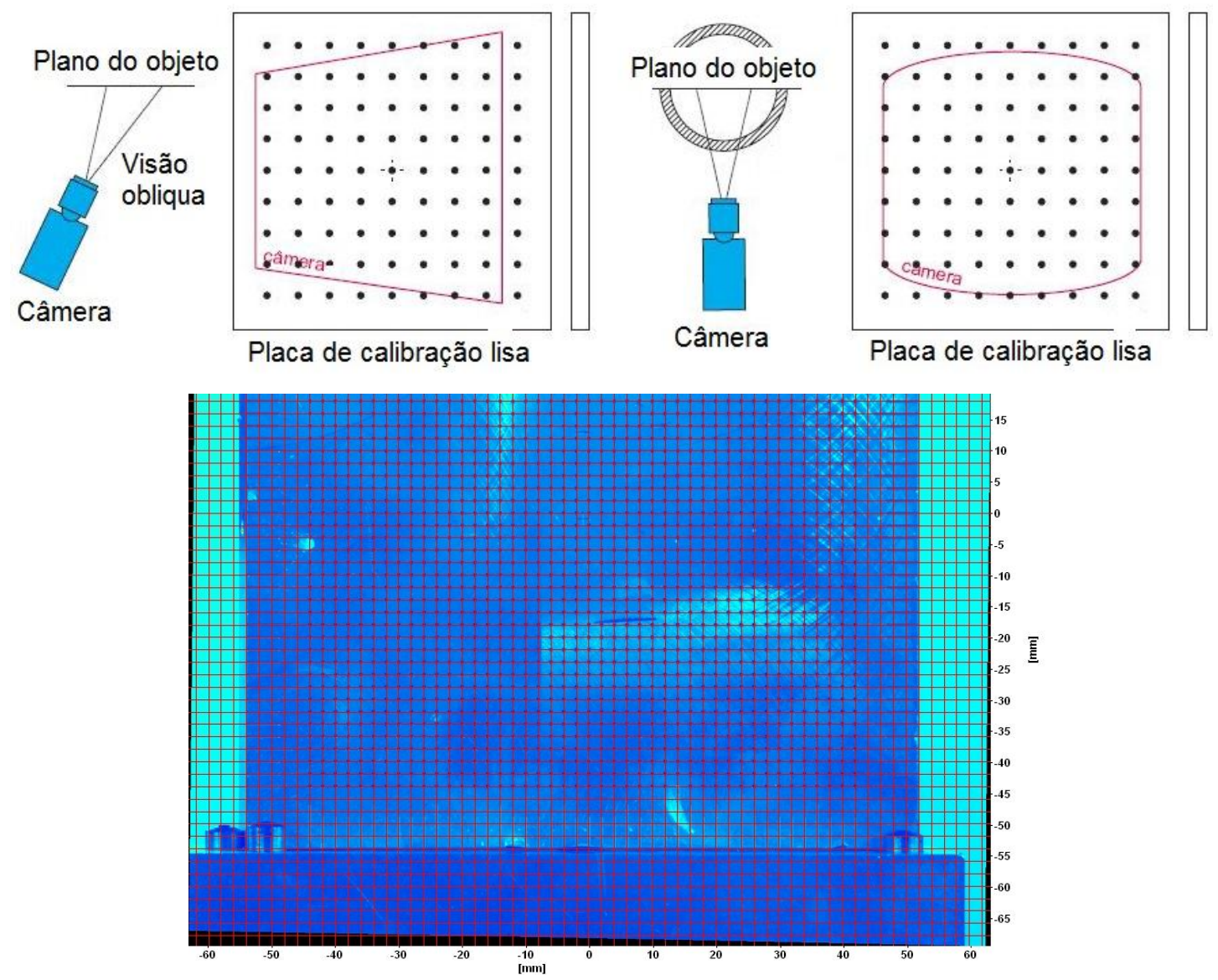

Figura 3.23. Calibração da imagem, utilizando uma placa de calibração. 


\subsection{Análise e quantificação das incertezas experimentais}

A caracterização da incerteza dos resultados experimentais permite avaliar quão bem as medições são realizadas em um trabalho, e o nível de confiança estatístico atribuído aos resultados. $O$ foco da análise da incerteza experimental deste trabalho é fornecer informação suficiente para avaliação do grau de confiança dos resultados. Para tanto, são declarados todos os componentes dos equipamentos necessários para o emprego das técnicas de diagnóstico e as respectivas análises de incertezas individuais, incluindo uma descrição concisa da propagação das incertezas para os resultados. Assim sendo, a estimativa da incerteza é baseada na análise de erros sistemáticos e na quantificação da repetibilidade dos experimentos.

A incerteza é fruto da imprecisão dos equipamentos de medição. O método de Kline-McClintock determina a incerteza propagando as incertezas individuais de cada fonte sobre essas medições [32, 43]. A melhor representação da incerteza relativa dos resultados, $u_{\text {Total }}$, é:

$$
u_{\text {Total }}= \pm\left[\sum_{i=1}^{n}\left(\boldsymbol{u}_{i}\right)^{2}\right]^{1 / 2}
$$

onde $u_{i}$ é cada uma das incertezas relativas às quantidades medidas e $n$ é o número dessas quantidades que contribuem como fontes de incerteza para medidas com PIV.

\subsubsection{Estimativa da incerteza no número de Reynolds do jato}

Nesta seção é apresentada uma análise da incerteza envolvida na obtenção dos resultados experimentais, em particular considerando o valor estimado do número de Reynolds do jato de combustível, principal parâmetro de similaridade do experimento.

A determinação da faixa de incerteza é dada pela estimativa de incerteza de cada equipamento utilizado para medição, fornecida pela calibração realizada pelo fabricante, segundo o método de Kline-McClintock [32], equação 8.

Os elementos que contribuem para a incerteza do número de Reynolds são: a vazão do fluido, a qual foi medida com o rotâmetro, o diâmetro do orifício do jato 
de combustível e a viscosidade e densidade do gás que são afetadas pela temperatura. O diâmetro do orifício do jato de combustível $D_{j}=7,1 \mathrm{~mm}$ foi medido por um paquímetro de $0,1 \mathrm{~mm}$ de resolução. Portanto, a estimativa da incerteza relativa do diâmetro é $u_{D_{j}}= \pm 0,01$.

A incerteza da pressão no manômetro (Wika; 232:54:115L), segundo a informação do fabricante, é de 2,5\%. A temperatura é medida por meio de um termopar digital (ECIL/WATLOW, 935), cuja incerteza é dada como sendo 0,25\%. A incerteza da vazão volumétrica, $\dot{V}$, corrigida obtida através do rotâmetro (OMEL, 3P5) é de 5\%. A incerteza relativa para a velocidade média é obtida a partida da expressão da razão entre a vazão volumétrica do gás e a área da saída do jato do queimador.

$$
U_{j}=4 \dot{V} / \pi D_{j}^{2}
$$

A equação da incerteza relativa da velocidade é obtida a partir da derivada da equação 9, considerando a incerteza do rotâmetro conhecida.

$$
u_{U_{j}}= \pm\left[\left(u_{\dot{V}}\right)^{2}+\left(u_{D_{j}}\right)^{2}\right]^{1 / 2}= \pm\left[(0,05)^{2}+(0,01)^{2}\right]^{1 / 2}= \pm 5 \%
$$

Da mesma forma, a incerteza relativa da densidade é obtida a partir da equação dos gases idéias que relaciona a densidade do gás com a pressão e a temperatura. A contribuição das incertezas fornecidas pelo termopar e pelo manômetro gera uma incerteza relativa à densidade do gás de $u_{\rho_{\text {gas }}}= \pm 2,5 \%$.

A incerteza relativa da viscosidade dinâmica é obtida através da lei de Sutherland, calculada para as condições deste trabalho por [28]. A qual, considerando a incerteza do termopar, resulta em $u_{\mu_{g a s}}= \pm 5,0 \%$ para a incerteza relativa da viscosidade dinâmica. A composição do combustível também contribui para a incerteza da densidade e da viscosidade. Entretanto, se o gás natural

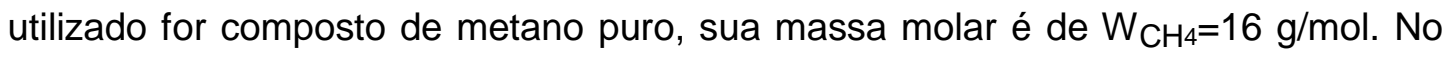
caso do gás natural composto de $15 \%$ de propano, a massa molar é de $20,2 \mathrm{~g} / \mathrm{mol}$, ou seja, há um acréscimo de $26 \%$ na massa molar do gás, o que influenciaria diretamente nos valores da densidade e da viscosidade. Assim, em trabalhos 
futuros é indispensável conhecer a composição do gás natural queimado, o que não foi feito neste estudo devido à ausência de um analisador de gases no laboratório.

O número de Reynolds do jato de combustível é definido como,

$$
\operatorname{Re}_{j}=\frac{U_{j} D_{j} \rho_{g a ́ s}}{\mu_{g a ́ s}} .
$$

As variáveis da equação 11 contribuem para a incerteza do $\operatorname{Re}_{j}$, a qual é determinada de modo similar aos casos precedentes como,

$$
u_{\operatorname{Re}_{j}}= \pm\left[\left(u_{U_{J}}\right)^{2}+\left(u_{D_{j}}\right)^{2}+\left(u_{\rho_{g a s}}\right)^{2}+\left(u_{\mu_{g a s}}\right)^{2}\right]^{1 / 2} \cong \pm 7,0 \%
$$

\subsubsection{Fontes de Incerteza em PIV aplicado a chamas}

A discussão sobre a incerteza em medições com a técnica PIV envolve os tópicos que afetam a incerteza desta técnica quando aplicada em chamas. As fontes de incerteza, abordadas resumidamente na sequência são, em ordem de importância, (i) termoforese, (ii) gradientes de índice de refração, (iii) emissão espontânea de luz pela chama e (iv) não uniformidade na dispersão de partículas no escoamento, ( $v$ ) imagem da partícula e, ( $v i)$ processamento das informações.

\subsubsection{Termoforese}

É o movimento das partículas submetidas à influência de um gradiente de temperatura. Esse fenômeno é observado em escala milimétrica. A tendência de deriva que a partícula possui enquanto exposta aos gradientes de temperatura, impostos pela chama, produz um erro sistemático nas medições de velocidade das partículas próximas à frente de chama. Uma estimativa do valor da velocidade de termoforese, $V_{t}$, pode ser realizada por [76].

$$
V_{t}=\frac{c}{3 \pi \mu d_{p}} F_{t} .
$$

As partículas, de diâmetro $d_{p}$ experimentam um acréscimo no valor da velocidade em relação ao escoamento devido à termoforese. A velocidade de termoforese é proveniente da força que age sobre as partículas, 
$F_{t}=p \lambda_{0} d_{p}^{2}(\nabla T / T)$, por parte do gradiente de temperatura, $\nabla T$, produzido pela chama. Estas partículas estão imersas em um fluido com viscosidade cinemática $\mu$, nas condições normais de pressão $p$ e temperatura $T$. Na equação 13, $c=1+\left(2 \lambda_{0} / d_{p}\right)$ é o fator de correção da lei de Stokes, onde $\lambda_{0}$ é o livre caminho médio. Assim sendo, considerando partículas de diâmetro $d_{p}=1 \mu m$, escoando em um fluido a pressão atmosférica, com variação de temperatura da ordem de $1.500 \mathrm{~K}$ entre os gases frescos e os gases queimados, a escala de gradiente de temperatura é estimada em $3.10^{5} \mathrm{~K} / \mathrm{m}$, considerando uma espessura média de chama de $5 \mathrm{~mm}$ e temperaturas típicas de frente de chama. A partir dos valores típicos de $\mu=17.10^{-6}$ Pa.s e $\lambda_{0}=70 \mathrm{~nm}$ (em condições ambiente) [51], os quais são corrigidos para uma temperatura média da chama, o valor da velocidade de termoforese nas condições dos experimentos realizados neste trabalho é de $2 \mathrm{~cm} / \mathrm{s}$, isto corresponde a uma incerteza, $\mu_{V t h}$, da ordem de $5 \%$ do valor da velocidade na esteira, onde a chama se estabiliza.

\subsubsection{Gradiente de índice de refração}

O aumento brusco da temperatura devido à presença de chama causa uma variação local no índice de refração, o que afeta a homogeneidade do plano de luz laser na área de medição, distorcendo a imagem. Desta forma, o gradiente de índice de refração contribui para a incerteza das medições PIV em chamas, $u_{\nabla n}$. Por outro lado, considerando que a espessura do plano de luz laser do PIV, de 500 $\mu \mathrm{m}$, é cerca de 5 vezes maior do que o tamanho de um pixel na região de medição, e que a diferença máxima no índice de refração devido a temperatura é de $10 \%$ [31], a distorção máxima que pode ocorrer de um pixel para outro é da ordem de $2 \%$, contribuindo assim para a incerteza.

A emissão espontânea de luz pela chama e a incandescência da fuligem podem saturar a matriz de sensores CCD da câmera, principalmente no segundo quadro do par de imagens capturadas, devido ao tempo de exposição relativamente grande (100 ms), quando comparado com o do primeiro quadro (10 $\mu \mathrm{s})$. Assim sendo, no segundo quadro, a intensidade da luz emitida pela chama pode ser da mesma ordem de grandeza do que a luz espalhada pelas partículas traçadoras. Isto 
pode impossibilitar o algoritmo de correlação de discernir os grupos de partículas nos pares de imagens durante o processamento realizado para calcular a velocidade. Buscando reduzir este efeito, neste trabalho é usado um filtro óptico passa-banda centrado em $532 \mathrm{~nm}$ e com largura de banda estreita $( \pm 5 \mathrm{~nm})$, a fim de reduzir a incerteza causada por este tipo de interferência. Ainda assim, em algumas situações experimentais a luminosidade da chama é superior à das partículas. Para eliminar esta luminosidade indesejada é realizado um pré-processamento das imagens de partículas, antes do cálculo do deslocamento, a fim de eliminar o sinal de emissão da chama e da fuligem, como visto anteriormente na seção 3.4.4. Os cuidados de utilizar um filtro óptico e pré-processar as imagens de partículas são tomados a fim de evitar a interferência do sinal de emissão espontânea da chama e radiação da fuligem. Então, acredita-se que seu efeito sobre a incerteza total das medidas realizadas com PIV seja desprezível. Porém, como a interferência nem sempre é rejeitada em sua totalidade, então, sua contribuição para incerteza será estimada como sendo uma ordem de grandeza inferior às demais, isto é, $\mu_{E}=$ $0,1 \%$.

\subsubsection{Incerteza devido à imagem das partículas traçadoras}

A dimensão das partículas influencia, em dois aspectos, a incerteza nas medições realizadas com técnica PIV. O primeiro é com relação à fidelidade com que elas acompanham o escoamento, principalmente no caso de escoamentos reativos turbulentos, conforme foi visto na seção 3.4.2.3. O segundo é quanto ao processamento das imagens, cuja correlação depende da dimensão da imagem das partículas nos quadros e dos respectivos deslocamentos.

O deslocamento das partículas na imagem também afeta a incerteza nas medidas realizadas com PIV. Uma simulação de deslocamentos de partículas em imagens foi realizada por [51], visando avaliar esta influência. Neste trabalho, a determinação dos efeitos causados na incerteza das medidas foi realizada variando os diâmetros das partículas e as dimensões de janela de interrogação. Tal como mostrado na Figura 3.24, os resultados indicam que a incerteza é minimizada para diâmetros aparentes de cerca de dois pixels,. Esta figura mostra que em PIV usando dupla exposição, o tamanho ideal das imagens de partículas é de 1,5 pixel para a correlação-cruzada. Quando as imagens de partículas são muito pequenas a incerteza aumenta, devido à dificuldade em estimar a correlação. 


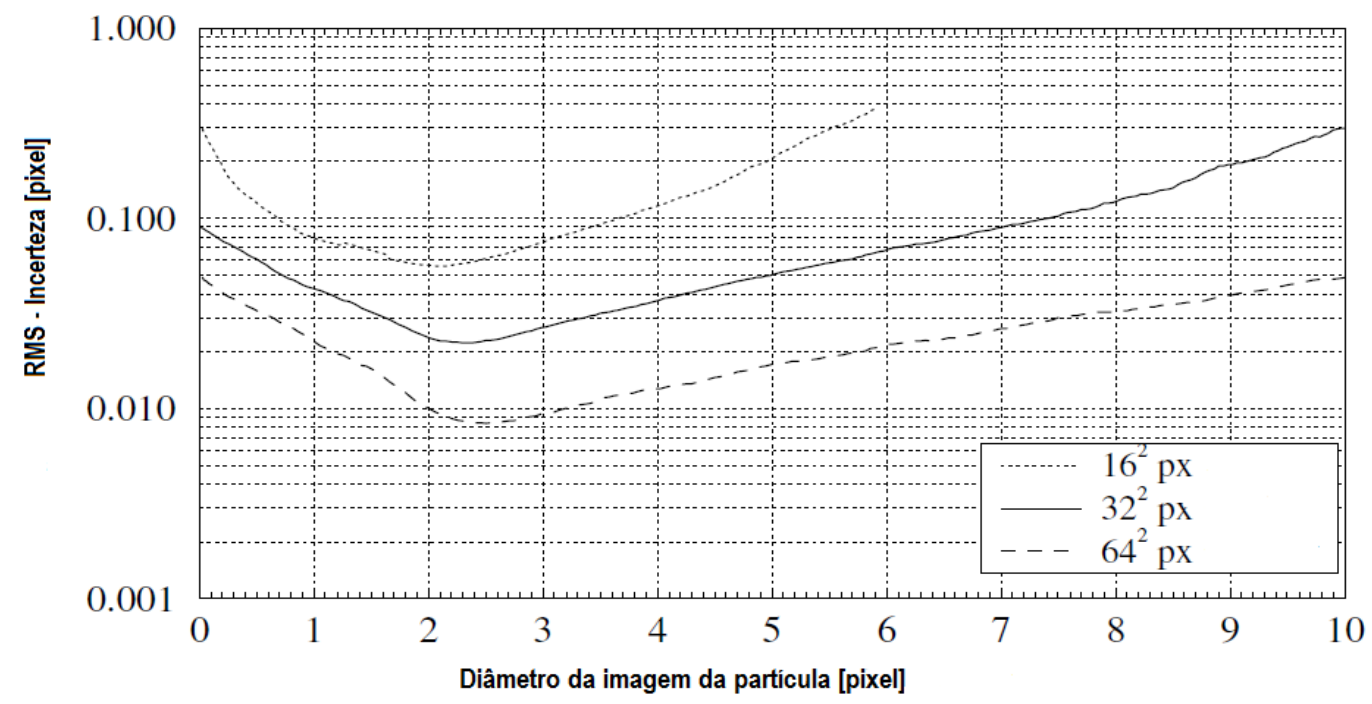

Figura 3.24. Determinação do diâmetro ideal de imagem de partícula em PIV [51].

Os resultados mostrados na Figura 3.24 também permitem notar que 0 tamanho da janela de processamento é um importante fator na redução da incerteza da medida, pois a incerteza é sempre maior para as janelas menores, qualquer que seja o diâmetro da partícula. O diâmetro que a partícula apresenta na imagem $d_{i}$ é determinado pelo módulo da soma de dois termos, sendo um termo regido pelo produto da magnificação pelo diâmetro real da partícula e, o outro termo regido pela espalhamento da luz por parte da partícula.

$$
d_{i}=\sqrt{\left(M d_{p}\right)^{2}+d_{d i f f}^{2}},
$$

onde $d_{\text {diff }}=2,44 f_{\#}(M+1) \lambda$ é o diâmetro mínimo dos anéis de difração que formam a imagem da partícula, $f_{\#}=11$ é a razão entre a distância focal e o diâmetro da abertura da lente da câmera utilizada neste trabalho, $\lambda=532 \mathrm{~nm}$ é o comprimento de onda da luz laser e $M=0,10$ é a magnificação da imagem. 0 diâmetro médio efetivo para as partículas utilizadas neste trabalho é de $1 \mu \mathrm{m}$. Desta forma, o diâmetro médio da imagem das partículas é de aproximadamente $13 \mu \mathrm{m}$, o qual ocupa 7 pixels, induzindo à uma incerteza de cerca de 0,1 pixel, isto é, $u_{d_{i}}= \pm 0,3 \%$ para o processamento com janelas de $32^{2}$ pixels, conforme mostrado na Figura 3.24. A incerteza para as partículas de diâmetro da ordem das que foram utilizadas neste trabalho tem seu valor aumentado quando as janelas de 
interrogação na fase de processamento são de 32x32 pixels se comparado com $64 \times 64$ pixels.

A relação sinal/ruído na imagem deve manter níveis abaixo de $10 \%$, considerando o uso de uma câmara CCD, para que o programa de processamento seja capaz de discernir as partículas como objeto da imagem. Assim, o erro sistemático tende de zero, utilizando o cálculo de correlação cruzada para PIV [66, 76].

\subsubsection{Incerteza no processamento das imagens de PIV}

Em PIV a velocidade é calculada a partir da razão entre o deslocamento dos grupos de partículas nas imagens e o intervalo de tempo, $\Delta t$, entre os instantes de captura dos dois quadros. Desta forma, atrasos na resposta da eletrônica do sistema introduzem incertezas. O sistema PIV possui alta frequência, $1 \mathrm{GHz}$, sendo capaz de realizar tarefas com resolução temporal da ordem de nanossegundos. Como a velocidade do escoamento é relativamente pequena, da ordem de $10 \mathrm{~m} / \mathrm{s}$, a incerteza da medida do intervalo de tempo $\Delta t$ entre a captura dos dois quadros é reduzida. Considerando-se que os intervalos de tempo utilizados neste trabalho são da ordem de microssegundos, a incerteza na captura das imagens, $u_{c a p}$, é da ordem de $0,01 \%$.

O erro aleatório no processamento das imagens PIV é estimado a partir das seguintes fontes: (i) correlação entre os pixels dos objetos na imagem, (ii) influência da chama na imagem e (iii) ajuste subpixel, as quais são determinadas por [51] através de simulações utilizando o método de Monte Carlo. A dispersão dos resultados em torno dos pontos máximos nos mapas de correlação, calculados pelo programa DaVis, como os apresentados na Figura 3.20, é de 3 pixels em janelas de 64 pixels na região de esteira, onde a correlação é fraca. Assim, é possível estimar uma incerteza devido à correlação, como sendo de no máximo 5\% para as imagens dos casos reativos, considerando que este valor é menor para os casos inertes, os quais apresentam melhor correlação entre os pares de imagens de partículas por não sofrerem os efeitos de termoforese como os casos reativos. O erro total no ajuste subpixel é expresso como a soma do erro sistemático e do erro aleatório. Há um erro sistemático para dimensões das partículas na imagem, devido ao método 
de determinação subpixel. A fim de obter imagens processadas com erros menores foi utilizado o método de alta precisão, chamado reconstrução ou interpolação de Whittaker [77]. O valor máximo de incerteza subpixel, $u_{s p}$, obtido por [51] em suas simulações alcança 3\%, ao qual é reduzida a incerteza na correlação entre os pares de imagens, $u_{\text {corr }}$. Este valor é encontrado nas regiões das imagens onde se situam os vórtices do escoamento e engloba o erro sistemático, relativo à determinação da dimensão do pixel na etapa de calibração. Este valor será adotado no presente estudo.

\subsubsection{Incerteza total das medidas PIV}

Considerando-se as diferentes fontes de incerteza descritas acima, isto é, (1) termoforese, (2) gradiente de índice de refração, (3) emissão espontânea da chama e radiação da fuligem, (4) imagem das partículas traçadoras, (5) na captura das informações, (6) na correlação entre as imagens das partículas no par de quadros e, (7) no ajuste subpixel, a incerteza máxima nas medidas PIV é:

$$
\begin{aligned}
& u_{P I V}= \pm\left[\left(u_{V_{t h}}\right)^{2}+\left(u_{\nabla n}\right)^{2}+\left(u_{E}\right)^{2}+\left(u_{d_{i}}\right)^{2}+\left(u_{c a p}\right)^{2}+\left(u_{s p}\right)^{2}\right]^{1 / 2}, \\
& u_{P I V}= \pm\left[(5 \%)^{2}+(2 \%)^{2}+(0,1 \%)^{2}+(0,3 \%)^{2}+(0,01 \%)^{2}+(3 \%)^{2}\right]^{1 / 2}= \pm 6 \%
\end{aligned}
$$

Para os escoamentos quimicamente inertes a incerteza total não levaria em conta a termoforese, o gradiente de índice de refração e a emissão espontânea da chama. Portanto a incerteza na medição de velocidade associada à técnica PIV aplicada aos casos inertes é de $3 \%$.

\subsubsection{Análise da incerteza nos resultados de PLIF}

As imagens obtidas com o sinal de fluorescência pela aplicação da técnica PLIF possuem erros sistemáticos influenciados principalmente por: (i) flutuações pulso a pulso da intensidade de luz do laser de bombeio, (ii) comprimento de onda de excitação (iii) ângulo de divergência do feixe e distribuição não-homogênea do plano de luz. As imagens são afetadas, também pela, (iv) corrente elétrica de 
alimentação da câmera, (v) atenuação e distorção da luz causada pelo sistema de detecção por reflexos no laboratório, (vi) desativação da fluorescência, Quenching.

Um monitor de energia é utilizado com o objetivo de determinar valores de referência de energia para cada pulso de luz laser utilizado para induzir a fluorescência. Este equipamento possui um conversor analógico-digital capaz de medir a energia de cada pulso de luz laser durante o processo de aquisição das imagens.

O comprimento de onda da luz laser utilizado para excitação deve ser ajustado com base na resposta da fluorescência, a qual é influenciada pelas condições do ambiente. O laser de corante é calibrado para produzir um feixe de luz com comprimento de onda com precisão da ordem de picômetros. Desta forma, antes de iniciar a captura das imagens experimentais é realizada uma varredura de comprimentos de onda em uma faixa do espectro que englobe a linha de fluorescência desejada, a fim de definir qual é o comprimento de onda da luz laser de excitação que produz a melhor resposta da fluorescência. Assim, é obtida a melhor relação sinal/ruído para a fluorescência do $\mathrm{OH}$, minimizando a incerteza.

Os fótons oriundos da fluorescência do radical $\mathrm{OH}$, induzida pela luz laser, são capturados pelo sistema de detecção, apresentado na seção 3.3.3.5. A incerteza das medidas com PLIF é associada ao ruído de fundo do CCD e à distribuição do feixe de luz laser no plano de medição. A determinação do ruído de fundo e da distribuição de energia do plano de luz laser são parte integrantes do experimento, e são utilizadas na etapa de pós-processamento das imagens.

O ruído de fundo é produzido pela alimentação elétrica do sistema. Então, medidas são realizadas antes da aquisição das imagens de um experimento, com a câmera tampada, a fim de medir o ruído eletrônico na matriz CCD para, em seguida, subtrair esta informação da imagem final. É utilizada a média de cem imagens do sinal eletrônico de fundo do CCD, mostrada na Figura 2.25a. O valor máximo e mínimo de ruído de fundo nesta imagem média é de 62,1 e 54,3 counts, respectivamente. A média dos valores de intensidade dos pixels da imagem é igual a 55,8 counts e desvio padrão de 0,9 counts, produzindo uma incerteza de $2 \%$.

A correção da não-homogeneidade da distribuição de energia no plano de luz laser é realizada a partir da distribuição espacial da luz, perpendicular ao eixo do feixe, cuja não-homogeneidade contribui para a incerteza dos resultados, pois o sinal de fluorescência induzida é proporcional ao sinal da luz laser utilizada para 
excitação, ver equação 1. Assim, a espessura média do plano laser, medida tal como o descrito na seção 3.3.3.3, também influencia no valor da intensidade de fluorescência medida. Os componentes ópticos do sistema de detecção também podem afetar o sinal de fluorescência, devido às variações locais de transmissão. Para evitar esta causa de distorção são utilizados componentes ópticos de alta qualidade e baixa divergência.

Para avaliar a distribuição de intensidade de luz laser de excitação no plano formado na seção de medida são utilizadas imagens do plano de luz laser, as quais foram obtidas através do sinal de espalhamento Rayleigh. Para isso, a polarização da luz deve ser ajustada de modo que se torne ortogonal ao plano de luz. 0 ambiente deve ser totalmente obscurecido e deve ser eliminado qualquer reflexo existente no laboratório. A imagem do plano de luz laser deve ainda ser pósprocessada, a fim de eliminar a presença indesejável de partículas dispersas no ar, comumente de poeira, que interferem significativamente na formação da imagem do feixe de luz laser, devido à natureza do espalhamento. Este pós-processamento é realizado eliminando-se partículas com imagem maior que 1 pixel, aplicando um filtro, a fim de suavizar as bordas e eliminar os sinais de baixa intensidade em relação à média, rejeitando o ruído.

Foram obtidas 1000 imagens do plano de luz laser, utilizando espalhamento Rayleigh, a fim de obter uma representação da distribuição de luz do plano laser, mostrada na Figura 2.25b. Os valores máximo e mínimo de ruído de fundo medidos nesta imagem média do plano de luz laser é de 65,9 e 56,7 counts, respectivamente. A média dos valores de intensidade dos pixels da imagem é igual a 59,4 counts e o desvio padrão de 1,3 counts, o que leva a uma incerteza de aproximadamente $2 \%$. Cabe ressaltar que estas medidas são realizadas na ausência de chamas. Como o sinal de fluorescência que será medido em presença de chama é diretamente proporcional ao sinal de excitação (laser incidente) a variação da distribuição de intensidade do plano laser é reduzida através de um procedimento de convolução [40] entre as imagens experimentais com a imagem do plano de luz laser, realizada pelo programa Davis. 


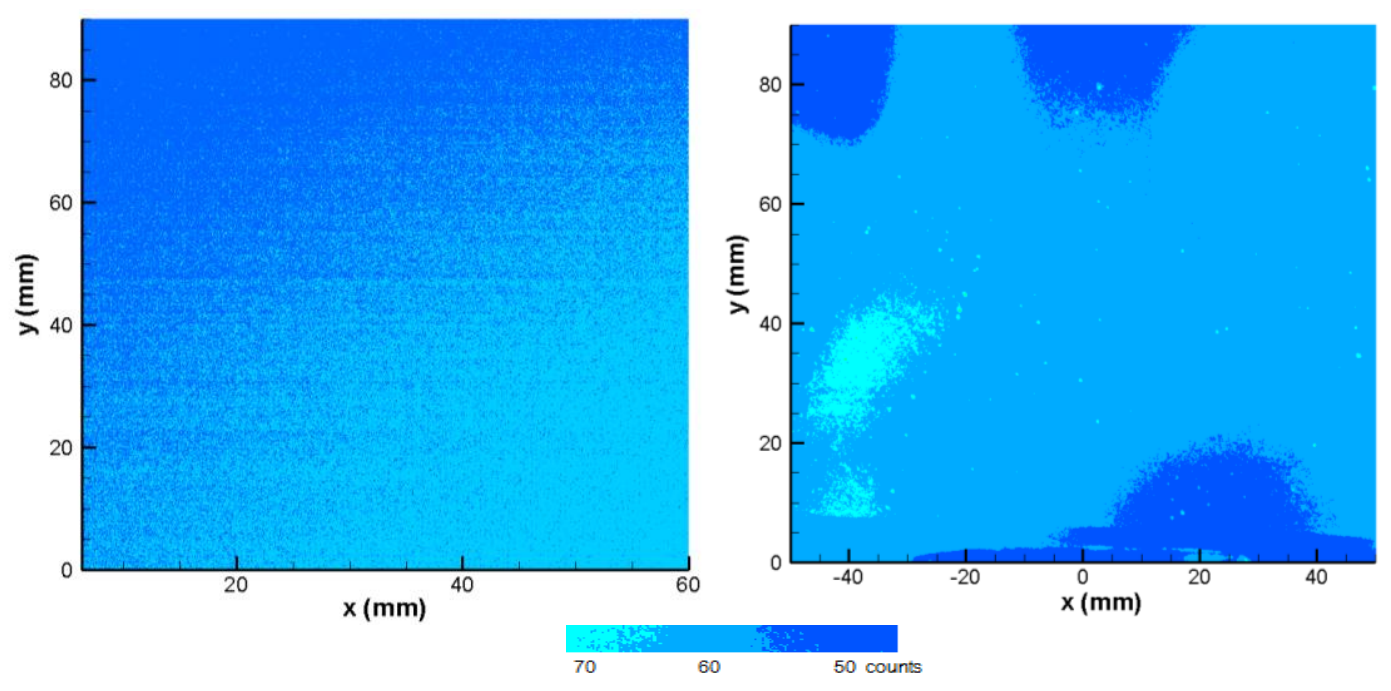

Figura 3.25. Imagem produzida pelo ruído de fundo da matriz CCD (esquerda) e; Imagem do feixe de luz laser obtida por espalhamento Rayleigh (direita).

Uma das limitações da técnica PLIF é a sublimação dos elétrons nas moléculas excitadas (Quentching), ou seja, a desativação da excitação de uma molécula de $\mathrm{OH}$ sem a emissão de fótons de fluorescência, na qual a dissipação da energia ocorre por meio de colisões eletrônicas. Os fatores que influenciam na sublimação são, principalmente, o aumento da pressão e a interação entre o composto fluorescente e outras sustâncias presentes no sistema, dentre os quais se destacam o oxigênio e impurezas existentes no escoamento [33], cujas concentrações, variáveis ponto a ponto, não são medidas. Assim, um mesmo sinal de fluorescência pode ser obtido para diferentes valores da concentração de $\mathrm{OH}$, em função, por exemplo, da quantidade de $\mathrm{O}_{2}, \mathrm{H}_{2}, \mathrm{H}_{2} \mathrm{O}$ e $\mathrm{CH}_{4}$. Este trabalho fooi realizados em condições ambiente de temperatura e pressão e a reação ocorre com o ar. A incerteza na medida da intensidade do sinal de fluorescência devido à sublimação é de $25 \%$, considerando o tempo de captura do sinal, $15 \mathrm{~ns}$, e a taxa de sublimação do $\mathrm{OH}$ em uma chama de $\mathrm{GN}, 20.10^{6} \mathrm{~s}^{-1}$, segundo determinado em [68]. Assim, a incerteza relativa às medições realizadas com PLIF é,

$$
u_{P L I F}= \pm\left[\left(u_{B G}\right)^{2}+\left(u_{I P}\right)^{2}+\left(u_{Q}\right)^{2}\right]^{1 / 2} \cong \pm 25 \% \text {. }
$$




\subsection{Comentários finais}

A abordagem experimental utilizada envolve duas técnicas ópticas de medição, PLIF e PIV, empregadas simultaneamente. As medidas foram realizadas em um queimador corpo rombudo, o qual possui características que o tornam ideal para este estudo, tais como o amplo acesso óptico, a simetria geométrica e a capacidade de estabilizar diversos tipos de chama. Os sistemas de medição foram apresentados separadamente, enfatizando os fenômenos físicos, os componentes que os constituem, a montagem e suas características, assim como a captura e 0 processamento das informações. A comparação com os trabalhos existentes na literatura, apresentados no capítulo 2, permite situar este trabalho em relação ao estado da arte. Os trabalhos mais avançados medem o campo de velocidade em 3D, simultaneamente com mais de um escalar, entre eles $\mathrm{O} \mathrm{OH}, \circ \mathrm{CH}, a$ temperatura, etc. ou, então, realizam medidas com alta resolução temporal, visando explorar os efeitos turbulentos instantâneos. Comparando-se os equipamentos utilizados neste trabalho com os da literatura nota-se que a resolução espacial dos resultados é semelhante àquela obtida com medições multi-escalares/PIV-3D, porém, deve-se ressaltar que neste trabalho foram consideradas apenas duas dimensões do campo vetorial e um único escalar. Por outro lado, esta resolução espacial é maior que as obtidas nos trabalhos de alta taxa de aquisição. Entretanto, a resolução temporal deste trabalho, $3,3 \mathrm{~Hz}$, é muito inferior aos trabalhos atuais, de até $5 \mathrm{kHz}$.

A calibração do PIV foi realizada através da comparação com resultados obtidos com a técnica de anemometria de fio quente, e também com resultados de cálculos, visando obter os níveis de confiança das medidas. O mesmo não foi feito para a técnica PLIF, pois os resultados são utilizados, neste trabalho, apenas para mapear a frente de chama, a fim de visualizar a estrutura da chama e estudar sua interação com o escoamento. $\mathrm{O}$ uso de medidas de concentração de $\mathrm{OH}$ é desnecessário para este fim.

A análise das incertezas envolvidas nas medições foi apresentada detalhadamente. A quantificação da incerteza nas medições de cada técnica é realizada individualmente a partir da contribuição de cada fonte de incerteza envolvida na metodologia, as quais são propagadas visando obter um resultado global para a incerteza da medição. 
A incerteza no número de Reynolds do jato é baseada na contribuição das incertezas na medida da vazão do jato, no diâmetro de saída do jato e na medida da pressão e temperatura. Uma maneira de reduzir a incerteza do número de Reynolds é utilizar equipamentos de medição de vazão e do diâmetro de saída do jato com incertezas menores. Além disso, uma menor incerteza pode ser obtida controlando a composição do gás, a fim de determinar com precisão a densidade e viscosidade nas condições de temperatura e pressão do experimento.

A incerteza relativa às medidas de velocidade associada à técnica PIV, de $6 \%$ para os escoamentos reativos e de $3 \%$ para os escoamentos inertes. A incerteza na medição é atribuída, principalmente, às partículas dispersas no escoamento, as quais devem ser pequenas o bastante para acompanhar mesmo as flutuações mais intensas, ocupar uma pequena porção da imagem, evitar a termoforese e apresentar boa uniformidade na dispersão. Além disso, outros fatores influenciam na incerteza em PIV, tais como as emissões espontâneas da chama e a radiação emitida pela fuligem, os gradientes de índice de refração na região de medição e, os efeitos do processamento das imagens. Para reduzir a incerteza nas medidas PIV é necessário controlar a dispersão e o diâmetro das partículas traçadoras e filtrar os ruídos na imagem. Entretanto, o efeito da termoforese, responsável por uma contribuição significativa, é intrínseco à técnica e dificilmente pode ser reduzido.

A incerteza nas medidas PLIF, 25\%, inclui fatores tais como a energia de cada pulso de luz laser, o ângulo de divergência do feixe, o ruído de fundo, a homogeneidade da intensidade no plano de luz, a distorção da imagem devido à imperfeições nos componentes ópticos e reflexos. Estes fatores podem ser corrigidos com procedimentos de pós-processamento de imagens. Existe um fator de incerteza que é difícil de ser avaliado e que pode causar grandes erros que é a desativação da excitação por parte de colisões entre as moléculas e, principalmente, o oxigênio do ambiente. Estas fontes de incerteza afetam, sobretudo, as medidas de concentração de $\mathrm{OH}$, sendo menos influentes no mapeamento da frente de chama que é o objetivo deste tipo de medida no presente estudo. 


\section{Análise de Resultados e Discussões}

Neste capítulo são apresentados: (i) os resultados experimentais obtidos no presente trabalho, (ii) a análise dos resultados de velocidade obtidos com PIV para caracterizar a dinâmica do escoamento do queimador utilizando neste trabalho em situações quimicamente inerte e reativa, (iii) os resultados obtidos com PLIF, capturados simultaneamente com PIV, os quais servem de base para caracterizar as chamas e identificar os regimes de combustão do experimento desenvolvido neste trabalho.

A caracterização detalhada da chama turbulenta passa, necessariamente, pela medição da velocidade do escoamento, permitindo analisar a interação do escoamento turbulento com a chama. $O$ estudo da distribuição de velocidade e de sua correlação com a fluorescência do radical $\mathrm{OH}$ permitirá, a termo, $\mathrm{O}$ desenvolvimento de novos modelos capazes de descrever os diferentes regimes de combustão.

Assim, será apresentada a caracterização do escoamento dos casos quimicamente inertes e reativos relacionados na Tabela 2 segundo as condições de vazão de combustível e ar. O valor médio da velocidade do jato de combustível também é apresentado, a fim de auxiliar a análise. Além disso, são mostrados os intervalos de tempo entre os quadros da técnica PIV utilizados para medir a velocidade do escoamento. Os parâmetros de controle do ICCD para os casos reativos medidos utilizando PLIF são: atraso $=675 \mathrm{~ns}$, abertura $=15 \mathrm{~ns}$ e ganho $=70 \%$, com um tempo de exposição do CCD de $1 \mathrm{~ms}$.

Tabela 2. Parâmetros do escoamento para os casos estudados.

\begin{tabular}{|c|c|c|c|c|c|c|}
\hline Caso & gás & $\begin{array}{c}\text { Vazão jato } \\
(\mathbf{N m} \mathbf{3} / \mathbf{h})\end{array}$ & $\begin{array}{c}\text { Velocidade } \\
\text { jato }(\mathbf{m} / \mathbf{s})\end{array}$ & $\begin{array}{c}\mathbf{N}=\text { Reynolds do } \\
\text { jato }\end{array}$ & $\begin{array}{c}\text { Velocidade } \\
\text { ar }(\mathbf{m} / \mathbf{s})\end{array}$ & $\begin{array}{c}\mathbf{d t} \\
(\boldsymbol{\mu s})\end{array}$ \\
\hline 1 & $\mathbf{N}_{\mathbf{2}}$ & $1,90 \pm 0,15$ & $13,30 \pm 0,90$ & $6066 \pm 425$ & $4 \pm 0,01$ & 27 \\
\hline 2 & $\mathbf{N}_{\mathbf{2}}$ & $0,60 \pm 0,05$ & $4,20 \pm 0,25$ & $1915 \pm 135$ & $8 \pm 0,02$ & 45 \\
\hline 3 & $\mathbf{C H}_{4}$ & $2,55 \pm 0,15$ & $17,90 \pm 1,10$ & $8148 \pm 570$ & $4 \pm 0,01$ & 22 \\
\hline 4 & $\mathbf{C H}_{4}$ & $0,76 \pm 0,05$ & $5,30 \pm 0,30$ & $2428 \pm 170$ & $4 \pm 0,01$ & 55 \\
\hline 5 & $\mathbf{C H}_{4}$ & $2,55 \pm 0,15$ & $17,90 \pm 1,10$ & $8148 \pm 570$ & $8 \pm 0,02$ & 22 \\
\hline 6 & $\mathbf{C H}_{4}$ & $0,76 \pm 0,05$ & $5,30 \pm 0,30$ & $2428 \pm 170$ & $8 \pm 0,02$ & 55 \\
\hline
\end{tabular}




\subsection{Hipótese de Boussinesq}

Dentre os resultados que serão apresentados na sequência, destaca-se o tensor de Reynolds. O tensor das tensões de Reynolds consiste de 9 componentes em uma matriz disposta da seguinte forma,

$$
\rho \tau_{R}=\left(\begin{array}{lll}
\overline{V_{1}^{\prime 2}} & \overline{V_{1}^{\prime} V_{2}^{\prime}} & \overline{V_{1}^{\prime} V_{3}^{\prime}} \\
\overline{V_{2}^{\prime} V_{1}^{\prime}} & \overline{V_{2}^{\prime 2}} & \overline{V_{2}^{\prime} V_{3}^{\prime}} \\
\overline{V_{3}^{\prime} V_{1}^{\prime}} & \overline{V_{3}^{\prime} V_{2}^{\prime}} & \overline{V_{3}^{\prime 2}}
\end{array}\right) .
$$

Cada um dos componentes deste tensor é definido como $\overline{V_{i}^{\prime} V_{j}^{\prime}}$, onde $V^{\prime}$ é a flutuação da componente da velocidade em torno de seu valor médio, $\bar{V}$. Note-se que, por simetria, $\overline{V_{i}^{\prime} V_{j}^{\prime}}=\overline{V_{j}^{\prime} V_{i}^{\prime}}$. Como as medidas são realizadas em duas dimensões, apenas as componentes no plano $x_{1} x_{2}$ são consideradas, isto é, são medidas apenas as componentes longitudinal, transversal e a componente cruzada dos tensores de Reynolds $\overline{V_{1}^{\prime 2}}, \overline{V_{2}^{\prime 2}}$ e $\overline{V_{1}^{\prime} V_{2}^{\prime}}$, respectivamente.

A modelagem da turbulência, geralmente, emprega a hipótese de Boussinesq para determinar o tensor de Reynolds, associando a este a taxa de deformação do escoamento médio através da relação [50],

$$
-\overline{V_{i}^{\prime} V_{j}^{\prime}}=2 v_{t} S_{i j}-\frac{2}{3} K \delta_{i j},
$$

onde $v_{t}$ é a viscosidade turbulenta, $K=1 / 2\left(\overline{V_{i}^{\prime} V_{j}^{\prime}}\right)$ é a energia cinética turbulenta, $\delta_{i j}$ é o delta de Kronecker e $S_{i j}$ é o tensor taxa de deformação média,

$$
S_{i j}=\frac{1}{2}\left(\frac{\partial \overline{V_{j}}}{\partial x_{i}}+\frac{\partial \overline{V_{i}}}{\partial x_{j}}\right)-\frac{1}{3} \frac{\partial \overline{V_{k}}}{\partial x_{k}} \delta_{i j} .
$$

Este tensor pode ser simplificado para escoamentos com simetria de revolução, como é o caso do escoamento produzido pelo queimador utilizado neste trabalho, o que será demonstrado mais adiante. Assim sendo, considerando um escoamento estatisticamente bidimensional, isto é, estatisticamente independente de $x_{3}$, que não varia sob reflexões em torno do eixo de coordenada $x_{3} \mathrm{e}$, para a função densidade de probabilidade PDF da velocidade, $f(V ; x, t)$, obedece, 


$$
\begin{gathered}
\frac{\partial f}{\partial x_{3}}=0 \\
f\left(V_{1}, V_{2}, V_{3} ; x_{1}, x_{2}, x_{3}, t\right)=f\left(V_{1}, V_{2},-V_{3} ; x_{1}, x_{2},-x_{3}, t\right),
\end{gathered}
$$

essas condições implicam que $\overline{V_{3}}=-\overline{V_{3}}$, isto é, $\overline{V_{3}}=0$. Por similaridade isso faz $\overline{V_{1}^{\prime} V_{3}^{\prime}}=0$ e $\overline{V_{2}^{\prime} V_{3}^{\prime}}=0$. Com estas simplificações as tensões de Reynolds consistem em,

$$
\begin{aligned}
-\overline{V_{1}^{\prime 2}}+\frac{2}{3} K & =v_{t}\left[2\left(\frac{\partial \overline{V_{1}}}{\partial x_{1}}\right)-\frac{1}{3}\left(\frac{\partial \overline{V_{1}}}{\partial x_{1}}+\frac{\partial \overline{V_{2}}}{\partial x_{2}}\right)\right], \\
-\overline{V_{2}^{\prime 2}}+\frac{2}{3} K & =v_{t}\left[2\left(\frac{\partial \overline{V_{2}}}{\partial x_{2}}\right)-\frac{1}{3}\left(\frac{\partial \overline{V_{1}}}{\partial x_{1}}+\frac{\partial \overline{V_{2}}}{\partial x_{2}}\right)\right], \\
& -\overline{V_{3}^{\prime 2}}+\frac{2}{3} K=-\frac{v_{t}}{3}\left(\left(\frac{\partial \overline{V_{1}}}{\partial x_{1}}+\frac{\partial \overline{V_{2}}}{\partial x_{2}}\right)\right), \\
& -\overline{V_{1}^{\prime} V_{2}^{\prime}}=v_{t}\left(\frac{\partial \overline{V_{1}}}{\partial x_{2}}+\frac{\partial \overline{V_{2}}}{\partial x_{1}}\right) .
\end{aligned}
$$

Estas equações foram escritas sob esta forma a fim de enfatizar que a hipótese de Boussinesq associa o desvio da distribuição isotrópica à taxa de deformação média. Note-se que, devido à equação de continuidade, nos escoamentos incompressíveis,

$$
\frac{\partial \overline{V_{1}}}{\partial x_{1}}+\frac{\partial \overline{V_{2}}}{\partial x_{2}}=0
$$

o que implica que, se a hipótese de Boussinesq se aplica das equações 23 e 25, $\overline{V_{1}^{\prime 2}}$ é proporcional a $\overline{V_{2}^{\prime 2}}$. Quando ocorre combustão na mistura, o divergente da velocidade está relacionado a variações de densidade, as quais não são medidas no presente estudo. Note-se que variações de densidade no meio influenciam as componentes $\overline{V_{i}^{\prime 2}}$ sempre da mesma forma.

A seguir a notação indicial será abandonada em prol da notação $V x=V_{2}$ e $V y=V_{1}$ e também $R x x=\overline{V_{1}^{\prime 2}}, R y y=\overline{V_{2}^{\prime 2}}$ e $R x y=\overline{V_{1}^{\prime} V_{2}^{\prime}}$. 
A intensidade turbulenta pode ser escrita como [50],

$$
I_{t}=\sigma_{V_{y}} / \bar{V}_{y},
$$

onde $\sigma_{V_{y}}$ é o desvio padrão da componente da velocidade $V y$, cujo valor é obtido através de $\sqrt{R y y}$. O valor da intensidade turbulenta na região de escoamento de ar, $|x / D|=0,75$, é obtido a partir das medidas de velocidade.

Os resultados das medições serão analisados à luz da hipótese de Boussinesq, isto é, a conexão entre a taxa de deformação média e o tensor de Reynolds será considerada. Em particular, o desvio em relação à isotropia das componentes da diagonal principal do tensor de Reynolds será examinado. Cabe antecipar que esta análise não poderá ser completa, pois a medida de velocidade realizada não permite determinar uma escala de tempo (ou de comprimento) da turbulência. Somente assim seria possível conhecer a viscosidade turbulenta.

\subsection{Escoamento quimicamente inerte}

O estudo da estrutura do escoamento em dois casos quimicamente inertes, nos quais o jato central é composto de Nitrogênio, permitirá antecipar alguns dos comportamentos das propriedades turbulentas que serão observados quando da presença de combustão. Os casos 1 e 2 da Tabela 1, foram escolhidos por representarem diferentes situações na região de recirculação. $O$ caso 1 , no qual a quantidade de movimento do jato de nitrogênio é três vezes maior do que no caso 2 , o escoamento é dominado pelo jato. Por outro lado, no caso 2 ocorre a predominância do escoamento de ar, em relação ao caso 1.

\subsubsection{Análise do escoamento no caso 1 (dominado pelo jato)}

A Figura 4.1 apresenta o campo de velocidade do escoamento no caso 1. São apresentadas três imagens do campo vetorial de velocidade instantânea seguidas pela média da distribuição de vetores velocidade. Os resultados instantâneos apresentam pouca flutuação na região de escoamento do ar. Para o caso 1 , o valor da intensidade turbulenta é de aproximadamente 0,14 que equivale a $3,5 \%$ da média da componente $V y$ da velocidade na região de escoamento de ar. 
Não é possível verificar a formação e dissipação de vórtices nas sequências de imagens instantâneas, devido à baixa taxa de aquisição do sistema, $3,3 \mathrm{~Hz}$.
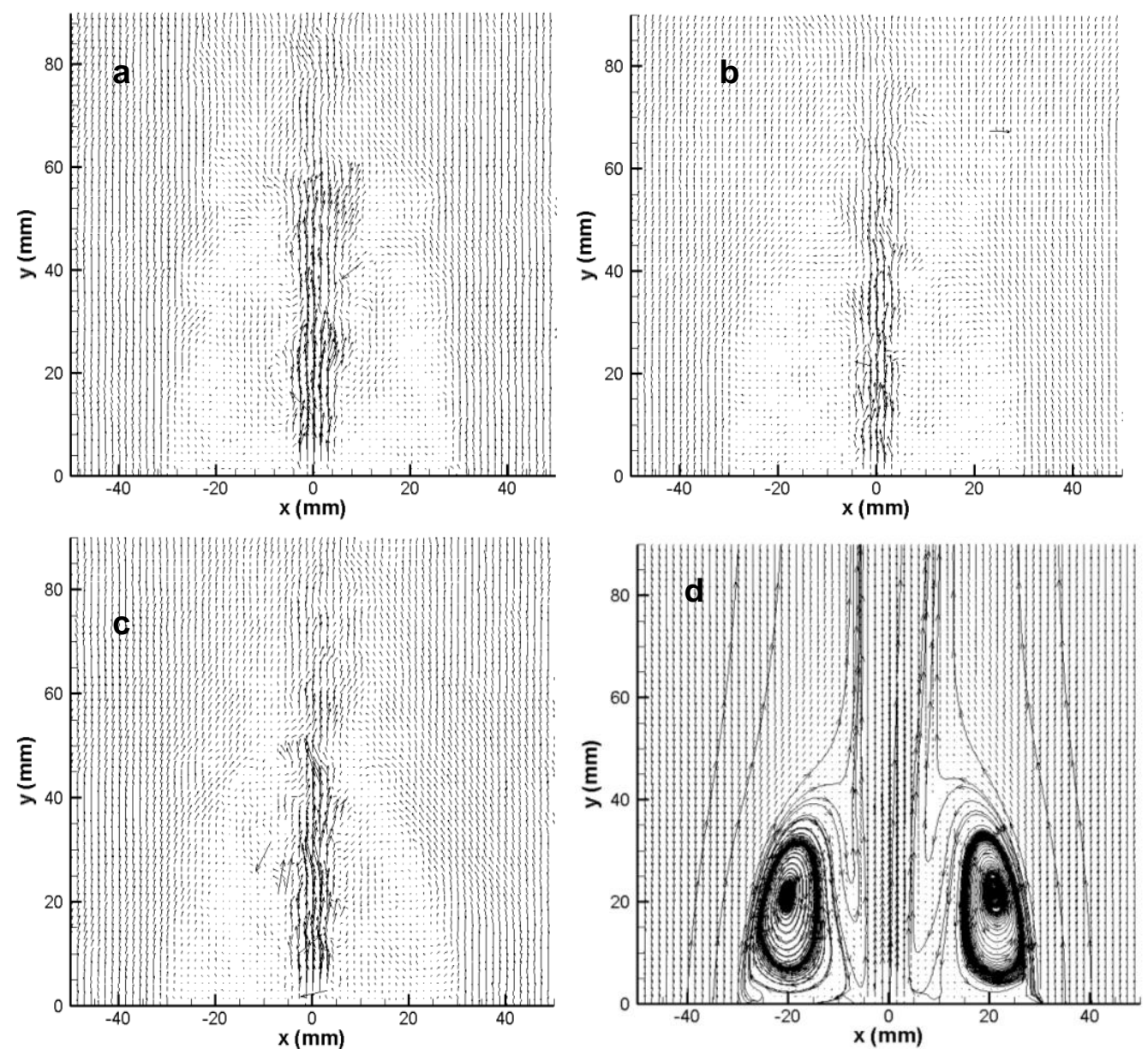

Figura 4.1. Caso 1: Projeção no plano xy: $(a, b, c)$ Vetores velocidade instantâneos;

(d) Vetor velocidade médio e linhas de corrente.

O jato central atravessa a região de esteira, onde há um vórtice toroidal, como pode ser verificado pelas linhas de corrente, Figura 4.1d. Isto se deve ao fato da quantidade de movimento do jato ser, em média, mais que o dobro da quantidade de movimento do ar, o que pode ser verificado a partir das medidas de velocidade apresentadas nos cortes transversais mostrados na Figura 4.2, os quais também confirmam a alta simetria do escoamento em torno de $x / D=0$. A assimetria da componente longitudinal de velocidade é inferior a 10\%, ou seja, é da mesma ordem de grandeza da incerteza experimental de medição. Corrobora-se, neste caso, a hipótese de simetria de revolução utilizada na formulação da hipótese de Boussinesq. Esta hipótese de simetria de revolução é verificada nos demais casos. 

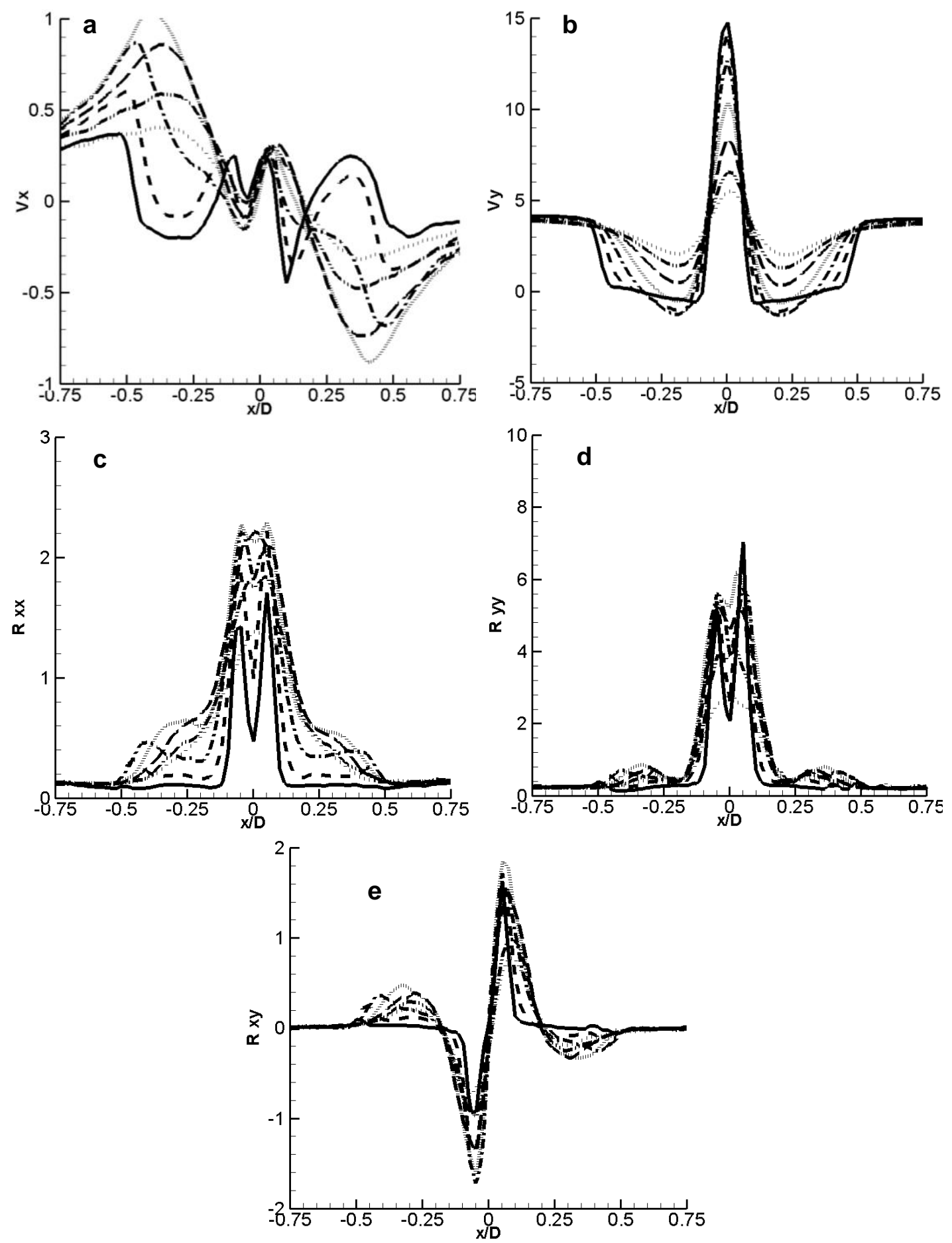

Figura 4.2. Caso 1: Evolução na direção transversal ( $x$ ), para posições longitudinais espaçadas de $10 \mathrm{~mm}$ a partir da superfície do queimador, das componentes longitudinal (Vy) e transversal (Vx) da velocidade [m/s] e das componentes $R$ xx, yy e $x y$ do tensor de Reynolds $\left[\mathrm{m}^{2} / \mathrm{s}^{2}\right] .-10,--20, \ldots 30, \ldots 40,---50, \ldots$ $60, \ldots 70 \mathrm{~mm}$. 
A Figura 4.2 mostra a evolução das componentes transversal e longitudinal e, também, dos tensores de Reynolds no escoamento. As componentes da velocidade e do tensor de Reynolds mostradas podem ser divididas em subdomínios, são elas: a região de escoamento de ar $|x / D|>0,50$, a região de esteira $0,10<|x / D|<0,50$ e a região do jato central $x / D<0,1$.

Na região de esteira, a componente transversal da velocidade, $V x$, mostrada na Figura 4.2a, alcança os maiores valores absolutos na região de recirculação do que no centro do jato. Para $|x / D|>0,50, V x$ mostra a existência do processo de arraste do ar pelo escoamento da esteira do corpo rombudo. A Figura 4.2a mostra variações abruptas de $V x$ nas fronteiras do jato com a esteira, com valores absolutos ligeiramente maiores do lado positivo, ou seja, em $x / D=0,1$ do que no lado negativo $x / D=-0,1$.

A componente longitudinal da velocidade, $V y$, mostrada na Figura 4.2b, apresenta valores constantes e próximos a $4 \mathrm{~m} / \mathrm{s}$ na região de escoamento de ar, $(x / D \mid>0,50)$, atingindo cerca de $15 \mathrm{~m} / \mathrm{s}$ na região do jato central a $10 \mathrm{~mm}$ a jusante do orifício de saída. Este valor decresce ao longo da linha de centro até cerca de 5 $\mathrm{m} / \mathrm{s}$ em $y=70 \mathrm{~mm}$. Na região de esteira $(0,10<|x / D|<0,50)$, os valores de $V y$ diminuem chegando assumir valores negativos entre $y=20$ e $40 \mathrm{~mm}$, devido à região de recirculação, aumentando bruscamente nas imediações do jato. Neste caso, a esteira atua como fronteira entre o jato central e o ar.

Os resultados experimentais mostram, tal como poderia ser esperado neste escoamento fortemente dominado pelo jato, com base nas equações 23-25, que os valores das tensões de Reynolds, $R x x, R y y$, mostradas nas Figuras 4.2c,d, respectivamente, são relacionados com as taxas de deformação médias, $S x x, S y y$, do escoamento e, também, entre si. A componente $R x y$, mostrada na Figura 4.2e, é relacionada com a taxa de deformação, $S x y$, o escoamento.

As componentes do tensor de Reynolds comprovam as características do escoamento tipo jato, neste primeiro caso, pois apresentam os maiores valores ao longo das fronteiras entre o jato e a esteira, local de maiores taxas de deformação e cisalhamento médio. As componentes $R x x$, yy são pequenas na região de 
escoamento do ar, $0,3 \mathrm{~m}^{2} / \mathrm{s}^{2}$, onde o gradiente de velocidade é nulo, Figura $\mathbf{4 . 2} \mathbf{b}$. Nesta mesma região a componente $R x y$ é nula, indicando que há isotropia da turbulência. Os valores das tensões aumentam para $0,5 \mathrm{~m}^{2} / \mathrm{s}^{2}$ na região de esteira, principalmente nas medidas realizadas acima da zona de recirculação, $40<y<70 \mathrm{~mm}$. Os máximos valores ocorrem na fronteira esteira/jato, onde $R x x=2, R y=7 \quad \mathrm{e}$ $|R x y|=2 \mathrm{~m}^{2} / \mathrm{s}^{2}$. Nota-se que, na parte central do jato, ocorre uma diminuição nos valores das componentes do tensor de Reynolds nas proximidades da superfície do queimador, isto é, para $y<20 \mathrm{~mm}$.

Uma análise dos resultados de $R x x$ e $R$ yy mostrados na Figura 4.2c,d, permite verificar que a hipótese de Boussinesq é satisfeita, por duas razões. Primeiro, os valores de ambas as tensões correspondem à maior taxa de deformação média, segundo, pois parece existir uma relação direta entre $R x x$ e $R$ yy. A Figura 4.2 também permite verificar que existe uma proporcionalidade entre a taxa de deformação média por cisalhamento e $R x y$. Assim, a análise qualitativa, considerando a incerteza experimental dos resultados indica que a hipótese de Boussinesq para escoamentos incompressíveis é satisfeita em todas as regiões do escoamento. Na esteira, $0,10<|x / D|<0,50$, parece ocorrer um pequeno desvio da proporcionalidade entre as tensões normais, porém, este pode estar relacionado a maior dificuldade de se medir com acurácia os pequenos valores de $V x$ diante dos maiores valores de $V y$.

\subsubsection{Análise do escoamento no caso 2 (dominado pela esteira)}

A Figura 4.3 apresenta o comportamento do campo de velocidade do escoamento no caso 2, seguindo a mesma disposição apresentada na Figura 4.1. Porém, a intensidade turbulenta (eq. 28), para o caso 2, é de aproximadamente 0,11 que equivale a $1,5 \%$ da média da componente $V_{y}$ da velocidade na região de escoamento de ar. Este valor é menor se comparado com o caso 1 de 3,5\%. 

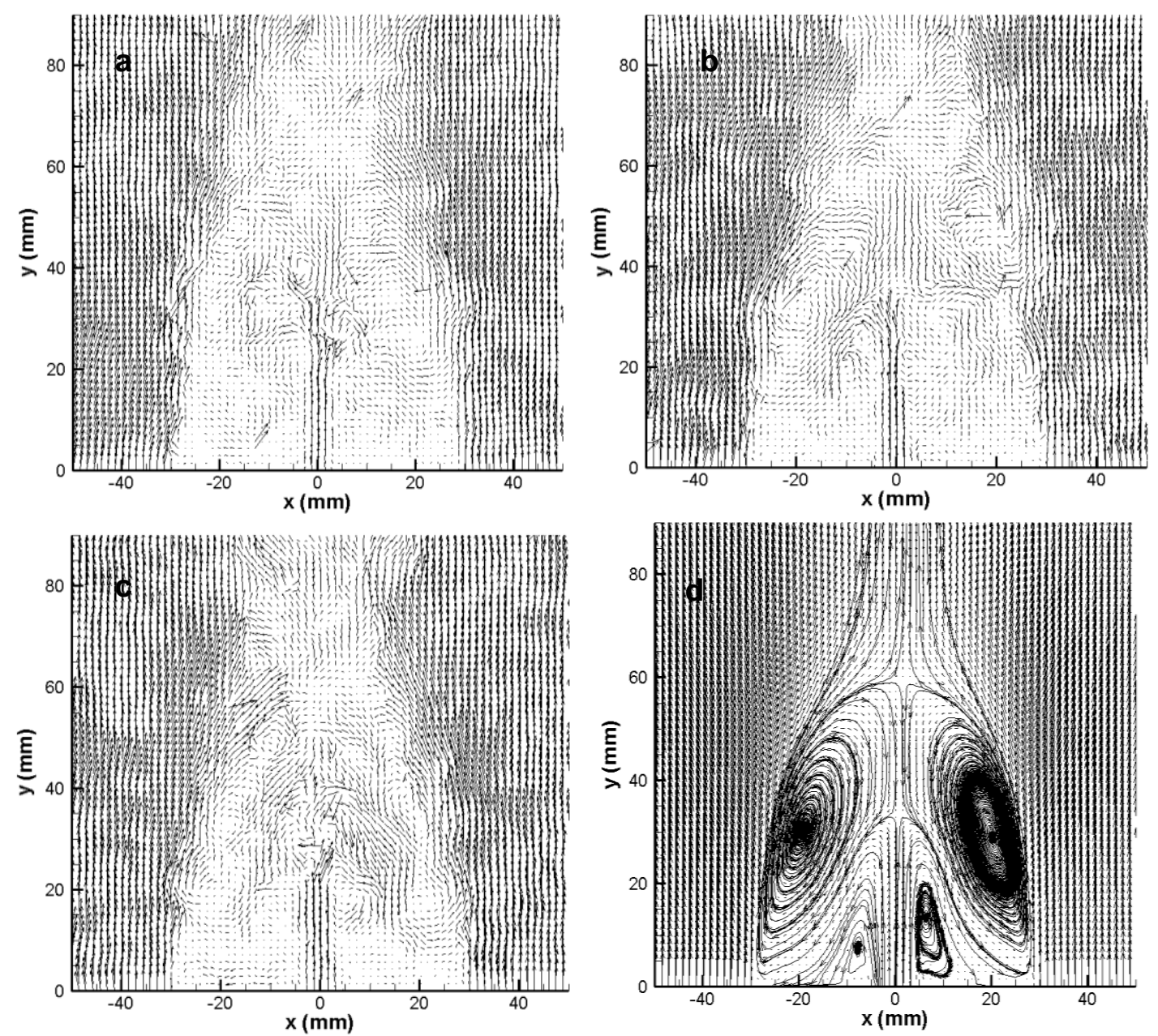

Figura 4.3. Caso 2: Projeção no plano $x y$ : $(a, b, c)$ Vetores velocidade instantâneos; (d) Vetor velocidade médio e linhas de corrente.

As medidas instantâneas apresentam pouca flutuação na região de escoamento do ar e na região do jato para $\quad y<20 \mathrm{~mm}$, a partir do qual ocorre o desaparecimento do jato. Na imagem média, Figura 4.3.d, são encontradas duas zonas de recirculação toroidais que produzem dois pontos de estagnação ao longo de $x / D=0$. As linhas de corrente destacam estes pontos, localizados no eixo de simetria, em $y=30$ e $60 \mathrm{~mm}$, o que pode ser comprovado nos perfis longitudinais mostrados na Figura 4.5, que serão discutidos mais adiante. Este comportamento se deve ao fato da quantidade de movimento do jato ser, em média, menor que a quantidade de movimento do ar, quando comparado com o escoamento tipo jato no caso 1. A Figura 4.4 mostra a evolução dos valores dos resultados das medidas realizadas para o caso 2 em diversas alturas em relação à superfície do queimador. 

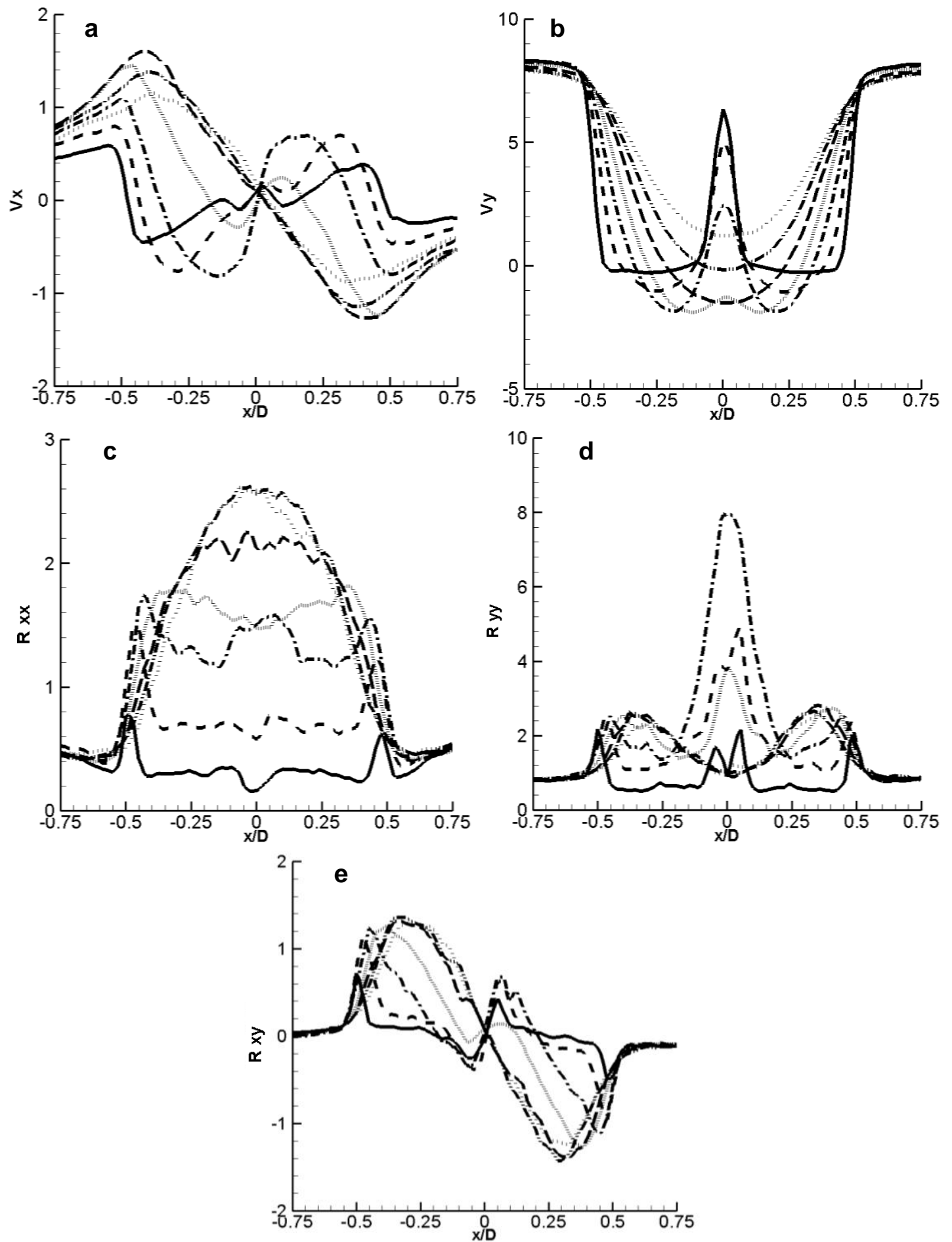

Figura 4.4. Caso 2: Evolução na direção transversal ( $x$ ), para posições longitudinais espaçadas de $10 \mathrm{~mm}$ a partir da superfície do queimador, das componentes longitudinal (Vy) e transversal $(\mathrm{Vx})$ da velocidade [m/s] e das componentes $R x x$, yy e xy do tensor de Reynolds $\left[\mathrm{m}^{2} / \mathrm{s}^{2}\right] .-10,---20, \ldots 30,-.40,---50,-\cdot$ $.60, \ldots 70 \mathrm{~mm}$. 
A componente da velocidade $V_{y}$ permite notar que a partir da altura de $y=30 \mathrm{~mm}$ há uma forte interação entre o jato e o ar em toda a região de esteira, produzindo turbulência intensa, evidente nos perfis dos tensores de Reynolds. $O$ escoamento do jato é interrompido a partir de $y=40 \mathrm{~mm}$, onde há um bloqueio do jato por parte do escoamento anular. A presença das zonas de recirculação é verificada nas componentes de velocidade na zona de esteira, sendo condizente com o processo de espalhamento do jato na região de esteira. Os valores de $V_{y}$, são constantes e próximos a $8 \mathrm{~m} / \mathrm{s}$ na região de escoamento de ar. Ao longo da linha do jato central a velocidade atinge no máximo cerca de $7 \mathrm{~m} / \mathrm{s}$ a $y=10 \mathrm{~mm}$, diminuindo drasticamente até cerca de $-2 \mathrm{~m} / \mathrm{s}$ entre $40<y<60 \mathrm{~mm}$. A partir de $y=70 \mathrm{~mm}$ a região de mistura se torna mais homogênea e tende a ser dominada pelo escoamento de ar anular com velocidade de $V_{y}=1 \mathrm{~m} / \mathrm{s}$.

As componentes do tensor de Reynolds, mostradas nas Figuras 4.4c,d,e, comprovam que, no caso 2 , o escoamento é dominado pelo jato a montante de $y=40 \mathrm{~mm}$ e pela esteira a jusante desta região. A componente $R x x$, que é praticamente uniforme na região de esteira, apresenta valores absolutos maiores a medida que o escoamento evolui de montante para jusante. Além disso, até $y=30 \mathrm{~mm}$ ocorrem máximos locais nas fronteiras entre o escoamento de ar e a esteira, os quais se intensificam e se espalham na região onde ocorre a mistura entre a esteira e o escoamento de ar.

A componente longitudinal do tensor de Reynolds, $R$ yy, apresenta máximos locais com valores semelhantes entre si, cerca de $2 \mathrm{~m}^{2} / \mathrm{s}^{2}$, em $|x / D|=0,50$ e $|x / D|=0,10$. para $y=10 \mathrm{~mm}$. Estes valores aumentam gradualmente até $y=40 \mathrm{~mm} \mathrm{e}$, em particular, atingem valores próximos àqueles vistos no caso 1 , em que o jato predomina, cerca de $4 \mathrm{~m}^{2} / \mathrm{s}^{2}$. A comparação entre as Figuras 4.4c e 4.4d mostra que não há proporcionalidade entre $R x x$ e $R$ yy em $|x / D|<0,25$, a jusante de $y=30 \mathrm{~mm}$ o que indica que a hipótese de Boussinesq não poderia ser usada para calcular este escoamento. 
A componente $R$ xy apresenta um valor absoluto máximo de $1 \mathrm{~m}^{2} / \mathrm{s}^{2}$ na região de esteira. Na direção longitudinal, há uma tendência de deslocamento dos máximos valores de $R x y$, a partir da fronteira entre escoamento de ar, $|x / D|=0,50$, em direção ao centro, $|x / D|=0$, isto é, a turbulência é transportada para o centro conforme o escoamento passa a ser dominado pela esteira. Este é outro indicativo de que a estrutura do escoamento é dominada pela esteira, sendo o jato pouco determinante no processo de transporte turbulento.

Contrariamente ao que acontece no caso 1 , apenas a hipótese de Boussinesq não parece ser suficiente para descrição do transporte turbulento no escoamento do caso 2. Portanto, um modelo matemático destinado à simulação numérica deste não deve utilizar a hipótese da viscosidade turbulenta, Eq. 21, mas um modelo de transporte dos tensores de Reynolds.

\subsubsection{Evolução na linha central, casos inertes}

A fim de completar a discussão acima, é analisada a componente longitudinal da velocidade, $V y$, e as componentes longitudinal $R$ yy e transversal $R x x$ dos tensores de Reynolds ao longo da linha central, $x / D=0$, mostradas na Figura 4.5, em particular nos casos 1 e 2. A análise dos resultados dos casos reativos, também mostrados nesta figura, será realizada posteriormente. 
$\mathrm{N}_{2}$

caso 1

caso 2
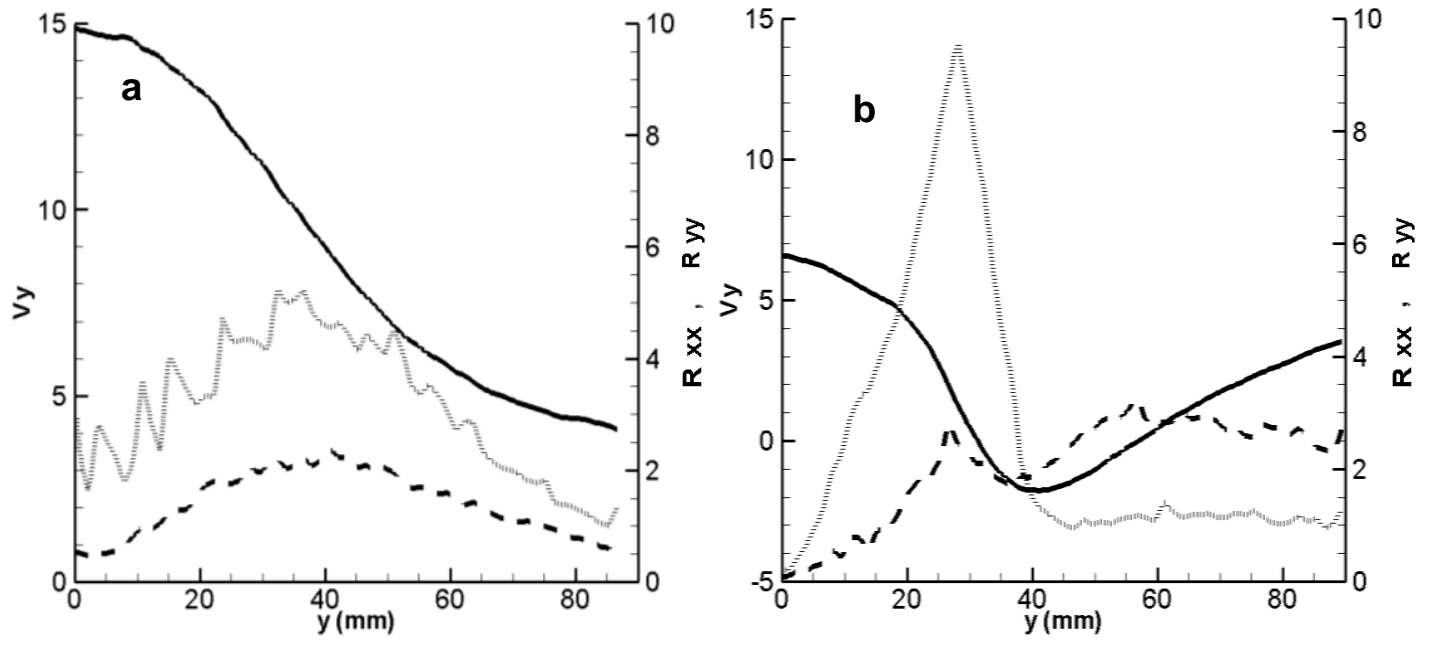

$\mathrm{CH}_{4}$

caso 3

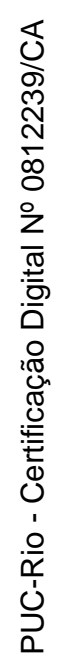

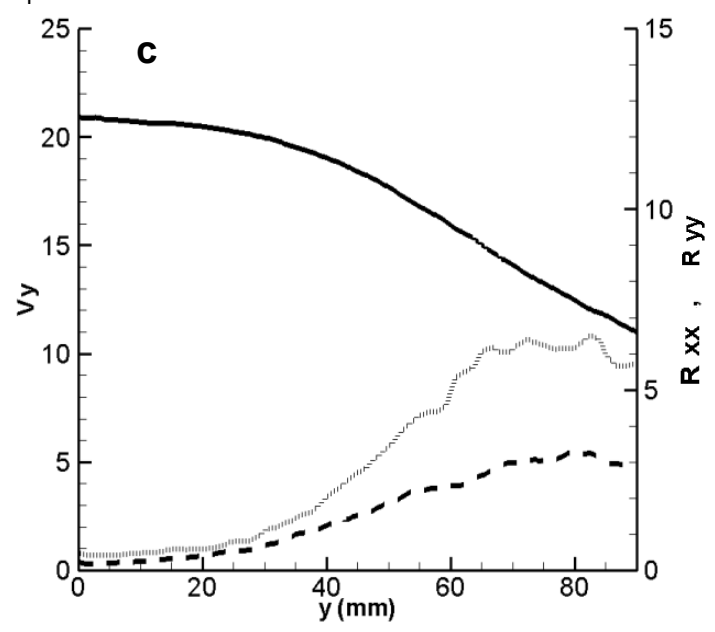

caso 4
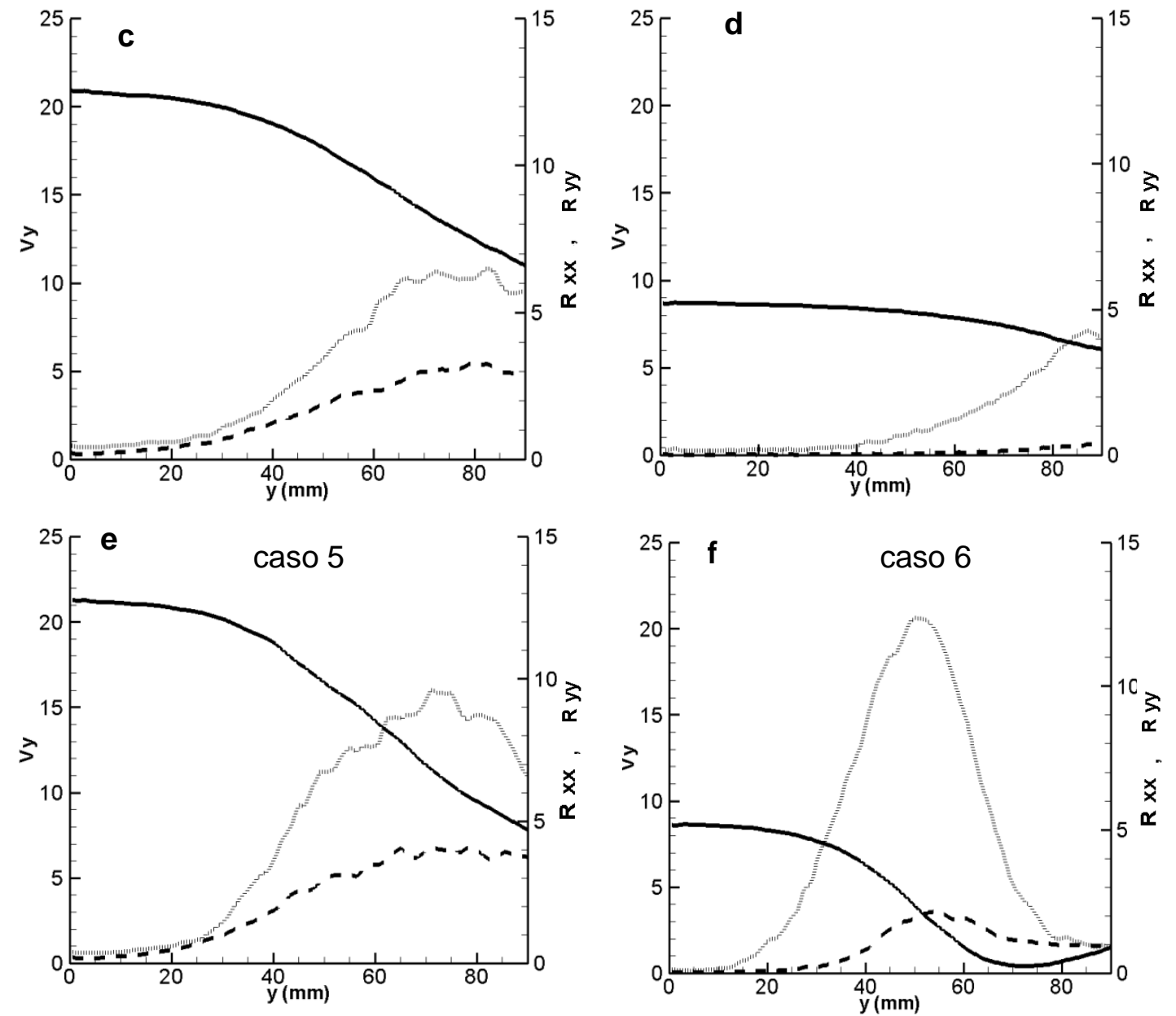

Figura 4.5 Evolução da componente longitudinal da velocidade média e das componentes, transversal e longitudinal, em [m/s] e dos tensores de Reynolds sobre a linha central, em $\left[\mathrm{m}^{2} / \mathrm{s}^{2}\right]$, respectivamente. $-V x,--R x x, \cdots R y y$. 
No caso 1, Figura 4.5a, a componente longitudinal da velocidade do jato, $V y$, sofre uma queda, de 15 para $5 \mathrm{~m} / \mathrm{s}$ em aproximadamente $60 \mathrm{~mm}$, a partir desta altura o valor da velocidade continua uma suave tendência em diminuir. No caso 2 , Figura 4.5b, Vy sofre uma forte queda de cerca de 7 para $-2 \mathrm{~m} / \mathrm{s}$ em aproximadamente $40 \mathrm{~mm}$. Até esta região o escoamento é dominado pelo jato. A jusante desta altura a tendência de queda no valor da velocidade se inverte e dá inicio à um suave aumento até $3 \mathrm{~m} / \mathrm{s}$ em $y=90 \mathrm{~mm}$, com um comportamento de escoamento dominado pela esteira. Neste processo, $b y$ assume o valor zero em duas posições, mais especificamente em 30 e $50 \mathrm{~mm}$, confirmando a existência de dois pontos de estagnação no escoamento e a posição da zona de mistura entre 0 jato e o escoamento de ar sobre a linha de centro.

No caso 2 as componentes do tensor de Reynolds são proporcionais e apresentam um máximo na região de maior taxa de deformação entre $20<y<30 \mathrm{~mm}$, o que, novamente, é conforme a hipótese de Boussinesq. Porém, a hipótese de Boussinesq parece ser verificada apenas no desenvolvimento inicial do escoamento, até cerca de $y=30 \mathrm{~mm}$, onde há uma relação direta entre $R x x$ e $R y y$. A partir deste ponto, as tendências destas duas componentes são contraditórias, o que viola a hipótese de Boussinesq.

Particularmente, $R y y$, atinge valores de cerca de $10 \mathrm{~m}^{2} / \mathrm{s}^{2}$, onde há uma interrupção do jato, principalmente entre $20<y<30 \mathrm{~mm}$ e se situa a fronteira com a zona de recirculação. Nesta fronteira 0 jato concorre com a zona de mistura causando queda brusca de $V y$ na direção longitudinal. Nota-se que os valores de $R$ yy assumem o menor valor $y=40 \mathrm{~mm}$, como era de se esperar, pois 0 jato encontra a zona de recirculação e o valor da derivada de $V y$ na direção longitudinal é nulo. A jusante de $y=50 \mathrm{~mm}$ os valores de $R x x$ e $R y y, 3$ e $1 \mathrm{~m}^{2} / \mathrm{s}^{2}$, respectivamente, são praticamente constantes. Passando por um ponto de estagnação em $y=50 \mathrm{~mm}$, O valor do módulo da derivada de $V y$ na direção longitudinal é praticamente constante, o que está de acordo com a hipótese de Boussinesq. Assim, na região onde o jato é interrompido os resultados obtidos indicam que a hipótese de Boussinesq não é válida. 


\subsection{Escoamento Reativo}

Nesta seção são discutidos os resultados obtidos para os quatro diferentes tipos de chama turbulenta, não pré-misturada, de gás natural e ar. Para cada um dos casos estudados são apresentadas três imagens instantâneas da intensidade de fluorescência do radical químico $\mathrm{OH}$ sobrepostas pelos respectivos campos vetoriais de velocidade, obtidos simultaneamente no plano de simetria do queimador. Os cálculos de elementos de chama laminares realizados em [12] indicam que, em uma primeira aproximação, a posição da superfície estequiométrica instantânea corresponde ao máximo de concentração - e logo máximo de fluorescência - do OH. É analisado em seguida o comportamento da média do sinal de fluorescência de $\mathrm{OH}$ sobreposta pelas linhas de corrente, as quais foram calculadas a partir de 1000 imagens instantâneas. De modo análogo aos casos 1 e 2, também serão discutidos os comportamentos dos valores médios das componentes da velocidade e do tensor de Reynolds. Por fim, é discutido o comportamento da intensidade de fluorescência, em termos da evolução da média $\bar{I}$ e do valor RMS, $I_{R M S}=\sqrt{1 / 1000 \sum_{1}^{1000}\left(\bar{I}-I_{i}\right)^{2}}$, correspondente. Os resultados quantitativos são apresentados em gráficos cujos valores foram extraídos a partir de 8 cortes transversais em intervalos de $10 \mathrm{~mm}$ acima da superfície do queimador. É importante ressaltar que os valores médios e RMS de intensidade de fluorescência do $\mathrm{OH}$ foram normalizados utilizando o valor máximo de intensidade para cada caso, não sendo assim possível comparar quantitativamente os casos entre si.

Nas Figuras 4.6 a 4.17, são discutidos os quatro tipos de chamas encontradas nos casos de 3 a 6 do presente trabalho. As medidas de velocidade $e$ do sinal de fluorescência do radical $\mathrm{OH}$ foram realizadas em quatro diferentes condições experimentais, determinadas pela vazão de combustível e ar do queimador, correspondentes às condições nominais de funcionamento mostradas na Tabela 1. Estes tipos de chama foram escolhidos por apresentarem características que podem ser encontradas em diversos regimes de combustão não pré-misturados, tal como a chama do tipo jato apresentada no caso 3; chamas suspensas com pré-mistura parcial, em regime de elemento de chama, como mostram os casos 4 e 5; e a chama do caso 6 , na qual a intensa turbulência do escoamento afeta a estabilização, produzindo um regime de efeitos transientes [49]. 
A região com sinal de fluorescência do $\mathrm{OH}$ é admitida como representativa da presença da chama, conforme visto no Capítulo 2. A resolução da imagem é tal que a dimensão de cada pixel na imagem é de aproximadamente $90 \mu \mathrm{m}$, ou seja, tem-se cerca de 10 pixels no interior da frente de chama instantânea.

\subsubsection{Análise do escoamento no caso 3}

Neste caso, como no caso 1, o escoamento é dominado pelo jato. Os resultados instantâneos e a média de velocidade e fluorescência de $\mathrm{OH}$ sobrepostos são mostrados na Figura 4.6. A presença de combustão eleva a temperatura e causa uma alteração na densidade dos gases. $O$ jato atravessa a região de esteira, onde há um vórtice toroidal, região de mistura entre o combustível, o ar e os produtos de combustão.
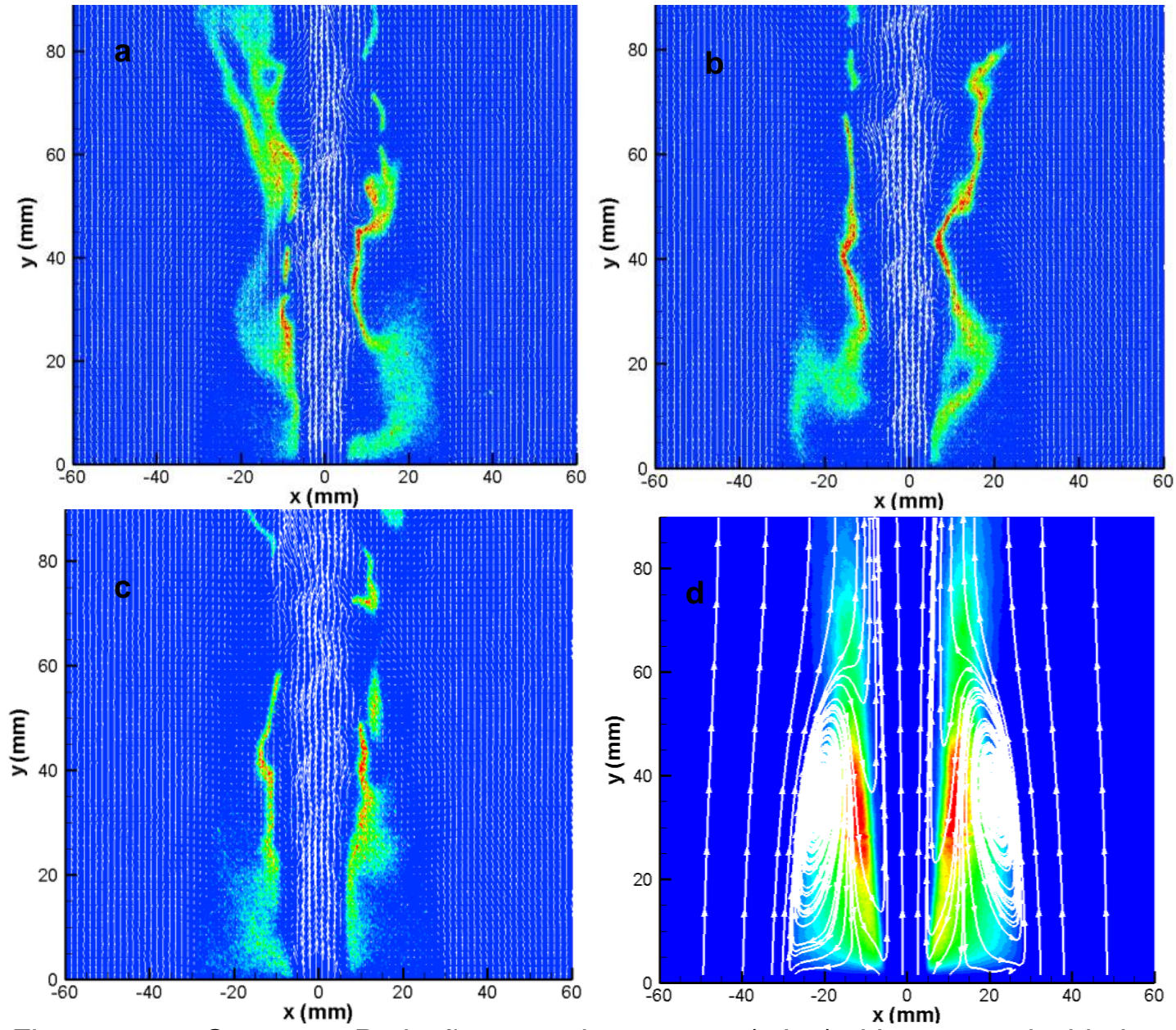

Figura 4.6. Caso 3: Projeção no plano $x y:(a, b, c)$ Vetores velocidade $e$ fluorescência do radical $\mathrm{OH}$ instantâneos; (d) Intensidade média de fluorescência de $\mathrm{OH}$ e linhas de corrente. 
A análise dos resultados mostrados na Figura 4.6 permite verificar as características de uma chama de difusão, em regime de elemento de chama, cujo escoamento é dominado pelo jato de combustível, no qual a frente de chama sugere uma separação entre o combustível do oxidante. Note-se que isto não pode ser confirmado, pois a concentração de combustível não foi medida nos experimentos. Esta chama se encontra estabilizada na região de esteira do escoamento, totalmente colada na superfície do queimador e, na maior parte do tempo, parece segregar combustível e oxidante. Nas regiões mais a jusante podem ser observadas extinções locais nas chamas instantâneas. A frente de chama instantânea também é bastante dobrada pelo escoamento. As extinções locais vistas nas chamas instantâneas não são aparentes na chama média, mas podem ser traduzidas por uma redução da intensidade média de fluorescência de OH e, maior flutuação RMS, como será discutido mais adiante. Nota-se que, neste caso, as chamas instantâneas e a média possuem uma diferença razoável. A chama média ocupa a zona de esteira, $0,10<|x / D|<0,50$. A chama média pode ser interpretada como uma probabilidade de se encontrar a frente de chama instantânea. As linhas de corrente do escoamento médio, mostradas na Figura 4.6d, sugerem que este caso apresenta uma zona de recirculação entre 20 e $50 \mathrm{~mm}$ a jusante da superfície do queimador, região com maior intensidade de fluorescência de $\mathrm{OH}$.

Os resultados obtidos da média da intensidade de fluorescência do $\mathrm{OH}$, mostrados na Figura 4.6, sugerem uma variação suave, de montante para jusante, ao contrário do que é visto nas chamas instantâneas, as quais, com frequência, são interrompidas. A intensidade turbulenta (eq. 28), para este caso é de aproximadamente 0,11 , o que equivale a $2,8 \%$ da média da componente $V y$ do escoamento de ar.

A Figura 4.7 mostra que há grande diferença entre a velocidade do jato e a velocidade do ar, 20 e $4 \mathrm{~m} / \mathrm{s}$, respectivamente, o que confirma que este caso é semelhante ao caso 1, onde a quantidade de movimento no jato é, em média, o dobro que no ar. 

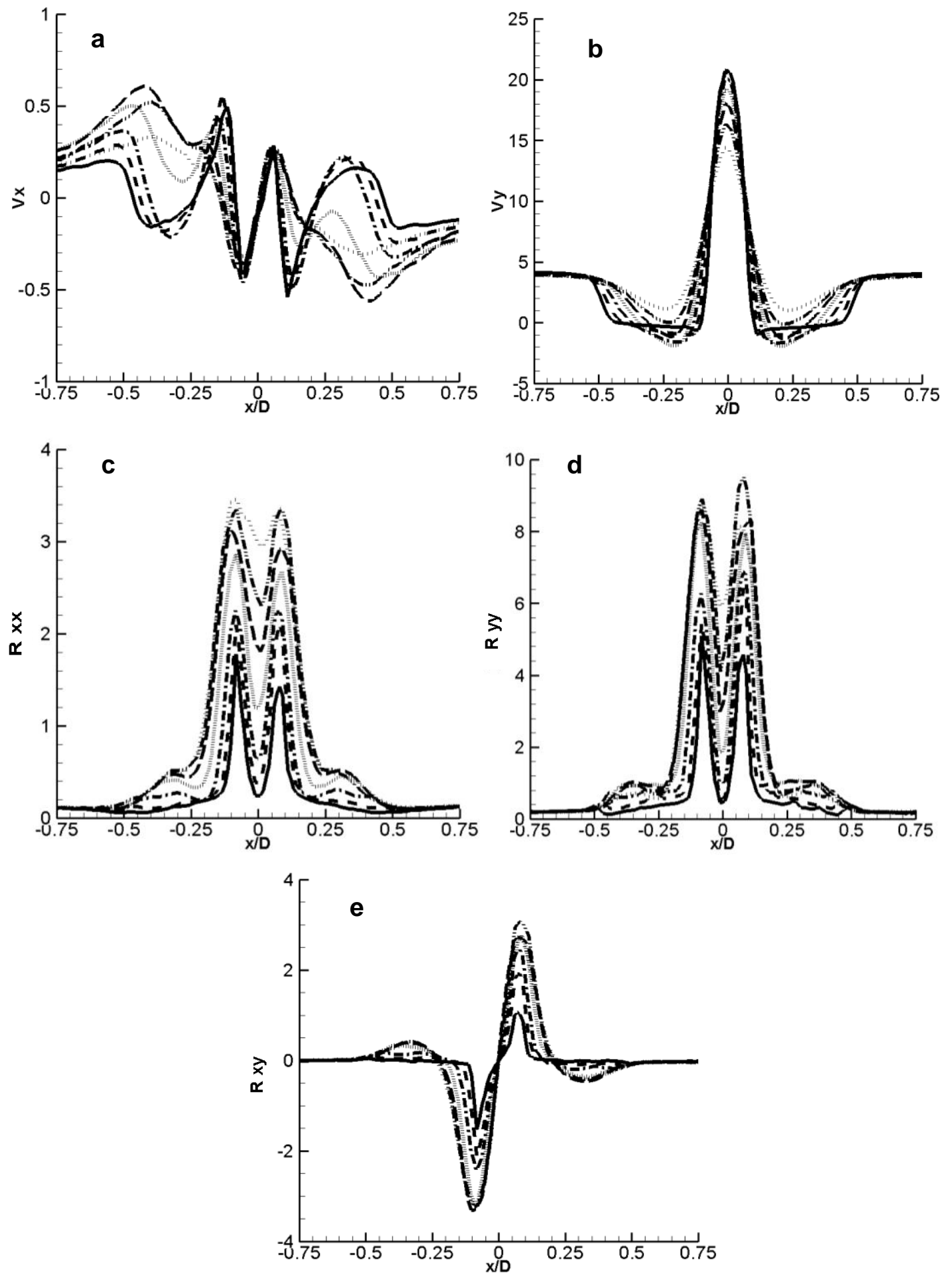

Figura 4.7. Caso 3: Evolução na direção transversal ( $x$ ), para posições longitudinais espaçadas de $10 \mathrm{~mm}$ a partir da superfície do queimador, das componentes longitudinal (Vy) e transversal $(V x)$ da velocidade $[\mathrm{m} / \mathrm{s}]$ e das componentes $x x, x y$ xy do tensor de Reynolds $\left[\mathrm{m}^{2} / \mathrm{s}^{2}\right] .-10,---20, \ldots 30,-.40,---50,-\ldots 60, \ldots 70 \mathrm{~mm}$. 
A Figura 4.7a mostra que $v x$ alcança os maiores valores absolutos na região de esteira, cerca de $0,6 \mathrm{~m} / \mathrm{s}$. A componente longitudinal da velocidade $V y$ é mostrada na Figura 4.7b, a qual permite verificar que o jato de combustível possui quantidade de movimento superior a do escoamento de ar. A componente $V y$ apresenta valores constantes e próximos a $4 \mathrm{~m} / \mathrm{s}$ na região de escoamento de ar. O jato central atravessa a região de esteira, apresentando também uma alta simetria do escoamento em torno de $x / D=0$. Há uma região de mistura intensa, produzindo uma zona recirculação. Esta recirculação também pode ser verificada pelos valores negativos de by presentes na esteira. Ao longo da linha do jato central Vy alcança cerca de $21 \mathrm{~m} / \mathrm{s}$, em $y=10 \mathrm{~mm}$ a jusante da saída, e diminui suavemente até cerca de $15 \mathrm{~m} / \mathrm{s}$, nos limites da área de medição, em $y=70 \mathrm{~mm}$.

As componentes dos tensores de Reynolds comprovam as características do escoamento tipo jato, assim como no caso 1, apresentando os maiores valores ao longo das fronteiras entre 0 jato e a esteira, $|x / D|=0,10$, onde ocorre a maior taxa de deformação e cisalhamento. Nas três componentes medidas, mostradas respectivamente nas Figuras $\mathbf{4 . 7 c , d , e , ~ o s ~ v a l o r e s ~ a o ~ l o n g o ~ d a ~ r e g i a ̃ o ~ d e ~}$ escoamento do ar $(|x / D|<0,50)$ são pequenos, cerca de $0,1 \mathrm{~m}^{2} / \mathrm{s}^{2}$. Os valores absolutos de $R x x$ e xy aumentam para $0,5 \mathrm{~m}^{2} / \mathrm{s}^{2}$ na região de esteira, enquanto que $R$ yy alcança $1 \mathrm{~m}^{2} / \mathrm{s}^{2}$ nos perfis acima da zona de recirculação, $40<y<70 \mathrm{~mm}$. O valor máximo, $10 \mathrm{~m}^{2} / \mathrm{s}^{2}$, é obtido pela componente $R$ yy na fronteira entre a esteira e o jato. Nota-se que ocorre uma diminuição nos valores destas componentes na parte central do jato, particularmente nas proximidades da superfície do queimador em $y=20 \mathrm{~mm}$, nas proximidades das fronteiras entre o jato e a esteira, pois as taxas de deformação e cisalhamento no interior do jato são praticamente nulas. A jusante de $y=20 \mathrm{~mm}$, na esteira, $0,10<|x / D|<0,50$ os valores de ambas as componentes do tensor de Reynolds aumentam gradativamente. Os resultados da Figura 4.7 comprovam que este escoamento é dominado pelo jato, sendo assim análogo ao do caso 1.

Uma análise de $R x x$ e $R$ yy mostrados na Figura 4.7c,d, permite supor que a hipótese de Boussinesq é satisfeita, assim como no caso 1, pois seus maiores 
valores correspondem à maior taxa de deformação média e, também, pela relação direta entre $R x x$ e $R y y$, verificada nas equações 23 e 24 . Em outras palavras, a anisotropia do tensor de Reynolds está ligada à taxa de cisalhamento.

A Figura 4.8 mostra a média e o RMS da fluorescência do radical $\mathrm{OH}$.
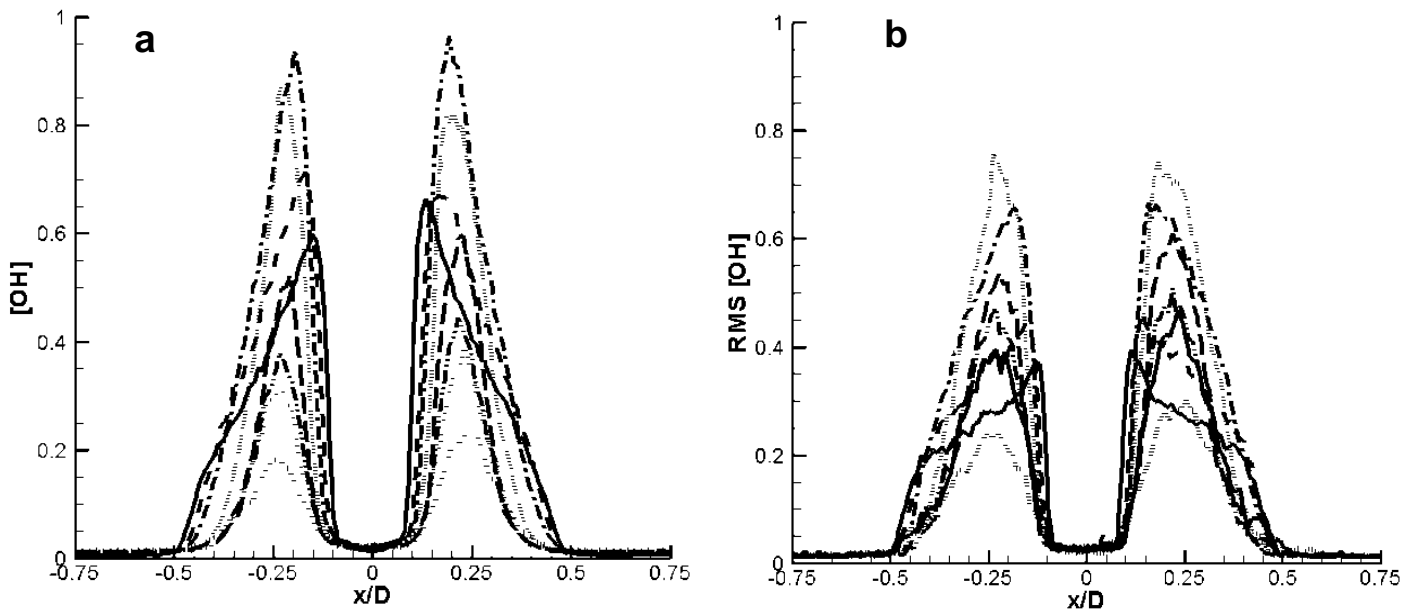

Figura 4.8. Média e RMS da fluorescência do radical $\mathrm{OH}$ do caso 3. - 10, - - -20,... 30, . . 40, - - 50, - . 60, . . $70 \mathrm{~mm}, \ldots . . .80 \mathrm{~mm}$.

Tal como mostrado na região de esteira, $0,10<|x / D|<0,50$, A frente de chama média encontra-se praticamente colada à face do queimador, como pode ser verificado pela grande intensidade relativa da média de fluorescência do $\mathrm{OH}(0,6)$, em $y=10 \mathrm{~mm}$ e, pela baixa flutuação de posição, $I_{R M S}=0,3$. Estes resultados sugerem, também, que a espessura da base da chama média ocupa quase toda a região de esteira, cerca de $20 \mathrm{~mm}$ na direção transversal. Esta espessura se mantém praticamente constante ao longo de toda a chama média de montante para jusante, diferentemente das chamas instantâneas que apresentam espessuras variáveis, sempre mais finas que a média. Os valores de intensidade de fluorescência aumentam na região de recirculação, entre $30<y<40 \mathrm{~mm}$, atingindo valores entre 0,8 e 1,0. Esta relativa homogeneidade na distribuição da fluorescência de $\mathrm{OH}$ na direção longitudinal do escoamento reflete a ausência de flutuação na altura em que a chama é ancorada. A Figura 4.8a mostra que, para $y<40 \mathrm{~mm}$, há uma queda sensível na intensidade de fluorescência do $\mathrm{OH}$, de 0,5 em $y=50 \mathrm{~mm}$ para até $0,2 \mathrm{em} \quad y=80 \mathrm{~mm}$. Nota-se também, que os resultados RMS mostrados na Figura 4.8b apresentam comportamento semelhante ao da 
média quanto à distribuição e, também, com valores máximos de $0,6<I_{R M S}<0,8$ para $30<y<40 \mathrm{~mm}$. Isto é devido às extinções, que provocam variação da posição da chama.

Estas características de chama de difusão, na qual a frente de chama separa o combustível do oxidante ao longo de toda a janela de medição, apesar de conter extinções locais, permite a modelagem utilizando modelos clássicos tais como os de elementos de chamas laminares.

\subsubsection{Análise do escoamento no caso 4}

Antes de iniciar a apresentação dos resultados obtidos no caso 4, é necessário fazer uma ressalva. Neste caso, na zona de recirculação próxima à superfície do queimador a concentração de fuligem é tal que sua intensidade luminosa, no segundo quadro de PIV, é da mesma ordem de grandeza que a da luz espalhada pelas partículas traçadoras. Assim, as imagens de partículas capturadas para calcular o campo vetorial, via PIV, foram pré-processadas a fim de reduzir o ruído devido à radiação proveniente da fuligem, conforme discutido no Capítulo 3. Entretanto, este processo não é capaz de eliminar completamente o sinal devido à fuligem, o que ocasiona a presença de vetores espúrios. Como consequência, os resultados apresentados do campo de velocidade devem ser tomados com cautela.

A chama se encontra suspensa a jusante da superfície do queimador, como mostrado na Figura 4.9. Isto indica que ocorre uma pré-mistura parcial entre reagentes. A chama se estabiliza na esteira do queimador partir do ponto de ancoramento nas proximidades das fronteiras entre o escoamento de ar, $|x / D|=0,5$. As chamas instantâneas são mostradas na Figura 4.9a,b,c. As linhas de corrente mostradas na Figura 4.9d indicam uma zona de restrição a jusante da zona de recirculação. Neste caso, a turbulência não é suficiente para causar extinções locais. A intensidade turbulenta no escoamento de ar para o caso 4 é de aproximadamente 0,11 , ou seja, $2,8 \%$ da média, em $x / D=0,75$. 

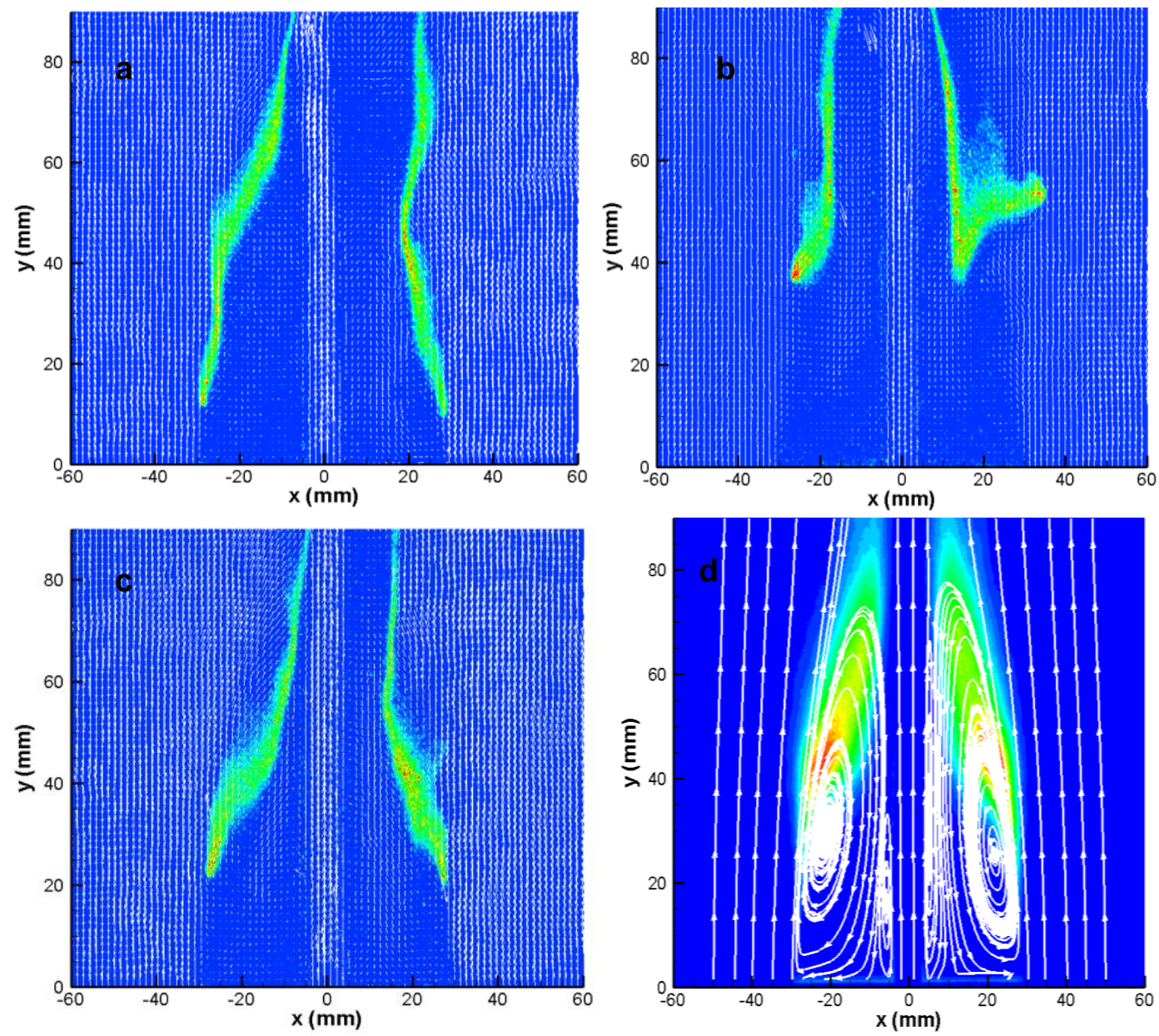

Figura 4.9. Caso 4: Projeção no plano xy: $(a, b, c)$ Vetores velocidade e fluorescência do radical $\mathrm{OH}$ instantâneos; (d) Intensidade média de fluorescência de $\mathrm{OH}$ e linhas de corrente.

As chamas instantâneas sugerem que, neste caso, a frente de chama, cuja espessura é da ordem de $5 \mathrm{~mm}$, é pouco perturbada pela interação com 0 escoamento turbulento, apresentando pequeno deslocamento lateral. Entretanto, a posição longitudinal da base da chama flutua consideravelmente, o que permite a formação de uma pré-mistura parcial de grau variável entre reagentes e produtos, com isto esta região pode conter uma mistura fora dos limites de inflamabilidade e, consequentemente, a chama é levantada. Esta chama pode ser identificada como em regime de elemento de chama, pois uma porção considerável do combustível parece atravessar a região de recirculação sem reagir, formando uma chama com características de chama de difusão. É possível notar diferenças entre a chama 
média e as chamas instantâneas, primeiro, na altura de ancoramento da chama, a qual varia de $20 \mathrm{~mm}$ para até $40 \mathrm{~mm}$ nas chamas instantâneas, sendo que na média é, obviamente, bem definida (20 mm); segundo, na espessura da chama média, a qual é maior que as instantâneas a jusante da zona de recirculação, $y>40 \mathrm{~mm}$. Isto quantifica a grande variação na posição transversal da frente de chama, $20 \mathrm{~mm}$ em média, cobrindo a região de esteira, $0,10<|x / D|<0,50$. As chamas instantâneas mostram poucos dobramentos da frente de chama. Novamente, a chama média é pouco representativa da instantânea, pois a riqueza de detalhes das chamas instantâneas é perdida pelo procedimento de média. A chama média possui uma região de intensidade média de fluorescência do $\mathrm{OH}$ maior a jusante da zona de recirculação, $\quad y>40 \mathrm{~mm}$, caracterizada pelos dois vórtices toroidais do escoamento, os quais são identificados pelas linhas de corrente na Figura 4.9d. Um destes vórtices é encontrado na fronteira entre o jato e a esteira, $|x / D|=0,10$, nas proximidades da saída do jato de combustível $(y=15 \mathrm{~mm})$ e o outro, com maior diâmetro, se encontra próximo da fronteira entre a esteira e o escoamento de ar $(|x / D|=0,50)$ e, mais a jusante do primeiro $(y=30 \mathrm{~mm})$.

Observa-se, na Figura 4.9d, que a espessura da frente de chama média aumenta de 5 para $20 \mathrm{~mm}$, quando a altura a jusante da superfície do queimador varia de 20 para $50 \mathrm{~mm}$, respectivamente. Isto é uma indicação do aumento das flutuações turbulentas que ocorrem da base para o topo da chama e caracteriza uma região de mistura turbulenta no escoamento. Nota-se, também, que a superfície de chama parece se extinguir a jusante de $y=80 \mathrm{~mm}$, indicando a possível existência de uma extinção parcial da frente de chama a jusante da janela de medição.

A figura 4.10 mostra os perfis das componentes de velocidade e tensões de Reynolds medidas para o caso 4. Esta figura mostra que há uma diferença entre a velocidade do jato e a velocidade do ar, 8 e $4 \mathrm{~m} / \mathrm{s}$, respectivamente, o que confirma que este caso é semelhante ao caso 1. Esta diferença entre a velocidade do jato e a velocidade do ar pode ser verificada na Figura 4.10b. Isto faz com que o caso 3 também apresente características de um escoamento dominado pelo jato, tal como no caso 1. A componente $V x$, Figura 4.10a, possui valores absolutos maiores na região da esteira, os quais são menores do que no caso 3. 

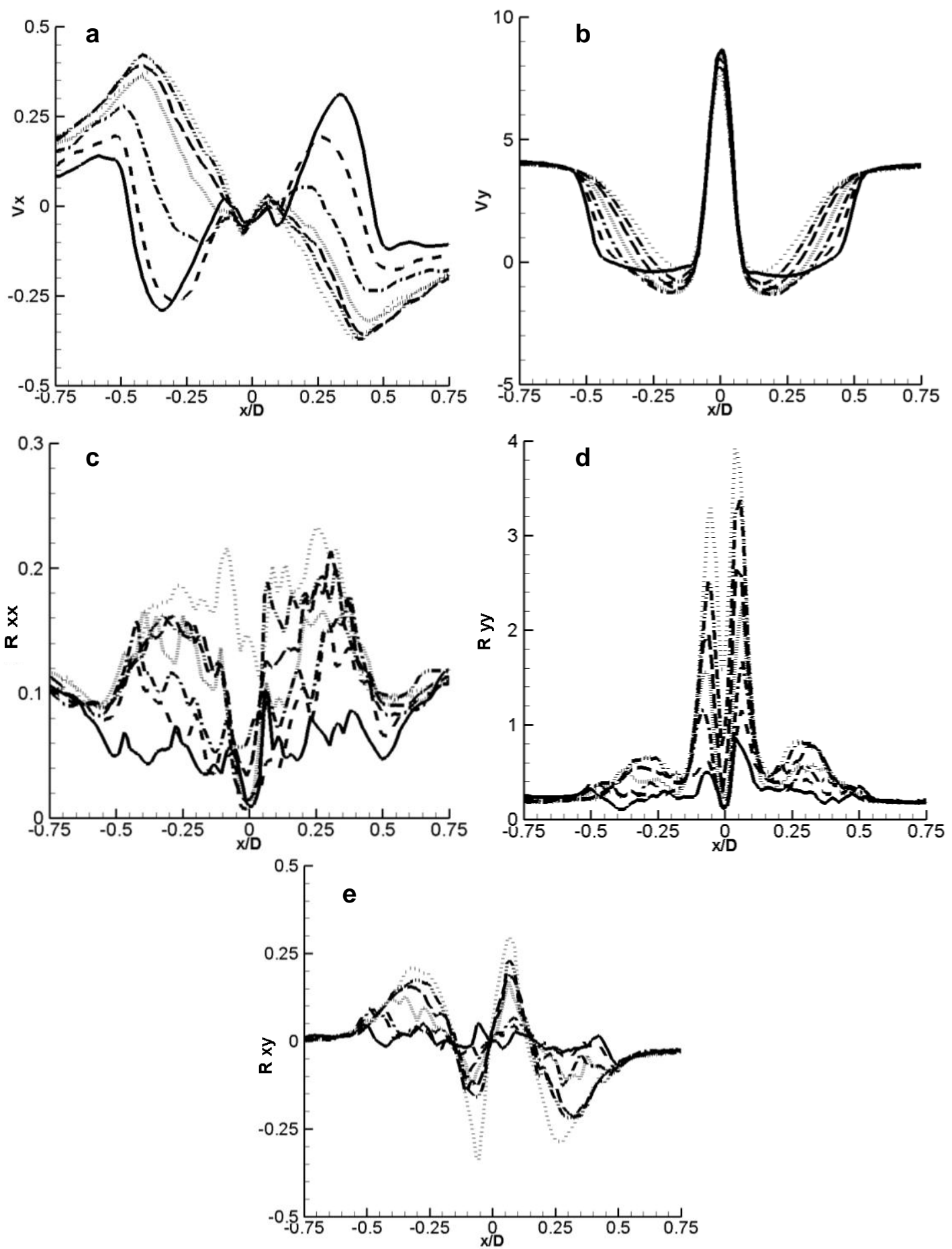

Figura 4.10. Caso 4: Evolução na direção transversal $(x)$, para posições longitudinais espaçadas de $10 \mathrm{~mm}$ a partir da superfície do queimador, das componentes longitudinal (Vy) e transversal $(V x)$ da velocidade $[\mathrm{m} / \mathrm{s}]$ e das componentes $x x, x y$ e $x y$ do tensor de Reynolds $\left[\mathrm{m}^{2} / \mathrm{s}^{2}\right]$. - 10,- - -20, . .30,- . $40,---50,-.60, \ldots 70 \mathrm{~mm}$. 
As componentes do tensor de Reynolds, $R$ yy e $R$ xy mostradas na Figura 4.10d,e, sugerem as características de um escoamento dominado pelo jato, assim como no caso 1 e no caso 3 . De fato, os maiores valores de $R$ yy ocorrem longo das fronteiras entre o jato e a esteira. Os valores das tensões de Reynolds são pequenos na região de escoamento do ar. O nível de ruído em $R x x$ é muito grande, possivelmente devido à presença de fuligem na área de medição, o que dificulta a correlação entre as imagens de partículas. Os resultados indicam que não há correlação entre $R x x$ e $R y y$, o que contraria a hipótese de Boussinesq.

A Figura 4.11 mostra a Média e RMS da fluorescência do radical OH.
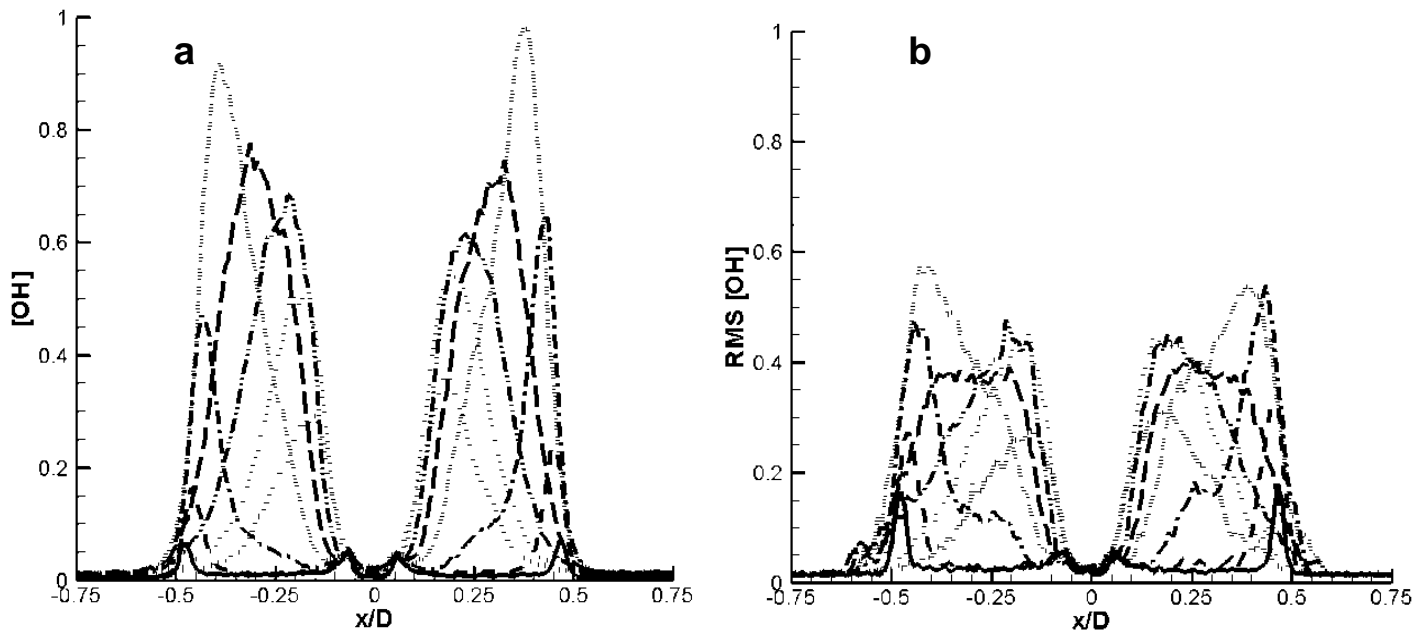

Figura 4.11. Média e RMS da fluorescência do radical OH do caso 4. - 10, - - -20,... $30,-.-40,---50,-\ldots 60, \ldots 70 \mathrm{~mm}, \ldots . . .80 \mathrm{~mm}$.

A média da intensidade de fluorescência de $\mathrm{OH}$, mostrada na Figura 4.11a, confirma que a chama é suspensa cerca de $20 \mathrm{~mm}$. O máximo valor do sinal médio de fluorescência para $y=10 \mathrm{~mm}$, na fronteira do ar com a esteira, é de cerca de 0,05. Contrariamente ao caso 3, a chama não está ancorada na superfície do queimador, logo, há tempo para que uma pré-mistura parcial entre os reagentes e produtos ocorra a montante da frente de chama. A distribuição de intensidade apresenta um aumento brusco na fluorescência do $\mathrm{OH}$ de 0,2 , em $y=30 \mathrm{~mm}$, para 1,0 em $y=40 \mathrm{~mm}$, sendo que o máximo é situado no interior da zona de recirculação média, $40<y<50 \mathrm{~mm}$. Além disso, nesta região, ocorre um aumento na espessura da frente 
de chama de $10 \mathrm{~mm}$, em média, para $20 \mathrm{~mm}$. A jusante de $y=50 \mathrm{~mm}$ a espessura e a intensidade de fluorescência tornam a diminuir, alcançando 0,3 com $10 \mathrm{~mm}$ de espessura em $y=70 \mathrm{~mm}$. Este comportamento pode estar relacionado ao estiramento aerodinâmico da chama, o qual é causado pelo escoamento mostrado na Figura 4.9d, principalmente na zona de recirculação a jusante de $y=50 \mathrm{~mm}$.

A Figura 4.11b mostra os valores RMS da intensidade de fluorescência do $\mathrm{OH}$. É notável que, para $y \leq 20 \mathrm{~mm}$, os valores RMS são maiores do que a média, o que confirma que esta região de ancoramento da chama é submetida a fortes flutuações. Mais a jusante, em $y=30 \mathrm{~mm}$, os valores RMS e médios são cerca de 0,4 e 0,6, respectivamente, o que caracteriza uma chama mais estável, com menos variação na direção transversal e, também, sem a influência das interrupções da superfície de chama, como no caso 3. Cabe lembrar que as interrupções do caso 3 , elevam os valores RMS em cerca de $30 \%$, na região mais a jusante da janela de medição, $y>60 \mathrm{~mm}$, e apresentam maior variação na direção longitudinal do que neste caso. Outra diferença entre os casos 3 e 4 é que, agora, os valores RMS parecem evoluir da fronteira entre o ar e a esteira em direção à fronteira entre a esteira e o jato, $0,5<|x / D|<0,1$, enquanto que no caso 3 os máximos valores de RMS se encontram quase sempre na mesma posição na direção transversal, $|x / D|=0,25 \pm 0,1$.

Enfim, todos os resultados apontam para uma frente de chama média com elevado grau de simetria em torno do eixo do jato central, $x / D=0$, com características de chama de difusão, a jusante de $y=40 \mathrm{~mm}$ e, com predominância do jato de combustível na estrutura do escoamento. A jusante do ponto de ancoramento a frente de chama separa o combustível e oxidante. Além disso, neste caso não há extinção local, como visto no caso 3, o que simplifica a modelagem das chamas. Por outro lado, na base da chama existe uma pré-mistura parcial, apresentando possivelmente natureza propagativa diferente da chama de difusão, na vizinhança da superfície do queimador, na qual não há chama separando o combustível do oxidante, o que a torna a chama mais difícil de modelar do que a do caso 3. 


\subsubsection{Análise do escoamento no caso 5}

A chama do caso 5, mostrada na Figura 4.12, apresenta características comuns aos dois casos reativos anteriores, 3 e 4 . A semelhança com o caso 3 é devido à interação com a turbulência do escoamento que afeta a frente de chama causando dobras importantes, com pequenos raios de curvatura, e extinções locais. Estas características dificultam a análise utilizando modelos de elementos de chama, que não são capazes de levar em conta estes dobramentos.
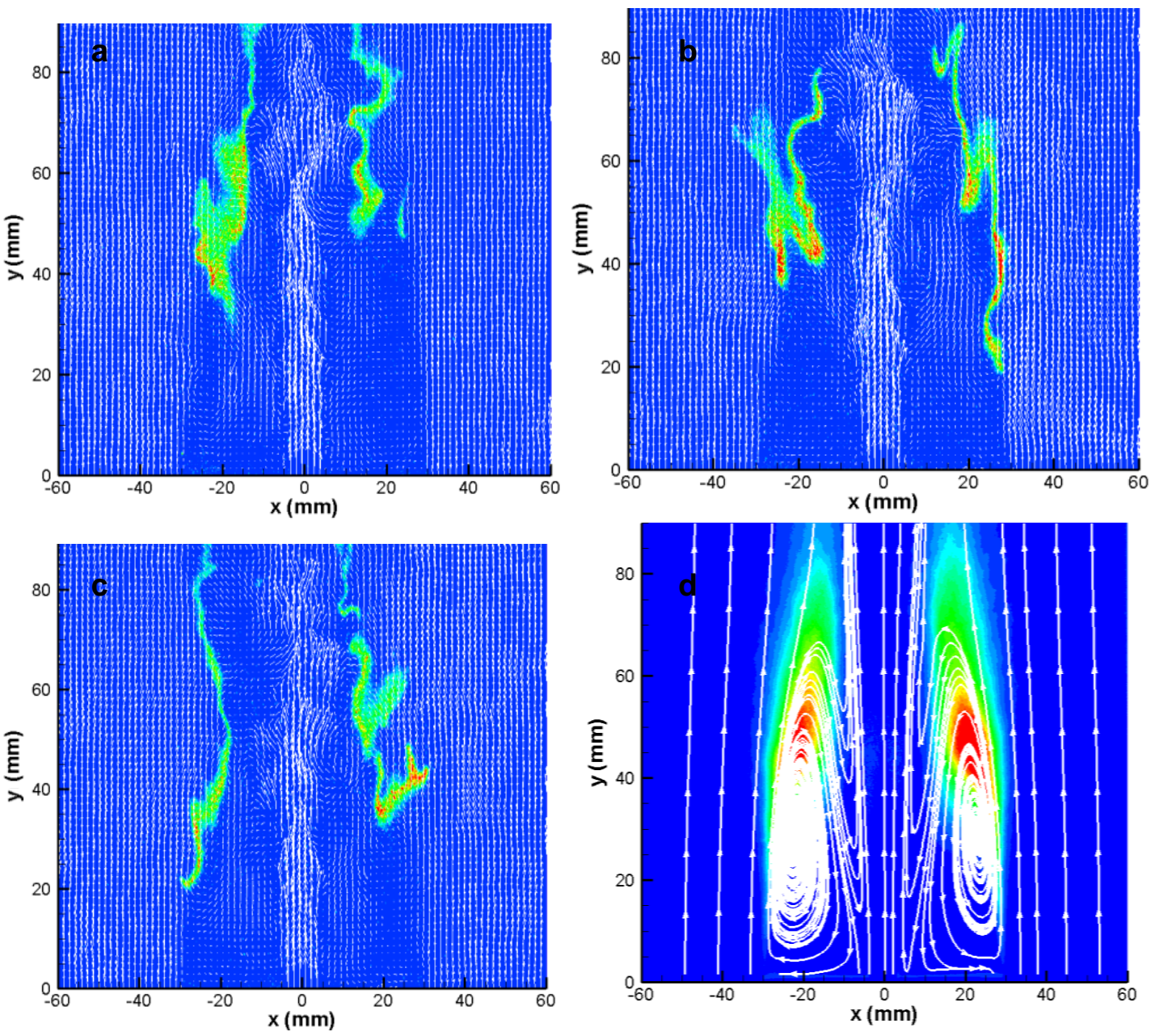

Figura 4.12. Caso 5: Projeção no plano $x y:(a, b, c)$ Vetores velocidade $e$ fluorescência do radical OH instantâneos; (d) Intensidade média de fluorescência de $\mathrm{OH}$ e linhas de corrente.

Assim como a do caso 4, esta chama é descolada, o que indica que (i) há uma formação de pré-mistura local entre reagentes e produtos antes da combustão; ou (ii) devido ao carregamento de ar pela presença da zona de recirculação forma- 
se uma mistura e ocorre um aumento na altura de ancoramento produzido pela natureza de propagação da chama. Mais a jusante $(y=50 \mathrm{~mm})$ a chama possui características de chama de difusão, onde a frente de chama separa o combustível do oxidante. Esta chama talvez (ainda) possa ser identificada como em regime de elemento de chama, pois apesar de haver uma pré-mistura parcial, uma grande porção dos reagentes atravessa a região de recirculação sem reagir, formando uma chama de difusão mais a jusante. Uma análise mais aprofundada da superfície de chama seria necessária para avaliar esta questão [12].

A chamas instantâneas mostradas na Figura 4.12a,b,c sugerem que, neste caso, a frente de chama é bastante perturbada pela interação com o escoamento turbulento, apresentando grande assimetria na direção transversal, porém, com pouco movimento lateral. A chama se estabiliza predominantemente na fronteira entre $\mathrm{o}$ ar e a esteira e evolui de montante para jusante, para a fronteira entre a esteira e o jato. Além disso, a posição longitudinal da base da chama também flutua (menos do que no caso 4) cerca de $10 \mathrm{~mm}$. É possível notar diferenças entre a chama média e as chamas instantâneas, tal como a altura de ancoramento da chama, a qual varia entre $20 \mathrm{~mm}$ e $40 \mathrm{~mm}$ nas chamas instantâneas, enquanto a média está suspensa cerca de $30 \mathrm{~mm}$. Neste caso, alguns detalhes das chamas instantâneas são perdidos no cálculo da chama média, assim como visto no caso 3 e 4. A espessura da chama média, de até $20 \mathrm{~mm}$, é maior que os $5 \mathrm{~mm}$ das chamas instantâneas. A maior espessura média é encontrada a jusante da zona de recirculação, a qual se encontra situada entre $30<y<40 \mathrm{~mm}$, como mostram as linhas de corrente na Figura 4.12d. Este aumento na espessura ocorre devido a variação da posição da frente de chama na região de esteira e, também, pelo dobramento da frente de chama instantânea. A chama média cobre a região de esteira, $0,10<|x / D|<0,50$, em $40<y<60 \mathrm{~mm}$. Neste caso, a intensidade turbulenta é de aproximadamente 0,13 que equivale a $1,5 \%$ da velocidade média, na região $|x / D|=0,75$.

A evolução de $V x$ e $V y$ é similar àquela obtida no caso 4, conforme pode ser visto na Figura 4.13. Esta figura mostra os perfis das componentes de velocidade e tensões de Reynolds medidas para o caso 5. Os resultados mostram uma diferença entre a velocidade do jato e a velocidade do ar, 20 e $8 \mathrm{~m} / \mathrm{s}$, respectivamente, o que confirma que este caso é semelhante ao caso 1. 

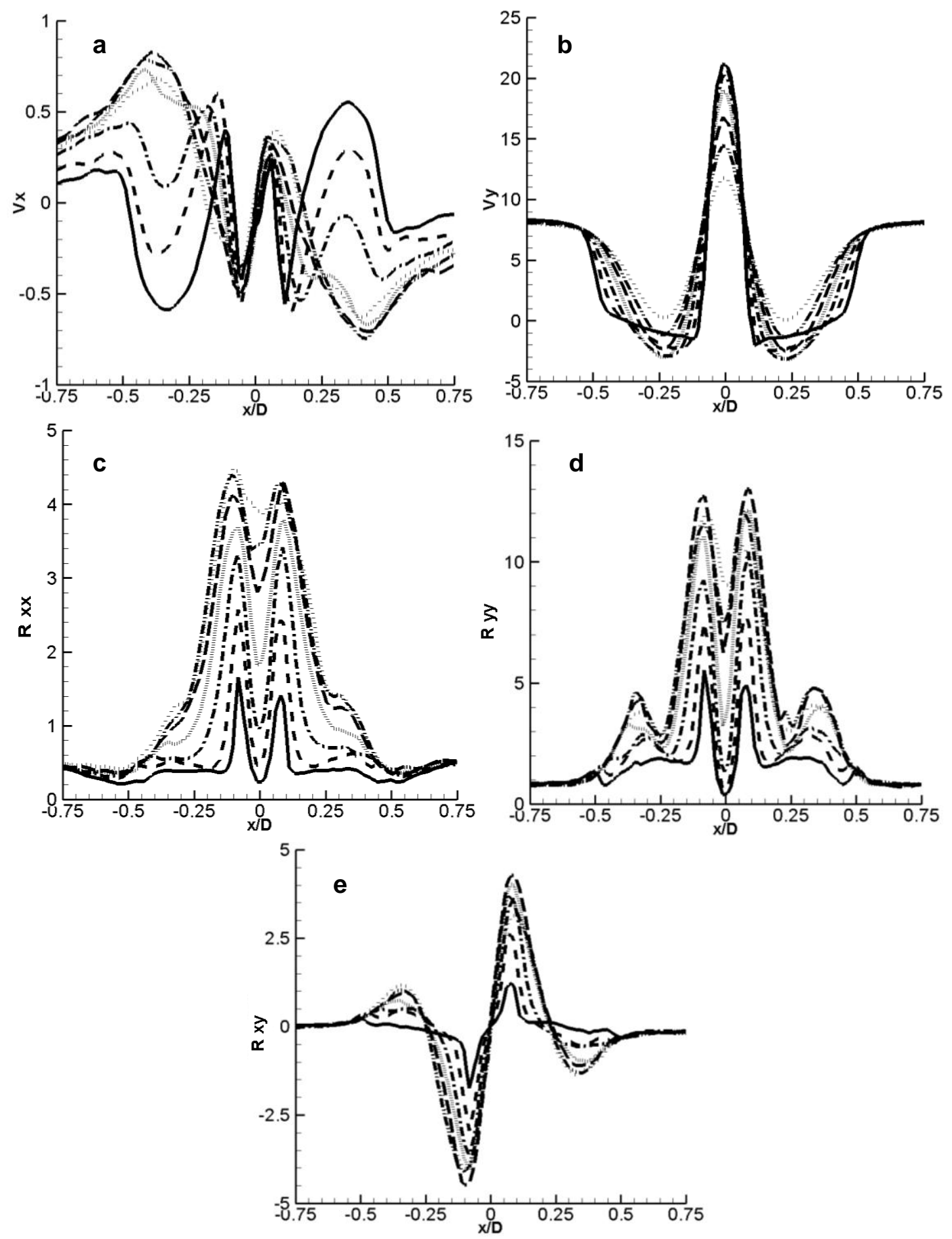

Figura 4.13. Caso 5: Evolução na direção transversal $(x)$, para posições longitudinais espaçadas de $10 \mathrm{~mm}$ a partir da superfície do queimador, das componentes longitudinal (Vy) e transversal $(V x)$ da velocidade [m/s] e das componentes $x x$, yy e $x y$ do tensor de Reynolds $\left[\mathrm{m}^{2} / \mathrm{s}^{2}\right]$. - 10, - -20, . 30,- . $40,---50,-.60, \ldots 70 \mathrm{~mm}$. 
$\mathrm{Na}$ fronteira entre a esteira e o jato ocorrem as maiores variações para ambas as componentes, de montante para jusante ao longo de toda a área de medição. Nota-se, novamente, uma alta simetria em torno de $x / D=0$. Os valores de $V x$, neste caso, são maiores que nos casos reativos precedentes, onde $V y$ do ar e do jato de combustível assume valores de 8 e $20 \mathrm{~m} / \mathrm{s}$, respectivamente. A componente $V y$ diminui suavemente de $22 \mathrm{~m} / \mathrm{s}$ em $y=10 \mathrm{~mm}$ para $12 \mathrm{~m} / \mathrm{s} \mathrm{em}$ $y=70 \mathrm{~mm}$ no jato. $\mathrm{O}$ jato de combustível atravessa a região de esteira sem apresentar ponto de estagnação.

As componentes $R x x, R y y$ e $R x y$ do tensor de Reynolds, mostradas na Figura 4.13c,d,e, apresentam um comportamento do escoamento dominado pelo jato, característicos dos casos 1 e 3 . Porém, os valores medidos são maiores, atingindo até o dobro dos valores no caso 1. Os máximos valores das tensões de Reynolds, neste caso, ocorrem próximos às fronteiras entre a esteira e o jato, $|x / D|=0,1$, onde a taxa de deformação é maior, conforme poderia ser esperado pela hipótese de Boussinesq. Uma diferença marcante entre o caso 5 e o caso 1 pode ser notada quando esta figura é comparada com a Figura 4.2. Na região de esteira os valores das componentes do tensor de Reynolds são maiores, em particular para $R x y$, entre $0,25<|x / D|<0,50$, ligeiramente a jusante da zona de recirculação, isto é $y=60 \mathrm{~mm}$. Isto ocorre, devido a flutuação da posição da chama produzida pela interação com a turbulência.

A isotropia do tensor de Reynolds parece ser afetada pela presença de chama, a qual, ao variar de posição, produz flutuações no escoamento devido à variação na densidade dos gases causada pelo aumento da temperatura. Isto produz um divergente de velocidade flutuante e, consequentemente, modifica os valores dos tensores de Reynolds na região de esteira, $0,25<|x / D|<0,45$, principalmente, na vizinhança do ponto de estabilização da chama, $y \leq 30 \mathrm{~mm}$. Assim, a intermitência do ancoramento da chama, em $20<y<40 \mathrm{~mm}$ na região de esteira, afeta significativamente os valores das tensões de Reynolds, principalmente a componente $R$ yy. Esta componente apresenta um máximo local de $13 \mathrm{~m}^{2} / \mathrm{s}^{2}$, em $|x / D|<0,1$, coincidente com a zona de máxima luminosidade de $\mathrm{OH}$ que se encontra cerca de $50 \mathrm{~mm}$ a jusante da superfície do queimador. Note-se, também, que nesta 
região de maior $R$ yy ocorre a máxima taxa de deformação, indicada pelo maior módulo de gradiente, ou seja, pela variação de $V y$ na direção $y$, a qual é de $3 s^{-1}$ na região entre $50<y<60 \mathrm{~mm}$, como era de se esperar segundo a hipótese de Boussinesq. Se comparada com os casos 3 e 4, a taxa de deformação também é maior na região de esteira, de 2 e $0,5 \mathrm{~s}^{-1}$, para $|x / D|<0,30$, entre $50<y<60 \mathrm{~mm}$, onde também são observados maiores valores para a componente $R x y= \pm 4 \mathrm{~m}^{2} / \mathrm{s}^{2}$, o que confirma a validade da hipótese de Boussinesq.

A Figura 4.14 mostra a Média e RMS da fluorescência do radical $\mathrm{OH}$.
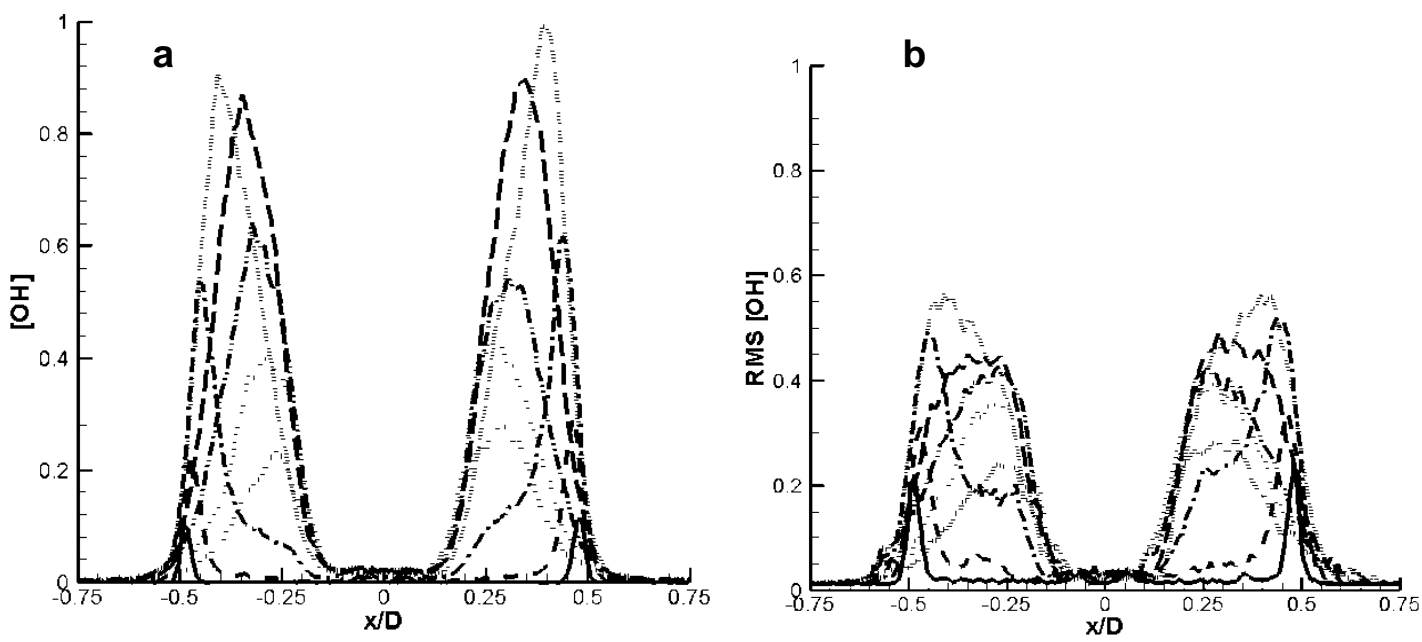

Figura 4.14. Média e RMS da fluorescência do radical $O H$ do caso 5. - 10, - - -20,... $30,-.40,---50,-.60, \ldots 70 \mathrm{~mm}, \ldots . . .80 \mathrm{~mm}$.

A intensidade média do sinal de fluorescência de $\mathrm{OH}$ na vizinhança da base do queimador é de 0,2 em $y=20 \mathrm{~mm}$ a jusante da superfície do queimador, na fronteira entre o ar e a esteira, $0,4<|x / D|<0,5$. Como no caso 4 , a chama média se estabiliza nas fronteiras entre o escoamento de ar e a esteira, evoluindo de montante para jusante para a fronteira entre a esteira e o jato, $|x / D|=0,1$ em $y>50 \mathrm{~mm}$. A distribuição da fluorescência do radical $\mathrm{OH}$ indica que a frente de chama turbulenta média encontra-se numa posição mais a jusante do que no caso 3 , cuja média de intensidade do $\mathrm{OH}$ é de aproximadamente 0,6 em $y=10 \mathrm{~mm}$, e semelhante ao caso 4 , cuja intensidade média é de 0,2 em $y=20 \mathrm{~mm}$. Isto caracteriza o descolamento vertical médio da frente de chama turbulenta. Além disto, o sinal de fluorescência do $\mathrm{OH}$ se intensifica de montante para jusante até 
atingir valores entre 0,8 e 1,0 na região entre $40<y<50 \mathrm{~mm}$, para em seguida diminuir suavemente para 0,2 em $y>80 \mathrm{~mm}$. Observa-se que a espessura da frente de chama média, aumenta de $5 \mathrm{~mm}$ para cerca de $20 \mathrm{~mm}$ quando a altura varia de 20 para $50 \mathrm{~mm}$, respectivamente, como visto no caso 4 .

A Figura 4.14b mostra que os valores RMS da intensidade de fluorescência do $\mathrm{OH}$, assim como no caso 4, são maiores do que a média para $y \leq 20 \mathrm{~mm}$, o que confirma que esta região de ancoramento da chama é submetida a fortes flutuações. Os valores RMS e médios são cerca de 0,4 e 0,6, em $y=30 \mathrm{~mm}$, o que caracteriza uma região de chama mais estável, com pouca variação na direção transversal e, também, com menos influência das interrupções, do que no caso 3. Os maiores valores de flutuação, entre 0,5 e 0,6, ocorrem principalmente na região entre $40<y<60 \mathrm{~mm}$ por toda a esteira, $0,1<|x / D|<0,5$. Os valores RMS parecem evoluir de montante para jusante, a partir da fronteira entre o ar e a esteira em direção à fronteira entre a esteira e o jato, na direção transversal em $0,5<|x / D|<0,1$, assim como no caso 4. Isto indica que a chama muda de posição dentro da região da esteira, de montante para jusante no escoamento.

\subsubsection{Análise do escoamento no caso 6}

A estrutura de cada uma das chamas instantâneas correspondentes ao caso 6, mostradas na Figura 4.15a,b,c, apresenta grandes diferenças entre si, assim como em comparação com a média. Estas modificações da estrutura da frente de chama são resultados característicos da interação com um intenso campo turbulento de velocidade. As chamas instantâneas são suspensas entre 20 e $50 \mathrm{~mm}$ a jusante da superfície do queimador, o que evidencia a existência de que a prémistura parcial entre os reagentes e produtos pode ser mais extensa do que nos casos anteriores. As frentes de chama instantâneas apresentam espessura variável, de 5 até $30 \mathrm{~mm}$. Diferentemente dos casos 4 e 5 , quase não são notadas características de chama de difusão nas chamas instantâneas. Isto pode ser afirmado devido à maior extensão transversal das zonas em que o $\mathrm{OH}$ se encontra presente neste caso. Regiões cujo raio de curvatura é da mesma ordem de grandeza do que a espessura média são aparentes. As chamas instantâneas também mostram sinais de interrupção, extinções locais que sugerem a existência de regiões onde o combustível e ar se misturam em ausência de combustão. A 
Figura 4.15 apresenta uma chama média descolada da base do queimador, a qual possui uma grande região de pré-mistura, cerca de $40 \mathrm{~mm}$, o dobro de extensão em relação aos casos 4 e 5 . Assim, a estrutura da chama apresenta diferenças, porém é análoga aos demais casos. A imagem média da chama também permite notar que este caso apresenta um comportamento de pluma a jusante de $y=70 \mathrm{~mm}$. A superfície da chama média é mais espessa que nos casos anteriores devido à grande variação da estrutura interna das frentes de chamas instantâneas e à presença de descontinuidades. A Figura 4.15d mostra as linhas de corrente, as quais revelam que existem duas zonas de recirculação. A zona de recirculação principal está centrada em $y=40 \mathrm{~mm}$ e $20 \mathrm{~mm}$ a jusante se situa a região de máxima intensidade de $\mathrm{OH}$. Acredita-se que, a temperatura aumenta o empuxo que favorece a continuação do jato além da esteira.
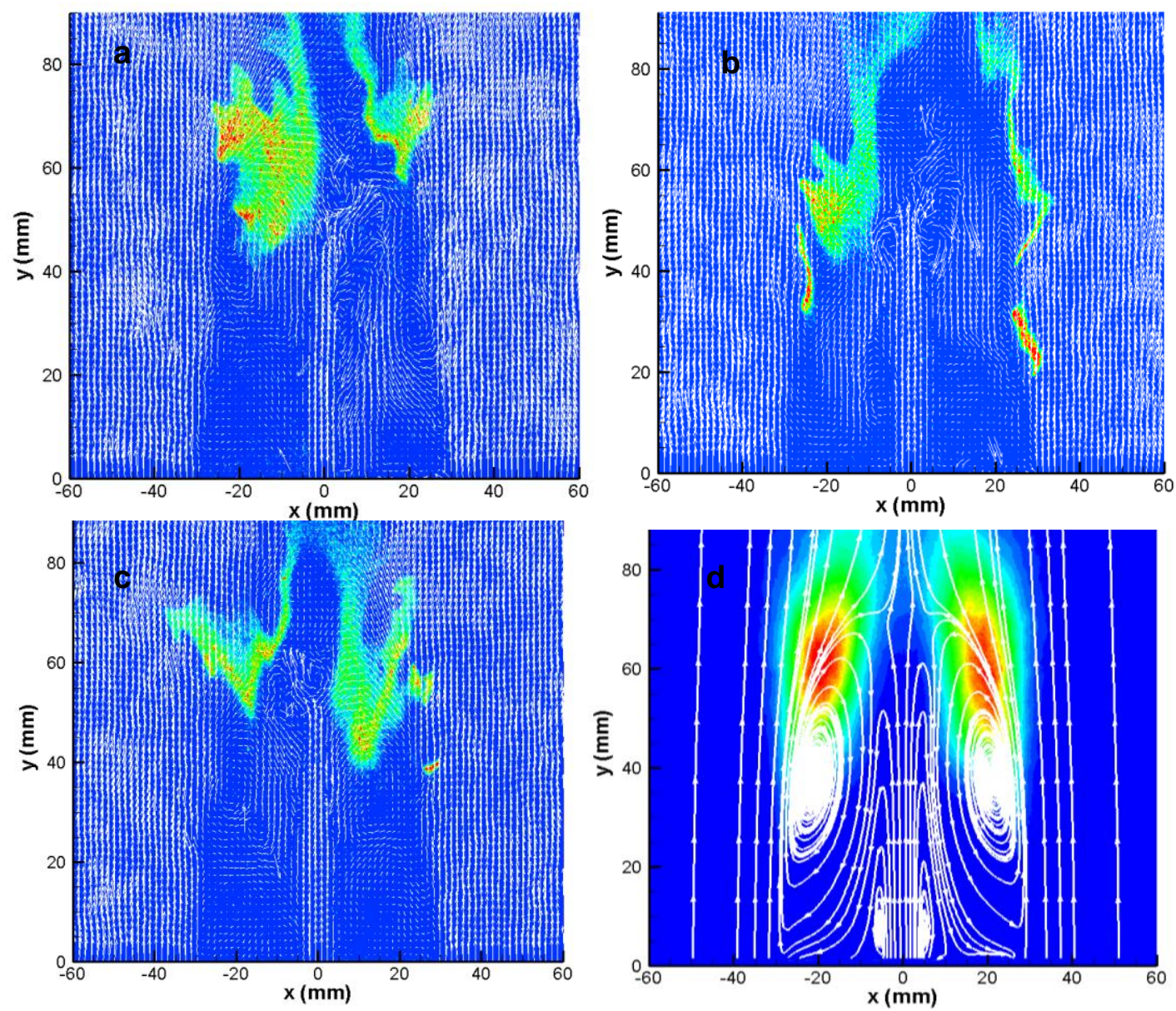

Figura 4.15. Caso 6: Projeção no plano xy: $(a, b, c)$ Vetores velocidade e fluorescência do radical $\mathrm{OH}$ instantâneos; (d) Intensidade média de fluorescência de $\mathrm{OH}$ e linhas de corrente. 

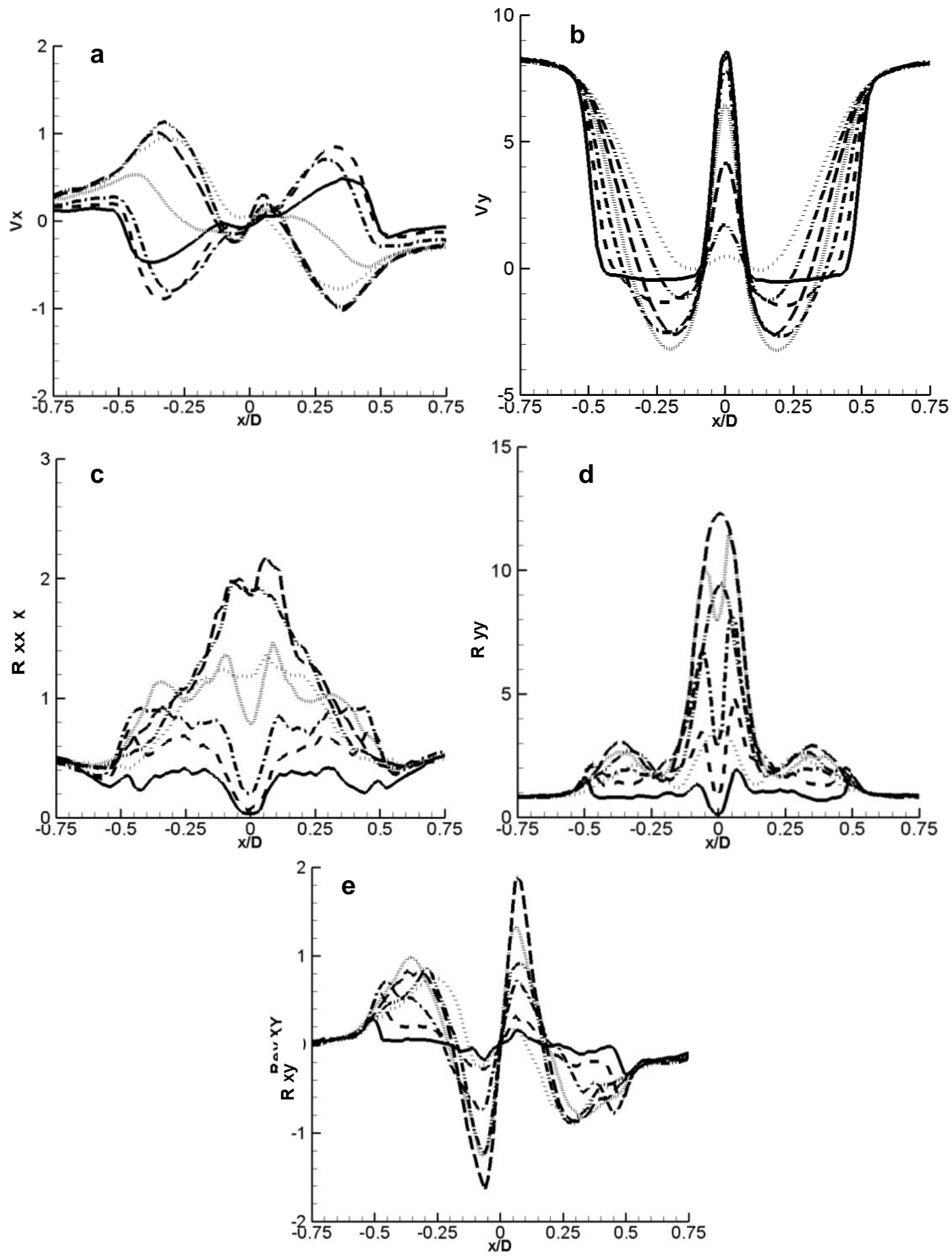

Figura 4.16. Caso 6: Evolução na direção transversal ( $x$ ), para posições longitudinais espaçadas de $10 \mathrm{~mm}$ a partir da superfície do queimador, das componentes longitudinal (Vy) e transversal $(V x)$ da velocidade [m/s] e das componentes $x x$, yy e $x y$ do tensor de Reynolds $\left[\mathrm{m}^{2} / \mathrm{s}^{2}\right] .-10,--20, \ldots 30,-$ $40,---50,-\cdots 60, \cdots 70 \mathrm{~mm}$. 
A figura 4.16 mostra os perfis das componentes de velocidade e tensões de Reynolds medidas para o caso 6 . Esta figura mostra que não há diferença entre a velocidade do jato e a velocidade do ar, 8 e $8 \mathrm{~m} / \mathrm{s}$, respectivamente, o que confirma que este caso é semelhante ao caso 2.

As Figura 4.16a,b mostram que a evolução das componentes da velocidade média, $V x$ e $V y$, é similar àquela obtida nos casos 4 e 5 , no que diz respeito às maiores variações em seus valores. Este caso corresponde aos maiores valores estudados de velocidade $V y$ do ar, porém, de menor velocidade do jato de combustível, ambos de $8 \mathrm{~m} / \mathrm{s}$. Variações bruscas de ambas as componentes de velocidade medidas ocorrem na fronteira entre a esteira e o jato, de montante para jusante ao longo de toda a área de medição. Os máximos valores de $V x$, neste caso, são ainda maiores que nos casos reativos precedentes, cerca de 1,2 m/s. Na região do jato a componente $V y$ diminui suavemente de $8 \mathrm{~m} / \mathrm{s}$ em $y=10 \mathrm{~mm}$ para praticamente zero em $y=70 \mathrm{~mm}$, considerando a incerteza da medição. Assim sendo, o jato de combustível é interrompido nesta região, apresentando um ponto de estagnação, vide Figura 4.5f.

Uma análise das componentes do tensor de Reynolds mostradas nas Figuras 4.16c,d,e comprova a maior complexidade do escoamento neste caso. Os maiores valores da componente $R x y$ ocorrem ao longo das fronteiras entre o jato $\mathrm{e}$ a esteira, assim como visto nos casos 2 e 4 . Os maiores valores estão nas fronteiras do jato com a esteira, a partir de $y>40 \mathrm{~mm}$, onde $R x x=2 \mathrm{~m}^{2} / \mathrm{s}^{2}$, $R y y=12 \mathrm{~m}^{2} / \mathrm{s}^{2}$ e $R x y=2 \mathrm{~m}^{2} / \mathrm{s}^{2}$. Os valores de todas as tensões de Reynolds medidas são menores, neste caso, em comparação com o caso 5 ao longo região de esteira e, também, na fronteira com o jato. Nota-se, também, que ocorre uma diminuição ao longo da direção transversal nos valores das tensões, $R x x$ e $R$ yy na parte central do jato, a montante de $y=50 \mathrm{~mm}$. Nesta ordenada ocorre a interrupção do jato. Os valores das tensões de Reynolds $R x x, R$ yy e $R$ yy aumentam a jusante desta região, na fronteira do jato e ao longo de toda linha de centro. $O$ comportamento das tensões de Reynolds, deste caso, também apresenta valores maiores na região de esteira, quando comparado com o caso 2 , quimicamente inerte, mais especificamente em $0,25<|x / D|<0,50$, a jusante de $y=50 \mathrm{~mm}$. O máximo 
valor da derivada de $V y$ na direção de $y$, cerca de - $250 \mathrm{~s}^{-1}$, é situado nas proximidades da saída do jato em $40<y<60 \mathrm{~mm}$, portanto, a maior taxa de deformação ocorre onde são obtidos os maiores valores de $R y y, 12 \mathrm{~m}^{2} / \mathrm{s}^{2}$, o que está de acordo a hipótese de Boussinesq. O mesmo acontece para $R x y$ nas fronteiras entre o escoamento do jato e a esteira. A tendência observada na região de esteira, principalmente para a componente $R x y$, contraría a hipótese de Boussinesq. Em $0,25<|x / D|<0,50$, ocorre uma variação gradativa de $V y$ na direção transversal devido à recirculação e à estabilização da chama. Portanto, são esperados valores pequenos das tensões de Reynolds na região de esteira, ao contrário do que ocorre de fato, como pode ser verificado nas Figuras 4.16c,d,e, em $y=40 \mathrm{~mm}$, onde $R x x=1 \mathrm{~m}^{2} / \mathrm{s}^{2}, R \quad y y=3 \mathrm{~m}^{2} / \mathrm{s}^{2}$ e $|R x y|=1 \mathrm{~m}^{2} / \mathrm{s}^{2}$.

Turbulência também é gerada em $0,3<|x / D|=0,45$ a partir da instabilidade do ponto de ancoramento da chama, a qual apresenta um comportamento de chama do tipo borda (edge flame) [49]. Em consequência, a intensa flutuação da chama torna o escoamento turbulento anisotrópico e o regime de combustão parece ser o de efeitos transientes [49]. Na região de escoamento de ar, $|x / D|=0,75$, a intensidade turbulenta é de aproximadamente 0,10 que equivale a $1,2 \%$ da velocidade média. Um exame mais aprofundado da estrutura da chama requer um processamento avançado das imagens instantâneas de forma a obter medidas de quantidades significativas, tais como a espessura, a densidade de superfície de chama, além de uma análise através de funções densidade de probabilidade. Esta análise está fora do escopo deste estudo.

A fim de realizar uma caracterização completa do escoamento, estudos futuros pretendem empregar a técnica de PIV estéreo, a qual permite obter resultados em 3D, a fim de produzir informações mais completas, isto é, os seis componentes do tensor de Reynolds. Assim, será possível calcular as componentes da anisotropia [50]. 
A Figura 4.17 mostra a Média e RMS da fluorescência do radical $\mathrm{OH}$.
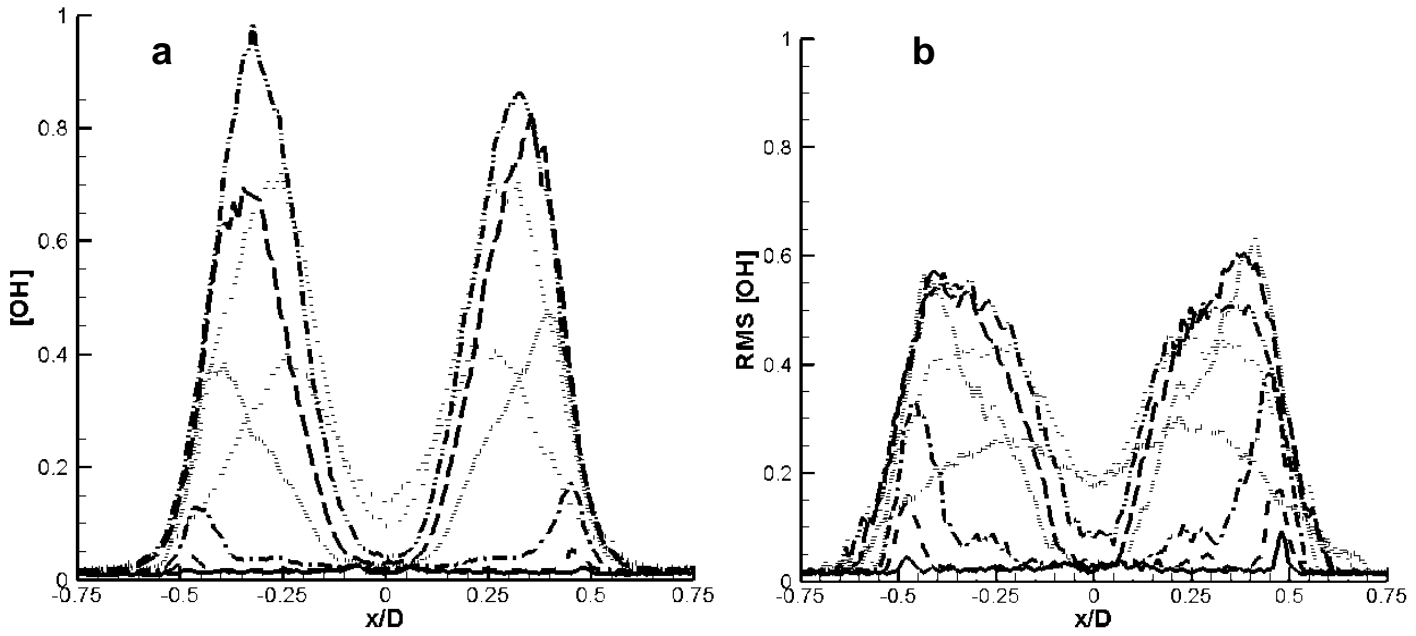

Figura 4.17. Média e RMS da fluorescência do radical $\mathrm{OH}$ do caso 6. - 10, - -20,... 30, . - 40, - - - 50, -..60, . . $70 \mathrm{~mm}, \ldots . . .80 \mathrm{~mm}$.

A Figura 4.17a, indica que a frente de chama é praticamente inexistente até $y=40 \mathrm{~mm}$, pois a intensidade de fluorescência média de $\mathrm{OH}$ não ultrapassa 0,1 . A base da chama se estabiliza nas fronteiras entre 0 ar e a esteira e a zona de reação encontra-se mais a jusante do queimador que nos casos 4 e 5 , isto é, até $y=80 \mathrm{~mm}$, onde a intensidade relativa é de 0,4 . O maior valor relativo de intensidade de fluorescência ocorre em $y=60 \mathrm{~mm}$, onde a espessura da frente de chama, cerca de $25 \mathrm{~mm}$, ocupa toda região de esteira. A jusante desta região a chama tende a se deslocar em direção ao jato, com menor espessura média, 10 $\mathrm{mm}$, como nos casos 4 e 5 . Além disso, a intensidade diminui em cerca de $50 \%$, de montante para jusante, ou seja, de 0,9 em $y=60 \mathrm{~mm}$ para 0,4 em $y=80 \mathrm{~mm}$.

A Figura 4.17b mostra que os valores RMS da intensidade de fluorescência do $\mathrm{OH}$, assim como no caso 4 e 5 , são maiores do que a média para $y \leq 30 \mathrm{~mm}$, o que confirma que a região de ancoramento da chama é submetida a flutuações ainda mais fortes que nos casos anteriores. Os valores RMS parecem evoluir, de montante para jusante, a partir da fronteira entre $\mathrm{o}$ ar e a esteira em direção à fronteira entre a esteira e o jato, assim como nos casos 4 e 5, o que indica que a chama muda de posição dentro da região da esteira, de montante para jusante no escoamento. Estes valores aumentam de $0,1 \mathrm{em} \quad y=20 \mathrm{~mm}$ para até $0,6 \mathrm{em}$ 
$50<y<70 \mathrm{~mm}$ e, tornam a diminuir para $0,2 \mathrm{em} y=80 \mathrm{~mm}$. Isto indica que a chama ocupa a região acima do ponto de estagnação do jato e, também, que sua posição varia além da esteira devido a turbulência. Note-se que, apenas neste caso, há presença de chama entre $70<y<80 \mathrm{~mm}$, na região do jato, $|x / D|<0,1$ e também, na região de escoamento de $\operatorname{ar},|x / D|>0,5$, entre $30<y<70 \mathrm{~mm}$, conforme mostram os resultados de intensidade média $(0,1)$, e de RMS $(0,2)$.

\subsubsection{Evolução na linha central, casos reativos}

Nos casos reativos 3, 4, 5 e 6, os resultados da evolução ao longo da linha central $(x / D=0)$ assumem comportamentos semelhantes aos casos quimicamente inertes detalhados na seção 4.1.4. No caso 3, Figura 4.5c, Vy passa por uma queda suave de 21 para cerca de $19 \mathrm{~m} / \mathrm{s}$ em aproximadamente $y=40 \mathrm{~mm}$, a partir desta altura o valor da velocidade continua com uma queda mais acentuada, chegando a aproximadamente $10 \mathrm{~m} / \mathrm{s}$ em $y=90 \mathrm{~mm}$. Este comportamento confere ao escoamento a predominância do jato central, assim como visto no caso 1. As componentes dos tensores de Reynolds $R x x$ e $R$ yy possuem a mesma tendência vista no caso 1 , isto é, os valores das tensões aumentam conforme a derivada em relação a y de Vy diminui, seguindo a hipótese de Boussinesq. Os valores máximos

de $R x x$ e de $R$ yy atingem cerca de $3 \mathrm{~m}^{2} / \mathrm{s}^{2}$ e $7 \mathrm{~m}^{2} / \mathrm{s}^{2}$, respectivamente, em $y=80 \mathrm{~mm}$.

No caso 4, Figura 4.5d, a componente $V y$ apresenta uma tendência de queda suave em seu valor, ou seja, a velocidade do jato na saída do queimador é de aproximadamente $9 \mathrm{~m} / \mathrm{s}$ e diminui apenas para $7 \mathrm{~m} / \mathrm{s}$ em $y=90 \mathrm{~mm}$. A componente $R x x$ é praticamente nula ao longo de toda janela de medição e a componente $R$ yy aumenta com o decréscimo da derivada de $V y$ em relação a $y, 0$ que estaria de acordo com a hipótese de Boussinesq. $R$ yy atinge $4 \mathrm{~m}^{2} / \mathrm{s}^{2}$ em $y=90 \mathrm{~mm}$. 
No caso 5, Figura 4.5e, é muito semelhante ao caso 3, alterando apenas os valores. Desta forma, Vy cai para 21 para cerca de $18 \mathrm{~m} / \mathrm{s}$ em $y=40 \mathrm{~mm}$, a partir dai o valor da velocidade continua a diminuir, porém, com maior intensidade, chegando a aproximadamente $8 \mathrm{~m} / \mathrm{s}$ em $y=90 \mathrm{~mm}$. O comportamento do escoamento neste caso é dominado pelo jato central, assim como no caso 1. As componentes dos tensores de Reynolds $R x x$ e $R$ yy possuem a mesma tendência crescente com a redução da derivada em relação a $y$ de $v y$, vista nos casos anteriores. Isto satisfaz a hipótese de Boussinesq. Os valores de $R x x$ atingem cerca de $4 \mathrm{~m}^{2} / \mathrm{s}^{2}$, enquanto que $R$ yy chega a valores próximos a $10 \mathrm{~m}^{2} / \mathrm{s}^{2}$, em $y=70 \mathrm{~mm}$, diminuindo para $7 \mathrm{~m}^{2} / \mathrm{s}^{2}$, em $y=90 \mathrm{~mm}$.

O caso 6, Figura 4.5f, apresenta um comportamento similar ao caso 2. Neste caso, o valor de $V y$ é reduzido de cerca de 8 para $5 \mathrm{~m} / \mathrm{s}$ em aproximadamente $40 \mathrm{~mm}$, a partir da qual a tendência de queda se torna acentuada. Em $y=70 \mathrm{~mm} 0$ valor de by pode ser considerado como zero, dentro da incerteza experimental das medidas, confirmando a existência de um ponto de estagnação no escoamento e indicando a posição da zona de mistura média entre o jato e o escoamento de ar anular sobre a linha de centro. A jusante desta região ocorre um comportamento semelhante ao de pluma. A evolução dos componentes do tensor de Reynolds a montante deste ponto $(y=20 \mathrm{~mm})$ está de acordo com a hipótese de Boussinesq, a jusante de $y=70 \mathrm{~mm}$, ou seja, os valores das componentes $R x x$ e $R$ yy possuem uma tendência em aumentar conforme o gradiente de $V y$ diminui. Isto acontece particularmente para a componente Ryy, a qual assume valores de $13 \mathrm{~m}^{2} / \mathrm{s}^{2}$, principalmente nas proximidades de $y=50 \mathrm{~mm}$. Porém, o valor do módulo da derivada de $V y$ aumenta após $y=80 \mathrm{~mm}$, enquanto, as tensões de Reynolds $R x x$ e $R y y$, ambos de $1 \mathrm{~m}^{2} / \mathrm{s}^{2}$, permanecem constantes, a jusante de $y=70 \mathrm{~mm}$, remetendo ao caso 2, onde a hipótese de Boussinesq não é valida. 


\subsection{Coeficiente de correlação}

A avaliação do grau de associação entre as duas variáveis é realizada por meio do coeficiente de correlação, que na presente seção é aplicado a quantidades turbulentas [50]. Nesta etapa do trabalho serão utilizados os valores de $R x x=\overline{V_{1}^{\prime 2}}$, $R y y=\overline{V_{2}^{\prime 2}} \quad \mathrm{e} \quad R x y=\overline{V_{1}^{\prime} V_{2}^{\prime}}$ para determinar o coeficiente de correlação das componentes flutuantes da velocidade,

$$
\rho_{12}=\frac{\overline{V_{1}^{\prime} V_{2}^{\prime}}}{\left[\overline{V_{1}^{\prime 2}} \overline{V_{2}^{\prime 2}}\right]^{1 / 2}}=\frac{R_{x y}}{\left[R_{x x} R_{y y}\right]^{1 / 2}}
$$

Note-se que $-1 \leq\left|\rho_{12}\right| \leq 1$. Valores positivos do coeficiente de correlação indicam que excursões positivas, a partir da média de $V_{1}$, são preferencialmente associadas com excursões positivas de $V_{2}$, e vice-versa. Inversamente, se excursões positivas de $V_{1}$ forem preferencialmente associadas com valores negativos de $V_{2}$, o coeficiente de correlação é negativo. Quando $\left|\rho_{12}\right|=1, V_{1}^{\prime}$ e $V_{2}^{\prime}$ são perfeitamente correlacionados, se $\left|\rho_{12}\right|=0$, estas flutuações não exibem correlação.

O coeficiente de correlação é apresentado na Figura 4.18 ao longo do eixo $x$ para $y=10,20,30,40,50,60$ e $70 \mathrm{~mm}$. Esta figura apresenta a evolução de $\rho_{12}$ para cada um dos casos abordados na Tabela 2. A análise dos resultados é realizada, principalmente, nas regiões de fronteira entre $o$ jato e a esteira e, também, entre a esteira e o escoamento de ar, as quais se encontram nos intervalos de $5<x<15 \mathrm{~mm}$ e $20<x<35 \mathrm{~mm}$, respectivamente.

Uma primeira análise destas figuras mostra que, em todos os casos, $\rho_{12}$ exibe um bom grau de simetria, em torno de $x=0$, para $y \geq 20 \mathrm{~mm}$. Assim, na discussão a seguir será realizada apenas para valores de $x$ positivos. Ademais, como o caso 4 exibe valores de $\rho_{12}$ demasiadamente ruidosos, este caso não será considerado na discussão. 
Caso 1

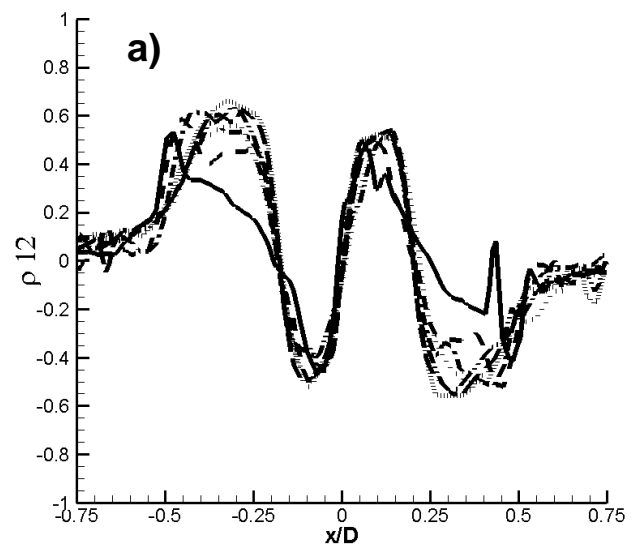

Caso 2

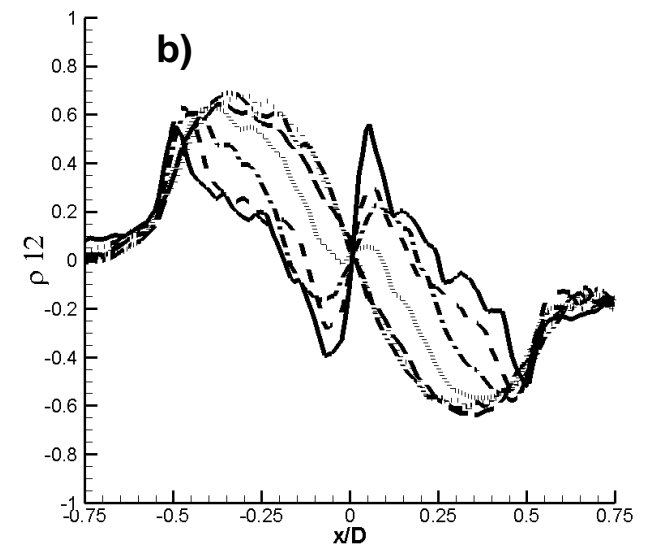

Caso 3

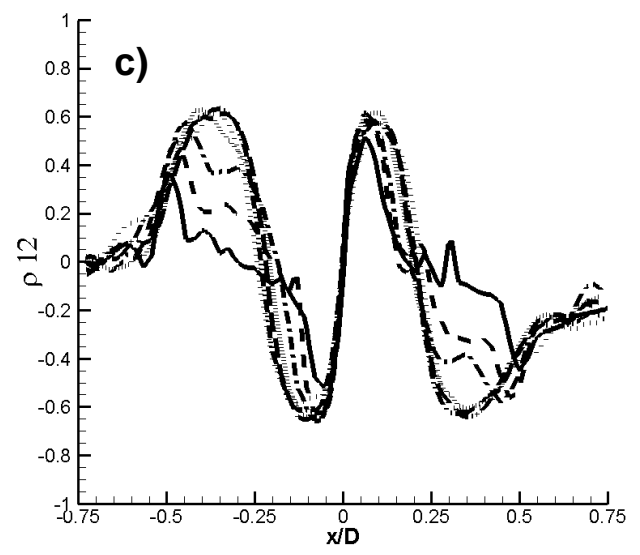

Caso 4

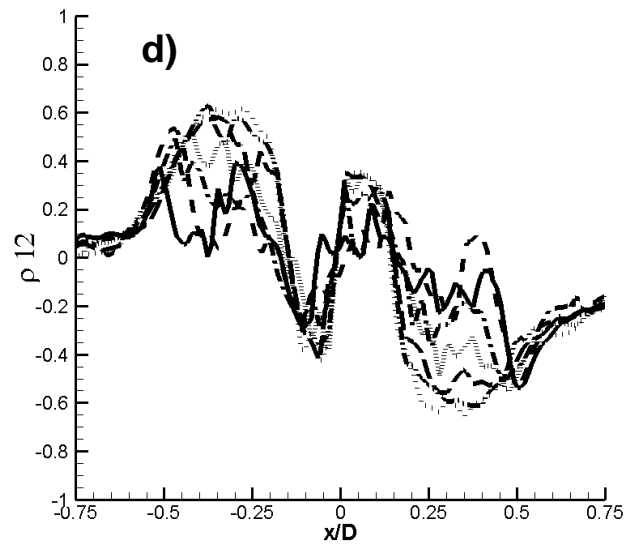

Caso 5

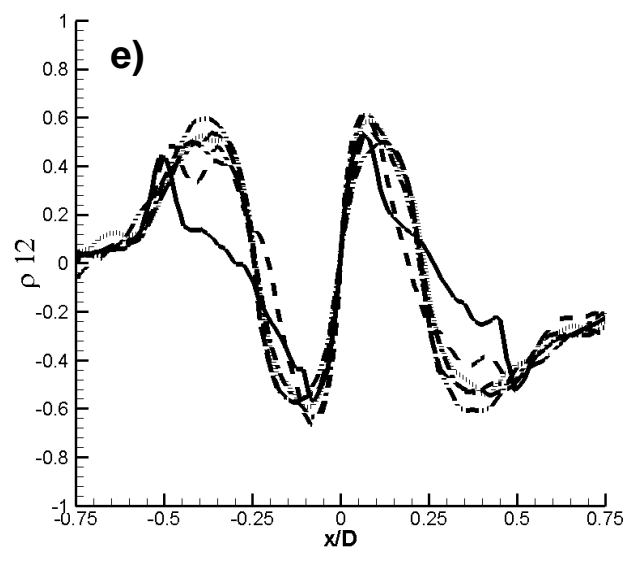

Caso 6

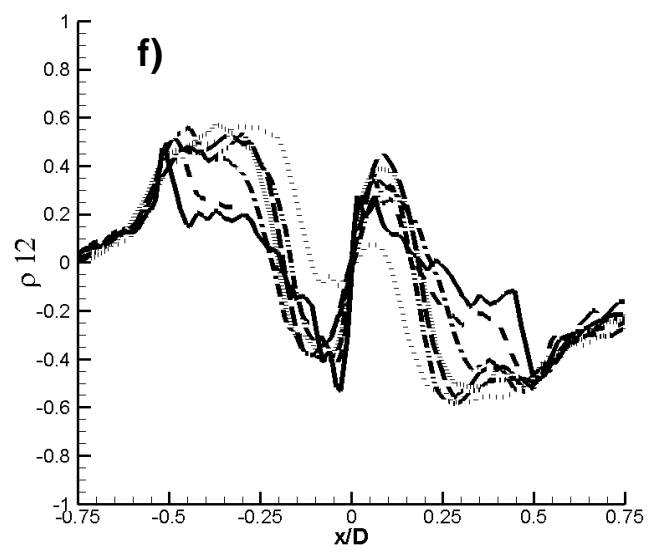

Figura 4.18. Valores do coeficiente de correlação, $\rho_{12}$, para os sete cortes transversais extraídos a jusante da superfície do queimador. -10, - -20, . 30, - $40,---50,-.60, \ldots 70 \mathrm{~mm}$. 
Conforme visto na seção 4.1, a turbulência não é homogênea, pois os gradientes de velocidade não são uniformes em ambas as direções. Um campo estatisticamente homogêneo é estatisticamente invariante sob translação do sistema de coordenadas [50]. Neste contexto, um campo estatisticamente homogêneo e invariante sob rotações e reflexões do sistema de coordenadas é, também, um campo estatisticamente isotrópico. Neste tipo de campo $\rho_{12}=0$. A hipótese de Boussinesq relaciona o desvio da distribuição isotrópica de energia do movimento turbulento à taxa de deformação média, conforme visto nas equações 23-26. Portanto, variações da taxa de deformação média sugerem desvios à isotropia da turbulência no escoamento e, em particular, da covariância. Assim, $\rho_{12}$ é uma outra forma de caracterizar a anisotropia do escoamento turbulento.

No caso 1, mostrado na Figura 4.18a, o coeficiente de correlação na região de escoamento de ar, $x / D>0,6$ é de $\rho_{12} \leq 0,1$. Este valor indica uma quase independência entre as flutuações dos componentes da velocidade e, logo, um escoamento turbulento praticamente homogêneo e isotrópico. A partir da região de ar, quando $x$ diminui, $\rho_{12}$ decresce até atingir um mínimo local de $-0,6$, em $x / D \sim 0,3$, para, em seguida, aumentar até $0,6 \mathrm{em} x / D \sim 0,15$. À medida que se aproxima do eixo $x=0, \rho_{12}$ volta a cair até 0 . Este comportamento e os valores medidos são notavelmente similares para todas as alturas $(y \geq 20 \mathrm{~mm})$, não sendo possível distinguir as curvas dentro do erro experimental. Assim, valores de $\rho_{12}$ positivos correspondem à vizinhança do jato, enquanto que $\rho_{12}$ negativos indicam a região de esteira, que constitui uma camada de mistura entre o ar e o jato. Este comportamento é a superposição de dois comportamentos clássicos de jato e de camada cisalhante [50]. A única exceção a este comportamento situa-se e $x / D \sim 0,3$ e $y \leq 30 \mathrm{~mm}$, onde se observa uma supressão da correlação entre $V_{1}^{\prime}$ e $V_{2}^{\prime}$. A origem deste comportamento não foi elucidada e será objeto de investigação em trabalhos futuros. Os valores do coeficiente de correlação aumentam nas regiões onde a taxa de deformação média é grande, isto é, onde o escoamento se distancia da homogeneidade, o que é condizente com a validade da hipótese de Boussinesq.

No caso 2, mostrado na Figura 4.18b, o coeficiente de correlação na região de escoamento de ar, $x / D>0,6$ é de $\rho_{12} \leq 0,1$. Assim como no caso 1 , este valor indica uma quase independência entre as flutuações dos componentes da velocidade $e$ escoamento homogêneo e isotrópico. Para $y=10 \mathrm{~mm}$, a partir da região de ar, 
quando $x$ diminui, $\rho_{12}$ decresce até atingir um mínimo local de $-0,6$, em $x / D \sim 0,5$, isto é, na camada de cisalhamento entre o ar e a zona de recirculação para em seguida aumentar até 0,5 em $x / D \sim 0,1$ na região do jato. Nesta região, o valor de $\rho_{12}$ diminui de montante para jusante passando por 0,3 para $20<y<30 \mathrm{~mm}$ até que o máximo local desaparece. Este desaparecimento coincide com aquele do jato, descrito na seção 4.3.1. O comportamento de $\rho_{12}$, neste caso, é bastante diverso daquele discutido para o caso 1, o que poderia ser esperado neste escoamento dominado pela esteira do corpo rombudo. A similitude observada para $y \geq 20 \mathrm{~mm}$ no caso 1 desaparece neste caso, que exibe uma evolução do comportamento de $\rho_{12} \operatorname{com} y$. De montante para jusante o valor extremo negativo de $\rho_{12}$ diminui (aumenta em módulo) até atingir -0,6. Este comportamento corrobora a maior importância, neste caso, da camada cisalhante formada na periferia do corpo rombudo. De maneira semelhante ao caso $1, \rho_{12}$ cai até zero à medida que se aproxima do eixo $x=0$.

Nos casos 3 e 5, mostrados nas Figuras 4.18c,e, o coeficiente de correlação apresenta um comportamento em tudo semelhante do caso 1. Note-se que estes casos são reativos, enquanto que o caso 1 é quimicamente inerte. Os valores extremos de $\rho_{12}$ e suas posições, em relação aos medidos no caso 1 , são praticamente inalterados em presença de combustão, nos casos 3 e 5.

Os resultados obtidos no caso 6 são mostrados na Figura 4.18f. Novamente, o coeficiente de correlação na região de escoamento de $\operatorname{ar}, x / D>0,6$ é de $\rho_{12} \leq 0,1$. Um exame dos resultados na região de recirculação indica que este caso contém ingredientes dos casos 1 e 2. A partir da região de ar, quando $x$ diminui, $\rho_{12}$ decresce até atingir um mínimo local de $-0,5$, em $x / D \sim 0,5$, para em seguida aumentar até $0,3 \mathrm{em} x / D \sim 0,1$ para $y=10 \mathrm{~mm}$. Este comportamento é semelhante ao do caso 1 . De maneira semelhante ao caso $1, \rho_{12}$ volta a cair até zero à medida que se aproxima do eixo $x=0$. Na região de jato o valor máximo de $\rho_{12}$ situa-se entre 0,3 e 0,4 para $y \leq 60 \mathrm{~mm}$, decrescendo somente, para 0,1 , em $y=70$ $\mathrm{mm}$. Nota-se que, para $\mathrm{y} \geq 20 \mathrm{~mm}$ o comportamento dos valores de $\rho_{12}$ passa a se assemelhar com 0 do caso 2. Na periferia do corpo rombudo, $0,25 \leq|x / D| \leq 0,5$, 0 comportamento de $\rho_{12}$ é mais complexo do que nos casos anteriores, parecendo exibir dois mínimos. A origem deste comportamento deveria ser analisada à luz das correlações entre as flutuações de velocidade e a luminescência de $\mathrm{OH}$, o que será explorado em estudos futuros. 


\section{Conclusões e perspectivas}

Neste trabalho foram apresentados resultados da caracterização de chamas turbulentas de gás natural e ar em uma situação na qual os reagentes encontram-se inicialmente não pré-misturados. As chamas estudadas foram estabilizadas a jusante de um queimador do tipo corpo rombudo, o qual é representativo de condições industriais e disponibiliza amplo acesso óptico para realização de experimentos empregando técnicas de diagnóstico laser. Para realização deste estudo foram implementadas modificações na instalação do queimador desde o trabalho precedente [28], visando obter uma melhoria na homogeneidade do escoamento de ar e, também, maior segurança na linha de abastecimento de combustível. O presente trabalho é o primeiro a realizar medidas simultâneas de PIV e PLIF em chamas no Brasil.

As principais vantagens da utilização destas técnicas ópticas é que, além de serem não-intrusivas, produzem como resultados imagens de alta resolução e baixa incerteza. Os resultados obtidos pelo emprego dessas técnicas permitiram a visualização da frente de chama instantânea, representada pela fluorescência do radical $\mathrm{OH}$, obtida por PLIF, sobreposta pela estrutura detalhada do escoamento, materializada pelo campo vetorial de velocidade, medido por PIV.

A pesquisa bibliográfica realizada mostrou os trabalhos nos quais as técnicas de diagnóstico laser em combustão foram aplicadas, a fim de medir um ou mais escalares, simultaneamente com velocidade. Estas medições envolveram diversos tipos de queimadores e câmaras de combustão, pré-misturadas ou não. Estas medidas foram realizadas em um ou mais planos de interesse e a reconstrução dessas informações produziram resultados em até três dimensões. Além disso, recentemente foram utilizados equipamentos com alta taxa de captura, de até $5 \mathrm{kHz}$, para medição do campo de velocidade simultaneamente à medição de um escalar. Medidas em alta taxa de captura permitiram examinar a evolução temporal das estruturas da chama. Devido a limitações de energia dos equipamentos laser esta medição se faz em áreas, de $60 \mathrm{~mm}^{2}$, menores do que as técnicas de baixa taxa de captura, da ordem de $100 \mathrm{~cm}^{2}$. Os resultados buscam descrever não somente a estrutura do escoamento reativo e os dois primeiros momentos estatísticos das propriedades aerotermoquímicas medidas, mas também a evolução da função densidade de probabilidade destas propriedades e de suas 
quantidades derivadas como, os tensores vorticidade ou taxa de deformação, taxa de estiramento, estruturas tridimensionais e mapeamento de gases não queimados.

A revisão bibliográfica também indicou que a medição simultânea de $\mathrm{OH}$ e $\mathrm{CH}$ permitiu estudar o movimento das estruturas de grandes escalas, cujos vórtices desempenham papel fundamental nas extinções locais da chama. Além disso, a comparação entre imagens de fluorescência de $\mathrm{OH}$ e $\mathrm{CH}$ realizadas simultaneamente mostraram que as estruturas de $\mathrm{CH}$ exibem uma correlação mais forte que as de $\mathrm{OH}$ com respeito às variações no escoamento resultantes da liberação de calor. Por outro lado, estudos paramétricos dos efeitos da turbulência no transporte escalar mostraram que os máximos de fluorescência de $\mathrm{OH}$ exibem uma forte correlação com a superfície de estequiometria da chama, o que faz da fluorescência do $\mathrm{OH}$ um marcador de frente de chama. Além disso, foram obtidas informações importantes sobre os mecanismos de estabilização das chamas descoladas, como a correlação entre a presença de $\mathrm{OH}$ e os máximos de vorticidade, indicando a ação do cisalhamento na zona de reação. Estes resultados experimentais mostraram diferentes tipos de interação entre 0 escoamento turbulento e a combustão, entre os fenômenos físicos envolvidos estão a deformação, a curvatura, o dobramento, o estiramento e a extinção da chama. Estes regimes e os seus limites fornecem informações importantes para o desenvolvimento de modelos.

No presente estudo, as maiores dificuldades em implementar a técnica óptica PIV, em escoamentos com chama, são aquelas associadas (i) à radiação emitida pela fuligem, que polui a imagem e (ii) à expansão dos gases, que dificulta 0 controle da dispersão das partículas traçadoras. A calibração do PIV foi realizada através da comparação com resultados obtidos com a técnica de anemometria de fio quente, e também com resultados de cálculos da velocidade a partir da vazão medida, visando obter bons níveis de confiança das medidas com PIV. O mesmo não foi feito para a técnica PLIF, porque é necessário empregar métodos de calibração para obter medidas de concentração de $\mathrm{OH}$, tais como o uso de tolueno como traçador ou como a comparação com resultados de simulação numérica de uma chama laminar simples (por exemplo, chama plana). Os resultados de fluorescência do $\mathrm{OH}$ foram utilizados apenas para identificar a frente de chama, com o intuito de visualizar a estrutura da chama e estudar sua interação com o escoamento. 
A análise das incertezas envolvidas nas medições foi apresentada detalhadamente. A quantificação da incerteza nas medições de cada técnica foi realizada a partir da contribuição de cada fonte de incerteza envolvida nas metodologias, as quais foram propagadas visando obter um resultado global para a incerteza da medição. No caso dos escoamentos com combustão, as incertezas das medições de velocidade e de fluorescência de $\mathrm{OH}$, associadas à medições em casos inertes e reativos com a técnica PIV são de 3\% e 6\%, e de $25 \%$ para PLIF.

A caracterização do escoamento foi realizada para casos quimicamente inertes e reativos correspondentes a diferentes condições de vazão do jato central e de ar no experimento. O estudo da estrutura do escoamento realizado nos dois casos quimicamente inertes, nos quais o jato central é composto de Nitrogênio, permitiu antecipar alguns dos comportamentos das propriedades turbulentas observadas quando da presença de combustão. Os casos foram escolhidos por representarem diferentes situações na região de recirculação, dos quais um é dominado pelo jato e no outro ocorre a predominância do escoamento de ar. Os resultados das medições foram analisados à luz da hipótese de Boussinesq, isto é, o mecanismo de conexão entre a taxa de deformação média e o tensor de Reynolds. Em particular, o desvio em relação à isotropia das componentes da diagonal principal do tensor de Reynolds foi examinado, mostrando que esta hipótese poderia ser aplicada quando o escoamento é dominado pelo jato, mas possivelmente não quando este é bloqueado na esteira do queimador.

Nos casos reativos estudados, onde o jato central é composto de gás natural, foram abordados os regimes de combustão não pré-misturados, entre eles: a chama do tipo jato; chamas suspensas com pré-mistura parcial, em regime de elemento de chama; e a chama na qual a intensa turbulência do escoamento afeta a estabilização, produzindo um regime de efeitos transientes importantes. As imagens instantâneas da frente de chama permitem notar que, com o aumento da turbulência, as chamas apresentam uma grande variação em sua estrutura interna e ocorrem descontinuidades na frente de chama e, consequentemente, a interpenetração dos reagentes e produtos na ausência de combustão. Estas características dificultariam a simulação numérica deste tipo de chama. Os resultados também permitem verificar que a curvatura de frente de chama instantânea está relacionada ao aumento da espessura da região onde $\mathrm{OH}$ é encontrado em média. O aumento da velocidade de ar anular causa o aumento da 
altura de ancoramento da chama a partir da superfície do queimador. Isto acarreta uma pré-mistura parcial dos reagentes com o combustível. Além disso, foram observadas diferentes características da chama, isto é, a pré-mistura parcial dos reagentes, a variação da altura de ancoramento da chama, a aparente separação entre combustível e oxidante por parte da frente de chama, como se espera em uma chama de difusão.

As imagens médias de fluorescência do $\mathrm{OH}$ possibilitaram identificar a região do escoamento onde a chama se estabiliza e fornecem uma indicação da superfície estequiométrica. As imagens médias de PLIF-OH mostram que o aumento da vazão do combustível é acompanhado de um progressivo alongamento da região central da frente de chama. Assim, o escoamento se torna dominado pelo jato central e, consequentemente, a chama se estabiliza nas proximidades da fronteira entre o jato e a esteira. A análise da chama média permitiu verificar a posição em que a chama tende a se estabilizar e a altura média de ancoramento. Os valores de RMS da fluorescência de $\mathrm{OH}$ indicaram a flutuação da frente de chama, tanto na posição quanto na intensidade.

Os resultados do campo vetorial de velocidade do escoamento permitiram verificar que na maioria dos escoamentos estudados o jato central predomina devido a sua maior quantidade de movimento, quando comparado com 0 escoamento de ar. Nestes casos, o jato central atravessa a região de esteira, onde há um vórtice toroidal que produz uma mistura intensa entre os reagentes. Em apenas um caso o escoamento é dominado pela esteira, onde também ocorre um vórtice toroidal e, logo a jusante, a interrupção do jato que cria um ponto de estagnação. O comportamento das componentes do tensor de Reynolds medidas neste trabalho também permitiu caracterizar as situações em que o escoamento é dominado pelo jato ou pela esteira, dependendo se os maiores valores destas componentes são encontrados na fronteira entre o jato e a esteira ou entre o ar e a esteira, respectivamente. Além disso, a análise desses resultados com base na direção longitudinal do escoamento, ou seja, de montante para jusante, indicou características do processo de transporte turbulento.

Notou-se que resultados dos casos reativos são semelhantes aos inertes, no que se refere ao comportamento da estrutura do escoamento com base na análise dos resultados de tensões de Reynolds. Além disso, a evolução da componente longitudinal da velocidade, $V y$, e das componentes longitudinal $R$ yy e transversal 
$R x x$ dos tensores de Reynolds foi analisada ao longo da linha de centro, em $x / D=0$, a fim de complementar a discussão dos resultados. Nos casos em que o escoamento é dominado pelo jato a hipótese de Boussinesq parece ser satisfeita, ou seja, os valores das componentes do tensor de Reynolds possuem uma tendência em aumentar conforme a taxa de deformação diminui (aumenta em valor absoluto). Apenas em algumas condições, particulares das regiões mais complexas do escoamento, quando ocorre interrupção do jato, é que os valores de $R x x$ e $R$ yy não apresentam correlação entre si e as tensões de Reynolds não acompanham a tendência da taxa de deformação, contrariando assim a hipótese de Boussinesq. Por exemplo, o valor máximo da derivada de $V y$ na direção de $y$, cerca de $-250 s^{-1}$, medido no caso 6 nas proximidades da saída do jato em $40<y<60 \mathrm{~mm}$, é também onde foram medidos os maiores valores de $R y y, 12 \mathrm{~m}^{2} / \mathrm{s}^{2}$, o que está de acordo com a hipótese de Boussinesq. Por outro lado, a tendência observada na região de esteira (neste caso 6), principalmente para a componente $R x y$, contraria a hipótese de Boussinesq. Em $0,25<|x / D|<0,50$ ocorre uma variação gradativa de $V y$ na direção transversal devido à recirculação e à estabilização da chama. Portanto, são esperados valores pequenos das tensões de Reynolds na região de esteira, ao contrário do que ocorre em $y=40 \mathrm{~mm}$, onde os valores são relativamente altos, $R x x=1 \mathrm{~m}^{2} / \mathrm{s}^{2}, \quad R y y=3 \mathrm{~m}^{2} / \mathrm{s}^{2}$ e $|R x y|=1 \mathrm{~m}^{2} / \mathrm{s}^{2}$, devidos à grande flutuação da posição da frente de chama e em sua estrutura, o que acarreta em alterações da densidade dos gases e, consequentemente, na variação da velocidade. Nos casos onde a hipótese de Boussinesq não é suficiente para descrição do transporte turbulento um modelo de transporte dos tensores de Reynolds deve ser considerado.

O coeficiente de correlação das flutuações de velocidade medidas na região de escoamento de $\operatorname{ar}(x / D>0,6)$ é de $\rho_{12} \leq 0,1$ para todos os casos estudados. Assim, este valor indica uma quase independência entre as flutuações dos componentes da velocidade, típicas de escoamento homogêneo e isotrópico. O comportamento apresentado na maioria dos casos é a superposição de dois comportamentos clássicos, de jato e de camada cisalhante. Os valores de $\rho_{12}$ medidos na vizinhança do jato são positivos, enquanto que na região de esteira os valores de $\rho_{12}$ são negativos, o que indica que esta é uma camada de mistura entre o ar e o jato. Nos 
casos dominados pelo jato os valores do coeficiente de correlação aumentam nas regiões onde o módulo da taxa de deformação média é grande, consequentemente, onde o escoamento se distancia da homogeneidade. Nos casos 2 e 6, em que a esteira do corpo rombudo predomina sobre o jato, os valores de $\rho_{12}$ são negativos.

Espera-se que, os resultados apresentados possibilitem a validação de novos modelos computacionais destinados à realização de simulações numéricas através dos quais seria possível caracterizar a chama em diferentes regimes de combustão. Porém, o desenvolvimento de novos modelos requer uma compreensão mais aprofundada da estrutura da chama, principalmente para os casos mais complexos, onde a hipótese de Boussinesq falha, através do estudo da espessura da frente de chama, da densidade de superfície de chama e de suas funções densidade de probabilidade.

A utilização simultânea de PLIF e PIV realizada neste trabalho deve ser seguida, em trabalhos futuros, de uma exploração mais exaustiva dos diferentes regimes de combustão e da caracterização de chamas obtidas a partir de outros combustíveis, inclusive líquidos, como os trabalhos que estão sendo desenvolvidos em paralelo a este, os quais utilizam o Etanol, combustível que é proveniente de fontes renováveis, e o Hidrogênio cujos produtos da queima não são poluentes. A fluorescência de outros radicais, tais como o $\mathrm{CH}$ e o $\mathrm{NO}$, pode ser medida fazendo uso do mesmo aparato experimental, trocando-se apenas o corante do laser e o filtro da câmera. Além disso, as medidas de velocidade podem ser realizadas em duas dimensões e aplicada uma reconstrução a fim de obter a terceira dimensão, através do emprego da técnica PIV estéreo, também disponível no sistema existente no laboratório. Isto permite uma análise mais completa pela determinação dos nove componentes do tensor de Reynolds no plano de interesse. Assim, será possível calcular as componentes da anisotropia, as quais são de fundamental importância nas simulações numéricas, por permitirem avaliar um escoamento de forma global.

Ademais, podem ser realizadas alterações no preparo dos experimentos utilizando diferentes vazões e outros tipos de queimador, como os que trabalham com pré-mistura de reagentes, ou aqueles em que combustível e ar encontram-se em escoamento contra-corrente. Pode-se também desenvolver um experimento de calibração da técnica PLIF a fim de obter medidas de concentração do radical $\mathrm{OH}$. 
Os próximos trabalhos também devem realizar pós-processamentos avançados dos resultados, como o cálculo de Funções Densidade de Probabilidade, conjuntas e de transporte dos escalares medidos, assim como as variáveis de progresso, a densidade de superfície de chama, e informações derivativas da turbulência. Isto visa proporcionar um melhor entendimento dos fenômenos envolvidos na combustão relacionados à interação entre a reação química e a turbulência, os quais são importantes para o desenvolvimento e validação de uma ampla gama de modelos

A conexão entre diagnóstico laser e simulação computacional é indispensável para auxiliar o desenvolvimento progressivo da análise de fenômenos envolvidos em combustão. Somente desta forma, é possível contribuir para o entendimento dos processos de combustão turbulenta e alcançar os objetivos de aumentar sua eficiência e diminuir as emissões de poluentes e particulados. 


\section{Bibliografia}

ANDERSON, P., BATH, A., GRÖGER, W., Laser induced fluorescence with tunable excimer lasers as a possible method for instantaneous temperature field measurements at high pressures: checks with an atmospheric flame, Applied Optics, vol. 27, pp. 365-378, 1988.

ALVAREZ, M. A., Desenvolvimento de um Queimador de Gás Natural para Estudos da Combustão em Escoamentos Turbulentos, Rio de Janeiro, Dissertação de Mestrado-Departamento de Engenharia Mecânica, Pontifícia Universidade Católica do Rio de Janeiro, pp. 155, 2006.

BAAWAIN, M. S., EL-DIN, M. G., SMITH, D. W., PIV/PLIF Study of Impinging Jet Ozone Bubble Column with Mixing Nozzles, Science \& Engineering, vol. 32, pp. 99-112, 2010.

BALANÇO ENERGÉTICO NACIONAL. https://ben.epe.gov.br/

BARLOW, R. S., Laser diagnostics and their interplay with computations to understand turbulent combustion, Proceedings of the Combustion Institute, vol. 31, pp. 49-75, 2007.

BenNetT, B. A., MCENALly, C. S., PFefFERle, L. D., Computational and experimental study of axisymmetric coflow partially premixed methane/air flames, Combustion and Flame, vol. 123, pp. 522-546, 2000.

BLEVINS, L. G. e GORE, J. P., Experimental study of temperature and $\mathbf{C H}$ radical location in partially premixed $\mathrm{CH}_{4}$ /air coflow flames, Combustion and Flame, vol. 118, pp. 684-696, 1999.

BOMBACH, R. e KÄPPELI, B., Simultaneous visualization of transient species in flames by planar-laser-induced fluorescence using a single laser system, Applied Physics B: Lasers and Optics, vol. 68, 1999. 
BOWMAN, C. T., HANSON, R. K., DAVIDSON, D. F., GARDINER, Jr., W. C., LISSIANSKI, V., SMITH, G. P., GOLDEN, D. M., FRENKLACH, M., WANG, H., GOLDENBERG, M., GRI-Mech version 2.11, http://www.gri.org, 1995.

BÖHM, B., HEEGER, C., BOXX, I., MEIER, W., DREIZLER, A., Time-resolved conditional flow field statistics in extinguishing turbulent opposed jet flames using simultaneous high speed PIV/OH-PLIF, Proceedings of the Combustion Institute, vol. 32, pp. 1647-1654, 2009.

BUTCHER, P. N. e COTTER, D., The elements of nonlinear optics, Cambridge University Press, pp. 344, 1990.

CAETANO, N. R., CUNHA, A. B., NOVGORODCEV, A. R., FIGUEIRA DA SILVA, L.F., Combustion Regime Identification on a Bluff-body Burner by Using Experimental PLIF-OH Images and RANS Numerical Simulations, $20^{\text {st }}$ International Congress of Mechanical Engineering, Gramado, 2009.

CHAUdHURI, S., KOSTKA, S., RENFRO, M. W., CETEGEN, B. M., Blow-off dynamics of bluff body stabilized turbulent premixed flames, Combustion and Flame, vol. 157, pp. 790-802, 2010.

CHEN, C., WU, B., JIANG, A., YOU, G., A new-type ultraviolet SHG crystal $\beta$ $\mathrm{BaB}_{2} \mathrm{O}_{4}$, Scientia Sinica, vol. 28, pp. 235, 1985.

CHEN, Y. e MANSOUR, M., Simultaneous Rayleigh scattering and laserinduced $\mathrm{CH}$ fluorescence for reaction zone imaging in high-speed premixed hydrocarbon flames, Applied Physics B, vol. 64, pp. 599-605, 1997.

DALLY, B. B., MASRI, A.R., BARLOW, R. W., FIECHTNER, G. J., FLETCHER, D. $F$., Instantaneous and mean compositional structure of bluff-body stabilized nonpremixed flames, Combustion and Flame, vol. 114, pp. 119-148, 1998. 
DEGARDIN, O., Effets des hétérogénéités de richesse sur la structure locale des flammes turbulentes, These de Docteur de L'linstitut National dês Sciences Appliquees de Rouen, pp.297, 2006.

DONBAR, J. M. , DRISCOLL, J. F., CARTER, C. D., Strain rates measured along the wrinkled flame contour within turbulent non-premixed jet flames, Combustion and Flame, vol. 125, pp. 1239-1257, 2001.

DUNN, M. J., MASRI, A. R., BILGER, R. W., Joint quantitative imaging of Rayleigh and OH LIF using saturated and linear fluorescence, Fourth Australian Conference on Laser Diagnostics in Fluid Mechanics and Combustion, The University of Adelaide, South Australia, 7-9/12, 2005.

ECKBRETH, A.C., Laser Diagnostics for Combustion Temperature and Species, CRC, 1996.

EGUSQUIZA, J. C. C., Redução das Emissões em Motores Diesel-gás, Rio de Janeiro, Dissertação de Mestrado-Departamento de Engenharia Mecânica, Pontifícia Universidade Católica do Rio de Janeiro, pp. 169, 2008.

FRANK, J. H., LYONS, K. M., LONG, M. B., Simultaneous scalar/velocity field measurements in turbulent gas-phase flows, Combustion and Flame, vol. 107, pp. 1-12, 1996.

FREIRE, A. P. S., ILHA, A., BREIDENTHAL, R., Turbulência, 5 $5^{\text {a }}$ Escola de Primavera em Transição e Turbulência, IME, Rio de Janeiro, 2006.

GAUTAM, S. C., PIV and PLIF measurements in homogeneous free jet flow, Master's Thesis in Mechanical Engineering, Texas Tech University, 2008.

GORE, J. P. e ZHAN, N. J., NO ${ }_{x}$ emission and major species concentrations in partially premixed laminar methane/air coflow jet flames, Combustion and Flame, vol. 105, pp. 414-427, 1996. 
GRIENEISEN, H.P., KURNIT, N.A., SZÖKE, A., Fluorescence induced by coherent optical pulses, Optics Communications, vol. 3, pp. 259-263, 1971.

HUANG, R. F. e LIN, C.L., Velocity fields of non-premixed bluff-body stabilized flames, Journal of Energy Resources Technology, vol. 122, pp. 88-93, 2000.

HUAPAYA, L. E. A., Caracterização numérica e experimental de uma chama turbulenta não pré-misturada, Rio de Janeiro, Dissertação de MestradoDepartamento de Engenharia Mecânica, Pontifícia Universidade Católica do Rio de Janeiro, pp. 169, 2008.

INSTITUTO BRASILEIRO DE PETRÓLEO. http://www.ibp.org.br

JANKOW, R., KILHAM, O., RENKEN, W., BENDER, R., Laser induced fluorescence emission (LIFE), Analytical Biochemistry, vol. 43, pp. 300-304, 1971.

KIEFER, J., LI, Z. S., ZETTERBERG, J., BAI, X. S., ALDÉN, M., Investigation of local flame structures and statistics in partially premixed turbulent jet flames using simultaneous single-shot $\mathrm{CH}$ and $\mathrm{OH}$ planar laser-induced fluorescence imaging, Combustion and Flame, vol. 154, pp. 802-818, 2008.

KLINE, S. J. e MCCLINTOCK, F. A., Describing uncertainties in single-sample experiments, Mechanical Engineering, 1953.

KOHSE-HÖINGHAUS, K. e JEFFRIES, J. B., Applied Combustion Diagnostics, Ed. Taylor\&Francis, 2002.

KOTHNUR, P. S., TSURIKOV M. S., CLEMENS N. T., DONBAR J. M., CARTER C. D., Planar imaging of $\mathrm{CH}, \mathrm{OH}$, and velocity in turbulent non-premixed jet flames, Proceedings of the Comb. Inst, vol. 29, pp. 1921-1927, 2002.

LACAVA, P. T. e MARTINS, C. A., Métodos experimentais de análise aplicados à combustão, Ed. Papel Brasil, 2010. 
LAKOWICZ, J. R., Principles of fluorescence spectroscopy, $3^{\text {a }}$ Ed., Vol. 1, pp. 954, 2006.

LAW, A. W. e WANG, H., Measurement of mixing processes with combined digital particle image velocimetry and planar laser induced fluorescence, Experimental Thermal and Fluid Science, vol. 22, pp. 213-229, 2000.

LUQUE, J., JEFFRIES, J. B., SMITH, G. P., CROSLEY, D. R., WALSH, K. T., LONG, M. B., SMOOKE, M. D., $\mathrm{CH}(\mathrm{A}-\mathrm{X})$ and $\mathrm{OH}(\mathrm{A}-\mathrm{X})$ optical emission in an axisymmetric laminar diffusion flame, Comb. Flame, vol. 122, pp. 172-175, 2000.

LYONS, K. M., WATSON, K. A., CARTER, C. D., DONBAR, J. M., On flame holes and local extinction in lifted-jet diffusion flames, Combustion and Flame, vol. 142, pp. 308-313. 2005.

MANUAL LAVISION GmbH, Davis 7.2, Tunable LIF, Göttingen, Alemanha, 2007.

MAUREY, C., CESSOU, A., LECORDIER, B., STEPOWSKI, D., Statistical flow dynamic properties conditioned on the oscillating stabilization location of turbulent lifted flame, Proceedings of the Comb. Inst, vol. 28, pp. 545-551, 2000.

McENALlY, C. S., PfEFferle, L. D., SChAFFER, A. M., LONG, M. B., MOHAMMED, R. K., SMOOKE, M. D., COLKET, M. B., Characterization of a coflowing methane/air non-premixed flame with computer modeling, RayleighRaman imaging, and on-line mass spectrometry, Proceedings of the Combustion Institute, vol. 28, pp. 2063, 2000.

MOFFAT, R. J., Contributions to the theory of single-sample uncertainty analysis, Journal of Fluids Engineering, vol. 104, pp. 250-258, 1982.

MUELLER, C. J., DRISCOLL, J. F., SUTKUS, D. J., ROBERTS, W. L., DRAKE, M. C., SMOOKE, M. D., Effect of unsteady stretch rate on $\mathrm{OH}$ chemistry during a flame-vortex interaction: to assess flamelet models, Combustion and Flame, vol. 100, pp. 323-331, 1995. 
MUÑIZ, L. e MUNGAL, M. G., Instantaneous flame-stabilization velocities in lifted-jet diffusion flames, Combustion and Flame, vol. 111, pp. 16-31, 1997.

PERRY, R. H. e GREEN, D. W., Perry's Chemical Engineers' Handbook, McGraw-Hill, p. 2640, 1997.

PETERSSON, P., OLOFSSON, J., BRACKMAN, C., SEYFRIED, H., ZETTERBERG, J., RICHTER, M., ALDÉN, M., LINNE, M. A., CHENG, R. K., NAUERT, A., GEYER, D., DREIZLER, A., Simultaneous PIV/OH-PLIF, Rayleigh thermometry/OH-PLIF and stereo PIV measurements in a low-swirl flame, Applied Optics, vol. 46, pp. 3928-3936, 2007.

PETROBRAS. http://www.agenciapetrobrasdenoticias.com.br/

POINSOT, T. e VEYNANTE, D., Theoretical and Numerical Combustion, Edwards R. T., pp. 520, 2005.

POPE, S. B., Turbulent Flows, Cambridge, pp. 749, 2000.

RAFFEL. M., WILLERT, C. E., WERELEY, S. T., KOMPENHANS J., Particle image velocimetry, a praticle guide, Göttingen, Springer, pp. 448, 2007.

REHM, J. E. e CLEMENS, N. T., The relationship between vorticity/strain and reaction zone structure in turbulent non-premixed jet flames, $27^{\circ}$ Symposium (International) on Combustion/The Comb. Inst, pp. 1113-1120, 1998.

REZENDE, S. M., A física dos materiais e dispositivos eletrônicos, Editora Universitária, UFPE, 1996.

ROESGEN, T., Optimal subpixel interpolation in particle image velocimetry, Experiments in Fluids, vol. 35, n. 3, pp. 252-256, 2003. 
ROTHAMER, D., SNYDER, J., HANSON, R., STEEPER, R., Two-wavelength PLIF diagnostic for temperature and composition, SAE World Congress, 2008.

RYUTA, H., AKIRA, I., MAKIHITO, N., ZHU, X. L., TADAO, T., Measurement of OH in a coflow diffusion flame by PLIF, Transactions of the Japan Society of Mechanical Engineers B, vol. 65, pp. 54-61, 1999.

SADANANDAN, R., STÖHR, M., MEIER, W., Simultaneous OH-PLIF and PIV measurements in a gas turbine model combustor, Applied Physics B: Lasers and Optics, vol. 90, pp. 609-618, 2008.

SANTOS, L. R., Medições de temperaturas de chamas de etanol utilizando fluorescência induzida por laser, São Paulo, Tese de doutorado, Instituto de Química-Universidade de São Paulo, pp. 122, 2005.

SHAO, D. e LAW, A. W., Turbulent mass and momentum transport of a circular offset dense jet, Journal of Turbulence, vol. 10, nㅡ 40, 2009.

SHIMURA, M., UEDA, T., CHOI, G., TANAHASHI, M., MIYAUCHI, T., Simultaneous dual-plane CH PLIF, single-plane $\mathrm{OH}$ PLIF and dual-plane stereoscopic PIV measurements in methane-air turbulent premixed flames, Proceedings of the Combustion Institute, vol. 33, pp. 775-782, 2011.

SICK, V. e WERMUTH, N., Single-shot Imaging of $\mathrm{OH}$ radicals and simultaneous $\mathrm{OH}$ radical/acetone Imaging with a tunable Nd:YAG laser, Applied Physics B, vol. 79, pp. 139-143, 2004.

SMOOKE, M. D., LIN, P., LAM, J., LONG M. B., Computational and experimental study of a laminar axisymmetric methane-air diffusion flame, Twenty-third Symposium on Combustion, The Comb. Institute, pp. 575-582, 1991.

SMOOKE, M. D., XU, Y., ZURN, R. M., LIN, P., FRANK, J. H., LONG, M. B., Computational and experimental study of $\mathrm{OH}$ and $\mathrm{CH}$ radicals in axisymmetric 
laminar diffusion flames, Twenty-Fourth Symposium (International) on Combustion, The Combustion Institute, pp. 813-822, 1992.

SMOOKE, M. D., ERN, A., TANOFF, M. A., VALDATI, B .A., MOHAMMED, R. K., MARRAN, D. F., LONG, M. B., Computational and experimental study of NO in an axisymmetric laminar diffusion flame, Twenty-Sixth Symposium (International) on Combustion, The Combustion Institute, pp. 2161-2170, 1996.

SMOOKE M. D., MCENALLY, C. S., PFEFFERLE L. D., HALL R. J., AND COLKET M. B., Computational and experimental study of soot formation in a coflow, laminar ethylene diffusion flame, Symposium (International) on Combustion, vol. 27, pp.1497-1505, 1998.

STANISLAS, M. e WESTERWEEL, J., Particle image velocimetry: recent improvements, Proceedings of the EUROPIV 2, pp. 426, 2004.

STEINBERG, A. M., DRISCOLL, J. F., CECCIO, S. L., Temporal evolution of flame stretch due to turbulence and the hydrodynamic instability, Proceedings of the Combustion Institute, vol. 32, pp. 1713-1721, 2009.

TAMURA, M., BERG, P. A., HARRINGTON, J. E., LUQUE, J., JEFFRIES, J. B., SMITH, G. P., CROSLEY, D. R., Collisional Quenching of $\mathrm{CH}(\mathrm{A}), \mathrm{OH}(\mathrm{A})$, and NO(A) in Low Pressure Hydrocarbon Flames, Combustion and Flame, vol. 114, pp. 502-514, 1998.

TANOFF, M. A., SMOOKE, M. D., OSBORNE, R. J., BROWN, T. M., PITZ, R. W., The sensitive structure of partially premixed methane-air vs. air counterflow flames, 26을 Symposium on Combustion, pp. 1121-1128, 1996.

THÉVENIN, D., RENARD, P. H., FIECHTNER, G. J., GORD, J. R., ROLON, J. C., Regimes of non-premixed flame-vortex interactions, Proceedings of the Combustion Institute, vol. 28, pp. 2101-2108, 2000. 
TROIANI, G., MARROCCO, M., GIAMMARTINI, S., CASCIOLA, C.M., Countergradient transport in the combustion of a premixed $\mathrm{CH} 4$ /air annular jet by combined PIV/OH-LIF, Combustion and Flame, vol. 156, pp. 608-620, 2009.

WALSH, K. T., LONG, M. B., TANOFF, M. A., SMOOKE, M. D., Experimental and computational study of $\mathrm{CH}, \mathrm{CH}^{\star}$, and $\mathrm{OH}^{*}$ in an axisymmetric laminar diffusion flame, Symposium (International) on Combustion, vol. 27, pp. 615, 1998.

WALSH, K. T., FIELDING, J., SMOOKE, M. D., LONG, M. B., LIÑÁN, A., A comparison of computational and experimental lift-off heights of coflow laminar diffusion flames, Proceedings of the Combustion Institute, vol. 30, pp. 357365, 2005.

WASON, A., CARNELL, W. F., RENFRO, M. W., Velocity and scalar measurements in neighboring lifted edge flames, Combustion Science and Technology, vol. 178, pp. 789-811, 2006.

WATSON, K. A., LYONS, K. M., DONBAR, J. M., CARTER, C. D., Scalar and velocity field measurements in a lifted $\mathrm{CH}_{4}$ /air diffusion flame, Combustion and Flame, vol. 117, pp. 257-271,1999.

WESTERWEEL, J., Fundamentals of digital particle image velocimetry, Measurement Science and Technology, vol. 8, pp. 1379-1392, 1997.

WHITTAKER, E. T., Expansions of the interpolation-theory, Proceedings of the Royal Society., Edinburgh, vol. 35, pp.181, 1915.

WILSON, G., Os grandes homens da ciência: suas vidas e descobertas, São Paulo, Ed. Nacional, 1940.

WROBEL, N. H. e PRATT, N. H., Laser induced sodium fluorescence measurements in a turbulent propane diffusion flame, Seventeenth Symposium (International) on Combustion, vol. 17, pp. 957-966, 1979. 


\section{Apêndice A}

Esquema de sistema de dispersão de partículas, composto por um leito fluidizado e um ciclone, os quais selecionam os diâmetros das partículas que passam por eles segundo as seguintes relações [46].

$$
\begin{array}{r}
d_{p_{\text {Leio }}}=\frac{3 C_{a}\left(\rho_{\text {gás }} \cdot U^{2}\right)}{\rho_{\text {part }} \cdot g} \\
d_{p_{\text {Cicone }}}=\frac{9 \mu b U}{2 \pi N\left(\frac{\rho_{\text {part }}}{\rho_{\text {gás }}}-1\right) \rho_{\text {gás }} U^{2}}
\end{array}
$$

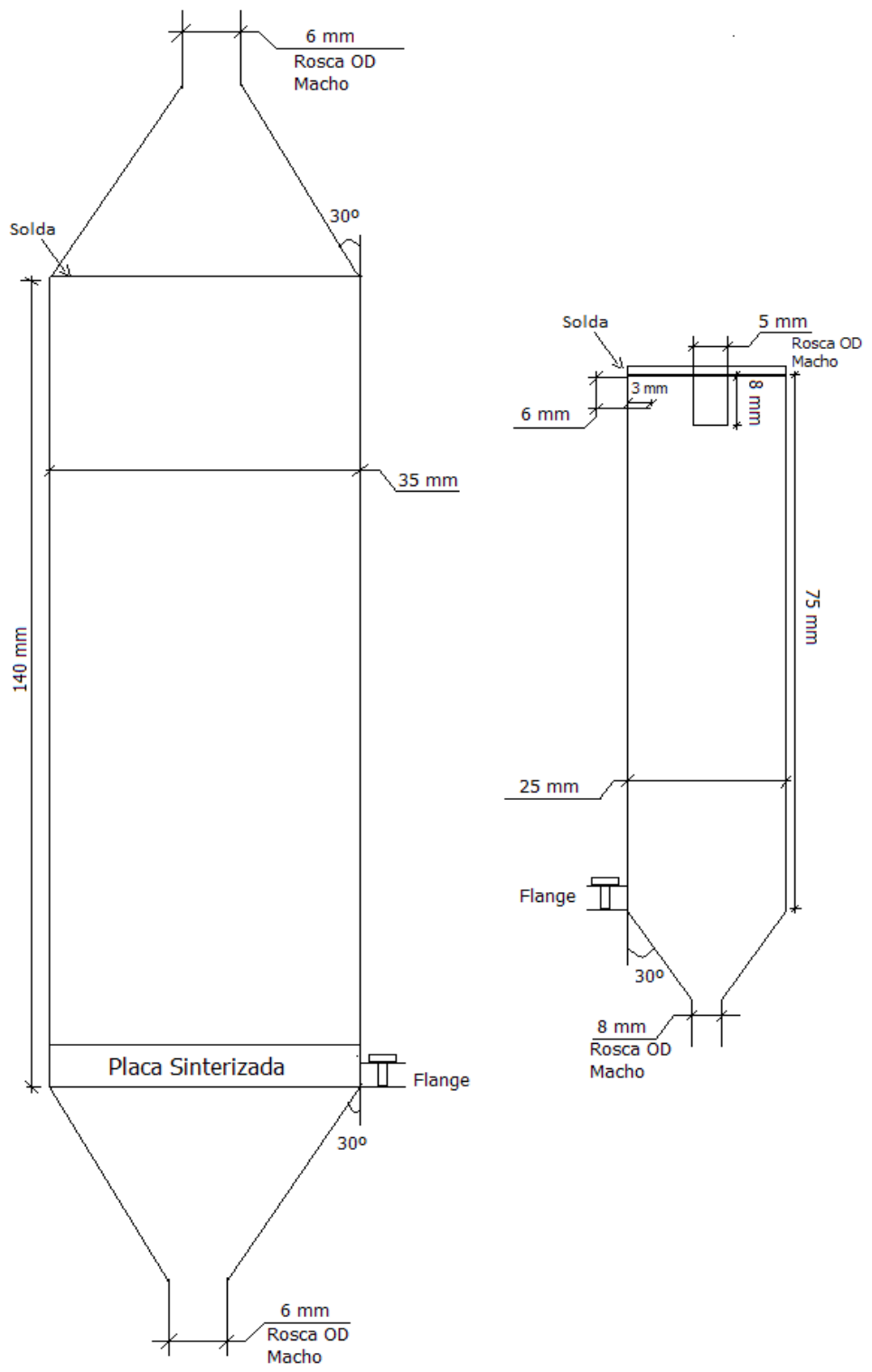




\section{Apêndice B}

As curvas a seguir apresentam os resultados para as medidas das duas componentes da velocidade, longitudinal (Vy) e transversal (Vx), da energia cinética turbulenta ( $k$ ) e das componentes $x x, x y$ e $x y$ do tensor de Reynolds realizadas a $5 \mathrm{~mm}$ a jusante da saída do queimador, a fim de fornecer informações para o desenvolvimento e validação de modelos numéricos. Os resultados experimentais obtidos neste estudo estão disponíveis, também, na forma digital junta à biblioteca da PUC-Rio.

\section{Caso 3}
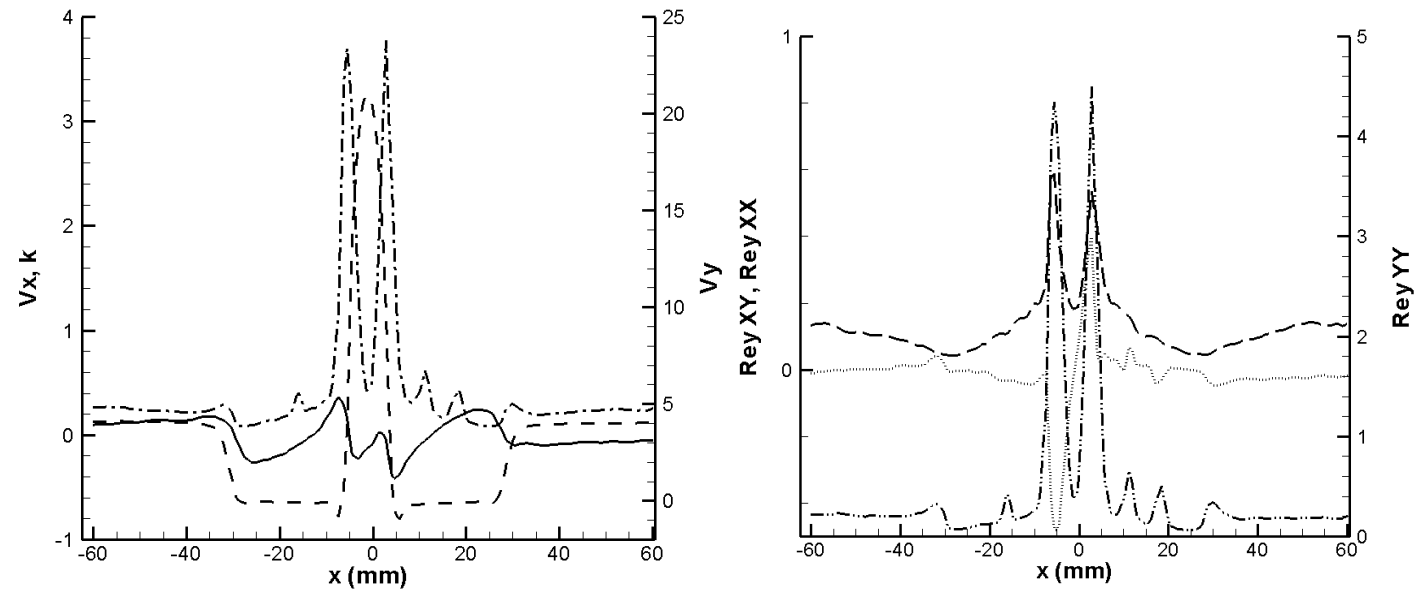

\section{Caso 4}
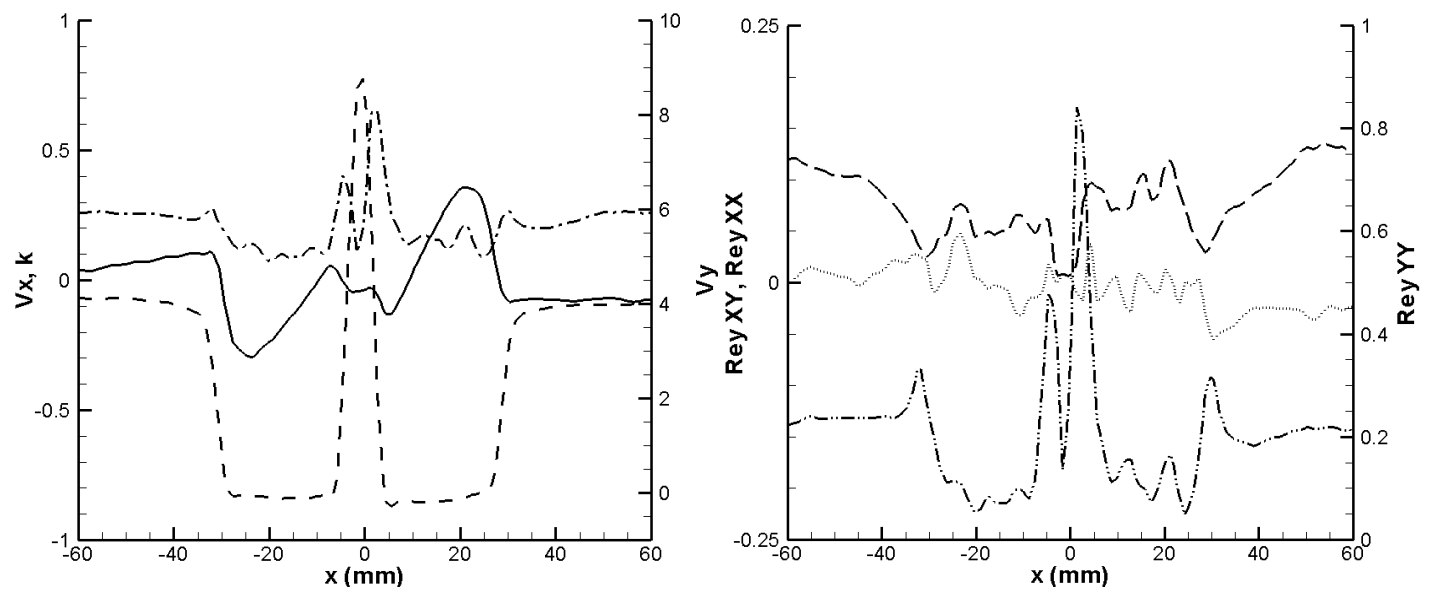


\section{Caso 5}
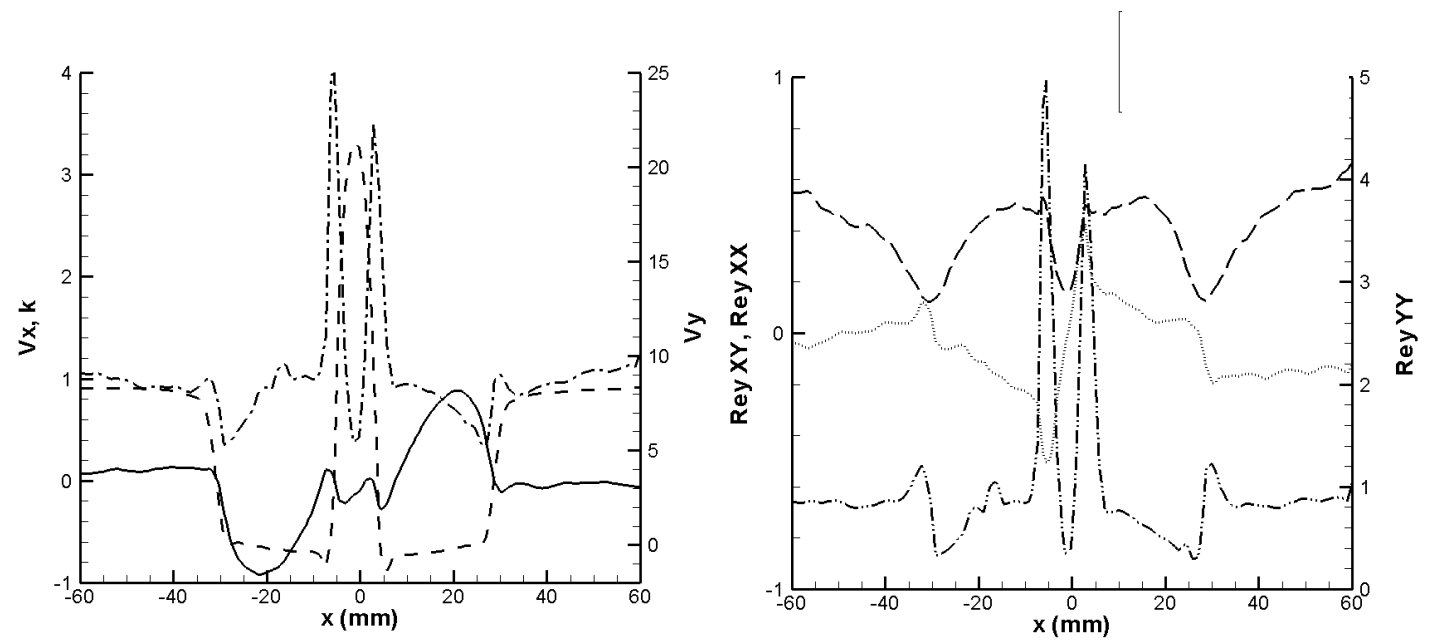

\section{Caso 6}
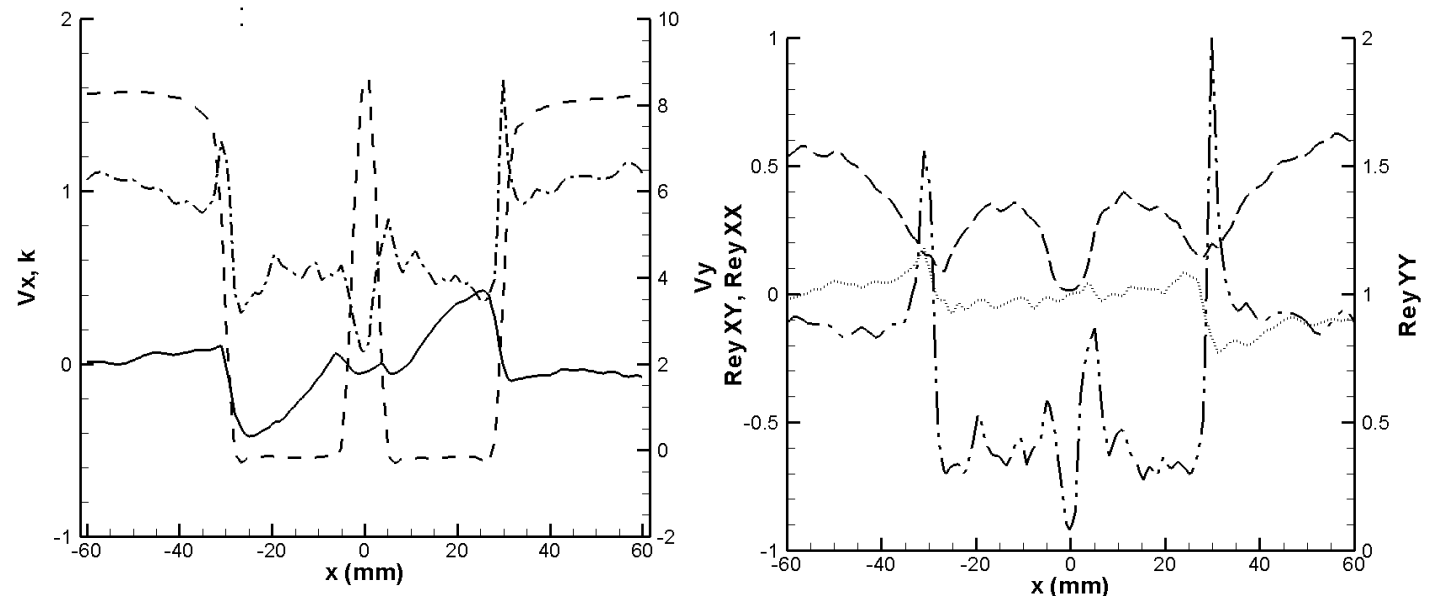

Evolução na direção transversal ( $x$ ), para posição longitudinal de $5 \mathrm{~mm}$ a jusante da superfície do queimador, das componentes longitudinal (Vy) e transversal $(V x)$ da velocidade $[\mathrm{m} / \mathrm{s}]$, a energia cinética turbulenta $(k)$ e das componentes $x x$, xy e $x y$ do tensor de Reynolds $\left[\mathrm{m}^{2} / \mathrm{s}^{2}\right] .-10,--20, \ldots 30, \ldots 40,--50, \ldots 60, \ldots 70 \mathrm{~mm}$. 